ESCOLA POLITÉCNICA DA UNIVERSIDADE DE SÃO PAULO

MARCIA APS

ClASSIFICAÇÃo DA ADERÊNCIA PNEU-PAVIMENTO PELO ÍNDICE COMBINADO IFI - INTERNATIONAL FRICTION INDEX PARA REVESTIMENTOS ASFÁLTICOS

São Paulo

2006 
MARCIA APS

\section{CLASSIFICAÇÃo DA ADERÊnCIA PNEU-PAVIMENTO PELO ÍNDICE COMBINADO IFI - INTERNATIONAL FRICTION INDEX PARA REVESTIMENTOS ASFÁLTICOS}

Tese apresentada à Escola Politécnica da Universidade de São Paulo para obtenção do Título de Doutor em Engenharia

Área de concentração:

Engenharia de Transportes

Orientadora:

Prof. ${ }^{a}$ Livre-Docente, Doutora

Liédi Légi Bariani Bernucci

São Paulo

2006 


\section{FICHA CATALOGRÁFICA}

\section{Aps, Marcia}

Classificação da aderência pneu-pavimento pelo índice combinado IFI - International Friction Index para revestimentos asfálticos / M. Aps. -- São Paulo, 2006.

$179 \mathrm{p}$.

Tese (Doutorado) - Escola Politécnica da Universidade de São Paulo. Departamento de Engenharia de Transportes.

1.Pavimentação asfáltica 2.Aderência pneu-pavimento 3.IFI International Friction Index I.Universidade de São Paulo. Escola Politécnica. Departamento de Engenharia de Transportes II.t. 


\section{FOLHA DE APROVAÇÃO}

\section{MARCIA APS}

CLASSIFICAÇÃO DA ADERÊNCIA PNEU-PAVIMENTO PELO ÍNDICE COMBINADO IFI INTERNATIONAL FRICTION INDEXPARA REVESTIMENTOS ASFÁLTICOS

Texto apresentado à Escola Politécnica da Universidade de São Paulo para obtenção do Título de Doutor

Área de concentração: Engenharia de Transportes

Aprovado em:

\section{Banca Examinadora}

Professora Livre-Docente, Doutora Liédi Légi Bariani Bernucci

Escola Politécnica da Universidade de São Paulo

Professor Livre-Docente Doutor José Alberto Quintanilha

Escola Politécnica da Universidade de São Paulo

Doutor Octávio de Souza Campos

Agência de Transporte do Estado de São Paulo

Doutor José Augusto Pereira Ceratti

Universidade Federal do Rio Grande do Sul

Doutor Ernesto Simões Preussler

Empresa Dynatest Engenharia Ltda. 


\section{Errata}

\begin{tabular}{|c|c|l|l|}
\hline Página & Linha & \multicolumn{1}{|c|}{ Onde se lê } & \multicolumn{1}{|c|}{ Leia-se } \\
\hline $\begin{array}{c}\text { Folha de } \\
\text { Aprovação }\end{array}$ & 16 & $\begin{array}{l}\text { Dr J osé Augusto } \\
\text { Pereira Ceratti }\end{array}$ & Dr J orge Augusto Pereira Ceratti \\
\hline Agradecimentos & 28 & $\begin{array}{l}\text { Dr J osé Augusto } \\
\text { Pereira Ceratti }\end{array}$ & Dr J orge Augusto Pereira Ceratti \\
\hline 52 & 7 & item 2.4 a seguir & item 2.5. \\
\hline 111 & 5 & (Calegare, 2001) & $\begin{array}{l}\text { Montgomery, Douglas C. } \\
\text { Introdução ao Controle Estatístico da Qualidade } \\
\text { LTC - 2004 - 4a Edição }\end{array}$ \\
\hline
\end{tabular}




\section{Dedicatória}

A minha mãe Irene, ao Ary e ao Aryzinho Aps (in memoriam) pai e irmão 


\section{Agradecimentos}

Agradeço a todos que contribuíram para a realização desta pesquisa, os quais tornaram esta tarefa possível, portanto considero que a elaboração de uma Tese de Doutorado é o resultado de um trabalho coletivo mesmo sendo sua a redação e a maioria das fases, responsabilidade e estresse predominantemente individual. Corro o risco de não dar conta de expressar esse "muitíssimo obrigada", como é devido, a muitos e tantos adorados familiares, amigos e colegas de profissão, tanto aos "antigos" e queridos quanto aos "novos" que se revelaram ao longo desse período.

É difícil exprimir a beleza que foi esse movimento de energias que aconteceu ao longo dessa travessia, onde se destacou também, além da formalidade, um sentido: o da formação de uma verdadeira rede de solidariedade e de muito, muito carinho. Para maior percepção desse sentido devo contar que esta não foi uma caminhada breve, mas uma jornada que parecia sem fim, principalmente pelos imprevistos pessoais de toda ordem, que me atropelaram. Essas muitas dificuldades, longe de obscurecerem o trajeto, aumentaram-lhe o brilho e ao invés de me deterem, impulsionaram-me com mais força. Portanto, agradeço:

- Em primeiro lugar a minha família, D. Irene (minha mãe), Matheus, Amanda e Liara (sobrinhos e cunhada) e tomo a liberdade de destacar meu irmão, Ary, que tinha tanto orgulho desse trabalho e que precocemente nos deixou sem ver a sua conclusão;

- Continuando com a família, agradeço a Prof. Dra. Liédi Légi Bariani Bernucci orientadora, amiga, parceira, que além de tudo abriu as portas de sua casa e me deu a oportunidade de ser o "quinto elemento"; por seu intermédio agradeço também ao Nick, ao André e ao Felipe que dividiram a esposa e mãe comigo;

- Ao Prof. Dr. Job Shuji Nogami que facilitou minha permanência em São Paulo nos primeiros anos da Tese, que se mostrou mais que um amigo - um pai; juntos, muitas vezes, dividimos angústias, desabafos e solidariedade, contamos nossas histórias de vida, choramos e rimos muito também;

- Ao Eng. Paulo R. M. Mesquita que com toda a sua paciência e seu companheirismo tornou meu trabalho menos solitário e mais suave; 
- Aos meus amigos de Santos que tão carinhosamente me substituíram em muitas ocasiões difíceis junto a minha família: Marilda, Solange, Rita e Nelsinho, Sarinha e D.Ana, Aninha e Fernando, Marisa e a minha fiel escudeira Nena, a vocês dedico o meu afeto!

- Ao IPT - Instituto de Pesquisa Tecnológica de São Paulo pelo incentivo, mesmo quando vinha na pergunta do Diretor Técnico Dr. Marcos Tadeu: Quando você vai terminar a Tese? Destaco ainda a equipe da Seção de Vias Terrestre e Estruturas os Engenheiros Mestres e amigos Elieni, menina de ouro, Marcus e Adérito que tanto contribuíram na reta final desta tese; o tecnólogo Rubens, o estagiário Jonas e os técnicos Jurandir, Camarão, Valmir, Alemão, Neguinha e Roberto; o Diretor Dr. José Maria, a estatística Lucinha; as secretarias e amigas Bete, Silmara e Leila; pela ajuda de cada um de vocês OBRIGADA!

- Ao Prof. Dr. José Alberto Quintanilha pelo auxílio na análise estatística dos resultados;

- Eng. João Menescal Fabrício da ECL Engenharia Consultoria e Economia SA, que acreditou nessa pesquisa e foi o responsável pela recomendação deste índice e do nosso trabalho publicado no Manual de Restauração de Pavimentos Asfálticos do DNIT;

- Aos amigos da USP - Prof. Dr. Hugo Pietrantônio; Prof. Dr. Denizar Blitzkow; Mestres: Oswaldo Sansone Rodrigues Filho, Edson de Moura, Rafael Reis, Humberto Nascimento; As Doutoras Andréa Severi e Sandra Bertollo; ao Pedro, aluno de iniciação cientifica; as maravilhosas: Conceição, Simone, Diomária e Cidinha e também ao Edson.

- A CAPES, pela bolsa no início do Doutorado;

- As empresas e aos órgãos: Concessionária Ecovias dos Imigrantes SA; ServengCilvisan SA; Ipiranga Asfaltos SA; Concessionária Nova Dutra na pessoa da Eng. Valéria Faria; Pirelli Pneus S. A, na pessoa do Engenheiro Luciano Santana e do Mestre Argemiro Costa; Doutor José Augusto Pereira Ceratti da UFRGS; Doutor Octávio de Souza Campos da ARTESP; INFRAERO - Superintendência Regional do Sudeste na pessoa do Eng. Lucínio Baptista da Silva e do Arquiteto Jaime Henrique Caldas Parreira, Superintendente do Aeroporto Campo de Marte; Eng. José Augusto de Oliveira do DAER; DNIT pela valorização do trabalho; Secretaria Municipal de Obras e Serviços Públicos da Prefeitura Municipal de Santos; aos alunos da UniSantos onde destaco os que participaram de ensaios de campo: Everton, Paulo Danilo, André, Caio, Fábio e Vitor - turma de 2004. 


\section{Resumo}

A caracterização da macrotextura e microtextura da superfície de pavimentos asfálticos pode ser obtida por meio de diversos tipos de equipamentos que possuem características distintas. Os resultados dos ensaios obtidos por esses diferentes equipamentos foram comparados e harmonizados por uma grande pesquisa desenvolvida pela PIARC (Permanent International Association of Road Congress, atualmente denominada de World Road Association) que converteu estes diferentes valores em um índice internacional combinado denominado de IFI - International Friction Index. Posteriormente, a ASTM especificou o emprego deste índice por meio da publicação da norma E 1960-98 Standard Practice for Calculating International Friction Index of a Pavement Surface.

Nesta tese foram avaliados a textura e o atrito em doze tipos de revestimentos asfálticos com características distintas: usinados a quente de diversas graduações, tratamentos superficiais, microrrevestimentos a frio e lamas asfálticas, por meio de aparelhagem portátil: ensaios de mancha de areia e Pêndulo Britânico, respectivamente. Estes diferentes revestimentos apresentam uma gama de textura variando de aberta e rugosa a fechada e polida. Os resultados geraram um banco de dados com 417 valores de campo, sendo 178 referentes à macrotextura, 166 à microtextura e 73 à drenabilidade. Com estes dados, foram calculados valores de IFI, compostos pelos parâmetros $\mathrm{Sp}$ e $\mathrm{F}_{60}$, resultando em 165 pares de valores. Com base na experiência prática e análises estatísticas, demonstrou-se a validade de uso de equipamentos portáveis para a determinação dos valores de IFI e estabeleceram-se critérios e faixas de classificação para a aderência em função do par de valores de IFI ( $\left.\mathrm{Sp} ; \mathrm{F}_{60}\right)$. Esta classificação possibilita os órgãos viários a usarem o IFI (Sp; $\left.\mathrm{F}_{60}\right)$ como uma ferramenta de gerência de pavimentos para avaliarem as condições de aderência em pista molhada de suas vias ou de locais específicos, objetivando, quando necessária, a realização de intervenções. 


\section{Abstract}

The characterization of the macrotexture and microtexture of asphalt pavements surfaces can be obtained by means of different types of equipment presenting different characteristics. The results of the essays obtained by these different equipment were compared and harmonized by an ample research developed by PIARC (Permanent International Association of Road Congress, now denominated World Road Association) which converts these different values into an international combined index denominated IFI - International Friction Index. Later, the ASTM specified the employment of this index by publishing norm E 1960-98 Standard Practice for Calculating International Friction Index of a Pavement Surface.

In this thesis, texture and friction were evaluated on twelve types of asphalt pavings with different characteristics: hot asphalt mixes of different gradations, asphalt surface treatments, cold-mixed micro-surfacing and slurry seals, by means of portable equipment, sand patch and British pendulum essays, respectively. These different pavings present a range of texture varying from open and rough to closed and polished. The results generated a database with 417 field values, being 178 related to macrotexture, 166 to microtexture and 73 to drainability. With these data, IFI values were calculated, composed by parameters $S p$ and $F_{60}$, resulting in 165 pairs of values. Based on practical experience and on statistical analyses, the validity of using portable equipment for determining the IFI values was demonstrated and classification criteria and bands for adherence were established in function of the pair of IFI values $\left(\mathrm{Sp} ; \mathrm{F}_{60}\right)$. This classification allows road organisms to use IFI (Sp; $\mathrm{F}_{60}$ ) as a pavement management tool to assess the adherence conditions on the wet lanes of their roads or on specific sites, aiming to conduct interventions, whenever necessary. 


\section{Sumário}

Capítulo 1 Introdução 1

1.1 Considerações Iniciais 1

1.2 Objetivos do Trabalho $\quad 6$

$\begin{array}{ll}1.3 \text { Metodologia da Pesquisa } & 8\end{array}$

Capítulo 2 Revisão Bibliográfica $\quad 10$

2.1 O Fenômeno Físico da Aderência e a Interação Pneu Pavimento 10

2.2 Características Físicas das Vias e sua Influência na Ocorrência de Acidentes 20

2.3 Medidas de Textura e de Atrito 29

2.3.1 Medidas de Textura $\quad 30$

2.3.1.1 Mancha de Areia $\quad 30$

2.3.1.2 Mancha de Graxa (Grease Patch) 33

2.3.1.3 Drenabilidade (Outflow) 34

2.3.1.4 Drenômetro LTP-EPUSP 35

2.3.1.5 Perfilômetros a Laser 36

2.3.1.6 Circular Track Meter - CT Meter 37

2.3.1.7 Mini Texture Meter 39

2.3.2 Medidas de Atrito $\quad 40$

2.3.2.1 Pêndulo Britânico (Estático) 40

2.3.2.2 Dynamic Friction Tester - DF Tester - DFT (Estático) 41

2.3.2.3 Mu-meter(Roda Oblíqua) 42

2.3.2.4 Stradograph (Roda Oblíqua) 43

2.3.2.5 Odoliograph (Roda Oblíqua) 44

2.3.2.6 SCRIM (Roda Oblíqua) 44

2.3.2.7 Equipamento de Roda Bloqueada 46

2.3.2.8 BV-11 (Roda Parcialmente Bloqueada) 47

2.3.2.9 SFT - Surface Friction Tester (Roda Parcialmente Bloqueada) 48

2.3.2.10 Grip Tester (Roda Parcialmente Bloqueada) 49 
2.3.11 Runway Friction Tester (Roda parcialmente Bloqueada) 50

2.4 A Influência do Tipo do Revestimento na Textura Superficial 52

2.4.1 Graduações de Misturas Asfálticas Usinadas 53

2.4.2 Tratamentos Superficiais Asfálticos 59

2.4.3 Microrrevestimentos e Lamas Asfálticas $\quad 60$

$\begin{array}{ll}\text { 2.4.4 Agregados } & 61\end{array}$

2.4.5 Efeito do Tipo de Revestimento Asfáltico no Coeficiente de Atrito 63

2.4.6 Efeito do Tipo de Revestimento Asfáltico na Geração de Ruído 65

2.5 Experimento Internacional de Comparação e Harmonização das Medidas de Textura 68 e Atrito e por meio do IFI - International Friction Index

2.5.1 Penn State Mode/ ou Modelo da Pensilvânia 72

2.5.2 Modelo da PIARC 73

2.5.3 Cálculo do Valor de IFI de Acordo com o Procedimento ASTM 79

2.6 Políticas e Recomendações de Aderência Quanto à segurança 82

2.6.1 Brasil 83

2.6.1.1 DNIT - Departamento Nacional de Infra-Estrutura de Transportes 83

2.6.1.2 ARTESP (Agência de Transportes do Estado de São Paulo) 85

2.6.2.Oceania 86

2.6.2.1 Nova Zelândia 86

2.6.2.2 Austrália $\quad 88$

2.6.3 Europa 88

2.6.3.1 Suíça $\quad 88$

$\begin{array}{ll}\text { 2.6.3.2 Espanha } & 89\end{array}$

2.6.4 América $\quad 90$

$\begin{array}{ll}\text { 2.6.4.1 Estados Unidos da América } & 90\end{array}$

Capítulo 3 Pesquisa de Campo $\quad 92$

3.1 Aeroportos 94

3.1.1 Aeroporto Internacional de São Paulo/Guarulhos 94

3.1.2 Aeroporto Internacional de São Paulo/Congonhas 95

3.1.3 Campo de Marte 96 
$\begin{array}{ll}3.2 \text { Rodovias } & 97\end{array}$

3.2.1 Via Anchieta - SP 150

3.2.2 Rodovia Santos Dumont - SP 75 99

3.2.3 Rodovia dos Bandeirantes - SP $348 \quad 99$

3.2.4 Rodovia Presidente Dutra - BR $116 \quad 100$

3.2.5- Rodovia Capivari - Osório RST/101 101

3.2.6 Valores de Pavimentos Rodoviários obtidos no LTP - EPUSP 102

3.3 Vias Urbanas 103

3.3.1 Corredor Tecnológico 103

3.3.2 Ruas da cidade de Santos 105

3.4 Circuitos de Provas $\quad 106$

3.4.1 Autódromo de Interlagos - José Carlos Pace 106

$\begin{array}{ll}\text { 3.4.2 Campo de Prova da Pirelli } & 107\end{array}$

Capítulo 4 Análise de Dados $\quad 109$

4.1 Banco de Dados e Grupo de Controle 111

4.2 Consistência do Banco de Dados da Amostra Treinamento por meio da Ferramenta Estatística Boxplot para valores de $\mathrm{F}_{60}$

4.3 Matrizes de Correlação e de Covariância 116

4.4 Faixas de Classificação de Valores de $\operatorname{IFI}\left(\mathrm{F}_{60}\right) \quad 123$

4.5 Efeito da Variação da Granulometria da Areia ou Micro Esfera de Vidro na Determinação da Macrotextura por meio do Ensaio ASTM E 965-96

Capítulo 5 Estudo de Caso - Seção Teste na Via Anchieta

5.1 A Seção-Teste na Via Anchieta 139

5.2 Ensaios Realizados e Resultados Obtidos 143

5.3 Análise dos Resultados Parciais $\quad 148$

5.3.1 Concreto Asfáltico Convencional (faixa III da DERSA - CAP 20) 148

5.3.2 Concreto Asfáltico Modificado (faixa IV-b do Instituto do Asfalto Norte- 149 americano Modificado por Borracha) 
5.3.3 SMA (Stone Matrix Asphalt) de Acordo com a Normalização Alemã com a Faixa 0/11 S

5.3.3.1 Dados Obtidos em Março de 2002

5.3.3.2 Dados Obtidos em Junho de 2003

\subsubsection{Dados Obtidos em Maio de 2006}

5.3.3.4 Comparação das Quatro Avaliações Realizadas

5.4 Análise dos Valores Calculados de $\operatorname{IFI}\left(\mathrm{Sp} ; \mathrm{F}_{60}\right)$ Visando às Necessidades de Intervenção

Anexo 1 Cálculo de $\mathrm{F}_{60}$ em Função de Sp 


\section{Lista de Figuras}

\section{Capítulo 1 Introdução}

Figura 1.1.1 Produção de veículos no Brasil, vendas internas e xportações (ANFAVEA, 2006)

Figura 1.1.2 Fatores contribuintes de acidentes

\section{Capítulo 2 Revisão Bibliográfica}

Figura 2.1.1 Esquema de um Tribosistema

Figura 2.1.2 Deslocamento da água pelo pneu de acordo com o conceito das 3 zonas (adaptado de Silva e Rodrigues Filho, 1981 e Haas, 1994)

Figura 2.1.3 Influência da textura e da profundidade dos sulcos dos pneus no número de atrito e na ocorrência de acidentes (Wambold et al., 1986)

Figura 2.1.4 Tipo de Superfície em função da classe de macrotextura e microtextura

Figura 2.2.1 Tempo de reação do motorista e tempo de parada do veículo

Figura 2.3.1 Aparelhagem usada para o ensaio de mancha de areia e procedimento de execução (modificado Wambold et Henry, 2002 e Aps e Bernucci, 2003)

Figura 2.3.2 Comparação do ensaio de Mancha de Areia para diversas texturas

Figura 2.3.3 Correlação entre resultados do ensaio de mancha de areia realizados por dois operadores (Wambold e Henry, 2002)

Figura 2.3.4 Ensaio de Mancha de Graxa (Wambold e Henry, 2002)

Figura 2.3.5 Drenômetro a) Detalhe do temporizador eletrônico b) FHWA e PTI Outflow Meter - USA c) Skiddabrader Outflow Meter - USA (Wambold e Henry, 2002)

Figura 2.3.6 Correlação entre dois drenômetros diferentes (Wambold e Henry, 2002)

Figura 2.3.7 Drenômetro LTP - USP a) Momento de liberação da água b) Medida do tempo de escoamento (Aps et al., 2003)

Figura 2.3.8 Perfilômetro a Laser a) FHWA Texture Van - USA b) Virginia DOT Laser Texture Meter - USA (Wambold et Henry, 2002)

Figure 2.3.9 a) Circular Track Meter (CT Meter)- Japan b) Virginia DOT Circular Track Meter (CT Meter) - USA (Wambold et Henry, 2002) 
Figura 2.3.10 a) Vista geral do CTM d) Vista do sensor a laser (Henry et al., 2002) 38 Figura 2.3.11 Comparação dos resultados obtidos com os ensaios de mancha de Areia e CT Meter (Hanson e Prowell, 2004)

Figura 2.3.12 Mini Texture Meter-UK (Wambold e Henry, 2002)

Figura 2.3.13 VTI Laser Texture System (MPD, ETD, RMS) - Sweden (Wambold e Henry, 2002)

Figura 2.3.14 Pêndulo Britânico (a) em uso pelo LTP-EPUSP (Aps et al, 2003) b) em uso pela FHWA (Wambold e Henry, 2002)

Figura 2.3.15 Dynamic Friction Tester (DF Tester) a) Japan (Wambold e Henry, 2002) (b) Vista Geral do DF Tester (Brown,2002)

Figura 2.3.16 $B P N$ versus $D F T \quad 42$

Figura 2.3.17 Mu Meter - FAA - USA (Wambold e Henry, 2002) 43

Figura 2.3.18 Stradograph (a) Vista geral do equipamento (b) Detalhe da roda oblíqua (Wambold e Henry, 2002)

Figura 2.3.19 Vista do Odoliograph em operação (Wambold e Henry, 2002)

Figura 2.3.20 (a) Vista geral do equipamento (b) Detalhe da roda em posição de medição

Figura 2.3.21 E-274 Locked Wheel Tester - USA (a) PTI K. J. Law b) MD DOT c) Penn State (d) International Cybernetics (Wambold e Henry, 2002)

Figura 2.3.22 LCPC Skid Trailer a) Vista geral b) Detalhe do reboque (Wambold e Henry, 2002)

Figura 2.3.23 Stuttgarter Reibungmesser (Wambold e Henry, 2002)

Figura 2.3.24 Skiddometer (Wambold e Henry, 2002)

Figura 2.3.25 BV-11 - FAA USA (Wambold e Henry, 2002)

Figura 2.3.26 a) Surface Friction Tester - FAA - USA; b) Surface Friction Tester Sweden; c) Modelo TC79; d) Modelo TC85; (Wambold e Henry, 2002)

Figura 2.3.27 a) Grip Tester-NASA; b) Grip Tester - Scotland ; c) Grip Testerversão rebocada; d) Grip Tester versão manual; (Wambold e Henry, 2002)

Figura 2.3.28 Runway Friction Tester FAA - USA (Wambold e Henry, 2002) 50

Figura 2.3.29 Norsemeter OSCAR (variable slip tester)-Norway, Wambold e Henry, $2002 \quad 51$

Figura 2.3.30 Komatsu Skid Traile

Figura 2.3.31 DWW Trailer 51 
Figura 2.3.32 Stuttgarter Reibungmesser

Figura 2.4.1.1 Distintas graduações de misturas asfálticas usinadas a quente

Figura 2.4.1.2 Dois tipos de concretos asfálticos de graduação densa e bem-graduadas, (Bernucci, 2005)

Figura 2.4.1.3 Concreto asfáltico com grooving na superfície, (Bernucci, 2005)

Figura 2.4.1.4 Corpo-de-prova extraído de revestimento tipo CPA, (Bernucci, 2005)

Figura 2.4.1.5 Aspecto de um SMA na faixa 0/11S da curva da onça na Via Anchieta, (Bernucci, 2001)

Figura 2.4.1.6 Diferença de graduação entre um $S M A$ (corpo-de-prova superior) e um concreto asfáltico (corpo-de-prova inferior), (Bernucci, 2001)

Figura 2.4.1.7 Aspecto final de um BBTM logo após sua execução na Rodovia Castelo Branco em setembro de 2005, (Bernucci, 2005)

Figura 2.4.2.1 Desenho esquemático de um tratamento superficial simples (modificado de Nascimento, 2003)

Figura 2.4.2.2 Desenho esquemático de um tratamento superficial duplo (modificado de Nascimento, 2003)

Figura 2.4.2.3 Aspecto da textura de um tratamento superficial tipo antipó, (Bernucci, 2005)

Figura 2.4.2.4 Aspecto da textura de um tratamento superficial duplo, (Bernucci, 2005)

Figura 2.4.3.1 Aspectos comparativos de mancha de areia em um concreto asfáltico (foto à esquerda) e em um microrrevestimento asfáltico a frio (foto à direita), (Moura, 1998)

Figura 2.4.4.1 Agregados já polidos na superfície de um concreto asfáltico, (Bernucci, 2005)

Figura 2.4.5.1 Valores de CAL em função da velocidade em três diferentes revestimentos asfálticos (Brosseaud, 2002)

Figura 2.4.5.2 Variação da textura com o coeficiente de atrito para diversos tipos de misturas asfálticas.

Figura 2.4.6.1 Nível de som para fontes típicas de ruído (Bernhard e Wayson, 2005)

Figura 2 4.6.2 Principais fontes do ruído gerado pelo tráfego de veículos (Donavan, 2004 apud Bernhard e Wayson, 2005) 
Figura 2.4.6.3 Variação da propagação de ruído em superfícies de diferentes texturas (Hanson e James, 2004)

Figura 2.5.2.1 Processo de harmonização da curva de atrito versus velocidade de deslizamento

Figura 2.5.2.2 Significado das distintas zonas de um diagrama de atrito - textura

Figura 2.5.3.1 Modelo do IFI

\section{Capítulo 3 Pesquisa de Campo}

Figura 3.1 Distribuição dos valores pelos diferentes tipos de revestimentos asfálticos

\section{Capítulo 4 Análise de Dados}

Figura 4.1 Modelo geral de um processo para o delineamento de experimento (Calegare, 2001)

Figura 4.2.1 Esquema da ferramenta estatística Boxplot

Figura 4.2.2 Boxplot dos valores de $\mathrm{F}_{60}$ para amostra treinamento

Figura 4.4.1 Valores da amostra treinamento e faixas de classificação da $3^{\text {a }}$ Tentativa (Limites aceitáveis)

Figura 4.4.2 Valores da amostra treinamento com valores $F_{60}$ até 0,34

Figura 4.4.3 Amostra treinamento e limites aceitáveis

Figura 4.4.4 Dados referentes a valores de Concreto Asfáltico convencional

Figura 4.5.1 Características da forma dos grãos a) Micro esfera de vidro b) Areia

Normal Brasileira c) Areia comum

Figura 4.5.2 Seleção de trechos homogêneos

Figura 4.5.3 Homogeneidade existente entre os trechos

Figura 4.5.4 Dispersão da micro esfera de vidro com a Areia Normal Brasileira

\section{Capítulo 5 Estudo de Caso}

Figura 5.1.1: Trincamento no concreto asfáltico devido à reflexão de trincas das placas de concreto de cimento Portland

Figura 5.1.2: Aspecto da textura superficial de revestimento asfáltico tipo $S M A(a)$, e vista geral da curva onde foi executado o trecho experimental com SMA na Via Anchieta (b) 
Figura 5.1.3 Tráfego total pedagiado em 2005 (ABCR, 2005)

Figura 5.1.4 Acidentes ocorridos na Via Anchieta de 1998 a 2002

Figura 5.2.1 Mancha de Areia realizada em trecho em Concreto Asfáltico e trecho em SMA contíguos da SP-150 (ensaios realizados em 21/11/02)

Figura 5.3.3.4.1 Boxplots dos ensaios de Mancha de Areia realizados em diversas datas para pavimentos asfálticos tipo SMA

Figura 5.3.3.4.2 Boxplots dos ensaios de Atrito realizados em três datas distintas para pavimentos asfálticos $S M A$

Figura 5.4.1 Valores de atrito versus valores de textura em função de limites sugeridos pelo DNIT, 2000

Figura 5.4.2 Valores de IFI, $(\mathrm{Sp})$ versus $\left(\mathrm{F}_{60}\right)$ em função de limites sugeridos na $4^{\mathrm{a}}$. Tentativa 


\section{Lista de Tabelas}

\section{Capítulo 1 Introdução}

Tabela 1.1.1 Fatores Contribuintes de Acidentes (modificado de Sabey, 1980)

\section{Capítulo 2 Revisão Bibliográfica}

Tabela 2.1.1 Cronologia do desenvolvimento do conhecimento do atrito (apud Silva, 1998)

Tabela 2.1.2 Hidroplanagem: total e parcial, modelo das 3 zonas (adaptado de Silva e Rodrigues Filho, 1981; Silva, 1981; Pottinger, 1986)

Tabela 2.1.3 Classificação da Textura (ASTM E-867, 1997)

Tabela 2.1.4 Valores de atrito de acordo com a AASHTO $(1994,2001)$ e Guzmán (1995)

Tabela 2.1.5 Cálculo de $D_{2}$ para os valores de atrito da Tabela 2.1.4

Tabela 2 5.2.1 Coeficiente de correlação das regressões lineares dos equipamentos de medição de atrito

Tabela 2.5.2.2 Coeficiente de correlação das regressões lineares dos equipamentos de medição de textura

Tabela 2.5.2.3 Repetibilidade das medidas realizadas no experimento internacional com os equipamentos de medição de atrito

Tabela 2.5.3.1 Valores de a e b para cálculo de Sp

Tabela 2.5.3.2 Relação de equipamentos que foram calibrados para obtenção de $F_{60}$

Tabela 2.6.1.1.1 Classificação da macrotextura superficial do revestimento (DNER, 1998)

Tabela 2.6.1.1.2 Valores limites de CAT e VRD propostos pelo Comitê Marshall, (DNER, 1998)

Tabela 2.6.1.1.3 Faixas de Classificação de $\mathbb{F} I-2^{\mathrm{a}}$ Tentativa

Tabela 2.6.1.2.1 Classificação da microtextura com o Pêndulo Britânico (ABPv1998)

Tabela 2.6.2.1.1 Níveis para investigação do atrito

Tabela 2.6.2.1.2 Níveis para investigação da textura 
Tabela 2.6.2.2.1 Valores estabelecidos para a textura

Tabela 2.6.2.2.2 Valores estabelecidos para o atrito

Tabela 2.6.3.1.1 Níveis de intervenção para textura

Tabela 2.6.3.1.2 Níveis de intervenção para atrito

Tabela 2.6.3.2.1 Valores de microtextura e macrotextura para recebimento de obras novas

Tabela 2.6.3.2.2 Valores de microtextura para intervenções

Tabela 2.6.4.1.1 Valores limites para atrito

Tabela 2.6.4.1.2 Valores de IFI $\left(\mathrm{F}_{60}\right)$

\section{Capítulo 3 Pesquisa de Campo}

Tabela 3.1.1.1 Valores obtidos para o Aeroporto Internacional de São Paulo/Guarulhos

Tabela 3.1.2.1 Valores obtidos para o Aeroporto - Congonhas

Tabela 3.1.3.1 Valores obtidos para o Campo de Marte

Tabela 3.2.1.1 Resultados coletados de macrotextura e microtextura de Reis (2002), e valores calculados de IFI-SP 150

Tabela 3.2.1.2 Resultados obtidos em 11/11/ 2002 - SP 150

Tabela 3.2.1.3 Resultados obtidos em 11/06/ 2003 e valores de IFI- SP 150

Tabela 3.2.1.4 Resultados obtidos de macrotextura, microtextura, drenabilidade, em maio de 2006 e valores de IFI calculados - SP 150

Tabela 3.2.2.1 Valores obtidos em campo e valores de IFI calculados - SP 75

Tabela 3.2.3.1 Valores obtidos em campo e valores de IFI calculados - SP 348

Tabela 3.2.4.1 Resultados obtidos em julho de 2000 e valores de IFI calculados - BR 116

Tabela 3.2.5.1 Resultados obtidos em agosto de 2002 (Oliveira et al., 2004) e valores de IFI calculados - RST 101

Tabela 3.2.5.2 Resultados obtidos em abril de 2004 (Oliveira et al., 2004) valores de IFI calculados - RST 101

Tabela 3.2.5.3 Resultados obtidos em setembro de 2004 (Oliveira et al., 2004) e valores de IFI calculados - RST 101 
Tabela 3.2.6.1 Resultados de obtidos em agosto de 2006 e valores de IFI calculados LTP - EPUSP

Tabela 3.3.1.1 Resultados obtidos dos ensaios e valores de IFI calculados

Tabela 3.3.1.2 Resultados obtidos em 24/03/06 e valores de IFI calculados

Tabela 3.3.2.1 Resultados obtidos e valores de IFI calculados (Aps et al., 2003-e)

Tabela 3.4.1.1 Resultados obtidos por meio do ensaio Mancha de Areia e Pêndulo 106 Britânico em março de 2003 e valores de IFI calculados

Tabela 3.4.2.1 Resultados obtidos por meio do ensaio Mancha de Areia, Pêndulo 107 Britânico e Drenabilidade em19/03/2003 e valores de IFI calculados

Tabela 3.4.2.2 Atrito obtido por meio de ônibus rodoviário monitorado, março 2003

\section{Capítulo 4 Análise de Dados}

Tabela 4.1.1 Resumo dos dados da pesquisa

Tabela 4.2.1 Banco de dados da amostra treinamento para valores de $F_{60}$

Tabela 4.3.1 Matriz de correlação linear para Concreto Asfáltico

Tabela 4.3.2 Matriz de covariância para Concreto Asfáltico

Tabela 4.3.3 Matriz de correlação linear Concreto Asfáltico modificado por SBS

Tabela 4.3.4 Matriz de covariância para Concreto Asfáltico modificado SBS

Tabela 4.3.5 Matriz de correlação linear para Camada Porosa de Atrito

Tabela 4.3.6 Matriz de covariância para Camada Porosa de Atrito

Tabela 4.37 Matriz de correlação linear para Grooving

Tabela 4.3.8 Matriz de covariância para Grooving

Tabela 4.3.9 Matriz de correlação linear para Microrrevestimento Asfáltico a Frio

Tabela 4.3.10 Matriz de covariância para Microrrevestimento Asfáltico a Frio

Tabela 4.3.11 Matriz de correlação linear para Stone Matrix Asfhalt (SMA) - 0/11

Tabela 4.3.12 Matriz de covariância para Stone Matrix Asfhalt (SMA) - 0/11

Tabela 4.3.13 Matriz de correlação linear para TSD com aplicação de Capa Selante

Tabela 4.3.14 Matriz de covariância para TSD com aplicação de Capa Selante

Tabela 4.3.15 Matriz de correlação linear para TSS com Lama Asfáltica 
Tabela 4.3.18 Correlação linear entre os valores de $F_{60}$ (calculados) e os valores obtidos em campo de HS ( $\mathrm{mm}$ ) e BPN

Tabela 4.4.1 Faixas propostas $1^{\text {a }}$ Tentativa (Aps et al.,2004-a)

Tabela 4.4.2 Faixas propostas $2^{\mathrm{a}}$ Tentativa (Aps et al.,2004-b)

Tabela 4.4.3 Faixas propostas $3^{\text {a }}$ Tentativa (Aps et al.,2005)

Tabela 4.4.4 Classificação da macrotextura com ampliação para sete categorias

Tabela 4.4.5 Faixas propostas $4^{\mathrm{a}}$ Tentativa

Tabela 4.4.6 Faixas de variação $\left(F_{60}\right)$ para a amostra treinamento

Tabela 4.4.7 Valores de IFI $\left(S p ; F_{60}\right)$ para recomendações do DNIT e da ARTESP

Tabela 4.5.1 Resultados obtidos para micro esferas de vidro

Tabela 4.5.2 Resultados obtidos para Areia Normal Brasileira em duas granulometrias

Tabela 4.5.3 Valores médios por trechos e tipo de material

Tabela 4.5.4 Desvio padrão por trechos e tipo de material

Tabela 4.5.5 Matriz de correlação linear (Pearson)

\section{Capítulo 5 Estudo de Caso}

Tabela 5.2.1 Resultados coletados de macrotextura e microtextura de Reis (2002) e cálculo de IFI em março de 2002

Tabela 5.2.2 Resultados obtidos do ensaio de macrotextura para a Via Anchieta em novembro de 2002 (Aps et al., 2003b)

Tabela 5.2.3 Resultados obtidos de macrotextura, microtextura, drenabilidade e cálculo de valores de IFI para a Via Anchieta em junho de 2003 (Aps et al., 2003b)

Tabela 5.2.4 Resultados obtidos do ensaio de macrotextura, microtextura e cálculo de valores de IFI em maio de 2006 realizados por técnicos do IPT

Tabela 5.3.1.1 Matriz de correlação linear (Pearson) para Concreto Asfáltico

Tabela 5.3.1.2 Matriz de covariância para Concreto Asfáltico

Tabela 5.3.2.1 Matriz de correlação linear (Pearson) para Concreto Asfáltico modificado

Tabela 5.3.2.2 Matriz de covariância para Concreto Asfáltico modificado

Tabela 5.3.3.1.1 Matriz de correlação linear (Pearson) para SMA - março 2002

Tabela 5.3.3.1.2 Matriz de covariância para SMA - março 2002

Tabela 5.3.3.2.1 Matriz de correlação linear (Pearson) para SMA - junho 2003 
Tabela 5.3.3.2.2 Matriz de covariância para SMA - junho 2003

Tabela 5.3.3.3.1 Matriz de correlação linear (Pearson) para SMA - maio 2006

Tabela 5.3.3.3.2 Matriz de covariância para SMA - maio 2006

Tabela 5.4.1 Faixas limites de valores de $\operatorname{IFI}\left(\mathrm{F}_{60}\right) 3^{\mathrm{a}}$ Tentativa

Tabela 5.4.2 Valores de $\mathrm{F}_{60}$ recalculados para outras velocidades 


\section{Lista de Abreviaturas}

\begin{tabular}{|c|c|}
\hline AASHTO & American Association of State Highway and Transportation Officials \\
\hline AIPCR & Association International Permanente des Congress de la Route \\
\hline ANFAVEA & Associação Nacional dos Fabricantes de Veículos Automotores \\
\hline ARTESP & Agência de Transportes do Estado de São Paulo \\
\hline ASTM & America Society for Testing and Materials \\
\hline BPN & British Number Pendulum \\
\hline CA & Concreto Asfáltico \\
\hline CAL & Coeficiente de Atrito Longitudinal \\
\hline CAT & Coeficiente de Atrito Longitudinal \\
\hline CBA & Código Brasileiro de Aeronáutica \\
\hline CBUQ & Concreto Betuminoso Usinado a Quente \\
\hline CCP & Concreto de Cimento Portland \\
\hline CEN & Comité Européen de Normalisation \\
\hline CPA & Camada Porosa de Atrito \\
\hline CS & Cape Seal \\
\hline DERSA & Departamento Rodoviário S/A \\
\hline DFT & Dynamic Friction Tester \\
\hline DIRENG & Diretoria de Engenharia da Aeronáutica \\
\hline DNER & Departamento Nacional de Estradas de Rodagem \\
\hline DNIT & Departamento Nacional de Infra-Estrutura de Transportes \\
\hline EPUSP & Escola Politécnica da Universidade de São Paulo \\
\hline $\boldsymbol{F A A}$ & Federal Aviation Administration \\
\hline FHWA & Federal Highway Administration \\
\hline IA & Asphalt Institute \\
\hline $\boldsymbol{I} \boldsymbol{F I}$ & International Friction Index \\
\hline IRI & International Roughness Index \\
\hline IPT & Instituto de Pesquisas Tecnológicas do Estado de São Paulo \\
\hline ISETH & Institute for Highways, Railroads and Rock Engineering \\
\hline
\end{tabular}




$\begin{array}{ll}\text { ISO } & \text { International Standards Organization } \\ \text { LTP } & \text { Laboratório deTecnologia de Pavimentação } \\ \text { MDP } & \text { Mean Profile Depth } \\ \text { NASA } & \text { National Aeronautics and Space Administration } \\ \text { NCHRP } & \text { National Cooperative Highway Research Program } \\ \text { OFT } & \text { Outflow Time } \\ \text { PFC } & \text { Porous Friction Course } \\ \text { PIARC } & \text { Permanent International Association of Road Congress atual World Road } \\ & \text { Association } \\ \boldsymbol{R M S} & \text { Root Mean Square of Texture Profile } \\ \text { SBR } & \text { Estireno - Butadieno - Borracha } \\ \text { SBS } & \text { Estireno - Butadieno - Estireno } \\ \text { SCRIM } & \text { Sideways Force Coefficient Routine Investigation Machine } \\ \text { SFT } & \text { Surface Friction Tester } \\ \text { SMA } & \text { Stone Matrix Asphalt } \\ \text { SRT } & \text { Skid Resistent Test } \\ \text { TRB } & \text { Transportation, Research Board } \\ \text { TRRL } & \text { Transport and Road Research Laboratory } \\ \text { TS } & \text { Tratamento Superficial } \\ \text { VRD } & \text { Valor de Resistência à derrapagem } \\ \end{array}$




\section{Lista de Símbolos}

$\mu$

$\mu_{\mathbf{a}}$

$\mu_{\mathbf{D}}$

$\mu_{\mathbf{h}}$

a

$\mathbf{a} \mathbf{e}$

A, B e C

$D_{1}$

$D_{2}$

$\mathbf{F}$

f

$\boldsymbol{F R}_{60}$

FRS

g

$\boldsymbol{G F}_{60}$

$\boldsymbol{G F}_{\boldsymbol{S}}$

GS

i

N

$\boldsymbol{S}$

t

$T_{x}$

$D_{m}$

$H_{M}$
Coeficiente de atrito

Coeficiente de atrito por adesão

Coeficiente de atrito devido ao deslizamento

Coeficiente de atrito por histerese

Taxa média de desaceleração

Constantes determinadas em função do equipamento utilizado

Constantes de calibração próprias para um determinado equipamento

Distância percorrida durante o tempo de reação do motorista

Distância referente ao tempo de parada do veículo após o início da frenagem

Força de atrito

Coeficiente de atrito longitudinal pneu-pavimento

Valor do atrito do equipamento convertido à velocidade de $60 \mathrm{~km} / \mathrm{h}$

Atrito medido pelo equipamento a velocidade de deslizamento $\mathrm{S}$

Aceleração da gravidade

Valor do atrito na "Curva de Referência"

Valor do atrito da "Curva de Referência", na velocidade de deslizamento S

Parâmetro que representa a influência da velocidade na "Curva de Referência"

Greide

Força Normal

Velocidade de deslizamento

Tempo de reação e percepção do motorista

Parâmetro de textura, determinado a partir de valores obtidos para a determinação da macrotextura em função do equipamento utilizado

Diâmetro médio da mancha de areia

Altura média da mancha de areia 
HG

v

Altura média da mancha de graxa

Velocidade do veículo 


\section{Capítulo 1 Introdução}

\subsection{Considerações Iniciais}

A qualidade do pavimento asfáltico, no Brasil, tem apresentado significativa melhora; novas técnicas e materiais têm sido utilizados na execução de camadas de rolamento de vias urbanas, rodovias e aeroportos. A indústria automobilística, além do aumento de sua produção, conforme pode ser observado na Figura 1.1.1 de acordo com dados publicados pela ANFAVEA (2006), Associação Nacional dos Fabricantes de Veículos Automotores, apresenta a evolução nos modelos dos veículos que estão, de acordo com os fabricantes, mais estáveis, velozes e silenciosos; a mesma constatação pode ser estendida para a indústria aeronáutica que vem produzindo aeronaves, cada vez mais estáveis e com recursos modernos de segurança.

A indústria de pneus oferece cada vez mais modelos apropriados para diversas situações de utilização, como aqueles para pistas sinuosas, os que proporcionam resposta rápida, os que oferecem aderência em pistas molhadas e outros para melhor dirigibilidade e segurança. A indústria de pneus tem mostrado a mesma preocupação para aeronaves, onde a elevada deformação é controlada e a aderência é uma das grandes preocupações.

A combinação desses fatores, camadas de rolamento confortáveis, veículos estáveis e esses associados a pneus aderentes, induz o motorista a praticar velocidades cada vez mais elevadas; quando qualquer um desses fatores ou a combinação deles deixa de ser capaz de manter o veículo em segurança, há a ocorrência de acidentes. Mais uma vez, a mesma situação pode ser estendida para o controle das aeronaves, que além de acidentes podem sofrer incidentes, principalmente nos pousos, onde se requerem boas condições da aeronave, habilidade do piloto e adequadas condições de pista quanto à aderência e irregularidade. 


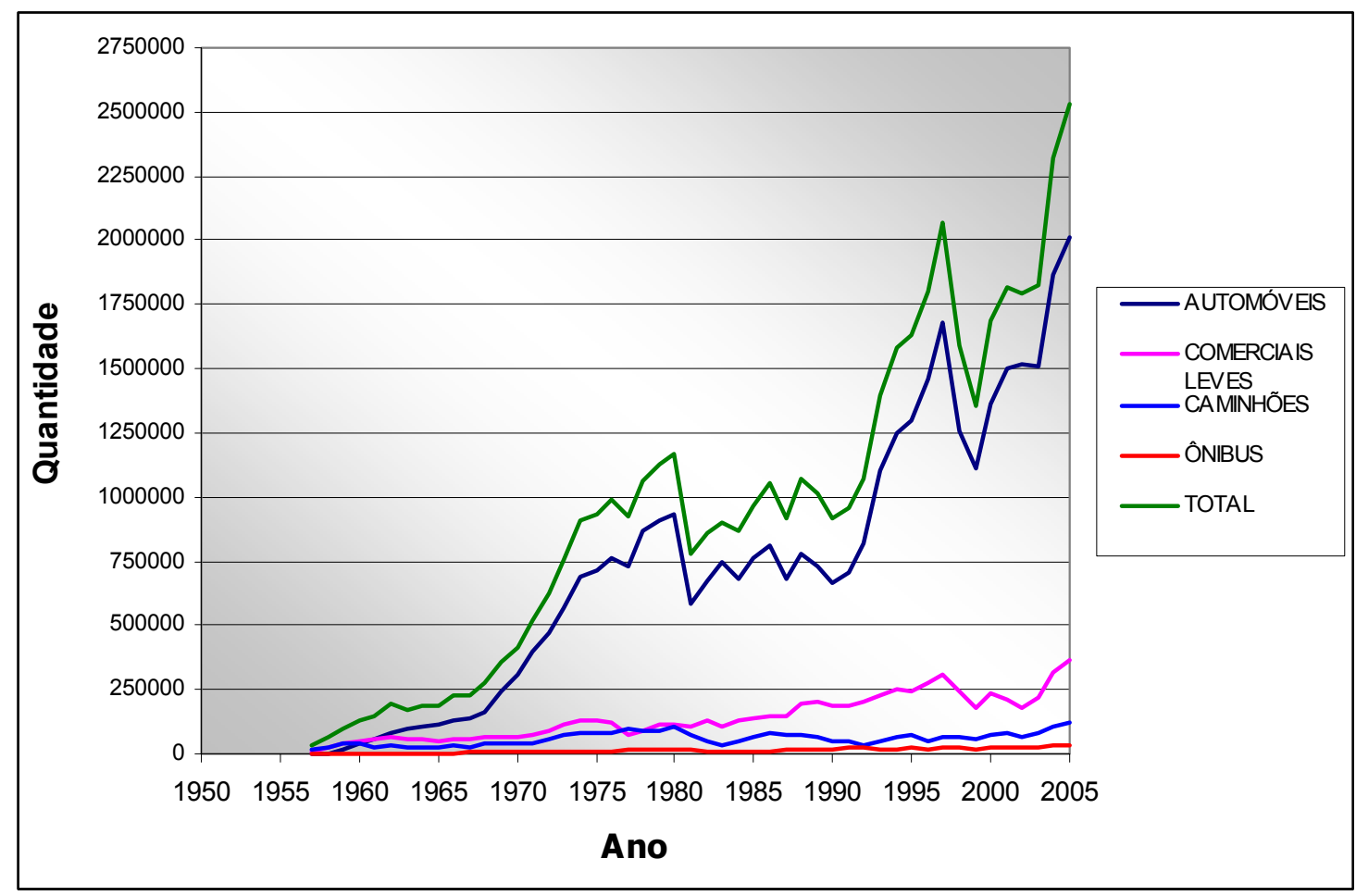

Figura 1.1.1 Produção de veículos no Brasil, vendas internas e exportações (ANFAVEA, 2006)

Ivey e Gallaway (1973) citam em termos de aderência, que quatro fatores contribuem para que um acidente ocorra. São eles: o motorista, devido ao seu comportamento, o veículo, de acordo com suas características, o pavimento, em função da camada de rolamento, e as condições do meio ambiente. As interfaces e as possíveis combinações desses fatores, conforme apresentado graficamente na Figura 1.1.2 com dados publicados por Sabey (1980). As mesmas interações são válidas para o caso aeroportuário: pista, piloto, aeronave e meio ambiente.

Considerando que em um sistema viário, acidentes são quaisquer eventos que produzam danos materiais ou humanos, e que segurança é a capacidade de deslocar-se e realizar atividades sem sofrer danos materiais, de integridade física e mesmo de conforto mental, verifica-se a complexidade das variáveis envolvidas quando se tenta diagnosticar a real causa de cada acidente.

Considerando que acidentes são quaisquer eventos que produzam danos materiais ou humanos e que incidente é qualquer evento que apresente risco potencial da 
ocorrência de acidentes, na aviação civil a investigação dos incidentes segue as mesmas características que a investigação de acidentes com o mesmo empenho de evitar a sua recorrência. O Código Brasileiro de Aeronáutica (CBA), Lei 7565, de 19 de dezembro de 1986, em seu artigo 25, estabelece que a infra-estrutura aeronáutica, também destinada a promover a segurança, a regularidade e a eficiência da aviação civil, é composta, dentre outros, pelo registro de acidentes em cada país (Aps et al., 2003-a).

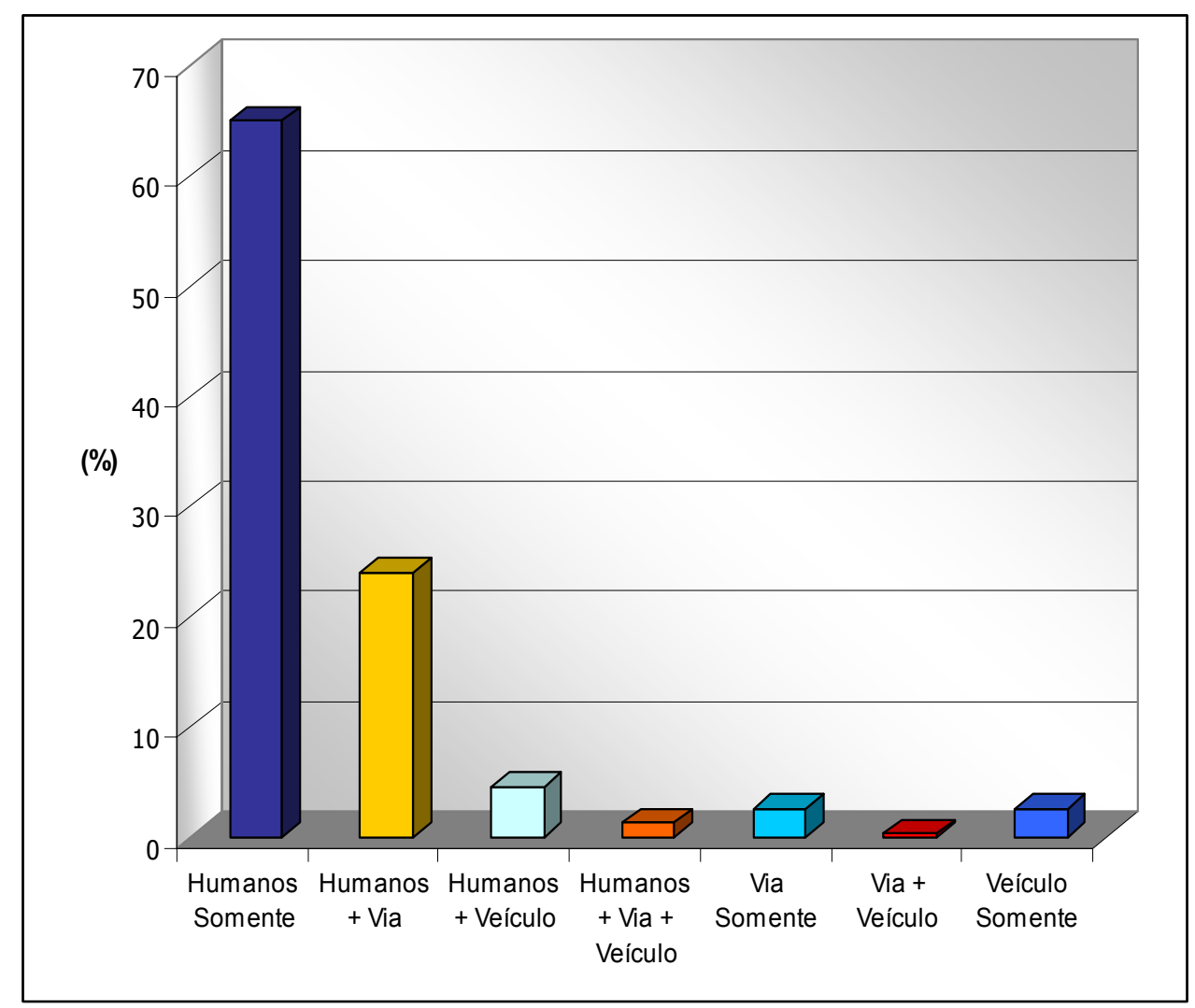

Figura 1.1.2 Fatores contribuintes de acidentes

Os acidentes e incidentes viários e aeroportuários podem ser usados como medida direta ou pelo menos indireta da segurança, pois eles testemunham a falta de segurança, ou seja, a insegurança que uma determinada via ou pista apresenta ${ }^{1}$.

Em uma pesquisa sobre fatores contribuintes de acidentes, realizada por Sabey (1980), foram estudados 2042 casos nos quais foram observadas 4688 ocorrências,

\footnotetext{
${ }^{1}$ Pietratônio, H.; Segurança Viária. Notas de Aula. EPUSP, SP, São Paulo - 2002.
} 
o que mostra que nem sempre um fator ocorre isoladamente. Nesta pesquisa, os fatores foram classificados em função de sua causa, como os devido às falhas humanas, da via e dos veículos. Como fatores humanos foram considerados as deficiências em ação, em comportamento e saúde, erros de percepção e de falta de habilidade. Projeto desfavorável, meio ambiente adverso, sinalização e obstáculos foram computados à via; e aos veículos, os defeitos em pneus, freios ou outras falhas devido à falta de manutenção.

Os resultados foram analisados por uma equipe multidisciplinar que os associou à causa, considerando as possíveis interações que ocorreram, conforme pode se observar na Tabela 1.1.1. É importante ressaltar o cuidado de interpretação desses dados, pois com freqüência no meio rodoviário assume-se que aproximadamente $2 \%$ dos acidentes são de responsabilidade exclusivamente da via; mas, como a Tabela 1.1.1 evidencia, esse valor representa isoladamente a contribuição da via e na maioria das vezes um acidente possui mais de um fator contribuinte, e quando são estudadas as interações entre os fatores contribuintes de acidentes, esse valor aumenta significativamente.

Pode ser claramente observado na Tabela 1.1.1 que os valores de acidentes referentes às deficiências da via incluindo aqueles onde participou em conjunto com outros fatores totalizaram $28 \%$.

Tabela 1.1.1 Fatores contribuintes de acidentes (modificado de Sabey, 1980)

\begin{tabular}{l|c|cc}
\hline \hline Fatores Contribuintes & $\begin{array}{c}\text { \% } \\
\text { Individuais }\end{array}$ & $\begin{array}{c}\text { Somatória } \\
\text { Envolvendo a Via } \\
\text { (\%) }\end{array}$ \\
\hline \hline Humanos Somente & 65 & \multicolumn{2}{|c}{} \\
\hline Humanos + Via & 24 & $\rightarrow$ & 24 \\
\hline Humanos + Veículo & 4,5 & & 1,25 \\
\hline Humanos + Via + Veículo & 1,25 & $\rightarrow$ & 2,5 \\
\hline Via Somente & 2,5 & $\rightarrow$ & 0,25 \\
\hline Via + Veículo & 0,25 & $\rightarrow$ & $\mathbf{2 8}$ \\
\hline Veículo Somente & 2,5 & & \\
\hline \multicolumn{1}{c|}{ Total } & $\mathbf{1 0 0}$ & & \\
\hline \multicolumn{1}{|r}{}
\end{tabular}


Essa participação média não reflete sua importância em locais específicos como curvas fechadas, regiões de declives, de condições climáticas adversas entre outros fatores condicionantes.

Além disso, as coletas de dados de acidentes, geralmente, não são precisas, pois dificilmente consegue-se registrar todos os acidentes que ocorrem em um determinado trecho em avaliação; aqueles em que há vitimas, possuem maior precisão de registros, proporcionalmente àqueles em que só ocorreram danos materiais (Sabey, 1980).

Sabendo-se que o usuário de um sistema viário espera que o pavimento forneça: segurança, conforto e economia, são necessários constantes estudos sobre a aderência que a camada de rolamento proporciona ao usuário. Para tal, é necessário o entendimento dos mecanismos da aderência.

A aderência pneu-pavimento no meio rodoviário, geralmente, é verificada por meio do coeficiente de atrito existente nesta interação. Na atualidade, a textura superficial vem sendo considerada como fator também determinante na aderência. Este fato vem sendo reconhecido recentemente, porém as recomendações são genéricas e os critérios propostos são de grande amplitude.

Diversos editais para a concessão e exploração das rodovias federais fixam padrões técnicos para a aceitabilidade dos vários serviços e obras que compõem os referidos editais. Entre esses padrões de exigências o item Condições de Segurança desses documentos, como por exemplo, DNER (2000), recomenda que: as condições de aderência pneumático-pavimento sejam as melhores possíveis, não vindo a comprometer a segurança do usuário. Especifica ainda, em caráter provisório, até a oficialização de normas nacionais sobre o tema, valores mínimos para a camada de rolamento, composta de misturas betuminosas, como segue: macro-rugosidade verificada por meio da altura de areia (HS) deve estar no intervalo de 0,60 a 1,20 mm; e a condição de atrito obtida por meio do pêndulo Britânico, expressa em valor de resistência à derrapagem, deve estar no intervalo de 47 a 75. (DNER, 2000). 
Observa-se que as faixas de valores para as condições de aderência, visando à segurança, contidas nesses editais, não especificam os valores em função dos diversos tipos de misturas asfálticas, do tráfego atuante, da velocidade limite, das variações climáticas - como as condições pluviométricas, das características geométricas, entre outros fatores e ainda das possíveis combinações desses.

Recentemente em 2006, o DNIT incluiu em seu Manual de Restauração de Pavimentos Asfálticos faixas de manchas de areia, valores mínimos do Pêndulo Britânico e faz referência às faixas de valores de IFI - International Friction Index, propostas originalmente em Aps et al. (2004-b).

Essa mesma preocupação pode ser observada em estudos relacionados a projetos geométricos como, por exemplo, Osório (2000), que em sua dissertação de mestrado, avaliou a consistência do traçado de rodovias, em relação ao projeto de curvas horizontais em rodovias de pista simples, e sugere em suas conclusões que sejam realizadas pesquisas que forneçam valores do coeficiente de atrito para a realidade brasileira, visando à aplicação em novos projetos viários e a avaliação dos alinhamentos existentes.

\subsection{Objetivos do Trabalho}

A caracterização da macrotextura e microtextura da superfície de pavimentos asfálticos pode ser obtida por meio de diversos tipos de equipamentos; com objetivo de uniformizar os resultados obtidos por meio desses ensaios, o Comitê de Características de Superfície (C1) da PIARC (Permanent International Association of Road Congress, atualmente denominada de World Road Association) ou AIPCR (Association International Permanente des Congrèss de la Route) realizou uma experiência internacional, em 1992, para a comparação e harmonização destes métodos de medidas de textura e atrito (Wambold et al., 1995). 
Os objetivos iniciais do Experimento Internacional da PIARC foram atingidos e as correlações entre equipamentos e a criação de um índice internacional IFI International Friction Index, foram realizados. Além deste objetivo, essencial para tratar de forma homogênea o critério da aderência a PIARC estabeleceu novas metas para o estudo deste índice (Wambold et al., 1995). A primeira delas foi a recomendação da publicação de normas para regulamentar o cálculo do IFI; esta meta foi atingida pela publicação da norma ASTM E 1960-98 Standard Practice for Calculating International Friction Index of a Pavement Surface.

A segunda meta é que os órgãos e as concessionárias que administram rodovias aceitem e utilizem essas normas, o que têm sido uma realidade na Europa e América do Norte; no caso brasileiro importante etapa foi alcançada com a publicação do Manual de Restauração de Pavimentos Asfálticos (DNIT, 2006) que já recomenda o uso do IFI com base em trabalho de Aps et al. (2004-b).

A terceira meta da recomendação da PIARC diz respeito à formação de grupos de trabalhos internacionais para fixar faixas de valores aceitáveis para a realização de intervenções que possam ser utilizadas em gerencia de pavimentos em todo o mundo.

De acordo com o exposto, o objetivo central desta tese é estabelecer critérios e faixas de classificação que definam os índices desejados ou mesmo os limites aceitáveis para a aderência em função do par de valores de IFI (Sp; $\left.\mathrm{F}_{60}\right)$ de pavimentos asfálticos. Para atingir o objetivo central as seguintes metas foram desenvolvidas:

a) Verificar a aplicabilidade da norma da ASTM E-1960-98 que define valores de IFI International Friction Index,

b) Demonstrar que valores de macrotextura e microtextura obtidos por meio de aparelhagem portátil podem ser empregados para o cálculo dos valores de IFI; 
c) Estimar as relações existentes entre as medidas de atrito, textura e drenabilidade variando as superfícies ensaiadas;

d) Estabelecer critérios e faixas de classificação para a aderência em função de $\operatorname{IFI}\left(\mathrm{Sp} ; \mathrm{F}_{60}\right)$.

\subsection{Metodologia da Pesquisa}

Para atingir os objetivos propostos várias etapas de estudo foram realizadas:

a) A compreensão dos fenômenos que ocorrem na interação pneu-pavimento, por meio da verificação dos mecanismos da física tradicional, normalmente usada no meio rodoviário e aeroportuário, com os conceitos de interdisciplinaridade preconizados pela Tribologia;

b) A Revisão bibliográfica dos tipos de equipamentos de medição das características de superfície, procedimentos de ensaio e métodos de cálculo de índices combinados; a partir deste conhecimento, optou-se por equipamentos portáteis incluindo a organização e seleção para aquisição de um Pêndulo Britânico para o LTP/USP;

c) A organização de uma estratégia de coleta de dados em campo, envolvendo a seleção dos tipos de revestimentos asfálticos que seriam avaliados. Foram considerados diversos tipos de superfícies asfálticas: Areia Asfalto (AA), Concreto Asfáltico com asfalto convencional (CA), Concreto Asfáltico modificado por Borracha (CA bor), Concreto Asfáltico modificado por Polímero do tipo SBS (CA SBS), Camada Porosa de Atrito (CPA), Capa Selante (CS), Concreto Asfáltico com Grooving (G), Lama Asfáltica (LA), Microrrevestimento Asfáltico a Frio (Micro), Stone Matrix Asfhalt (SMA) - tipo 0/11 e 0/16 e Tratamentos Superficiais, Simples e Duplo (TS); 
d) A concepção de faixas tentativas de classificação de valores de IFI com base na experiência profissional, conhecimentos de valores limites de macrotextura e microtextura, e tratamentos estatísticos de dados de campo. A partir de conceitos estatísticos decidiu-se utilizar os dados da Via Anchieta SP-150, coletados de forma sistemática e periódica, para validação das faixas classificatórias concebidas.

A partir da realização das etapas citadas acima, conclui-se a tese na $4^{\underline{a}}$ Tentativa de faixas classificatórias de superfícies asfálticas em relação à aderência pneupavimento, por meio do de um índice combinado IFI, que podem vir a ser utilizadas por órgãos viários, gestores e concessionárias para a realização de intervenções que possam ser utilizadas em gerencia de pavimentos. 


\section{Capítulo 2 Revisão Bibliográfica}

A aderência produzida na interação pneu-pavimento é um dos fatores que contribui para a segurança viária; camadas de rolamento com boa aderência, ou seja, com adequadas características superficiais podem reduzir a distância de frenagem, principalmente em pavimentos molhados, e manter em todo o tempo de percurso a trajetória desejada para o veículo. Para entendimento do que ocorre nessa interação há necessidade da revisão de alguns fenômenos e conceitos.

\subsection{O Fenômeno Físico da Aderência e a Interação Pneu Pavimento}

De acordo com a norma de terminologia G40 da ASTM (2001), força de atrito é a força tangencial resistente, atuante na interface entre dois corpos, resultante da ação de uma força externa de um corpo que se move ou tende a se mover sobre o outro; e coeficiente de atrito é a razão dessa força tangencial, resistente ao movimento entre dois corpos, e a força normal aplicada a estes corpos. Matematicamente o coeficiente de atrito é descrito pela equação 2.1.1.

$$
\mu=\frac{F}{N}
$$

Onde:

$$
\begin{aligned}
& \mu=\text { coeficiente de atrito; } \\
& F=\text { força de atrito; } \\
& N=\text { força normal. }
\end{aligned}
$$

A evolução do conhecimento do atrito com o passar do tempo foi descrita por Dowson (1979) apud Silva (1998) e apresentada na Tabela 2.1.1. 
Tabela 2.1.1 Cronologia do desenvolvimento do conhecimento do atrito (apud Silva, 1998)

\begin{tabular}{l|c|l}
\hline \hline \multicolumn{1}{c|}{ Autor } & Ano & \multicolumn{1}{c}{ Conhecimento } \\
\hline \hline Leonardo da Vinci & 1495 & $\begin{array}{l}\text { A força de atrito é proporcional a força normal; } \\
\text { A força de atrito independe da área de contato; } \\
\text { A força de atrito é igual a 0,25 da força normal. }\end{array}$ \\
\hline Robert Hooke & 1685 & $\begin{array}{l}\text { O atrito por rolamento é menor para materiais com } \\
\text { maiores módulos de elasticidade. }\end{array}$ \\
\hline Isaac Newton & 1687 & $\begin{array}{l}\text { O atrito em sistemas lubrificados depende das } \\
\text { propriedades viscosimétricas do fluído. }\end{array}$ \\
\hline Guillame Amontons & 1699 & $\begin{array}{l}\text { Confirma a independência entre atrito e área de } \\
\text { contato; de ditro de } \\
\text { Materiais diferentes apresentam valores de atrito } \\
\text { diferentes; } \\
\text { O atrito é causado pela interferência entre asperezas. }\end{array}$ \\
\hline J. T. Desaguulies & 1725 & $\begin{array}{l}\text { Forma o primeiro banco de dados sobre o atrito para } \\
\text { vários pares de materiais; } \\
\text { Introduz o conceito de coesão entre superfícies. }\end{array}$ \\
\hline \hline Leonnard Euler & 1750 & $\begin{array}{l}\text { Introduz o símbolo } \mu \text { para o coeficiente de atrito; } \\
\text { Conceitua o atrito estático; } \\
\text { Estabelece que o coeficiente de atrito estático é maior } \\
\text { que o dinâmico. }\end{array}$ \\
\hline A. Coulomb & 1785 & $\begin{array}{l}\text { Sugere que atrito possui uma componente de adesão e } \\
\text { outra de deformação; } \\
\text { Analisa o tempo de resposta da força de atrito; } \\
\text { Sugere que a força de atrito é causada pelo } \\
\text { intertravamento de asperezas. }\end{array}$ \\
\hline & $\begin{array}{l}\text { Estima que coeficiente de atrito entre metais de } \\
\text { elevada dureza é igual a 1/6; } \\
\text { Propõe que metais de baixa dureza apresentam } \\
\text { maiores coeficientes de atrito; } \\
\text { Estabelece que o coeficiente de atrito de metais } \\
\text { lubrificado depende do lubrificante e não do metal. }\end{array}$ \\
\hline
\end{tabular}

$\mathrm{Na}$ interação do pneu com o pavimento são possíveis duas situações extremas de contato, as quais vão definir os mecanismos de aderência e desgaste: o pneu rodando e o pneu sob deslizamento na superfície do pavimento com a roda travada, durante uma frenagem de emergência. Dois mecanismos, a aderência e o desgaste, são desenvolvidos na área de contato do pneu com o pavimento, em um veículo em movimento. Há uma zona maior onde o atrito por rolamento é predominante e zonas menores, onde a força de atuante supera o limite de aderência iniciando-se deslizamentos localizados. 
Normalmente, no meio rodoviário, assume-se que o coeficiente de atrito pneupavimento é composto de duas parcelas: o atrito devido à adesão, proveniente da atração molecular das superfícies (forças de van der Waals), e o atrito devido à perda por histerese, resultante da deformação cíclica da superfície dos pneus, pelas asperezas do pavimento, conforme expresso na Equação 2.1.2. Este comportamento combinado é conseqüência direta da viscoelasticidade da borracha, e traduz-se na perda de energia através da geração de calor devido aos movimentos intermoleculares.

$$
\mu d=\mu a+\mu h
$$

Onde:

$$
\begin{aligned}
& \mu d=\text { coeficiente de atrito devido ao deslizamento; } \\
& \mu a=\text { coeficiente de atrito devido à adesão; } \\
& \mu h=\text { coeficiente de atrito devido à histerese. }
\end{aligned}
$$

O termo aderência refere-se ao limite de atrito, desenvolvido entre os pneus do veículo e a superfície da camada de rolamento do pavimento, que assegura a mobilidade e dirigibilidade do veículo.

Um enfoque mais atual é analisar este mesmo fenômeno sob o ponto de vista da tribologia. A palavra tribologia tem raízes gregas onde tribos significa atrito e logos do Latim estudo; foi utilizada pela primeira vez em 1966 por um comitê do governo Britânico, de acordo Hutchings (1992) e teve como primeira publicação um dicionário na Universidade de Oxford, de acordo com Aguillón (2002).

Tribologia é a ciência que estuda o atrito, a lubrificação e o desgaste de superfícies em engenharia. A tribologia, de acordo com Moore (1975) apud Silva (1998), considera o conceito da interdisciplinaridade, pois integra os conhecimentos da física, da química, da mecânica, da termodinâmica e das ciências dos materiais.

Em determinadas situações não se conhece o mecanismo de desgaste atuante, pois diferentes mecanismos operam simultaneamente, como a adesão, a abrasão, a fadiga da superfície e a corrosão, os quais dependem da estrutura do tribosistema. 
Esta estrutura é composta de corpo, contra-corpo, interface e meio ao redor, conforme pode ser observado na Figura 2.1.1. É preciso conhecer também a forma de ação dos elementos, rolamento, deslizamento, impacto e/ou escoamento, e os parâmetros como a carga, a velocidade, a temperatura e o tempo.

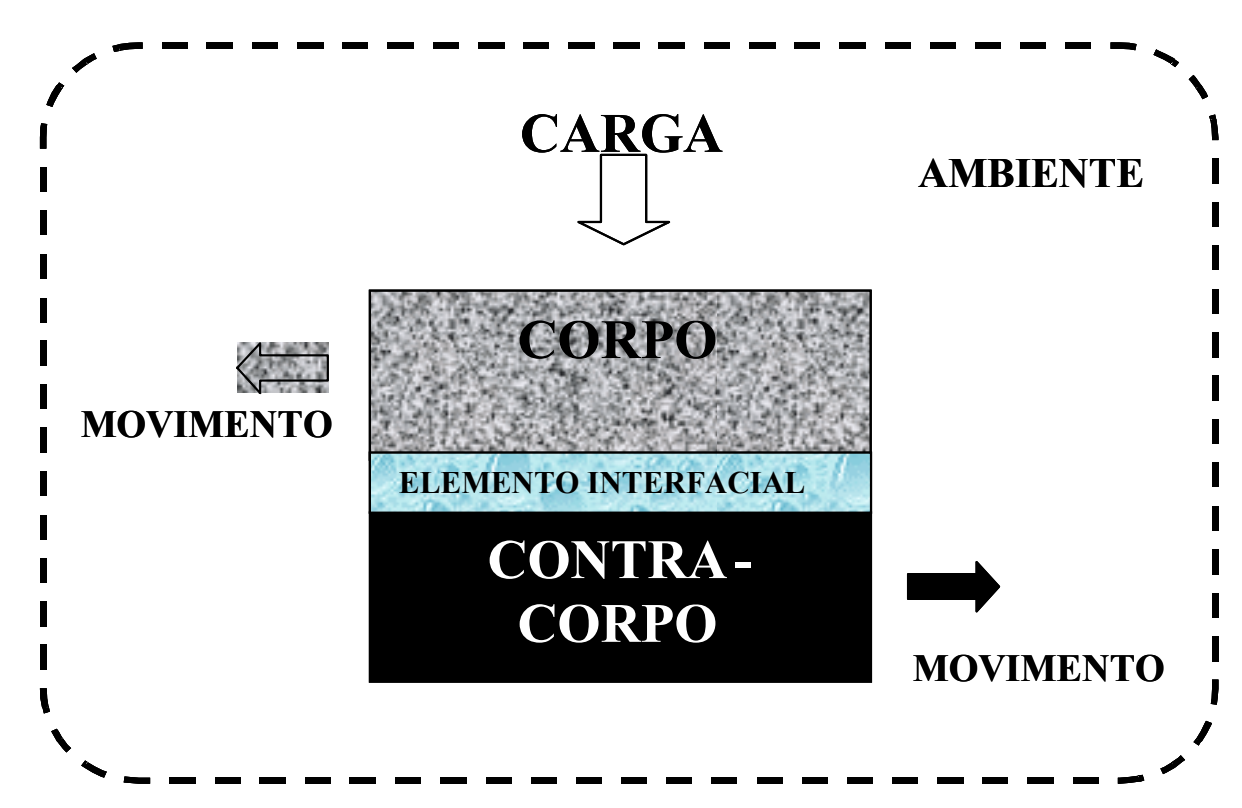

Figura 2.1.1 Esquema de um Tribosistema

Seguindo os conceitos da tribologia pode-se considerar o pavimento como "corpo", o pneu como "contra-corpo" e o "elemento interfacial" é a lubrificação por meio do ar ou da água.

Quando este fenômeno se dá em função do contato do pneu de um veículo com a camada de rolamento de um pavimento, sabe-se que poderá ocorrer o rolamento ou deslizamento do pneu sobre o pavimento, dependo da situação a que estiver exposto.

O coeficiente de atrito obtido para um determinado pavimento está vinculado ao equipamento com o qual se realizou o ensaio, que pode utilizar um sistema com rodas que giram livres ou são bloqueadas durante o ensaio. Esses coeficientes são denominados de Coeficiente de Atrito Longitudinal - CAL ou Coeficiente de Atrito Transversal - CAT (López, 1995; Poncino, 2001). 
1. Coeficiente de Atrito Longitudinal - CAL - está associado à força que se desenvolve na área de contato pneu-pavimento quando se arrasta uma roda travada; este ensaio simula melhor a resistência ao deslizamento em frenagens emergenciais ou quando um veículo é freado, acelerado ou desacelerado no sentido longitudinal.

2. Coeficiente de Atrito Transversal - CAT - está associado à força que se desenvolve na área de contato pneu-pavimento, perpendicular ao plano de rotação da roda, quando esta circula formando um ângulo em relação à sua direção de rotação (forças tangenciais); este ensaio simula melhor a resistência ao deslizamento transversal necessária para manter o veículo em curvas ou derrapagens.

Para os dois coeficientes os valores variam em função das condições do ensaio como: o tipo dos pneus (lisos ou com ranhuras), a espessura da lâmina de água, o ângulo de inclinação da roda (ângulo de deriva) e a velocidade do equipamento.

Os fatores que mais afetam a resistência ao deslizamento podem ser divididos em dois grupos de acordo com sua importância (IRC 1976). O primeiro grupo contempla:
a) Os agregados;
b) A natureza ou textura da superfície,
c) A presença de água principalmente devido às condições climáticas, chuvas e neve;
d) A geometria da via;
e) As características dos pneus;
f) A velocidade do veículo;
g) A intensidade de tráfego.

Como fatores que afetam a resistência ao deslizamento, em segundo grau, estão:

a) O tipo de revestimento do pavimento; 
b) Os métodos de construção e manutenção da via;

c) A temperatura;

d) O sistema de freios e suspensão do veículo;

e) A carga por roda;

f) E a presença de óleo na camada de rolamento.

Condições inadequadas de aderência na interação pneu-pavimento podem ocasionar acidentes em um sistema viário seja urbano, rodoviário ou aeroportuário.

Pesquisas realizadas nos EUA indicaram que, aproximadamente, $14 \%$ de todos os acidentes fatais com automóveis ocorreram sob condições de pistas molhadas (Pottinger, 1986). Foi verificado, também, em pesquisas feitas pelo Comitê Nacional de Segurança de Transportes, nos EUA, que a freqüência de acidentes em pistas molhadas é quatro vezes superior àquela que ocorre em pistas secas (Wambold, 1986).

Quando os pneus do veículo se deslocam sobre uma pista molhada, devido à presença de lâmina de água, desenvolvem-se pressões hidrodinâmicas na área de contato do pneu com o pavimento. Essas pressões aumentam com a velocidade do veículo, e dependendo da textura oferecida pela via, podem atingir valores altos de tal modo que tendem a levantar os pneus sobre uma onda que se forma à sua frente. Se a carga aplicada aos pneus pelo peso do veículo for menor que a resultante proveniente das pressões hidrodinâmicas, os pneus deslizarão sem manter contato direto com o pavimento, perdendo o controle direcional, fenômeno conhecido como hidroplanagem.

Nessas condições, o atrito se reduz a valores insuficientes para manter dirigibilidade, perde-se o controle direcional e a capacidade de frenagem. Para que a roda volte a transmitir os esforços necessários à condução do veículo, durante o processo de hidroplanagem, a velocidade deve ser reduzida sensivelmente. 
Silva e Rodrigues Filho (1981) comentam que pesquisas realizadas pela NASA (National Aeronautics and Space Administration) mostraram que a região de contato do pneu com o pavimento molhado pode ser dividida em três zonas distintas, esquematizadas na Figura 2.1.2. São elas:

Zona 1: representada por Z1 na Figura 2.1.2, é a região da área de contato recoberta por uma espessa lâmina d'água, sujeita à hidroplanagem dinâmica, também denominada "zona molhada". Nessa zona, o pneu em movimento empurra a água para frente, formando uma onda.

Zona 2: representada por Z2 na Figura 2.1.2, é a região da área de contato recoberta por uma delgada lâmina d'água, sujeita à hidroplanagem viscosa, também denominada "zona de transição ou intermediária". Devido à pequena espessura da lâmina d'água o pneu passa a ter contato parcial com o pavimento.

Zona 3: representada por Z3 na Figura 2.1.2, é a região da área de contato, teoricamente, sem presença d'água, ocorrendo, portanto, o contato direto entre o pneu e o pavimento. $O$ atrito que passa a existir contribui para a desaceleração e o controle do veículo. Esta zona é denominada "zona seca ou de contato" (Pottinger,1986, Haas,1994, Silva,1981).

A porcentagem destas áreas vai depender da velocidade do veículo, da textura do pavimento, da pressão interna dos pneus e da manobra que está sendo realizada. As características e os fenômenos envolvidos, tal como as propriedades relevantes em cada umas destas três zonas, podem ser vistas resumidamente na tabela 2.1.2.

A eliminação da água da área de contato entre o pneu e o pavimento requer um determinado tempo, que é função conjunta da macrotextura e microtextura oferecida pela superfície do pavimento. A macrotextura, em conjunto com os sulcos que compõem o desenho da banda de rodagem do pneu, tem por função permitir que grande parte da água existente na "Zona 1" possa ser drenada. Esta característica é 
função da graduação dos agregados, do projeto da mistura, da camada de rolamento e do grau de polimento da superfície ou dos agregados empregados nesta camada.

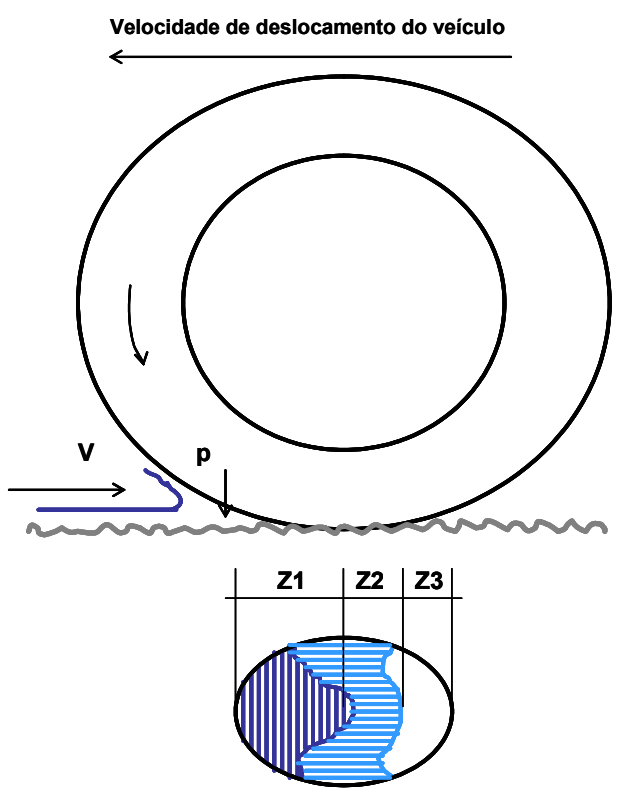

Figura 2.1.2 Deslocamento da água pelo pneu de acordo com o conceito das 3 zonas (adaptado de Silva e Rodrigues Filho, 1981 e Haas, 1994)

Tabela 2.1.2 Hidroplanagem: total e parcial, modelo das 3 zonas (adaptado de Silva e Rodrigues Filho, 1981; Silva, 1981; Pottinger, 1986)

\begin{tabular}{cccc}
\hline Parâmetros & $\begin{array}{c}\text { Hidroplanagem } \\
\text { Total }\end{array}$ & Hidroplanagem Parcial & Contato \\
\hline Zona & Z 1 & Z 2 & Z 3 \\
\hline $\begin{array}{c}\text { Condição do } \\
\text { Pavimento }\end{array}$ & Molhado & Úmido & Seco \\
\hline Tipo de interação & Deslizamento & Contato parcial & Rolamento \\
\hline $\begin{array}{c}\text { Propriedade } \\
\text { relevante }\end{array}$ & Macrotextura & Microtextura & Macro e Micro \\
\hline $\begin{array}{c}\text { Fenômeno } \\
\text { ocorrente }\end{array}$ & $\begin{array}{c}\text { Hidroplanagem } \\
\text { dinâmica }\end{array}$ & Hidroplanagem Viscosa & Atrito \\
\hline \hline
\end{tabular}

A microtextura de um pavimento é responsável por romper a película de água remanescente na zona 2 permitindo o restabelecimento do contato entre o pneu e o pavimento.

Acidentes devido à hidroplanagem, geralmente, ocorrem em casos especiais, onde as velocidades são altas, as espessuras de lâmina d'água são elevadas e a pressão 
sobre o pneu é superior à sua pressão de contato e este desliza sobre a superfície d'água. Normalmente, ocorrem em pontos isolados dos pavimentos com macrotextura fechada, onde a drenagem superficial é ruim e as velocidades são superiores a $100 \mathrm{~km} / \mathrm{h}$. Mesmo a água formando apenas uma lâmina muito delgada sobre o pavimento, conhecida como filme, o risco de acidente continua existindo, pois esse filme atua como um lubrificante, diminuindo, por conseqüência, a resistência ao deslizamento (Guzmán, 1995).

Confirmando essas conclusões, o estudo feito por Hankin e outros (Wambold, 1986), com base em 500 casos de acidentes analisados, todos em pistas molhadas, mostrou e os seguintes resultados:

1- Os pavimentos nos locais dos acidentes apresentaram pequena macrotextura;

2- As profundidades dos sulcos dos pneus eram pequenas;

3- Os valores dos coeficientes de atrito nos locais de acidentes eram baixos; e

4- As velocidades dos veículos imediatamente antes dos acidentes eram altas.

O principal problema é zona molhada e pode-se verificar na Figura 2.1.3 a importância da textura da camada de rolamento na ocorrência de acidentes.

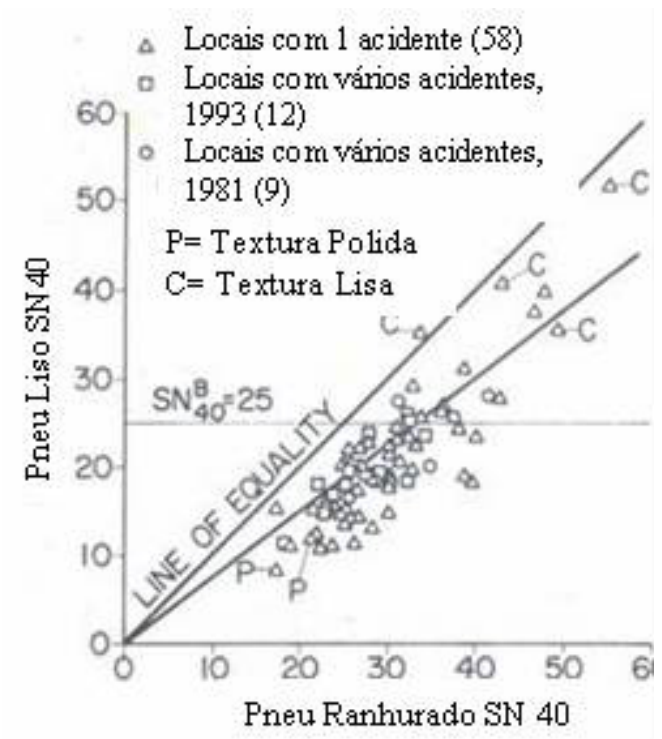

Figura 2.1.3 Influência da textura e da profundidade dos sulcos dos pneus no número de atrito e na ocorrência de acidentes (Wambold et al., 1986) 
No Congresso Mundial da PIARC (Permanent International Association of Road Congress, atualmente denominada de World Road Association) realizado em Bruxelas em 1987 foram definidas três classes de textura: a microtextura, a macrotextura e megatextura (Wambold et al, 1995). Foram estabelecidos os limites entre os limites entre os domínios de escalas de irregularidades de superfícies de pavimentos rodoviários por meio do critério de comprimento de ondas (horizontal) e amplitude (vertical) conforme pode ser visto na Tabela 2.1.3 (ASTM E-867,1997).

A microtextura depende basicamente da aspereza dos agregados da superfície e pode ser classificada por rugosa ou polida, também chamada esta última de lisa.

A macrotextura depende basicamente da graduação da mistura utilizada na camada de rolamento e pode ser classificada por aberta ou grosseira e fechada ou fina.

Tabela 2.1.3 Classificação da textura (ASTM E-867, 1997)

\begin{tabular}{|c|c|c|}
\hline \multirow[b]{2}{*}{ Domínio } & \multicolumn{2}{|c|}{ Intervalo de dimensões } \\
\hline & Horizontal & Vertical \\
\hline Microtextura & $0-0,5 \mathrm{~mm}$ & $0-0,2 \mathrm{~mm}$ \\
\hline Macrotextura & $0,5 \mathrm{~mm}-50 \mathrm{~mm}$ & $0,2 \mathrm{~mm}-10 \mathrm{~mm}$ \\
\hline Megatextura & $50 \mathrm{~mm}-500 \mathrm{~mm}$ & $1 \mathrm{~mm}-50 \mathrm{~mm}$ \\
\hline Irregularidade & $0,5 m-50 m$ & $1 \mathrm{~mm}-20 \mathrm{~cm}$ \\
\hline
\end{tabular}

A superfície resultante depende, portanto, das características conjuntas da macro e microtextura. Estas combinações podem resultar em quatro tipos de textura a saber: rugosa e aberta; rugosa e fechada; polida e aberta; e polida e fechada. A Figura 2.1.4 resume as classes de microtextura e macrotextura. 


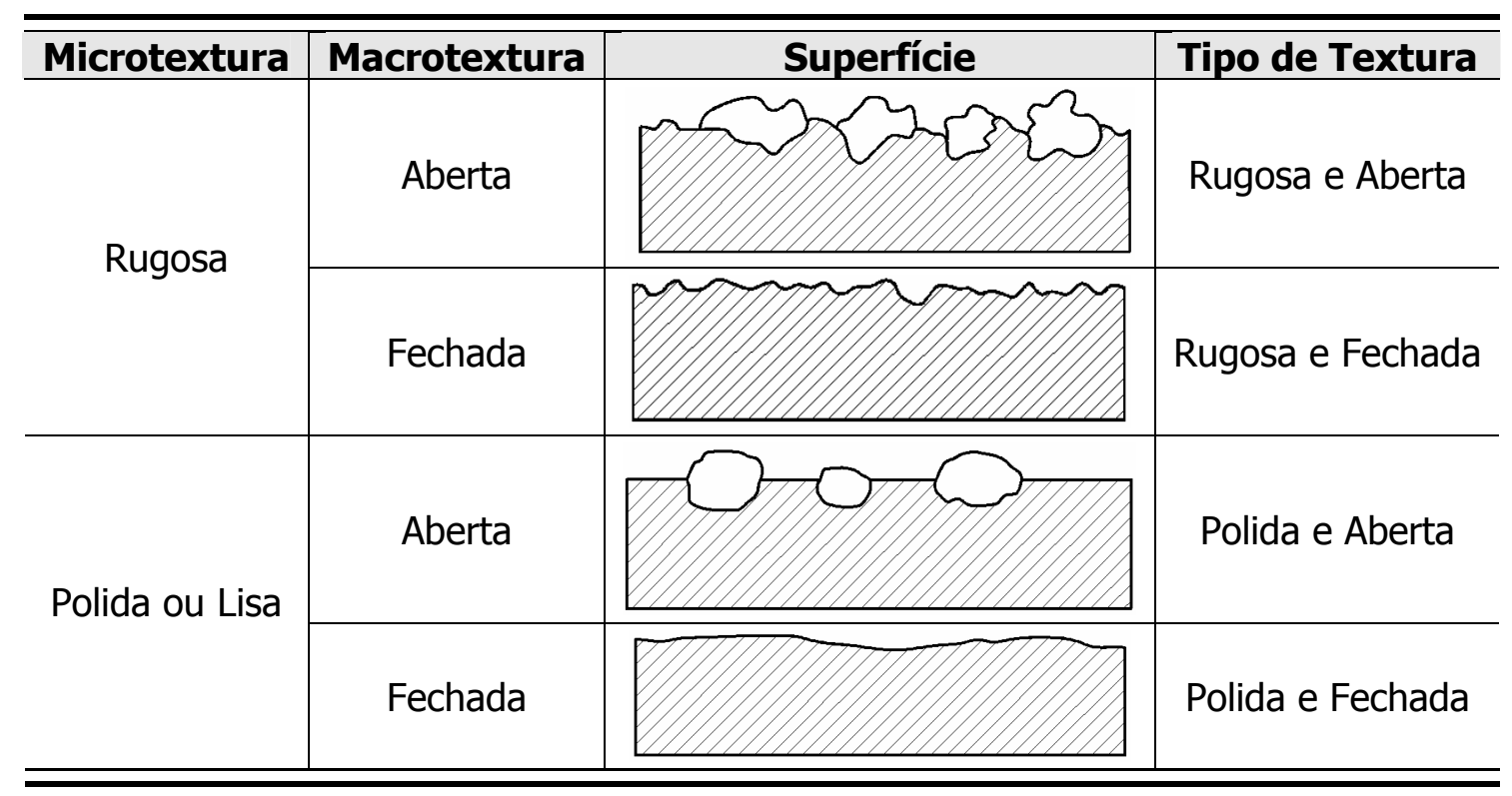

Figura 2.1.4 Tipo de superfície em função da classe de macrotextura e microtextura

\subsection{Características Físicas das Vias e sua Influência na Ocorrência de Acidentes}

As pesquisas que buscam relacionar a influência das características geométricas da via na ocorrência de acidentes são realizadas em seções pilotos, não refletindo a realidade de toda a rodovia, há necessidade da busca de mais dados quantitativos e qualitativos envolvendo essa relação (Nodari, 2003).

As características geométricas das vias têm influência na avaliação da aderência do pneu-pavimento e também na ocorrência de acidentes. A via projetada, construída e conservada adequadamente deve proporcionar ao motorista condições de conduzir o veículo de modo simples e consistente, e ainda seguro. Mesmo ao cometer uma falha, o motorista deve ter condições de retomar o controle do veículo antes que o acidente ocorra.

De um modo geral, em função das condições da via, o motorista pode ter o comportamento padrão esperado e a atenção afetada, influenciando a sua habilidade em manter o controle do veículo e em identificar situações de risco e ainda criando oportunidades de conflitos (TRB,1977; Nodari, 2003). 
De acordo com Nodari (2003), entre as características físicas das vias que influenciam na incidência de acidentes pode-se citar:

A conservação da camada de rolamento - ocorrência de defeitos em vias pavimentadas pode ser a causa de alguns acidentes. Estudos internacionais, realizados em países onde há rodovias de alto padrão, tais defeitos não se destacam na quantificação da ocorrência de acidentes; porém, no nosso país, esta situação é notória e tornou-se ainda mais evidente com o recente lançamento de um programa de "tapa-buracos" pelo governo federal. A presença de "panelas" provoca mais acidentes, geralmente, envolvendo motos e caminhões do que veículos de passeio.

A irregularidade dos pavimentos, associada aos defeitos que afetam o conforto, como por exemplo, remendos, recalques, elevações e afundamentos localizados (Aps, 2000), também podem provocar acidentes devido à perda de controle do veículo por meio do deslocamento das cargas, ocasionando o tombamento e/ou capotagem.

As condições de macrotextura e microtextura proporcionadas pelo revestimento podem resultar em acidentes por derrapagem em situações de frenagem ou manobras emergenciais, principalmente em pavimentos molhados.

A formação de lâmina de água sobre pavimentos é mais comum em trechos planos, com pouca inclinação transversal e em curvas de raios longos, ou ainda, em áreas onde há a presença de defeitos como afundamentos. O veículo em deslocamento sobre esses trechos pode perder a aderência entre o pneu e 0 pavimento ocasionando o fenômeno da hidroplanagem.

Além disso, a presença de água na superfície causa borrifo pela ação dos pneus em movimento, formando um fenômeno atrás do veículo denominado "spray", que impede a uma boa visibilidade dos veículos que circulam atrás ou lateralmente ao "spray". Complementarmente, a lâmina d'água na superfície pode causar reflexão 
das luzes dos faróis à noite, ocasionando um brilho que impede um bom conforto visual da pista, atrapalhando a atenção, confundindo o motorista.

\section{O desnível vertical entre faixa de rolamento e acostamento pode ocasionar a} perda de controle do veículo. Esse degrau pode ocorrer devido ao recapeamento da pista, deterioração ou ausência de acostamento e ainda pode ser vertical ou oblíquo; este último proporciona melhores condições de retomada do controle do veículo.

O traçado de curvas horizontais - o grau de curvatura e o comprimento podem gerar curvas potencialmente perigosas. Estudos apontam que a maioria dos acidentes que ocorrem em trechos curvos são as colisões frontais, laterais, contra objetos fixos, noturnas, as capotagens e as envolvendo motoristas alcoolizados. 0 alargamento de faixas e/ou acostamentos nesses trechos pode reduzir a ocorrência de acidentes.

Locais com deficiência de superelevação, valores reais menores do que os recomendados pelos órgãos, estão sujeitos à maior porcentagem de ocorrência de acidentes além do desconforto oferecido ao motorista. Valores mínimos e máximos são recomendados no Manual do DNER (1999).

As curvas verticais e rampas, ou seja, o perfil vertical é conseqüência da topografia do terreno, do nível de segurança oferecido pela rodovia e dos custos de construção disponíveis. A inclinação e o comprimento são os principais fatores que afetam a ocorrência de acidentes em rampas; rampas longas, com presença de veículos pesados tendem a registrar maior número de acidentes devido às diferenças de velocidades que se acentuam nessas condições de operação, (FHWA, 1992 apud Nodari 2003). O número de acidentes em rampas descendentes é $63 \%$ maior que em rampas ascendentes. Acidentes em declives também resultam maior percentual de feridos e mortes quando comparados aos acidentes em aclives.

A tortuosidade (DNER, 1999) deve ser evitada, e serem priorizados traçados contínuos com adoção de curvas de raio longo concordadas com tangentes curtas, 
com o objetivo de evitar o excesso de velocidade, o cansaço, sono do motorista e o ofuscamento noturno no cruzamento com outros veículos.

A combinação entre alinhamento horizontal e vertical é importante na definição da velocidade de operação e na determinação da distância de visibilidade.

As interseções são locais críticos onde o motorista deve tomar várias decisões ao mesmo tempo, a adoção de faixas adicionais ou canalização desse tráfego pode reduzir a ocorrência de acidentes. A iluminação artificial nas interseções pode melhorar os aspectos de segurança, reduzindo o número de acidentes, porém o uso de postes deve ser cauteloso, pois esses podem se tornar obstáculos perigosos. Quando o veículo colide com elementos, assim como os pilares de pontes, alguns dispositivos de drenagem, os muros de contenção, as árvores, os taludes, os postes de sinalização, entre outros elementos dispostos nas laterais das vias sofrem colisões que representam aproximadamente $25 \%$ dos acidentes fatais.

\section{As linhas demarcadoras das faixas de rolamento e os dispositivos que} produzem vibração ao volante, contribuem positivamente para os aspectos de segurança. As placas de sinalização (advertência, regulamentação e indicação) quando são claras, concisas e localizadas com antecedência suficiente para a tomada de decisão e em locais onde não haja muita solicitação do motorista podem contribuir para a redução de 20 a $62 \%$ dos acidentes. Os painéis de mensagem que são ativados pelos veículos, como aqueles que informam a velocidade, podem reduzir aproximadamente 30\% dos acidentes nos locais de implantação.

Os marcadores e balizadores instalados em curvas acentuadas, pontes estreitas ou obras podem melhorar a configuração do traçado e promover a redução de acidentes entre 30 e $60 \%$.

Estudos têm indicado faixas de valores de 10 a $40 \%$ na redução de acidentes em função do aumento da largura das faixas de rolamento e do acostamento. As larguras da faixa de rolamento e acostamento nas pontes devem ser 
mantidas no mesmo tamanho dos trechos adjacentes a elas. Além da largura, a existência de pavimentação nos acostamentos também proporciona melhoria da segurança.

A inclinação dos taludes recomendada pelo DNER (1999) é igual ou inferior a 1:6, para proporcionar áreas adjacentes mais seguras e diminuir os custos com instalações de defensas. A travessia para pedestre e o acesso a lotes lindeiros em rodovias devem ser devidamente localizados e projetados para a finalidade real de uso.

Conforme visto, as características geométricas das vias têm influência na avaliação da aderência pneu-pavimento e também na ocorrência de acidentes; um projeto geométrico consistente apresenta traçado de curvas, superelevação, curvas verticais e rampas, combinação entre alinhamento horizontal e vertical, interseções e larguras da faixa de rolamento, entre outros, capazes de proporcionar uma viagem segura e confortável.

Uma via deve, também, oferecer ao usuário condições de visibilidade para que ao surgimento de obstáculo inesperado, o veículo possa parar de maneira segura. Este fator é considerado na elaboração do projeto geométrico por meio do cálculo da distância de visibilidade de parada. Vale ressaltar que a distância de visibilidade de parada é utilizada no projeto de interseções, de curvas verticais e na determinação do tempo em semáforos, entre outras aplicações.

De acordo com o Manual de Projeto Geométrico de Rodovias Rurais (DNER, 1999), a distância de visibilidade de parada (Dp), conceitualmente, é a distância mínima necessária para que um veículo possa parar antes de atingir um determinado obstáculo inesperado, estando na velocidade de projeto ou próximo dela. Essa distância é composta de duas partes: a primeira é aquela percorrida durante o tempo de reação do motorista $\left(D_{1}\right)$ e a segunda é aquela referente ao tempo de parada do veículo após o início da frenagem $\left(D_{2}\right)$. 0 tempo de reação do motorista é o tempo necessário para que ele tenha a percepção de um determinado objeto (obstáculo), 
o reconhecimento da situação, a tomada de decisão e a prática de uma ação; e o tempo de parada é o tempo em que o motorista aciona o sistema de freios para iniciar o processo de frenagem somado ao tempo de subida da potência até o bloqueio das rodas e o tempo de frenagem efetivo até a parada do veículo.

Ao tempo de reação do motorista associam-se os fatores internos e externos inerentes ao ser humano. Internos são aqueles que dependem do próprio motorista e são conseqüência de seus traços sociológicos e físicos; estes fatores podem ser permanentes ou passageiros, como a motivação, a experiência, o estado de ânimo, o cansaço, a visão ou a habilidade ótica, o campo visual, a adaptação à luminosidade, a altura dos olhos, o equilíbrio, outros sentidos, a idade e o sexo. Como fatores externos podem-se considerar as condições climáticas, o uso do solo, o tráfego, as características da via e a distância do objeto (DNER, 1999). Todos esses fatores, internos e externos, influem na composição do tempo de reação do motorista que por sua vez compõe a distância de parada.

De acordo com a AASHTO (2000), o valor de 1,5 segundos deve ser adotado para o tempo de percepção, adicionando-se a esse valor o tempo necessário à reação de frenagem, que tipicamente é de 1,0 segundo, tem-se o tempo total de percepção e reação de 2,5 segundos. A Figura 2.2.1 mostra o tempo de reação do motorista e tempo de parada do veículo.

Em um projeto rodoviário, consideram-se as distâncias de visibilidade básicas como a de parada, a de tomada de decisão e a de ultrapassagem. A distância de visibilidade em rodovias irá fornecer informações para (Pontes, 1998):

a) Cálculo do comprimento da curva de concordância vertical convexa das rodovias;

b) Elementos para marcação de banquetas de visibilidade dos cortes em curva; e

c) Elementos para sinalização das rodovias. 


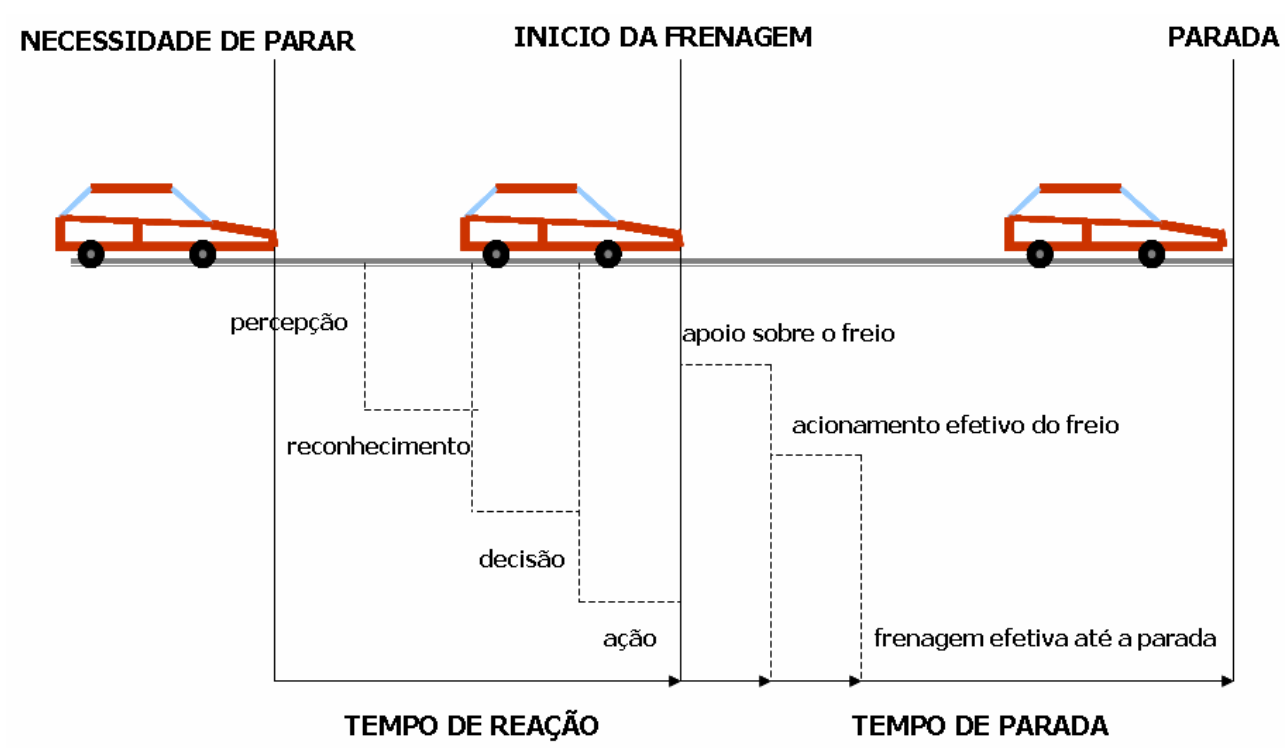

Figura 2.2.1 Tempo de reação do motorista e tempo de parada do veículo

A distância de parada pode ser determinada por meio da Equação 2.4.1, cujas parcelas $D_{1}$ e $D_{2}$ são obtidas por meio das Equações 2.4 .2 e 2.4.3, respectivamente. As equações 2.4 .2 e 2.4 .3 apresentam, respectivamente, as mudanças de unidades, de $\mathrm{m} / \mathrm{s}$ para $\mathrm{km} / \mathrm{h}$ e consideram o tempo de reação do motorista de 2,5 segundos.

$$
\begin{aligned}
& D_{P}=D_{1}+D_{2} \\
& D_{1}=v \cdot t=2,5 v(\mathrm{~m} / \mathrm{s})=2,5 \frac{v \cdot(\mathrm{km} / \mathrm{h})}{3,6}=0,7 v \\
& D_{2}=\frac{v^{2}}{2 \cdot g \cdot f}=\frac{(V / 3,6)^{2}}{2 \cdot 9,8 \cdot f}=\frac{V^{2}}{255 \cdot f}
\end{aligned}
$$

Onde:

$v=$ velocidade do veículo, em $\mathrm{km} / \mathrm{h}$;

$t=$ tempo de reação e percepção do motorista, considerado igual a 2,5 s;

$g=$ aceleração da gravidade considerada $9,8 \mathrm{~m} / \mathrm{s}^{2}$; e

$f=$ coeficiente de atrito longitudinal pneu-pavimento.

Para um trecho em rampa ascendente, aclive, a distância de frenagem será menor que a determinada pela equação de (D2) e maior no caso de descida, declive 
(AASHTO, 1994 e DNER, 1999). Considerando os efeitos das rampas a equação 2.4.3 pode ser divida em duas, uma para rampas ascendentes, Equação 2.4.4 e outra para rampas descendentes, Equação 2.4.5.

$$
\begin{aligned}
& D_{2}=\frac{V^{2}}{255 \cdot(f+i)} \\
& D_{2}=0,0039 \frac{V^{2}}{(f+i)}
\end{aligned}
$$

Onde:

$i=$ greide, em $\mathrm{m} / \mathrm{m}$ positivo $(+)$ se ascendente e negativo $(-)$ se descendente.

A fórmula acima é derivada da equação de Torricelli para desaceleração em movimento uniformemente acelerado, sendo 255 um fator de ajuste de unidades para velocidade em $\mathrm{km} / \mathrm{h}$, aceleração em $\mathrm{m} / \mathrm{s}^{2}$ e aceleração da gravidade $\mathrm{g}=9,81$ $\mathrm{m} / \mathrm{s}^{2}$.

A partir das considerações acima, a distância de visibilidade de parada pode ser escrita também em função da inclinação da via, conforme pode ser vista nas Equações 2.4.6 e 2.4.7.

$$
\begin{aligned}
& D_{2}=0,7 \cdot V \frac{V^{2}}{255 \cdot(f+i)} \\
& D_{2}=0,7 v+0,0039 \frac{V^{2}}{(f+i)}
\end{aligned}
$$

Em 2001 a AASHTO alterou a equação para o cálculo de D2 ou Dp, considerando a taxa de desaceleração, conforme pode ser visto na Equação 2.4.8.

$$
D_{2}=\frac{V^{2}}{2 \cdot a}
$$

Onde:

$a=$ taxa média de desaceleração, considerada $3,4 \mathrm{~m} / \mathrm{s}^{2}$. 
No Manual de Projeto Geométrico da AASHTO (1994; 2001), assumem-se alguns valores que não representam o que ocorre na prática ou deixa de considerar algumas variáveis que interferem na $D_{P}$, como os valores adotados para o coeficiente de atrito. Os valores dos coeficientes de atrito em função da velocidade, fornecidos nesses manuais, consideram a camada de rolamento do pavimento do tipo asfáltica ou de concreto de cimento Portland, sendo esses dois tipos em estado seco ou molhado, e interagindo com pneus em bom estado de conservação ou gastos. Porém a realidade sobre 0 atrito do pavimento é diferente dessas quatros simples situações apresentadas pela AASHTO (1994; 2001).

A Tabela 2.1.4 apresenta valores de atrito (pavimentos asfálticos molhados) de acordo com a AASHTO e valores de atrito em função da textura, macrotextura e microtextura, (áspera e aberta, áspera e fechada, polida e aberta e polida e fechada) apresentado por Guzmán (1995).

Como se pode observar assumir valores estimativos pode representar uma mudança da situação de segurança prevista pelo projetista. Calculando-se $D_{2}$ com os valores sugeridos na Tabela 2.1.4, teríamos as seguintes distâncias calculadas mostradas na Tabela 2.1.5.

Tabela 2.1.4 Valores de atrito de acordo com a AASHTO (1994,2001) Guzmán (1995)

\begin{tabular}{c|c|c|c|c|c}
\hline \hline $\begin{array}{c}\text { Velocidade } \\
(\mathbf{k m} / \mathbf{h})\end{array}$ & \multirow{2}{*}{ AASHTO } & \multicolumn{4}{|c}{ Guzmán (1995) } \\
\cline { 3 - 6 } & $\begin{array}{c}\text { áspera e } \\
\text { aberta }\end{array}$ & $\begin{array}{c}\text { áspera e } \\
\text { fechada }\end{array}$ & $\begin{array}{c}\text { polida e } \\
\text { aberta }\end{array}$ & $\begin{array}{c}\text { polida e } \\
\text { fechada }\end{array}$ \\
\hline \hline $\mathbf{5 0}$ & 0,36 & 0,7 & 0,6 & 0,3 & 0,25 \\
\hline $\mathbf{6 0}$ & 0,34 & 0,62 & 0,56 & 0,25 & 0,2 \\
\hline $\mathbf{7 0}$ & 0,32 & 0,6 & 0,49 & 0,22 & 0,18 \\
\hline $\mathbf{8 0}$ & 0,31 & 0,58 & 0,4 & 0,2 & 0,17 \\
\hline $\mathbf{9 0}$ & 0,31 & 0,57 & 0,35 & 0,2 & 0,16 \\
\hline $\mathbf{1 0 0}$ & 0,3 & 0,55 & 0,3 & 0,19 & 0,16 \\
\hline $\mathbf{1 1 0}$ & 0,3 & 0,55 & 0,24 & 0,18 & 0,15 \\
\hline $\mathbf{1 2 0}$ & 0,29 & 0,55 & 0,22 & 0,17 & 0,15 \\
\hline \hline
\end{tabular}


Tabela 2.1.5 Cálculo de $D_{2}$ para os valores de atrito da Tabela 2.1.4

\begin{tabular}{c|c|c|c|c|c}
\hline \hline \multirow{2}{*}{$\begin{array}{c}\text { Velocidade } \\
(\mathbf{k m} / \mathbf{h})\end{array}$} & \multirow{2}{*}{ AASHTO } & \multicolumn{4}{|c}{ Guzmán (1995) } \\
\cline { 3 - 6 } & & $\begin{array}{c}\text { áspera e } \\
\text { aberta }\end{array}$ & $\begin{array}{c}\text { áspera e } \\
\text { fechada }\end{array}$ & $\begin{array}{c}\text { polida e } \\
\text { aberta }\end{array}$ & $\begin{array}{c}\text { polida e } \\
\text { fechada }\end{array}$ \\
\hline \hline $\mathbf{5 0}$ & 27,23 & 14,01 & 16,34 & 32,68 & 39,22 \\
\hline $\mathbf{6 0}$ & 41,52 & 22,77 & 25,21 & 56,47 & 70,59 \\
\hline $\mathbf{7 0}$ & 60,05 & 32,03 & 39,22 & 87,34 & 106,75 \\
\hline $\mathbf{8 0}$ & 80,96 & 43,27 & 62,75 & 125,49 & 147,64 \\
\hline $\mathbf{9 0}$ & 102,47 & 55,73 & 90,76 & 158,82 & 198,53 \\
\hline $\mathbf{1 0 0}$ & 130,72 & 71,30 & 130,72 & 206,40 & 245,10 \\
\hline $\mathbf{1 1 0}$ & 158,17 & 86,27 & 197,71 & 263,62 & 316,34 \\
\hline $\mathbf{1 2 0}$ & 194,73 & 102,67 & 256,68 & 332,18 & 376,47 \\
\hline \hline
\end{tabular}

\subsection{Medidas de Textura e de Atrito}

As características de aderência, fornecidas pela textura e pelo atrito, representam um papel importante na segurança de vias urbanas, de rodovias e de aeroportos. O IFI (International Friction Index), a ser abordado em detalhes no item 2.5, é um dos parâmetros que pode ser usado para quantificar a aderência pneu-pavimento, e por conseqüência ser usado como ferramenta visando a redução de acidentes. Para se obter o valor de IFI (International Friction Index) é preciso realizar, com qualquer equipamento ou técnica homologada ou homologável a partir de critérios estabelecidos em experimento internacional, dois tipos de medidas sobre a superfície do pavimento, uma de atrito (FR) e outra de textura em mm (Tx) (Wambold et al., 1995).

Os equipamentos e métodos de avaliação variam muito de país para país, por esse motivo foi realizado o Experimento Internacional da PIARC (Permanent International Association of Road Congress, atualmente denominada de World Road Association) ou AIPCR (Association International Permanente des Congrèss de la Route) (Wambold et al., 1995). Neste Capítulo serão apresentados alguns dos 47 equipamentos, procedentes de 16 países, de medição de textura e atrito, utilizados no referido experimento internacional além de outros encontrados na literatura ou em uso no nosso país. 


\subsubsection{Medidas de Textura}

A macrotextura, cujo conceito foi abordado no item 2.1 e sua classificação na tabela 2.3, pode ser avaliada por três tipos de métodos (Wambold et al. (1995):

1. Método volumétrico conhecido como Mancha de Areia (MPD - Mean Profile Depth ou profundidade média do perfil);

2. Perfilômetros (RMS - Root Mean Square of Texture Profile ou raiz média quadrática do perfil da textura), que podem ser de três tipos. $O$ tipo a é o mais conhecido, o tipo $b$ apenas um modelo em uso, e o tipo c, não há modelo em serviço até o momento:

a. Laser;

b. Fotoseccionamento (Light Sectioning);

c. Água de Contato. (Stylus Contact Followers).

3. Drenômetros.

Alguns desses métodos citados serão apresentados devido a sua maior utilização.

\subsubsection{Mancha de Areia}

O ensaio de Mancha de Areia ou Altura de Areia é conhecido em países de língua inglesa como Sand Path, francesa como Hauter au Sable e espanhola como Circulo de Arena.

Esse ensaio é usado para a determinação da média da profundidade da altura da mancha de areia em superfícies de pavimentos com objetivo de obtenção das características de macrotextura, conforme preconizado pela ASTM E 965-96 (2001). O procedimento consiste em preencher os vazios da textura superficial do pavimento com um volume conhecido de $25000 \mathrm{~mm}^{3} \pm 150 \mathrm{~mm}^{3}$ de areia natural limpa e seca, uniforme, de grãos arredondados, que passa na peneira de abertura 0,3 mm e fica retida na peneira de abertura $0,15 \mathrm{~mm}$, ou com microesferas de vidro com as 
mesmas características granulométricas da areia. A superfície é limpa com auxílio de escova de mão macia e a areia é espalhada sobre a superfície seca por meio de um disco, com movimentos circulares e uniformes, preenchendo os vazios da superfície e obtendo uma área final aproximadamente circular. Mede-se o diâmetro do círculo da "mancha" obtida com a areia em quatro direções com aproximação visual de $5 \mathrm{~mm}$; o diâmetro médio Dm, será o resultado da média obtida nas quatro medições (ASTM, 2001). A altura Hm é expressa conforme a equação 2.3.1. A Figura 2.3.1 apresenta os equipamentos e materiais necessários para a realização do ensaio.

$$
H_{m}=\frac{V .4}{D_{m}^{2} \cdot \pi}
$$

Onde: $V=25000 \mathrm{~mm} 3$;

$D_{m}=$ diâmetro médio da mancha de areia $(\mathrm{mm})$;

$H_{m}=$ altura média da mancha de areia $(\mathrm{mm})$.
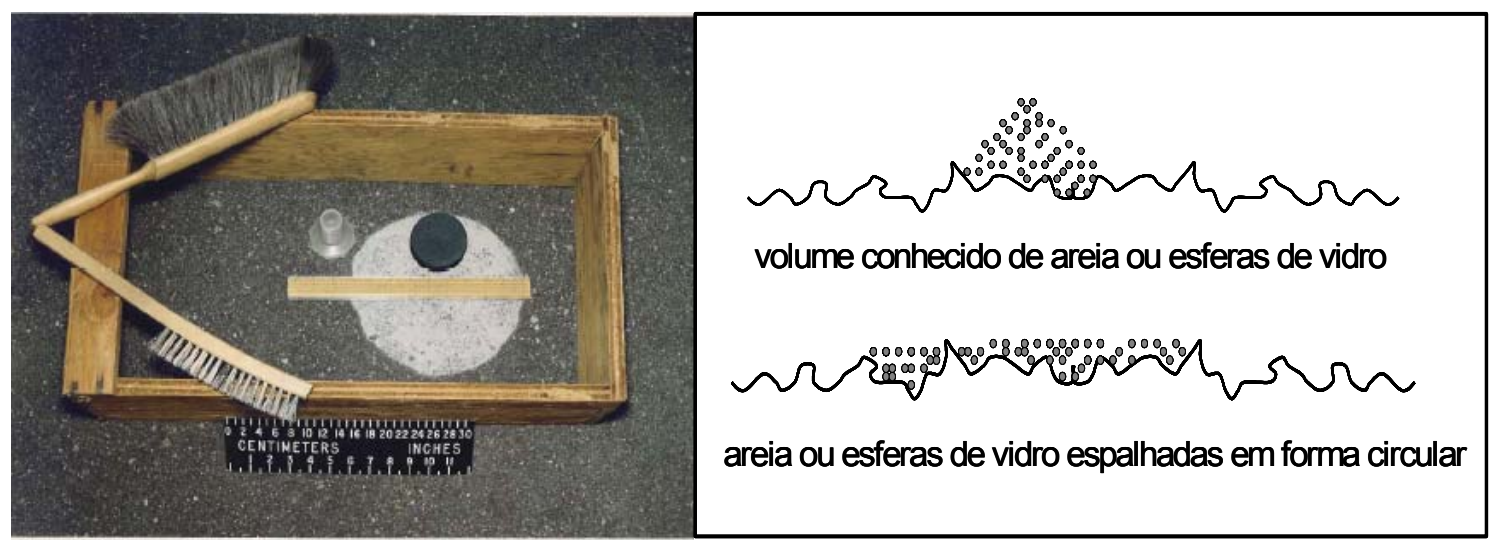

Figura 2.3.1 Aparelhagem usada para o ensaio de mancha de areia e procedimento de execução (modificado Wambold e Henry, 2002 e Aps e Bernucci, 2003)

A Figura 2.3.2 mostra três exemplos do ensaio de mancha de areia realizados pelo procedimento normalizado, cujos diâmetros são nitidamente diferentes devido à variação da macrotextura que depende da graduação da mistura asfáltica do revestimento. Observa-se nesta figura que a macrotextura está classificada segundo conceitos abordados no item 2.1. 


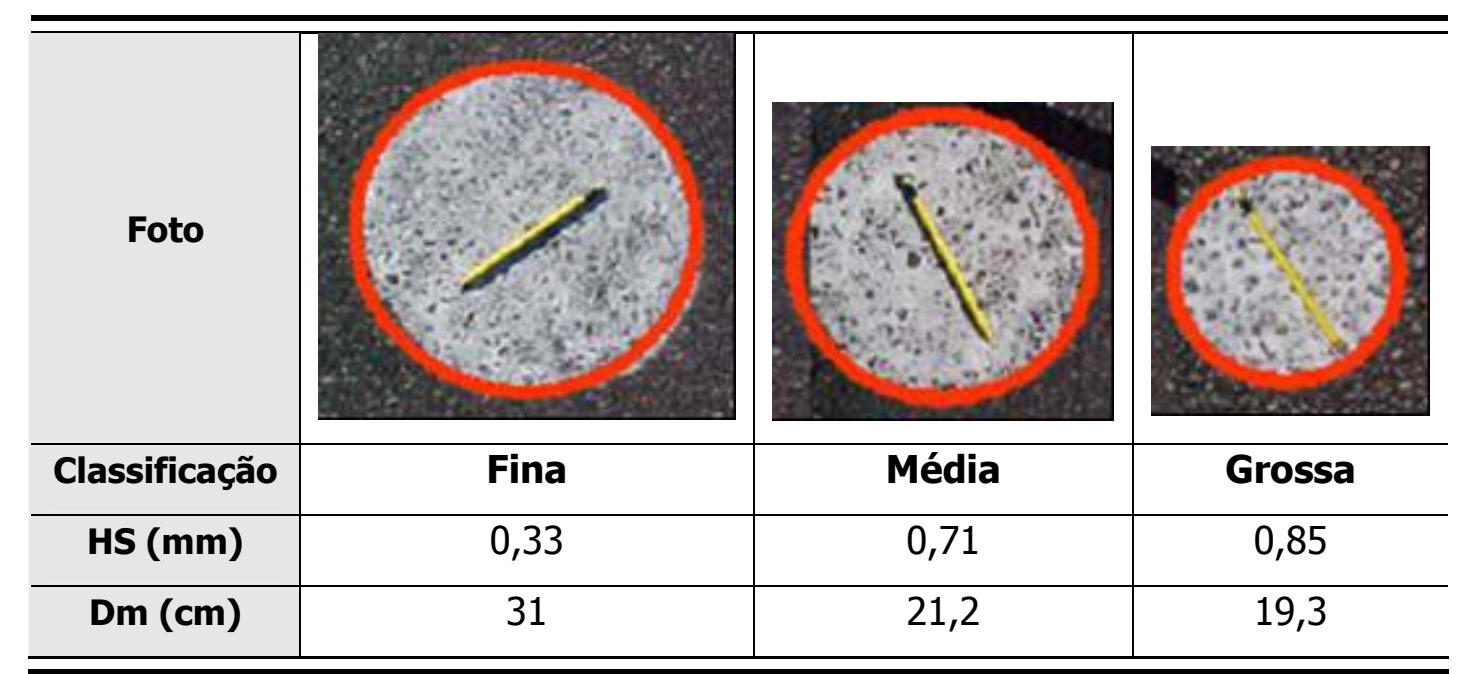

Figura 2.3.2 Comparação do ensaio de Mancha de Areia para diversas texturas

Embora possa parecer um ensaio de procedimento muito simplista, a repetibilidade desta técnica apresenta correlação forte. A Figura 2.3.3 mostra um experimento conduzido pela Nasa (Wambold e Henry, 2002); para estudar a variação do resultado do ensaio de mancha de areia em diferentes superfícies realizadas por dois operadores. Pesquisa realizada pela PIARC mostra resultados similares a estes da Nasa quanto à repetibilidade (Wambold et al., 1995).

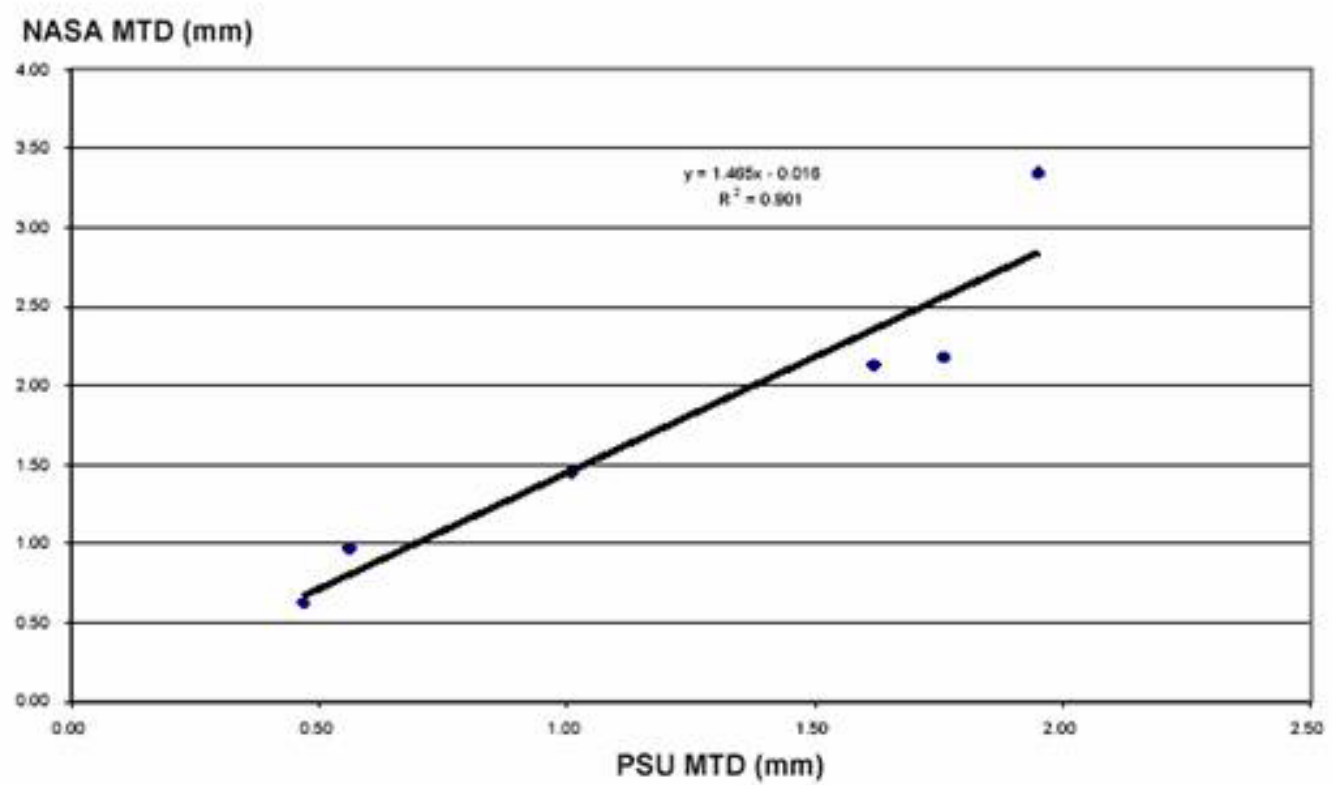

Figura 2.3.3 Correlação entre resultados do ensaio de mancha de areia realizados por dois operadores (Wambold e Henry, 2002) 


\subsubsection{Mancha de Graxa (Grease Patch)}

Trata-se de uma variação do método da Mancha de Areia, sendo mais utilizado em pavimentos de aeroportos. $\mathrm{O}$ procedimento consiste em preencher os vazios da textura superficial do pavimento com um volume conhecido de $16.000 \mathrm{~mm}^{3}$ de graxa de uso geral. Demarca-se a área de ensaio com duas fitas adesivas paralelas, espaçadas em $10 \mathrm{~cm}$, e como limite emprega-se uma terceira fita adesiva perpendicular fechando um dos extremos, conforme pode ser visto na figura 2.3.4. A superfície é limpa com auxílio de escova de mão macia e a graxa é espalhada sobre a superfície seca por meio de um pequeno rodo, preenchendo os vazios da superfície e formando uma área final de formato retangular. Mede-se o comprimento do retângulo com aproximação visual de $5 \mathrm{~mm}$. Calcula-se a área coberta e obtém-se a profundidade média da textura, conforme a Equação 2.3.2. A Figura 2.3.4 apresenta os equipamentos e materiais necessários para a realização do ensaio.

$$
H_{G}=\frac{V}{A}
$$

Onde:

$V=16000 \mathrm{~mm} 3 ;$

$A$ = área do retângulo da mancha de graxa $\left(\mathrm{mm}^{2}\right)$;

$H_{G}=$ altura média da mancha de graxa, profundidade média (mm).

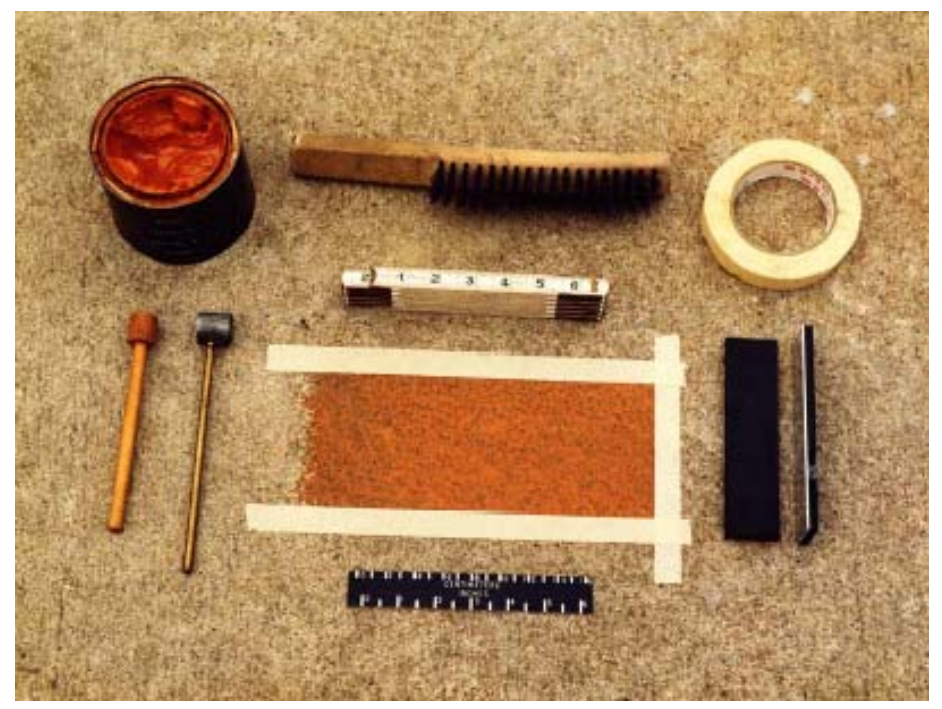

Figura 2.3.4 Ensaio de Mancha de Graxa (Wambold e Henry, 2002) 


\subsubsection{Drenabilidade (Outflow)}

Esse método avalia a capacidade da macrotextura de drenar a água através dos canais da superfície de um pavimento. Utiliza-se um cilindro transparente com um volume conhecido, acoplado ao fundo uma placa com um orifício circular, em contato com a superfície de pavimento. O cilindro é preenchido com água e mede-se o tempo em segundos que a água demora a escoar, passando por duas marcas existentes no tubo, demarcadas de forma a apresentar um volume conhecido. 0 tempo é medido manualmente com um cronômetro (Outflow Time-OFT).

Uma melhoria nesse equipamento foi a incorporação de um temporizador eletrônico, que mede o momento em que o nível de água cai de um elétrodo superior para um elétrodo situado mais baixo (Wambold et al, 1995; TRB, 2000). A Figura 2.3.5 apresenta dois tipos de drenômetros. Observa-se que estes sistemas podem ser empregados em pavimentos de concreto de cimento Portland (a) ou em pavimentos asfálticos, mesmo aqueles com grooving (b). O valor encontrado no ensaio com o drenômetro é correlacionável com a profundidade média da textura quando não utilizado em pavimento poroso ou drenante, com uma forte correlação linear com $\mathrm{R}^{2}$ = 0,99; este valor foi obtido com o drenômetro da NASA e deve ser analisado com cuidado, pois existem drenômetros de variadas dimensões (TRB, 2000).

Dispersão dos valores obtidos por meio do ensaio de Mancha de Areia e Drenabilidade, podem indicar limitações para texturas fechadas e muito abertas de pavimentos asfálticos convencionais, de acordo com Ferreira (2002) e Aps et al.(2003).

A Figura 2.3.6 mostra a correlação linear forte entre dois drenômetros diferentes, mostrando que certos aspectos geométricos destes equipamentos são facilmente contornáveis para a análise de resultados. 

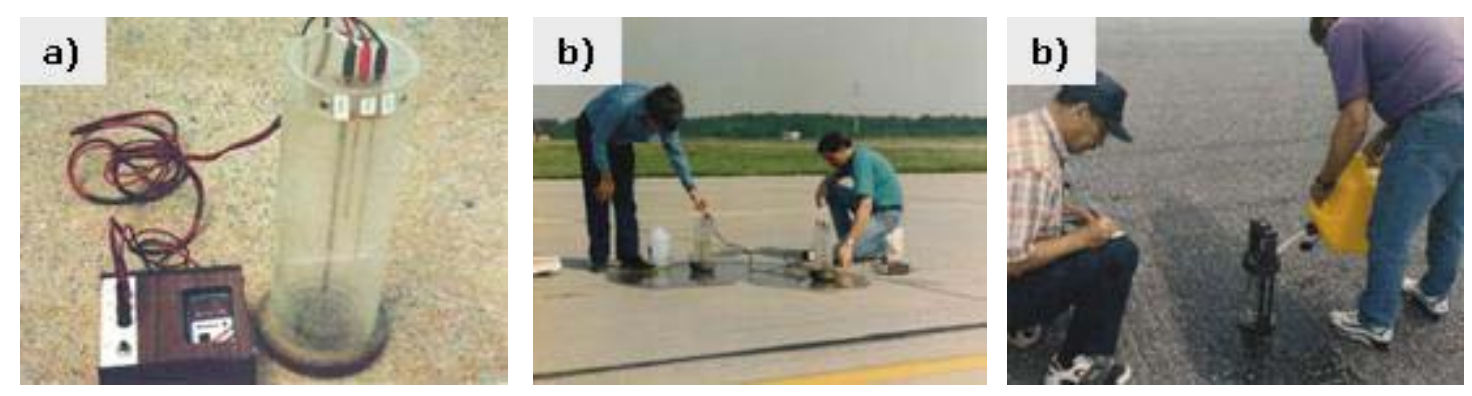

Figura 2.3.5 Drenômetro a) Detalhe do temporizador eletrônico b) FHWA e PTI Outflow Meter - USA c) Skiddabrader Outflow Meter- USA (Wambold e Henry, 2002)

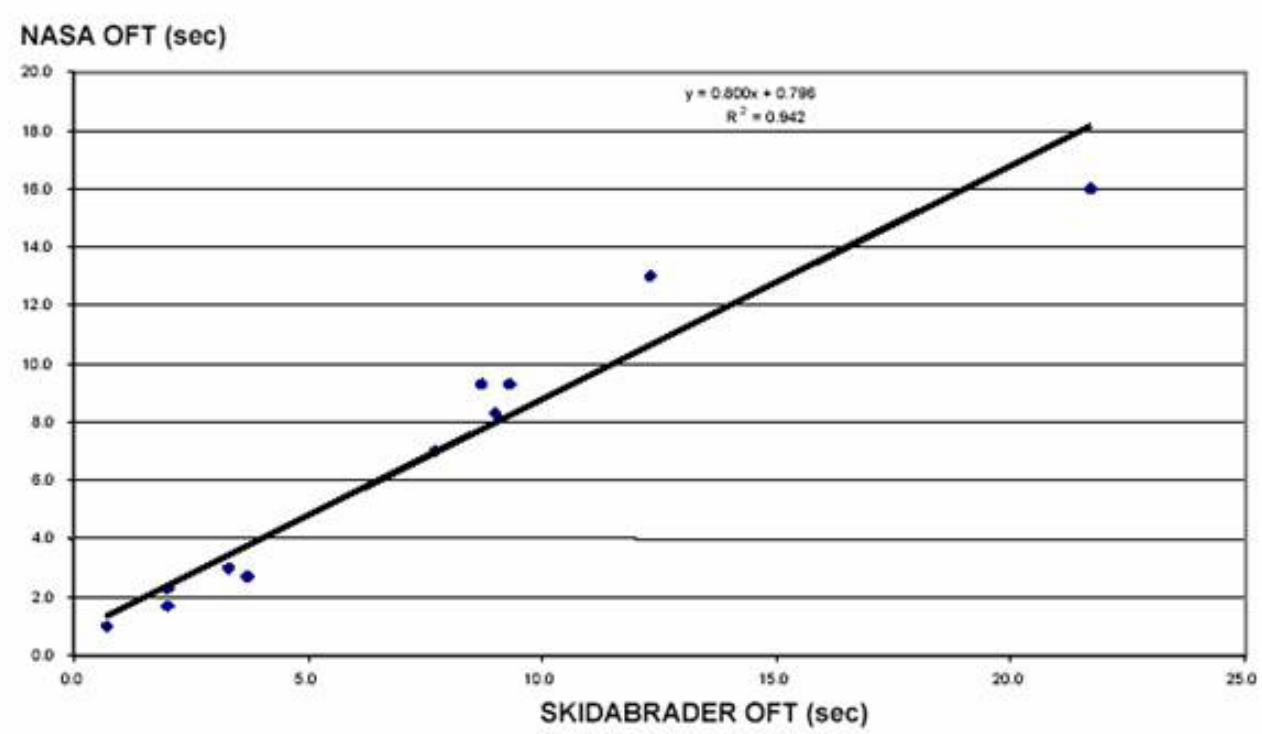

Figura 2.3.6 Correlação entre dois drenômetros diferentes (Wambold e Henry, 2002)

\subsubsection{Drenômetro LTP-EPUSP}

Desenvolvido aos moldes do Drenômetro do Institute of Highways, Railroads and Rock Engineering (ISETH) de Zurique, pelo Laboratório de Tecnologia de Pavimentação, da Escola Politécnica da Universidade de São Paulo (Momm, 1998). Esse equipamento permite medir o tempo de escoamento de água contida em cilindro de plástico transparente, de volume 0,73 litro, acoplado a um fundo com um orifício circular de $5 \mathrm{~cm}$ de diâmetro, em contato com a superfície do pavimento 
(Figura 2.3.7). Nesta figura a foto (a) mostra o momento de liberação da água e a foto (b) a medição do tempo de escoamento. 0 resultado desse ensaio é expresso em termos de tempo de escoamento ou de vazão de água escoada, cujo objetivo é de verificar a capacidade drenante da textura do pavimento frente a chuvas, visto a forte correlação que este ensaio possui com o de Mancha de Areia.
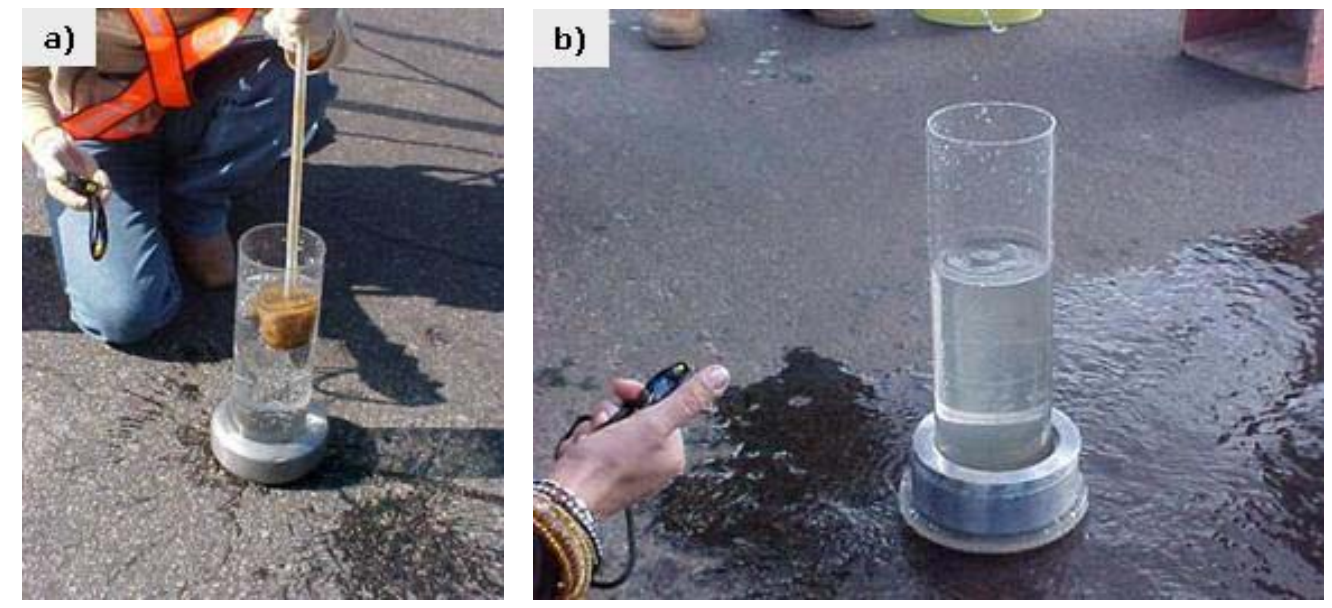

Figura 2.3.7 Drenômetro LTP - USP a) Momento de liberação da água b) Medida do tempo de escoamento (Aps e Bernucci, 2003-c)

\subsubsection{Perfilômetros a Laser}

O Perfilômetro a Laser pode ser instalado em equipamentos estacionários sobre uma viga onde o laser é acionado por um motor ou empurrado a mão, ou ser montado em um veículo que se desloca a velocidades de até $72 \mathrm{~km} / \mathrm{h}$. De um modo geral, esses equipamentos atuam projetando um raio (laser) sobre um ponto do pavimento e um receptor, situado na viga, mede a altura desse ponto sobre o pavimento, conforme preconizado pela ASTM E 1845 ou ISO 13473. A Figura 2.3.8 mostra dois exemplos de Perfilômetros a Laser. 

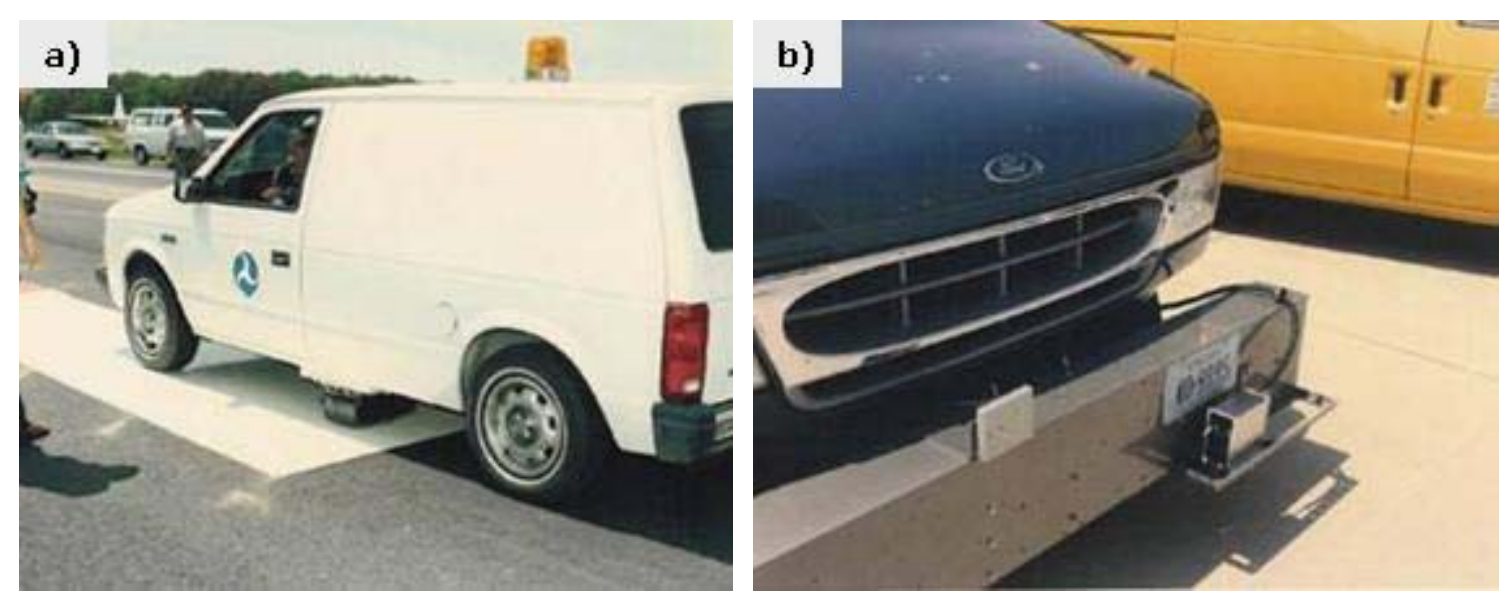

Figura 2.3.8 Perfilômetro a Laser a) FHWA Texture Van - USA b) Virginia DOT Laser Texture Meter - USA (Wambold e Henry, 2002)

\subsubsection{Circular Track Meter - CT Meter}

Este equipamento encontra-se em uso desde 1998 e pode ser usado em ensaios de laboratório ou de campo. O procedimento de ensaio é descrito na ASTM E 2157. É um equipamento a laser, que mede o perfil do pavimento de uma área circular com $284 \mathrm{~mm}$ de diâmetro e $892 \mathrm{~mm}$ de circunferência. O perfil é dividido em oito arcos iguais de circunferência, perfazendo 111,5 milímetros, e a profundidade média do perfil (MPD) é a média determinada para cada uma das áreas formadas. 0 equipamento é controlado por um computador portátil (TRB, 2000, Hanson e Prowell, 2004). A Figura 2.3.9 (a) e (b) mostra dois exemplos de CT Meter. A Figura 2.3.10 apresenta um terceiro equipamento, exibindo a parte inferior do mesmo como dispositivos de leitura com laser.

O CT Meter produz resultados comparáveis ao ensaio de Mancha da Areia com forte correlação, quando as misturas muito abertas foram excluídas, de acordo com pesquisa realizada por Hanson e Prowell (2004). Nesta pesquisa foram realizados cinco ensaios aleatórios com o CT Meter e a Mancha de Areia em cada uma das 45 seções teste. As medidas com CT Meter foram executadas antes da Mancha de Areia, de modo que o resíduo (esferas de vidro) não afetasse as leituras. A comparação dos resultados é mostrada na Figura 2.3.11. 

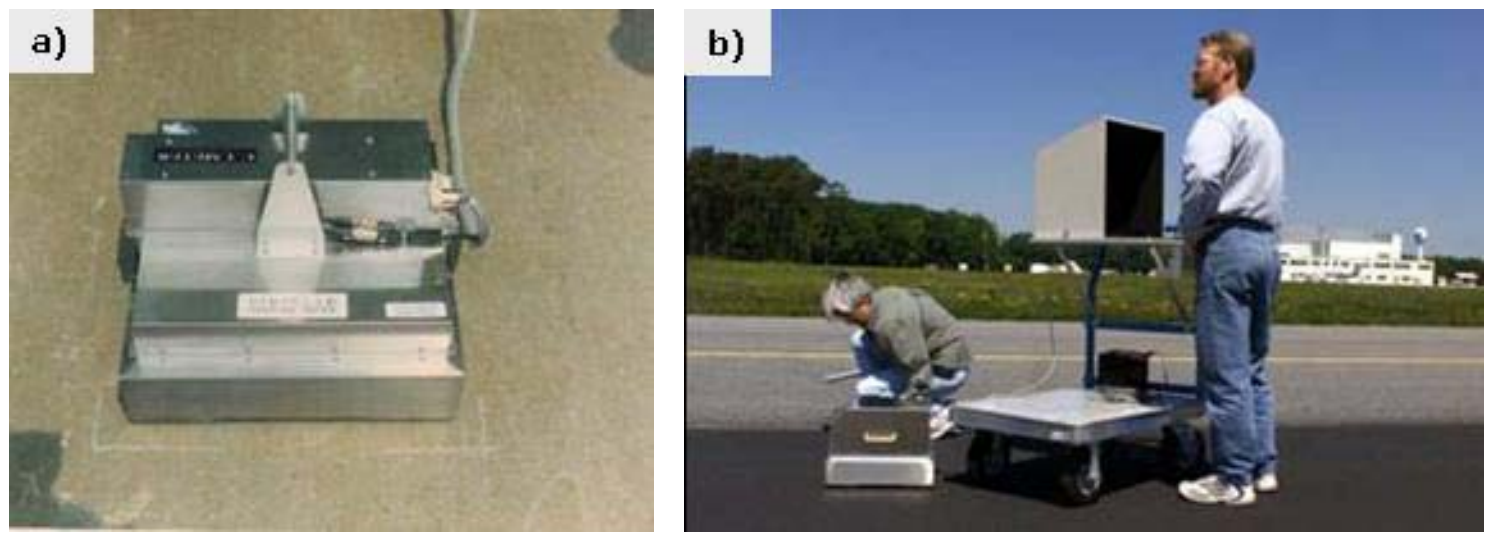

Figure 2.3.9 a) Circular Track Meter (CT Meter) - Japan b) Virginia DOT Circular Track Meter (CT Meter) - USA (Wambold e Henry, 2002)
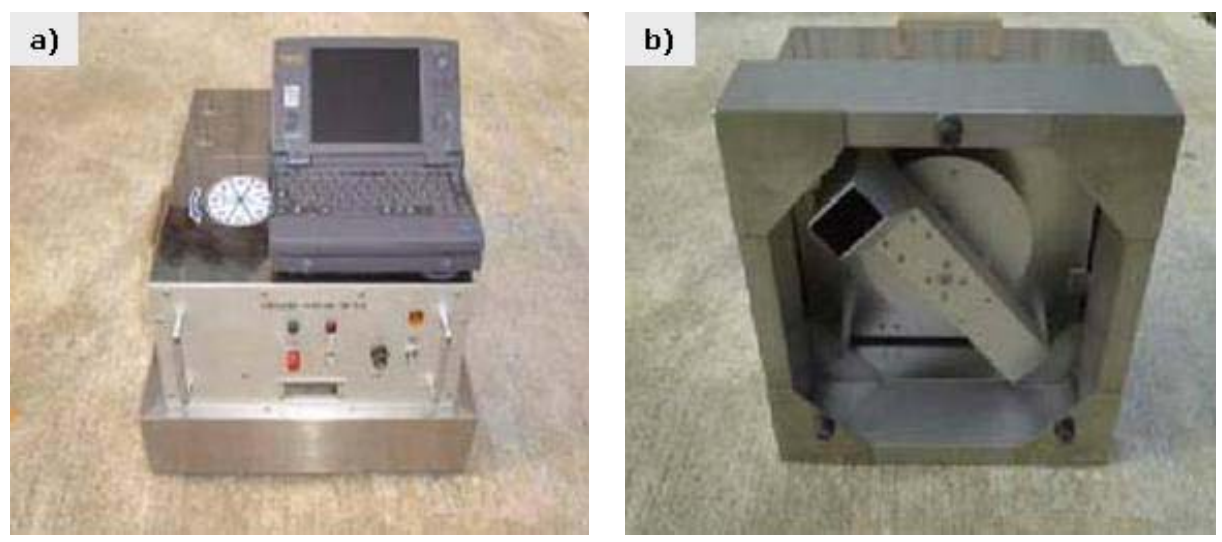

Figure 2.3.10 a) Vista do CTM d) Vista do sensor a laser (Henry et al., 2002)

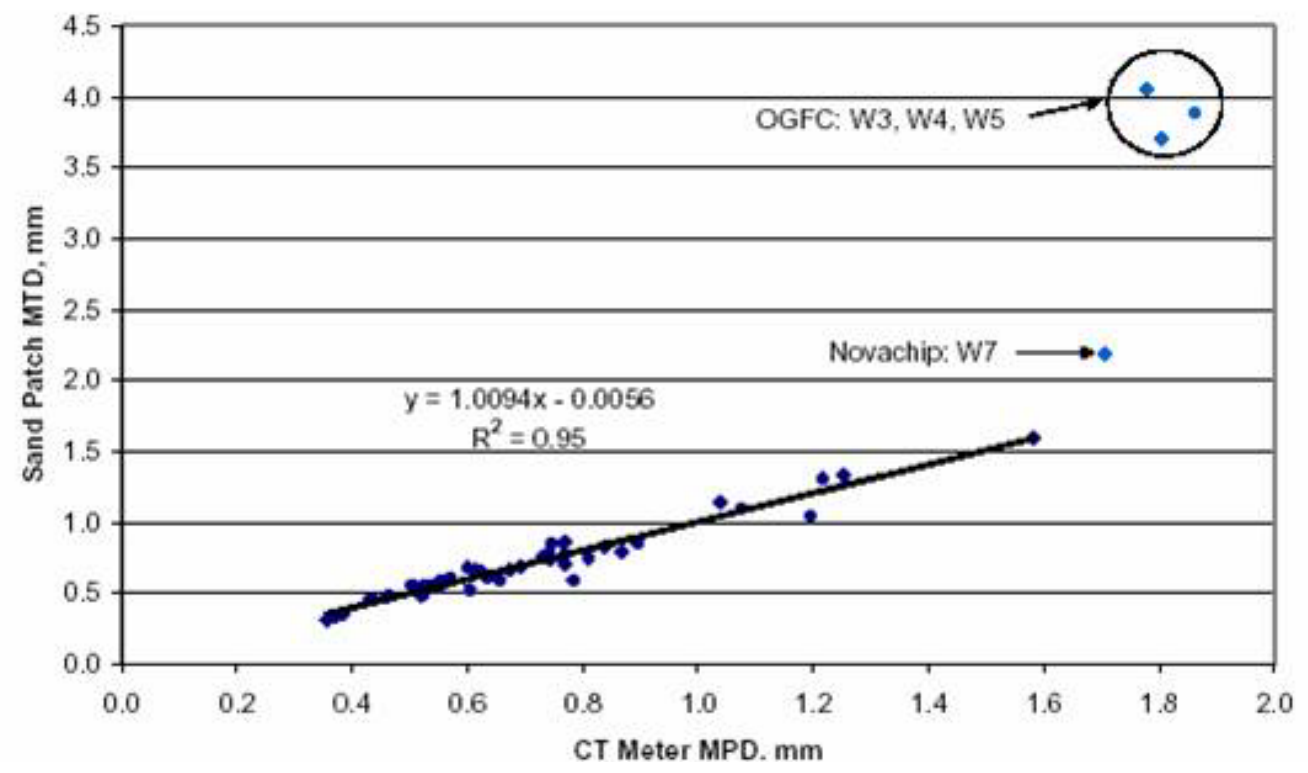

* Novachip - microrrevestimento asfáltico aberto e OGFC - Open Grad Friction Corse ou CPA Camada Porosa de Atrito

Figura 2.3.11 Comparação dos resultados obtidos com os ensaios de Mancha de Areia e CT Meter (Hanson e Prowell, 2004) 


\subsubsection{Mini Texture Meter}

Este equipamento pode ser usado para medir a textura da superfície de rodovias, aeroportos e calçadas. É operado manualmente, a uma velocidade entre 3 e $6 \mathrm{~km} / \mathrm{h}$ (velocidade de caminhada). O equipamento a laser projeta uma luz sobre a superfície avaliada, que reflete e mede a distância até a superfície. $O$ equipamento fornece os resultados impressos. A Figura 2.3.12 mostra uma vista geral do equipamento. A Figura 2.3.13 apresenta um outro exemplo de equipamento acoplado em um veículo, empregando raio laser, utilizado na Suécia.

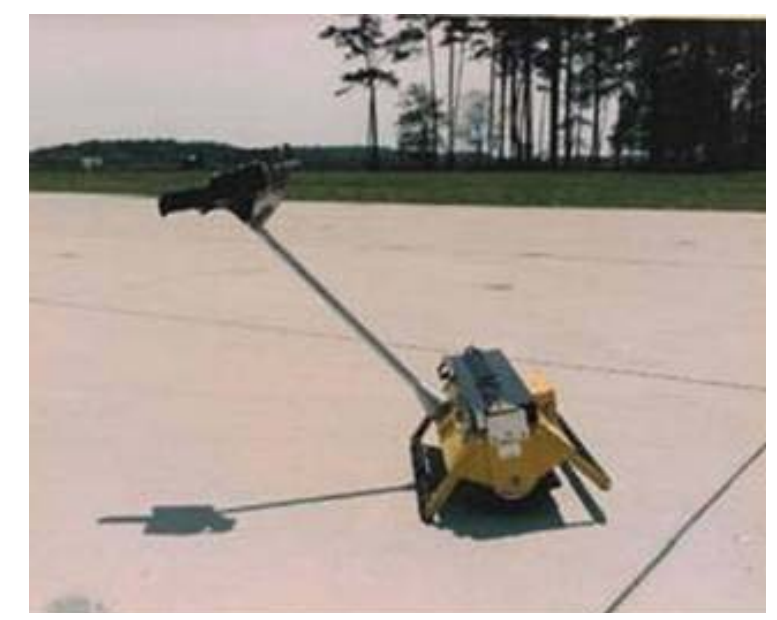

Figura 2.3.12 Mini Texture Meter - UK (Wambold e Henry, 2002)

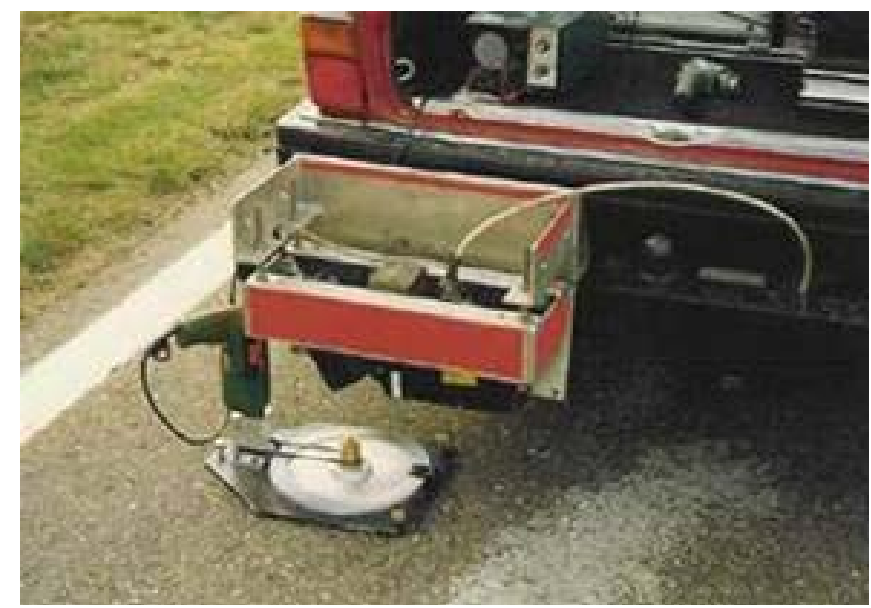

Figura 2.3.13 VTI Laser Texture System (MPD, ETD, RMS) - Suécia (Wambold e Henry, 2002) 


\subsubsection{Medidas de Atrito}

Os equipamentos de medida de atrito podem classificados em quatro tipos:

1. Estático;

2. Roda oblíqua;

3. Roda bloqueada;

4. Roda parcialmente bloqueada.

Esses equipamentos citados serão apresentados como exemplo, a seguir.

\subsubsection{Pêndulo Britânico (Estático)}

É um equipamento portátil e sua utilização é especificada pelo método da ASTM E303-93 (1998), podendo ser usado em laboratório e em ensaios de campo. Seu princípio de funcionamento baseia-se em um pêndulo padronizado com uma base de borracha, que é lançado em direção ao pavimento molhado, com o objetivo de medir-se a perda de energia por atrito da sapata de borracha do pêndulo quando esta desliza sobre a superfície do pavimento (ASTM, 1998). O valor é expresso em BPN (British Number Pendulum) ou SRT (Skid Resistent Test). A Figura 2.3.14 apresenta em (a) um vista geral do Pêndulo Britânico com haste posicionada no local de liberação para o atrito e (b) mostra a medição sendo realizada.
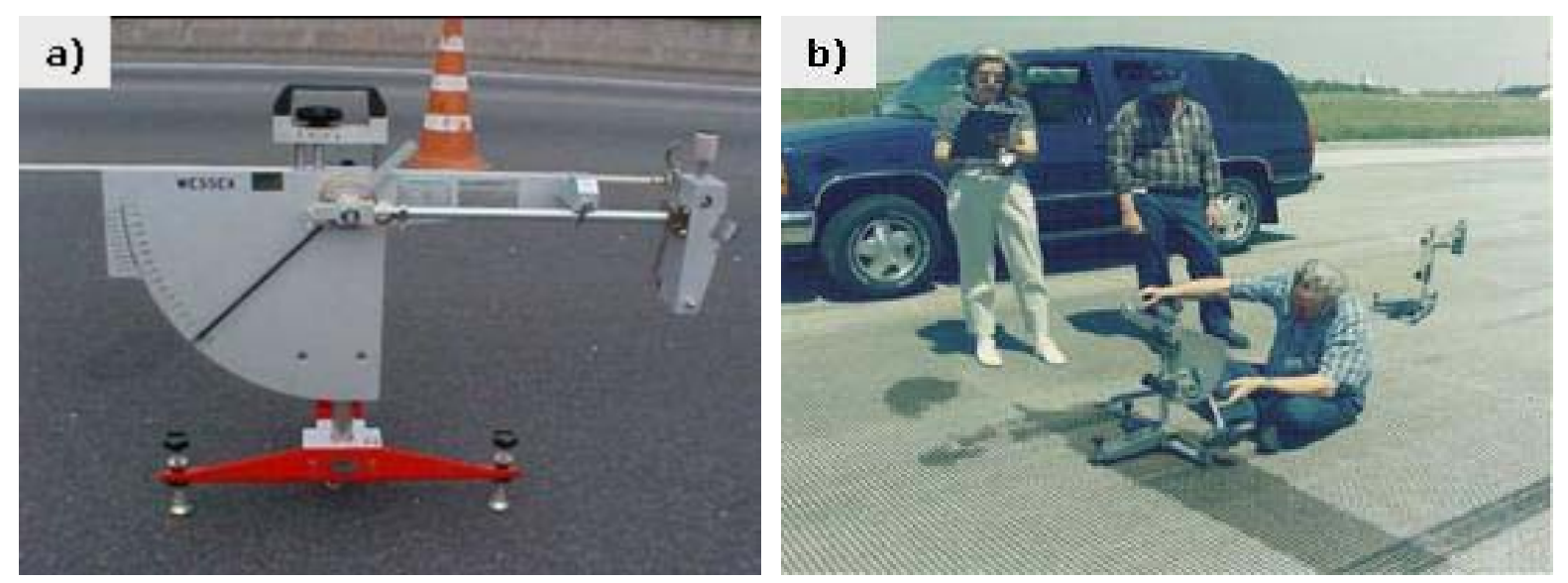

Figura 2.3.14 Pêndulo Britânico (a) em uso pelo LTP-EPUSP (Aps et al, 2003) b) em uso pela FHWA (Wambold e Henry, 2002) 


\subsubsection{Dynamic Friction Tester - DF Tester-DFT(Estático)}

O DFT é um equipamento portátil que permite a medida direta do atrito de vários tipos de superfícies pavimentadas, cujo procedimento está descrito na ASTM E 1911, 1998. O DFT consiste em um disco que gira na horizontal, em velocidade tangencial de $20 \mathrm{~km} / \mathrm{h}$ (há modelos que atingem $60 \mathrm{~km} / \mathrm{h}$ ), composto de três corrediças de borracha, (do mesmo tipo das borrachas usadas em pneus dos equipamentos de ensaio de atrito) que contatam a superfície, enquanto que a velocidade é reduzida em função do atrito gerado na área de contato. O equipamento possui um reservatório que despeja água na superfície que está sendo ensaiada. $\mathrm{O}$ atrito é calculado em função da velocidade.

A Figura 2.3.15 (a) mostra a condução de um ensaio empregando o DFT e (b) mostra uma vista do equipamento.
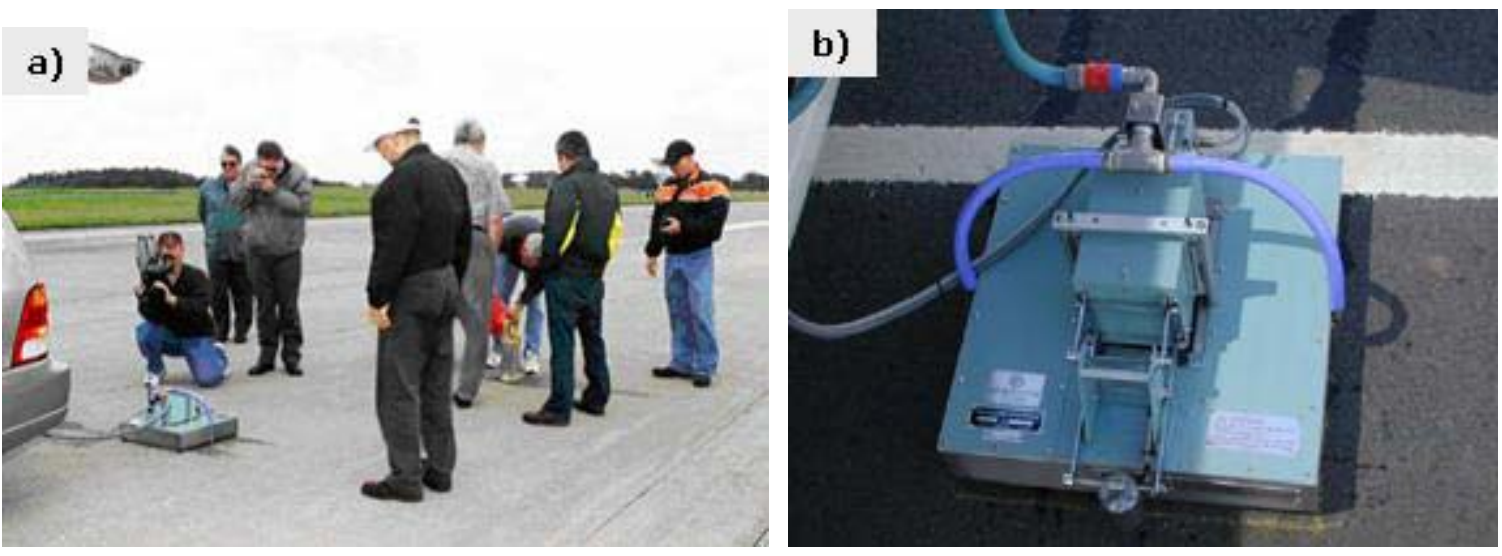

Figura 2.3.15 Dynamic Friction Tester (DF Tester) - a) Japan (Wambold e Henry, 2002) (b) Vista geral do DF Tester (Brown,2002)

A Figura 2.3.16 apresenta a forte correlação do DFT com o Pêndulo Britânico, cuja $\mathrm{R}^{2}$ é 0,86 . A seguir são apresentados os equipamentos de roda oblíqua medem o coeficiente de atrito transversal registram o esforço lateral produzido pela roda que forma um ângulo variável com a direção de avanço do equipamento. Alguns países que usam esse tipo de equipamento são: a Alemanha, a Bélgica, a Espanha, a Dinamarca, a França, a Itália e o Reino Unido. 


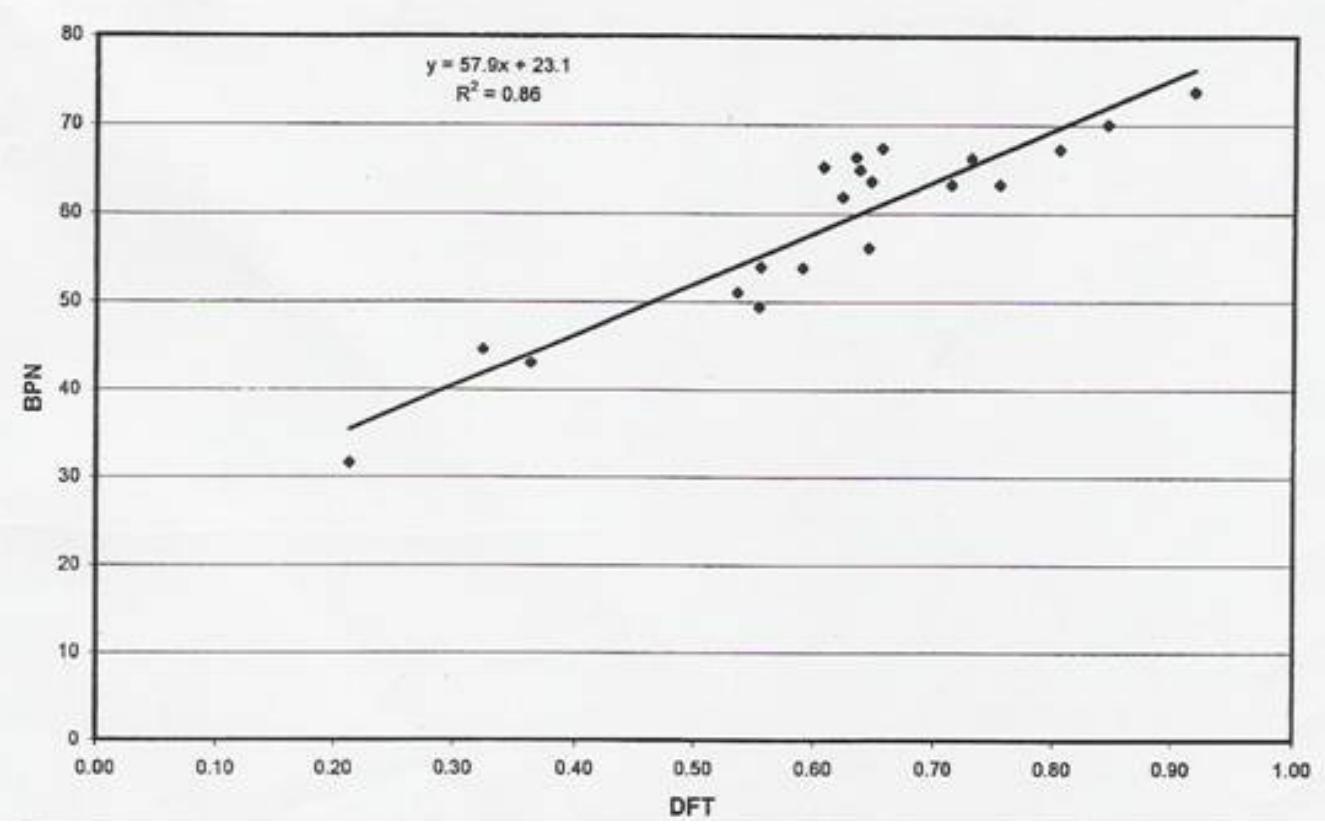

Figura 2.3.16 $B P N$ versus $D F T(T R B, 2000)$

\subsubsection{Mu-meter (Roda Oblíqua)}

Este equipamento é muito usado no Brasil em aeroportos pelo Ministério da Aeronáutica por meio de sua Diretoria de Engenharia - DIRENG e pela Infraero. Este é um equipamento de uso muito comum em pistas de pouso, mas que também pode ser utilizado em estradas, como fazem o estado do Arizona, nos E.U.A. e a província de Alberta, no Canadá.

Trata-se de um equipamento rebocado, constituído de três rodas, sendo duas destinadas a medir o coeficiente de atrito e a terceira para indicar as distâncias percorridas. As medidas podem ser feitas tanto para pavimento seco como para condição de pista molhada. Neste último caso, há um sistema espargidor que aplica uma película d'água de espessura média de $1 \mathrm{~mm}$ à frente das rodas sensoras. A velocidade do equipamento pode ser ajustável, sendo a mais comum de $65 \mathrm{Km} / \mathrm{h}$ e seu procedimento está descrito na ASTM E-670, 2000 (Cardoso et al, 1996) A Figura 2.3.17 (a) mostra uma vista geral do equipamento Mu-meter e (b) mostra uma foto do uso deste equipamento em aeroporto brasileiro. 


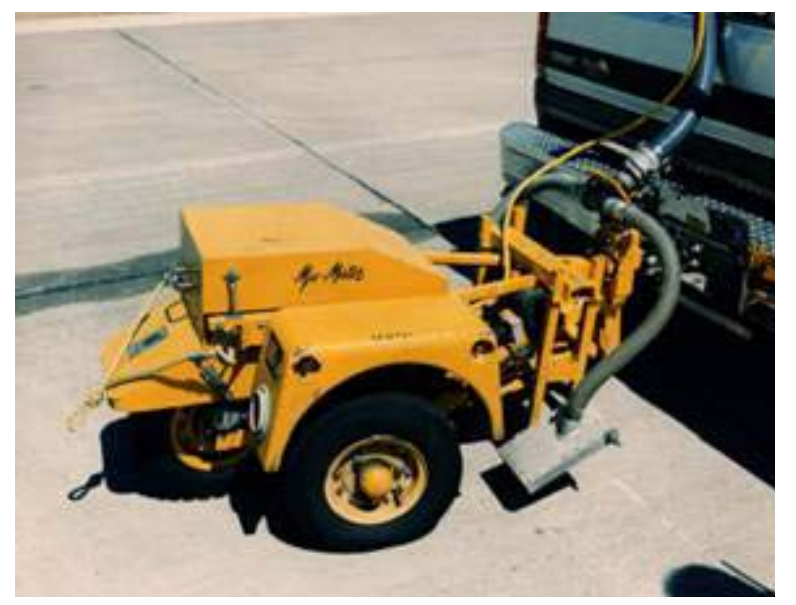

Figura 2.3.17 Mu-meter - FAA - USA (Wambold e Henry, 2002)

\subsubsection{Stradograph (Roda Oblíqua)}

Trata-se de um veículo com adaptação de um dispositivo que permite realizar medidas contínuas de atrito, através de duas rodas situadas em cada lado do eixo longitudinal do mesmo. A taxa de deslizamento das rodas pode variar de 0 a $15 \%$, podendo, também, operar segundo ângulos de 0 a 15 graus em relação ao eixo longitudinal do equipamento. A carga que atua sobre as rodas "medidoras" pode ser variada de 100 a $400 \mathrm{Kgf}$. A Figura 2.3.18 (a) mostra o veículo e (b) mostra o detalhe da roda em posição oblíqua para a medida do atrito.
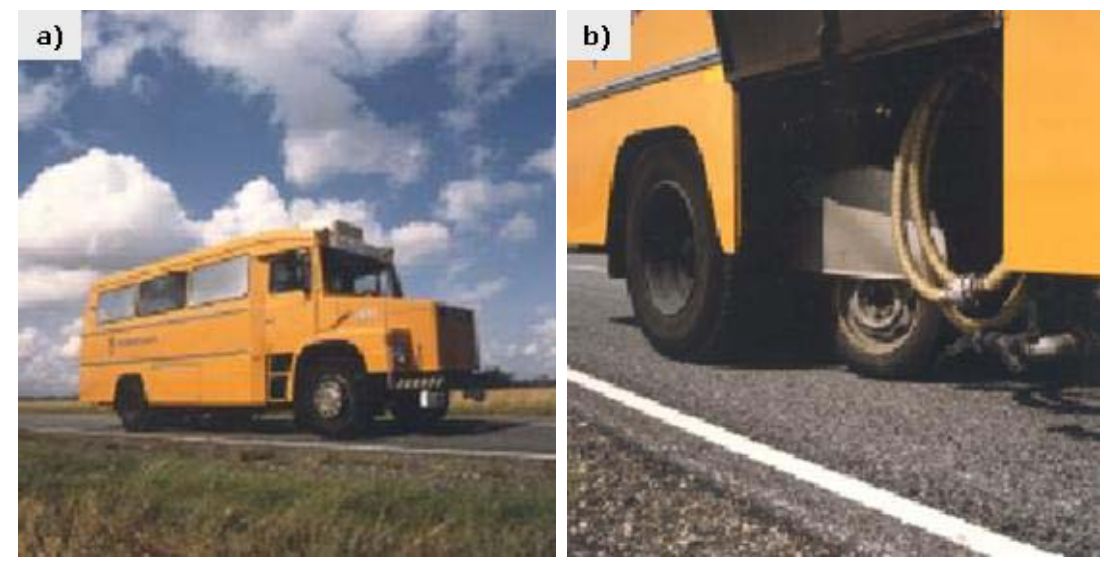

Figura 2.3.18 Stradograph (a) Vista geral do equipamento (b) Detalhe da roda oblíqua (Wambold e Henry, 2002) 
O equipamento pode registrar até sete parâmetros simultaneamente, como: força lateral direita, força lateral esquerda, força longitudinal direita; força longitudinal esquerda, velocidade de rotação das rodas esquerda e direita, cargas que atuam nas rodas esquerda e direita, e velocidade do veículo.

\subsubsection{Odoliograph (Roda Oblíqua)}

O Odoliograph é um equipamento de roda oblíqua, que não possuí sistema de armazenamento de água acoplado. Para as realizações dos ensaios deve ser utilizado em caminhão cisterna que vai a sua frente molhando o pavimento. A Figura 2.3.19 mostra o equipamento em uso.

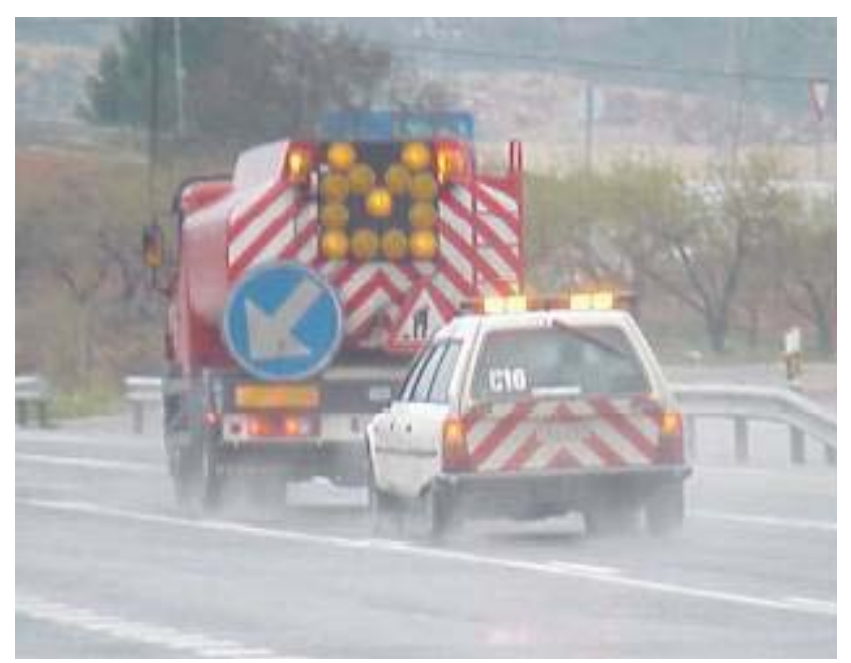

Figura 2.3.19 Vista do Odoliograph em operação (Wambold e Henry, 2002)

\subsubsection{SCRIM (Roda Oblíqua)}

O SCRIM - Sideways Force Coefficient Routine Investigation Machine, foi desenvolvido pelo TRRL (Transportation Road Research Laboratory) e vem sendo usado em vários países, como a Inglaterra, a França e os Estados Unidos. Durante a medição do coeficiente de atrito, ele trabalha com uma roda inclinada de 20 graus em relação ao eixo longitudinal do veículo que pode ser levantada quando não está 
em operação. Estes equipamentos são providos de dispositivo de espargimento de água, proporcionando uma lâmina de $1,0 \mathrm{~mm}$ de espessura nominal. A Figura 2.3.20 mostra (a) o equipamento e (b) o detalhe da roda oblíqua.
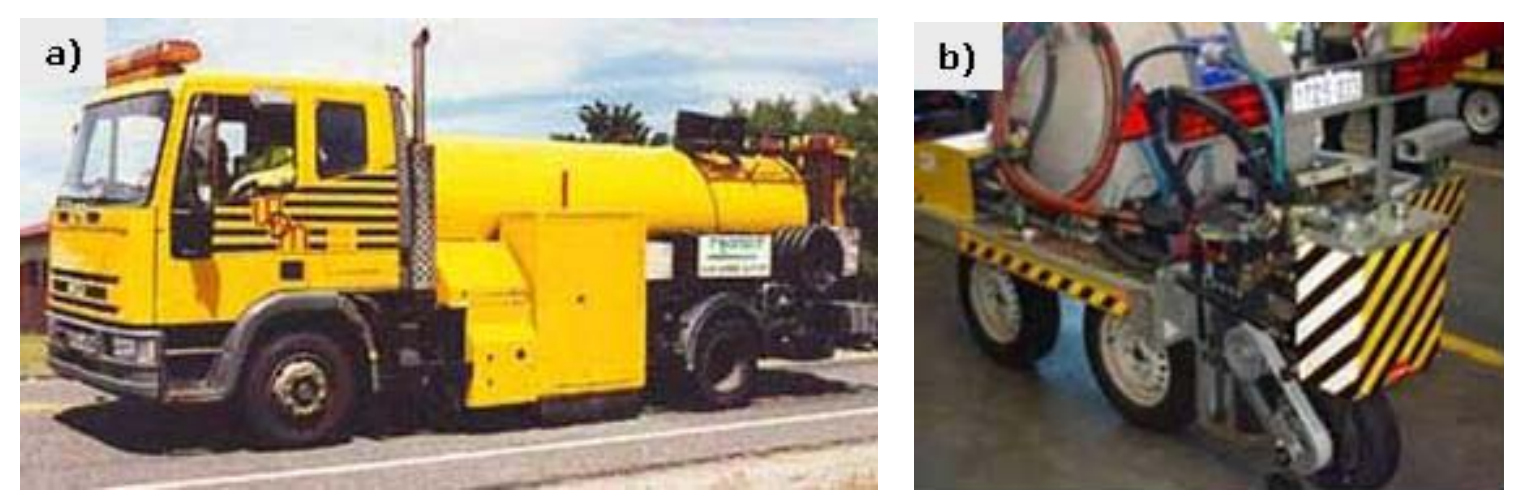

Figura 2.3.20 (a) Vista geral do equipamento (b) Detalhe da roda em posição de medição (Wambold et al., 1995)

\subsubsection{Equipamento de Roda Bloqueada}

Os EUA utilizam em seus 50 estados, equipamentos com roda bloqueada para a avaliação do atrito, seja para a realização da inspeção anual da malha rodoviária, ou para a investigação de pontos críticos de ocorrência de acidentes, ou ainda para a liberação de obras. A Suécia, a França, a Alemanha, a Grécia, a República Popular de China, a Suíça, o Japão e a Polônia utilizam em suas avaliações de atrito uma parcela de equipamentos com roda bloqueada. O Kuwait utilizava esse tipo de avaliação, porém durante a guerra do Golfo esse equipamento foi perdido.

Esses equipamentos produzem um bloqueio de $100 \%$. A velocidade relativa entre 0 pneu e o pavimento é igual à velocidade do veículo. Ao frear o veículo, mede-se a força média que é aplicada pelo tempo de um segundo, com a roda completamente bloqueada, referente ao atrito máximo. Estes equipamentos são providos de dispositivo de espargimento de água, proporcionando, geralmente uma lâmina de $0,5 \mathrm{~mm}$ de espessura nominal. Entre os equipamentos de roda bloqueada citam-se 0 
Locked Wheel Tester (Figura 2.3.21), o LCPC Skid Trailer (Figura 2.3.22), o Stuttgarter Reinbungsmesser (Figura 2.3.23) e o Skiddometer (Figura 2.2.24).
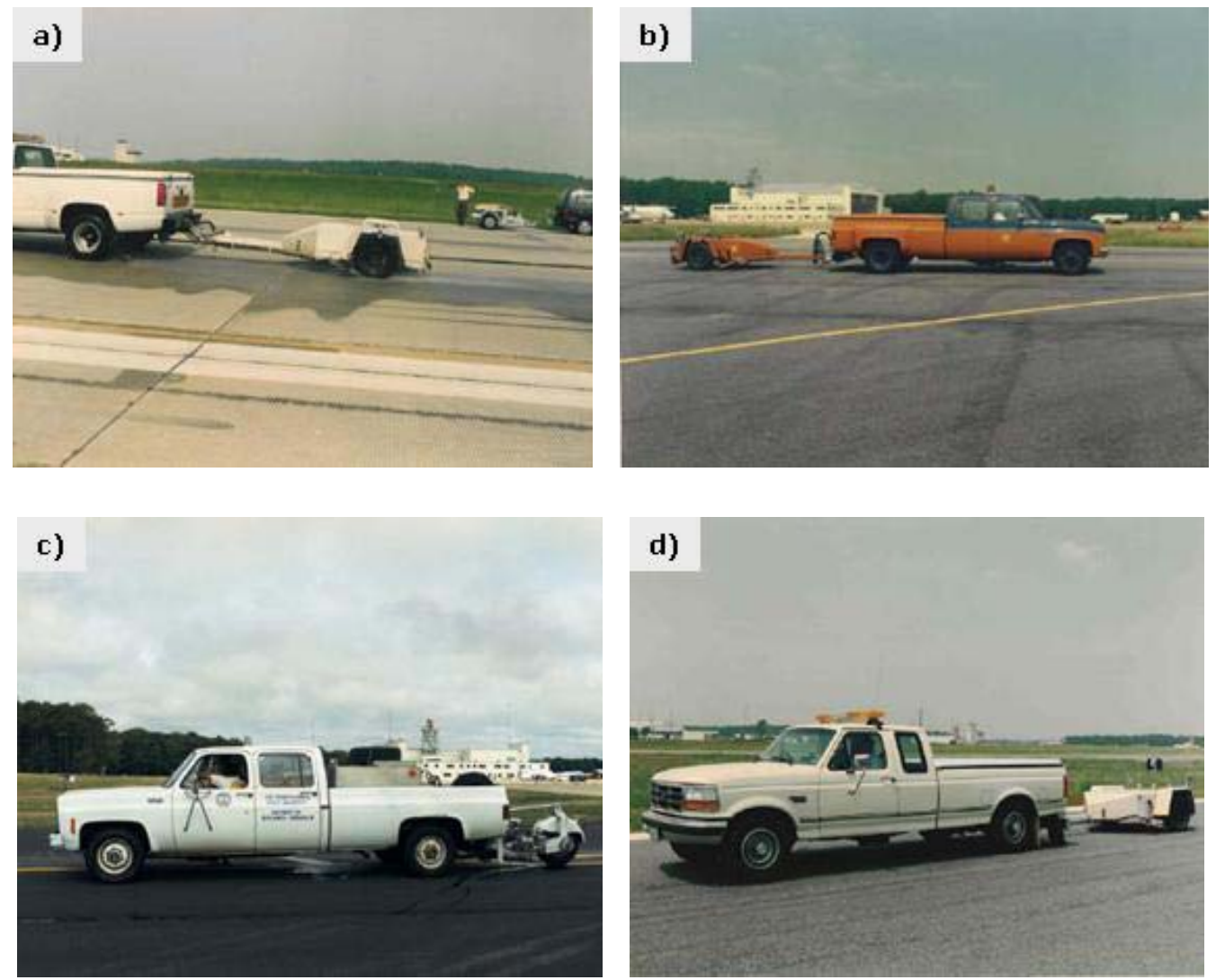

Figura 2.3.21 E-274 Locked Wheel Tester - USA (a) PTI K. J. Law

(b) MD DOT c) Penn State d) International Cybernetics (Wambold e Henry, 2002)
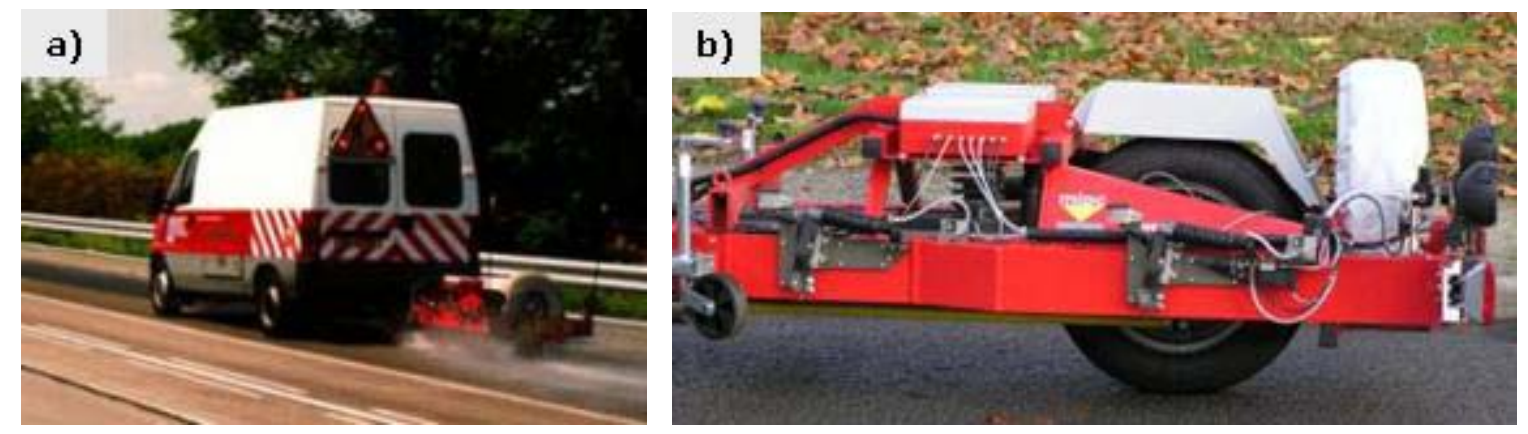

Figura 2.3.22 LCPC Skid Trailera) Vista geral b) Detalhe do reboque (Wambold e Henry, 2002) 


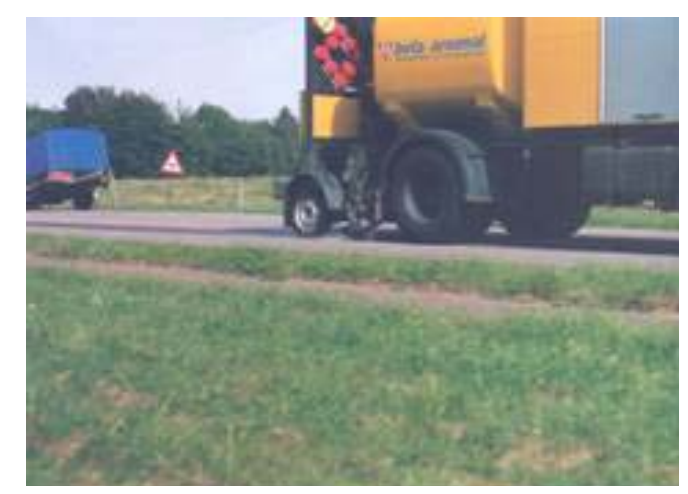

Figura 2.3.23 Stuttgarter Reibungsmesser (Wambold e Henry, 2002)

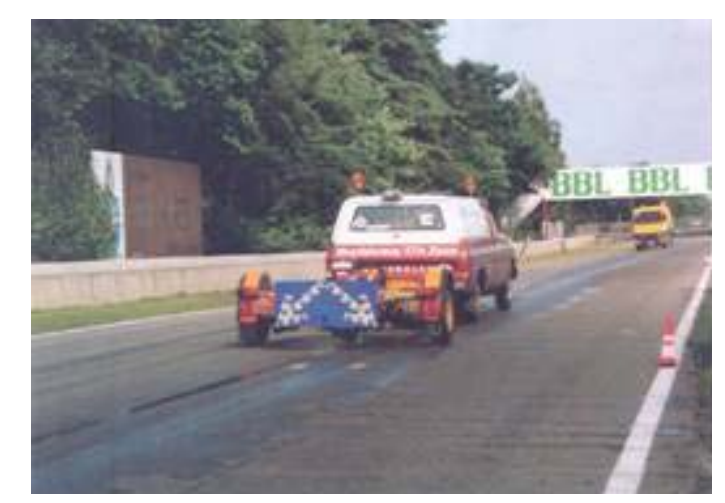

Figura 2.3.24 Skiddometer (Wambold e Henry, 2002)

A seguir serão apresentados os equipamentos de roda parcialmente bloqueada que consistem de uma variação dos equipamentos de roda bloqueada. Registra o atrito em função do grau de deslizamento, ou seja, o bloqueio é variável; desde a roda girando livremente ( $0 \%$ de deslizamento) até o bloqueio total $(100 \%$ de deslizamento). Alguns modelos desse tipo de equipamento estão descritos a seguir.

\subsubsection{BV-11 (Roda Parcialmente Bloqueada)}

É um equipamento que realiza as medidas de atrito de modo contínuo, constituído por um reboque de três rodas do tipo deslizômetro (skiddometer). A roda central que é responsável pela medida do atrito tem a rotação retardada operando com uma taxa de deslizamento controlada de $17 \%$ com o veículo em movimento. As outras duas rodas giram livremente e suportam o peso da estrutura do equipamento. Uma força de $100 \mathrm{kgf}$ é aplicada sobre a roda de medição que pode ser composta de 
pneus de baixa (200 kPa) ou alta pressão (700 kPa), (Silva, 1981; Araújo, 1994). A Figura 2.3.25 mostra uma vista geral do equipamento.

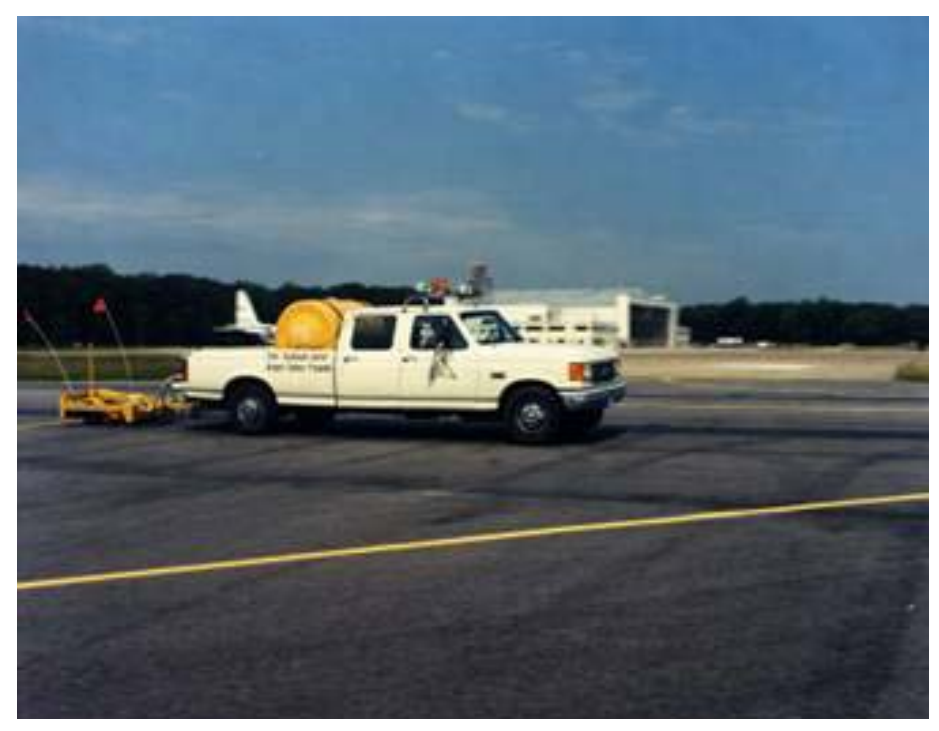

Figura 2.3.25 $B V$-11 - FAA USA (Wambold e Henry, 2002)

\subsubsection{SFT- Surface Friction Tester(Roda Parcialmente Bloqueada)}

É um equipamento montado em um veículo cujo princípio de funcionamento é o mesmo do $B V-11$. A medida contínua do atrito é realizada por uma quinta roda instalada sob o porta-malas, que opera com uma taxa de deslizamento de $15 \%$. Há um sistema de espargimento que permite a aplicação de uma lâmina d'água de espessura média $1 \mathrm{~mm}$, nas velocidades de ensaios, simulando as condições de pistas molhadas.

As informações são registradas em um computador portátil de bordo. Pode ser equipado de pneus de baixa (200 kPa) ou alta pressão (700 kPa) (Silva, 1981).

A Figura 2.3.26 mostra o equipamento em questão. 

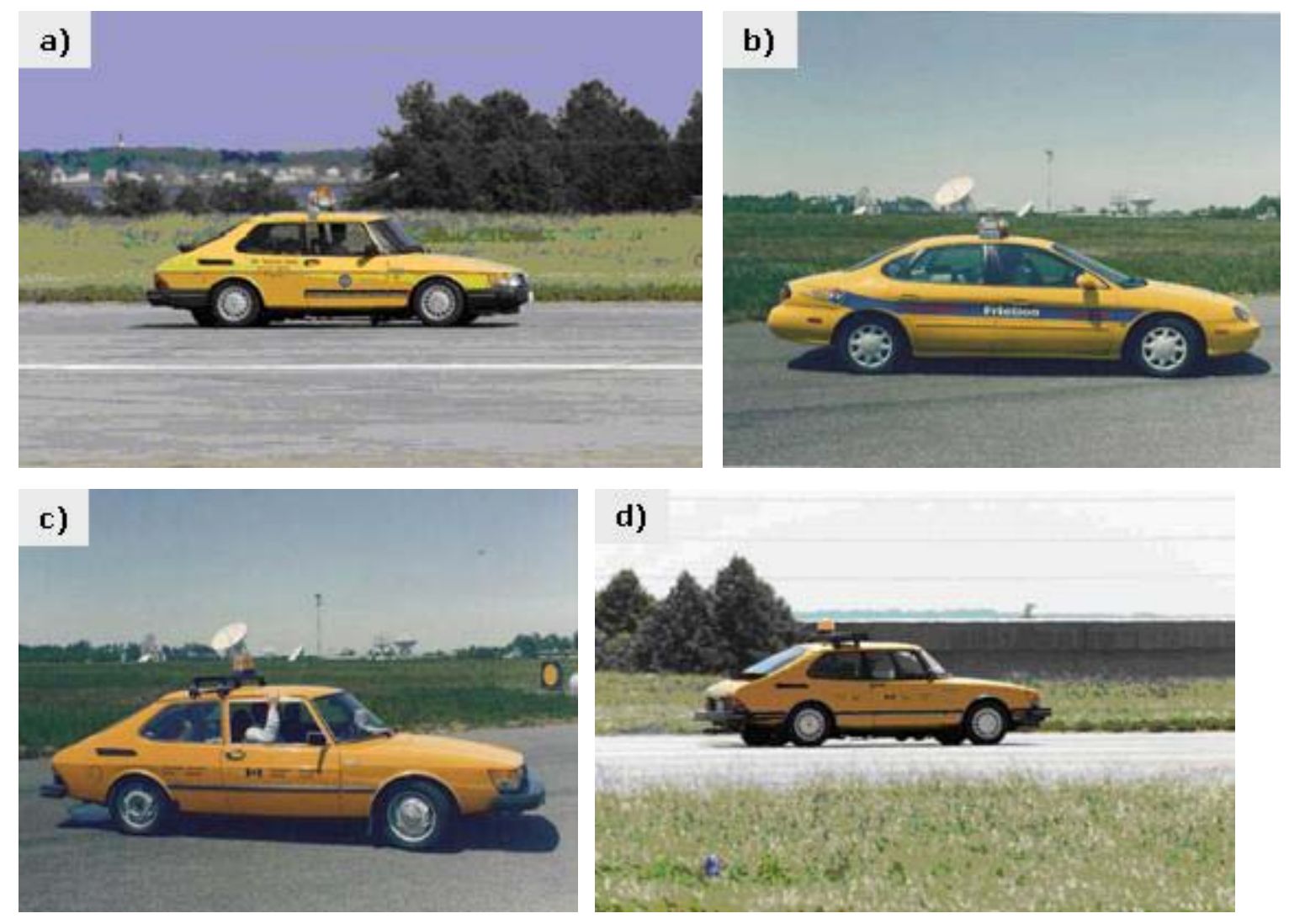

Figura 2.3.26 a) Surface Friction Tester - FAA - USA; b) Surface Friction Tester Sweden; c) Modelo TC79; d) Modelo TC85; (Wambold e Henry, 2002)

\subsubsection{Grip Tester (Roda Parcialmente Bloqueada)}

É um equipamento que também realiza as medidas de atrito de modo contínuo, constituído por um reboque de três rodas do tipo deslizômetro (skiddometer). A roda central que é responsável pela medida do atrito tem a rotação retardada operando com uma taxa de deslizamento controlada de $15 \%$ e pode atingir velocidade de deslocamento até $65 \mathrm{~km} / \mathrm{h}$.

Este equipamento encontra-se em operação no Brasil. A Figura 2.3.27 mostra diversas versões do Grip Tester, rebocáveis por veículos ou manuais. 

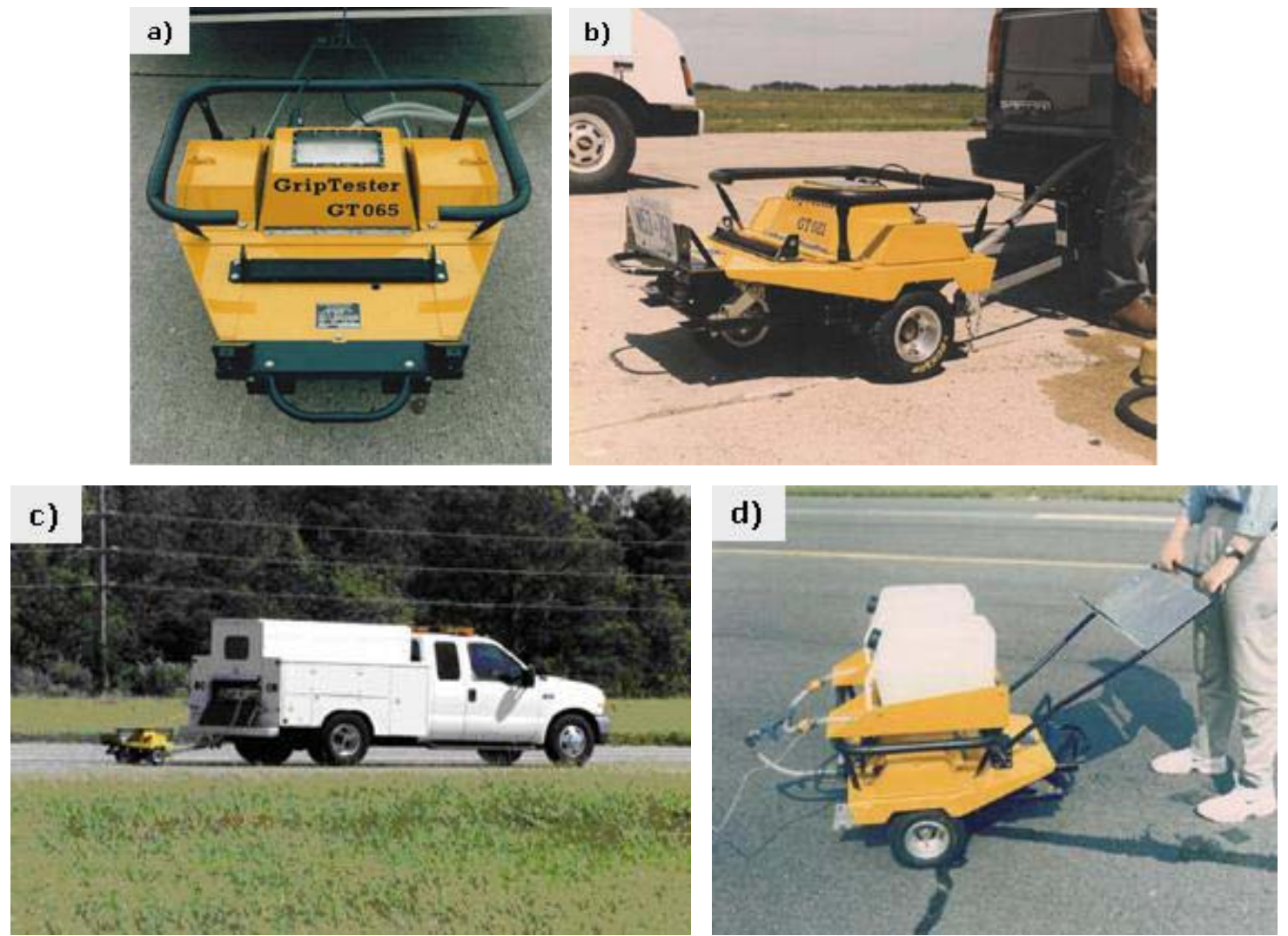

Figura 2.3.27 a) Grip Tester-NASA; b) Grip Tester-Scotland ; c) Grip Tester versão rebocada; d) Grip Testerversão manual;(Wambold e Henry, 2002)

\subsubsection{Runway Friction Tester(Roda Parcialmente Bloqueada)}

Este equipamento é montado dentro de um veículo do tipo Mini Van, cuja roda de medição de atrito está instalada no eixo traseiro. Essa roda que é responsável pela medida do atrito tem a rotação retardada operando com uma taxa de deslizamento controlada de 13,5\%. A Figura 2.3.28 mostra um equipamento em operação.

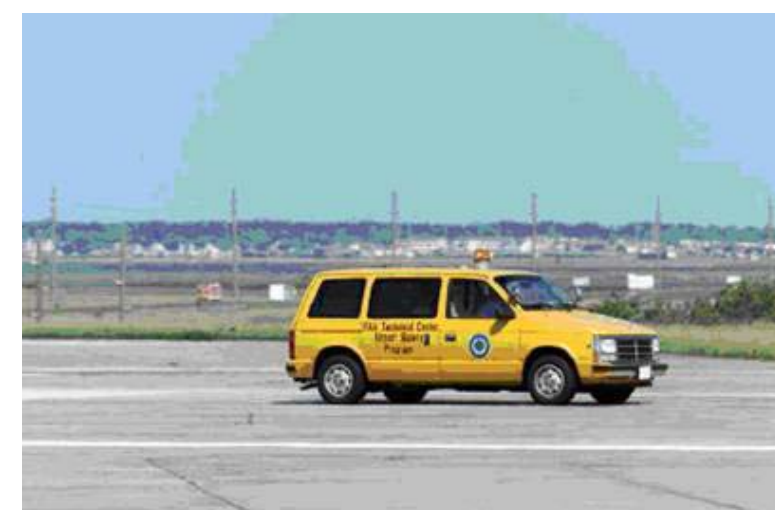

Figura 2.3.28 Runway Friction Tester FAA - USA (Wambold e Henry, 2002) 
Outros equipamentos de roda parcialmente bloqueada são mostrados nas Figuras 2.3.29 (Norsemeter OSCAR), 2.3.30 (Komatsu Skid Trailer), 2.3.31 (DWW Trailer) e 2.3.32 (Stuttgarter Reibungsmesser).

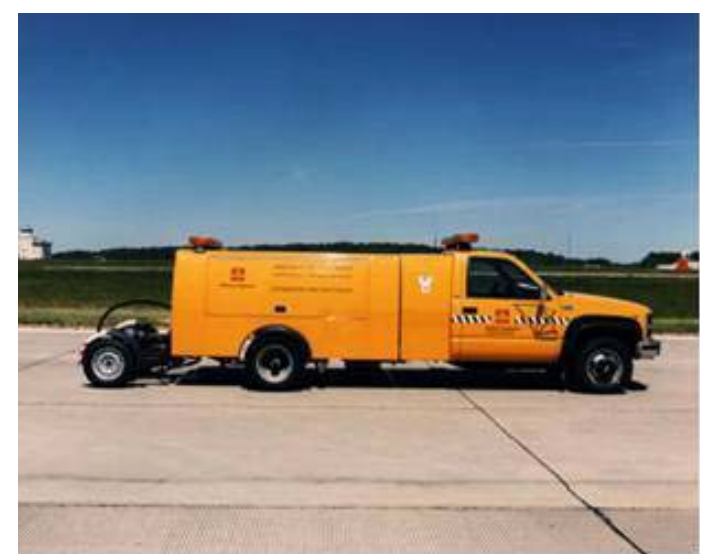

Figura 2.3.29 Norsemeter OSCAR (variable slip tester)-Norway (Wambold e Henry, 2002)

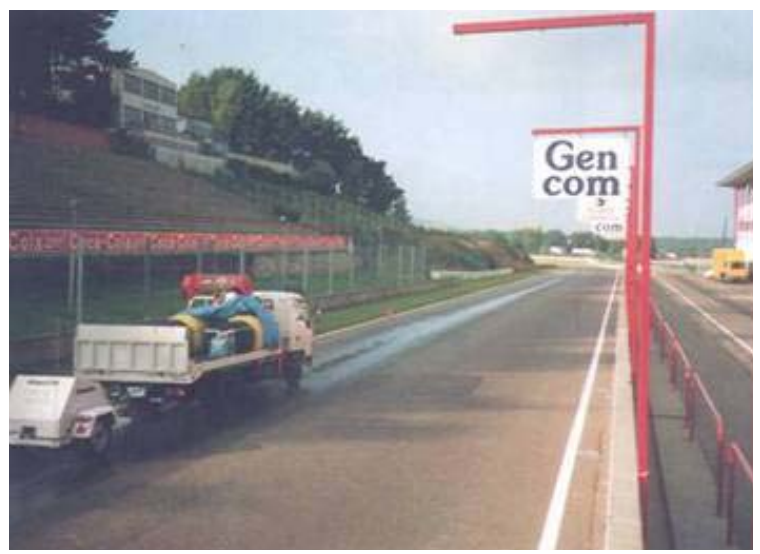

Figura 2.3.30 Komatsu Skid Trailer (Wambold et al., 1995)

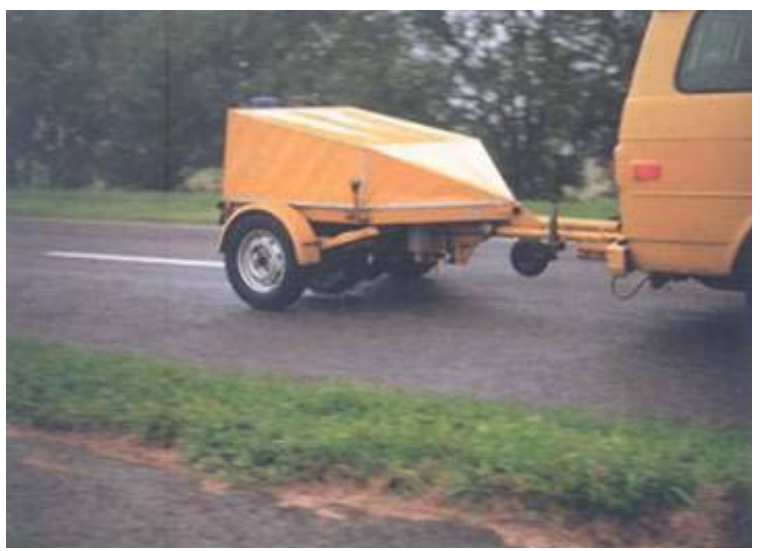

Figura 2.3.31 DWW Trailer (Wambold et al., 1995) 


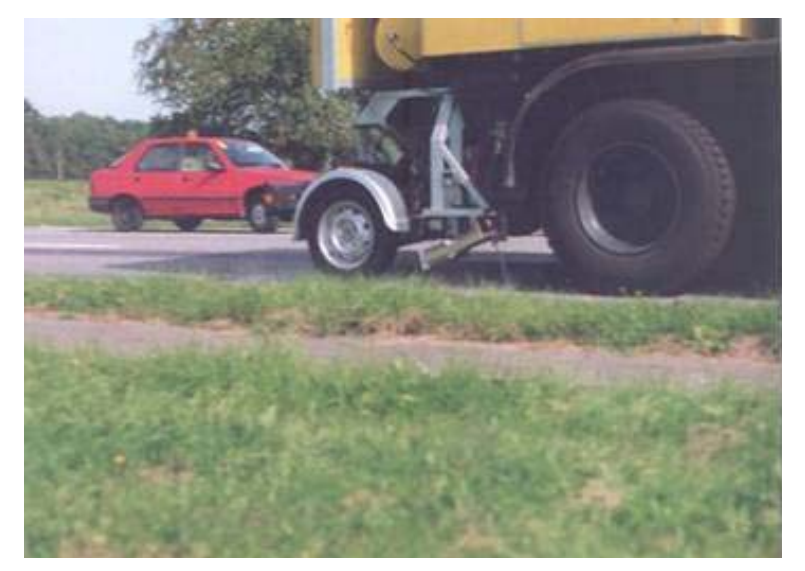

Figura 2.3.32 Stuttgarter Reibungmesser (Wambold et al., 1995)

Os diversos equipamentos e métodos, conforme visto acima, apresentam muita variabilidade nos resultados devido aos diferentes modos de medição dos valores de atrito, textura ou aderência. Com o objetivo de uniformizar esses valores o Comitê de Características de Superfície (C1) da PIARC desenvolveu uma experiência internacional de comparação e harmonização de métodos de avaliação (Noyce et al., 2005). Essa experiência está descrita no item 2.4 a seguir.

\subsection{A Influência do Tipo do Revestimento na Textura Superficial}

Os revestimentos asfálticos são largamente aplicados no Brasil na grande maioria dos pavimentos; por este motivo serão os abordados neste item para estabelecimento das relações de suas características com a textura superficial. Os revestimentos asfálticos podem ser:

a) Usinados a quente ou a frio, utilizando em geral usinas estacionárias para sua produção e equipamentos específicos para a distribuição dessas misturas e sua compressão;

b) Tratamentos superficiais que são constituídos de camadas alternadas de ligante asfáltico e de agregados, aplicadas por veículos especialmente projetados para esta distribuição; e 
c) Microrrevestimentos a frio e lamas asfálticas que são misturas realizadas por usinas móveis, acopladas sobre veículo que executa também sua distribuição.

As principais características das misturas asfálticas que influenciam na textura são: a distribuição granulométrica dos agregados e fíler; e natureza, forma e microtextura superficial dos agregados, principalmente os das frações graúdas (agregados retidos na peneira de abertura 4 ou $4,76 \mathrm{~mm}$ ). O ligante asfáltico influencia pouco na textura resultante; sua importância é indireta e relativa à resistência à desagregação dos revestimentos que podem, após uso pelo tráfego e ação das intempéries, sofrerem arrancamento de agregados, denominados na classificação de defeitos por desgaste da superfície, tendo como conseqüência a alteração da textura superficial.

Uma vez que a graduação, ou distribuição granulométrica, é uma das características marcantes que influenciam a macrotextura, será abordada neste item com mais detalhe.

\subsubsection{Graduações de Misturas Asfálticas Usinadas}

As misturas asfálticas usinadas são subdivididas em geral pelo padrão de distribuição granulométrica. Destacam-se três tipos mais usuais nas misturas asfálticas, principalmente usinadas a quente, ou seja, empregando asfaltos convencionais ou asfaltos modificados por polímeros (Bernucci et al., 2006):

a) Graduação densa e bem-graduada: curva granulométrica contínua e bemgraduada, de forma a proporcionar um esqueleto mineral com poucos vazios visto que os agregados de dimensões menores preenchem os vazios dos maiores. São graduações de elevada resistência ao cisalhamento graças ao arranjo dos grãos e grande entrosamento entre eles. Exemplo: concreto asfáltico CA - também denominado de concreto betuminoso 
usinado a quente CBUQ, areia-asfalto a quente, pré-misturado a quente; alguns pré-misturados a frio, entre outros;

b) Graduação aberta: curva granulométrica uniforme com agregados quase exclusivamente de um mesmo tamanho, de forma a proporcionar um esqueleto mineral com muitos vazios interconectados, com insuficiência de agregados miúdos e material fino (menor que $0,075 \mathrm{~mm}$ ) para preencher os vazios entre as partículas maiores, com objetivo de tornar a mistura com elevado volume de vazios com ar e, portanto, drenante, possibilitando a percolação de água no interior da mistura asfáltica. Exemplo: mistura asfáltica drenante, conhecida no Brasil por CPA (camada porosa de atrito); algumas classes de BBTM (Béton Bitumineux Très Mince - concreto asfáltico delgado);

c) Graduação descontínua: curva granulométrica com proporção dos grãos de maiores dimensões em quantidade dominante em relação aos grãos de dimensões intermediárias, completados por certa quantidade de finos, de forma a ter uma curva descontínua em certas peneiras, com objetivo de tornar o esqueleto mineral mais resistente à deformação permanente por maior número de contatos entre os agregados graúdos. Exemplo: SMA (Stone Matrix Asphalt ou matriz pétrea asfáltica); mistura sem agregados de uma determinada graduação (Gap-Graded); algumas classes de BBTM (Béton Bitumineux Très Mince - concreto asfáltico delgado).

A Figura 2.4.1.1 mostra um exemplo de distribuições granulométricas distintas, sendo a de Concreto Asfáltico bem-graduada, a de SMA descontínua e a de CPA aberta.

Entre as misturas usinadas, o tipo mais empregado no Brasil é o concreto asfáltico $\mathrm{CA}$, também denominado concreto betuminoso usinado a quente - CBUQ. De acordo com o arranjo granulométrico, estas misturas tendem a possuir maior entrosamento, maior densidade, serem mais fechadas e densas. Por este motivo, a textura 
superficial é tanto mais fechada quanto mais próxima sua curva for da de máxima densidade, ou quanto mais "fina" for esta graduação. A Figura 2.4.1.2 (a) mostra um aspecto de um concreto asfáltico muito denso, com curva granulométrica bem fechada gerando uma textura superficial também fechada; já a Figura 2.4.1.2 (b) mostra um concreto asfáltico com graduação mais grosseira, com maior consumo de agregados graúdos em contraposição ao tipo (a).

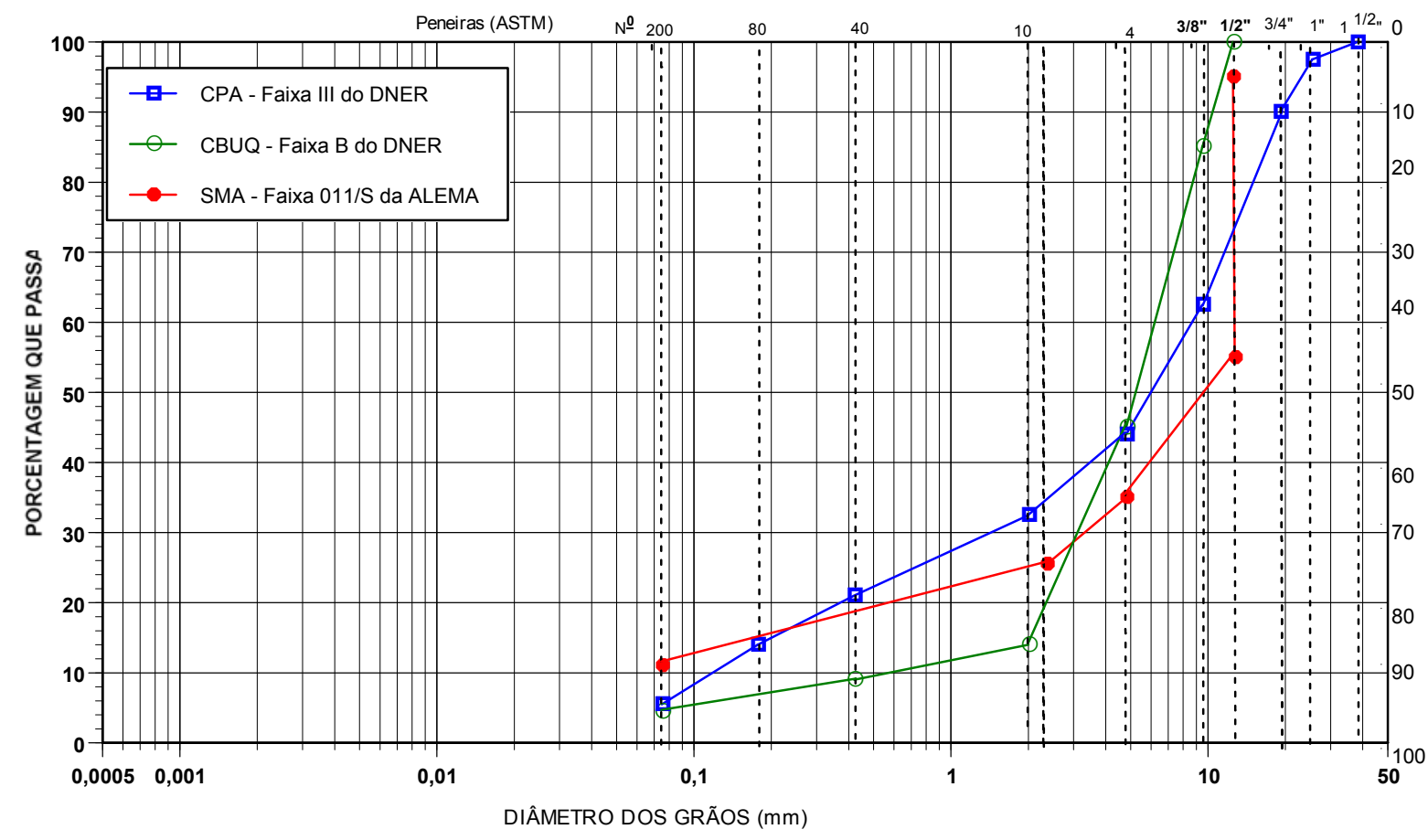

Figura 2.4.1.1 Distintas graduações de misturas asfálticas usinadas a quente

a)

b)
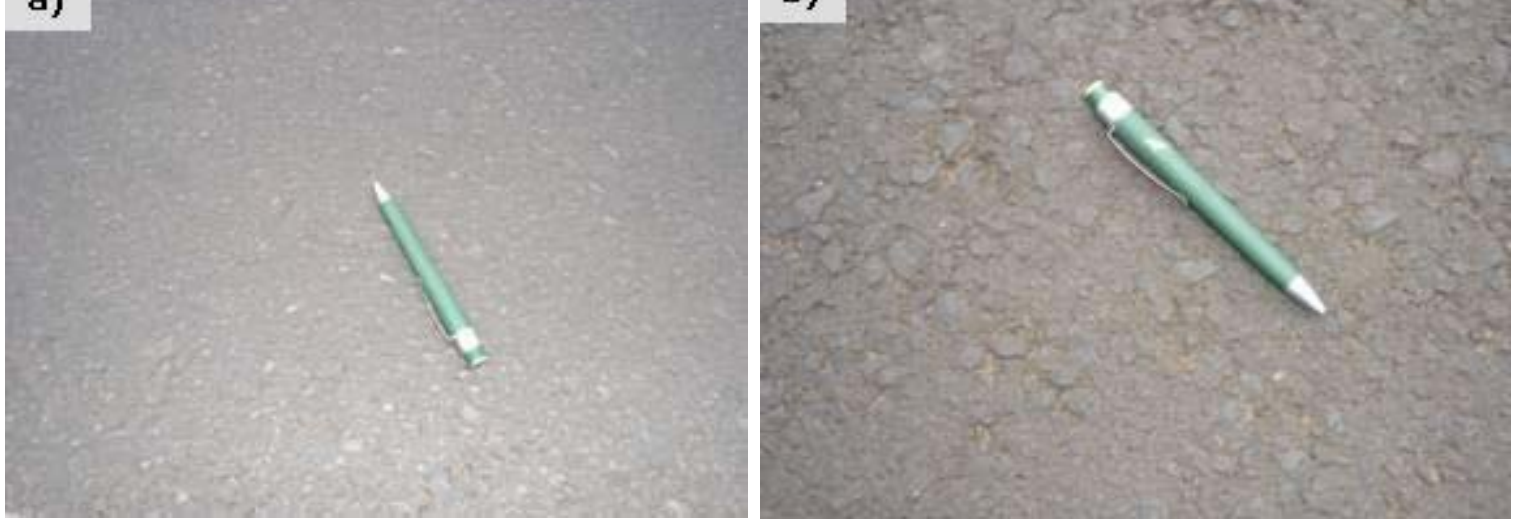

Figura 2,4.1.2 Dois tipos de concretos asfálticos de graduação densa e bemgraduadas, (Bernucci, 2005) 
Geralmente os concretos asfálticos não promovem uma textura superficial que supere 0,6 a 0,8 mm de altura média de mancha de areia. As graduações mais "finas" podem gerar misturas com macrotextura superficial fechada com altura de mancha na faixa de 0,4 a 0,5mm, como mostrado na Figura 2.4.1.2 (a) anterior. As graduações que tendem a ter maior diâmetro máximo de agregados e maior quantidade de agregados graúdos, com curva mais "aberta" tendem a fornecer melhores macrotexturas, como visto na Figura 2.4.1.2 (b) anterior.

Dada a dificuldade de promover uma boa macrotextura superficial nos concretos asfálticos, em aeroportos tem sido empregado o "grooving", que são ranhuras obtidas por fresagem na superfície do pavimento - Figura 2.4.1.3, de modo a aumentar a capacidade de escoamento superficial da água de chuva.

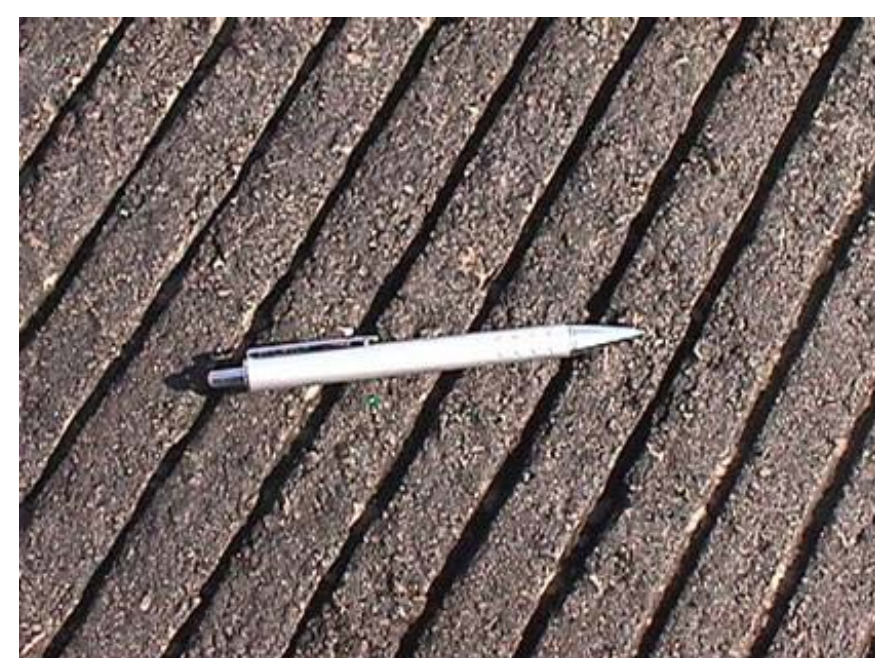

Figura 2.4.1.3 Concreto asfáltico com grooving na superfície, (Bernucci, 2005)

Na década de 90, foi introduzido no Brasil os concretos asfálticos drenantes ou CPA Camada Porosa de Atrito. A Figura 2.4.1.4 mostra um corpo-de-prova extraído de revestimento asfáltico tipo CPA, exibindo uma grande quantidade de vazios interligados e uma superfície aberta a muito aberta. Em geral, é muito difícil executar o ensaio de mancha de areia nestas superfícies, pois a areia penetra nos vazios com ar, falseando resultados. 


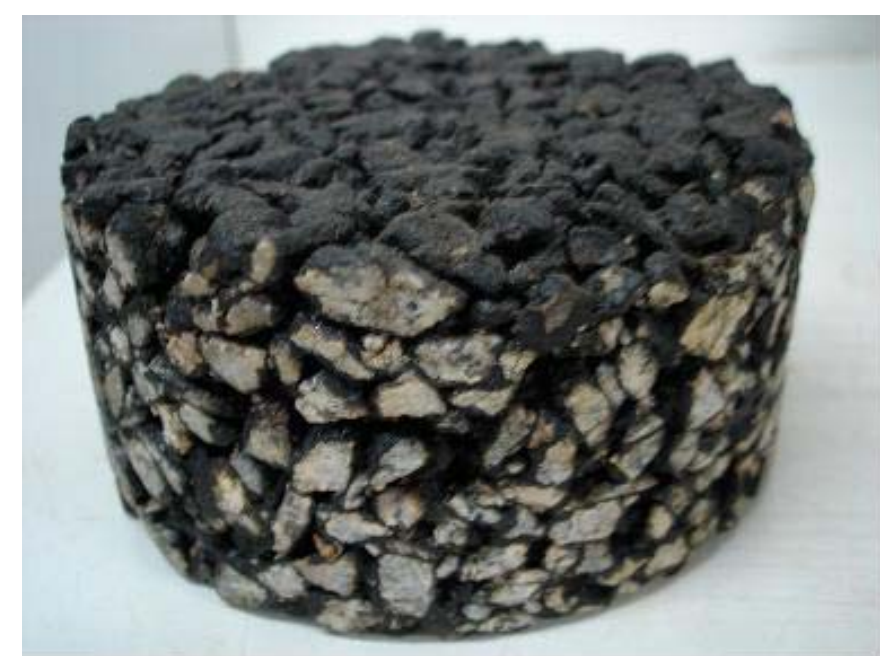

Figura 2.4.1.4 Corpo-de-prova extraído de revestimento tipo CPA, (Bernucci, 2005)

Em 2000, foi introduzida pioneiramente no Brasil a mistura asfáltica alemã tipo SMA no autódromo de Interlagos "José Carlos Pace". O SMA promove uma mistura em geral com boa macrotextura superficial decorrente da elevada quantidade de agregados graúdos. A Figura 2.4.1.5 mostra um aspecto da graduação peculiar do SMA logo após a execução na curva da onça da Via Anchieta em agosto de 2001. A título de comparação, a Figura 2.4.1.6 mostra dois corpos-de-prova sendo o superior de $S M A$ na faixa 0/11S e o inferior um concreto asfáltico na faixa $C$ do DNIT, com diâmetro máximo de $12,5 \mathrm{~mm}$.

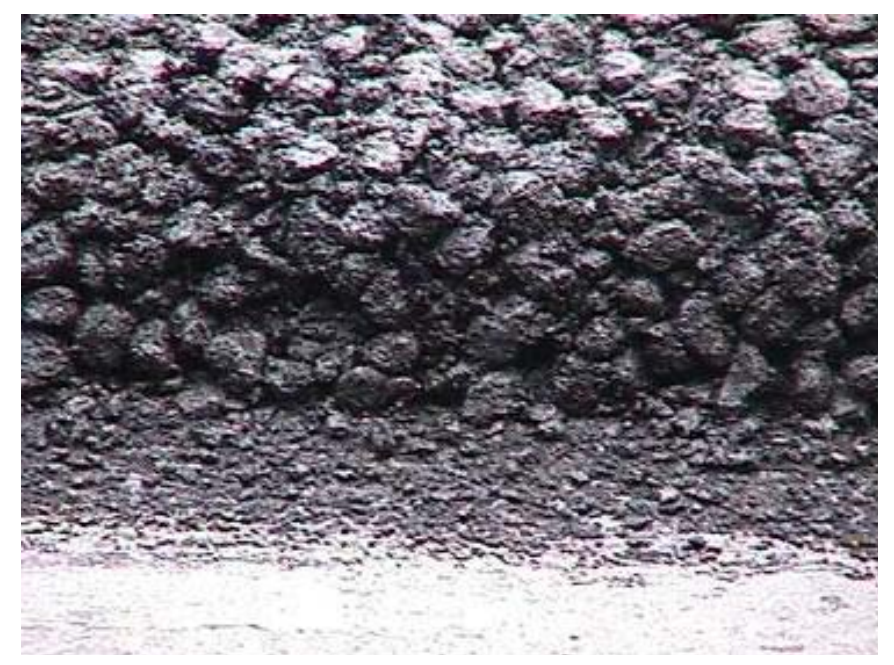

Figura 2.4.1.5 Aspecto de um $S M A$ na faixa 0/11S da curva da onça na Via Anchieta, (Bernucci, 2001) 


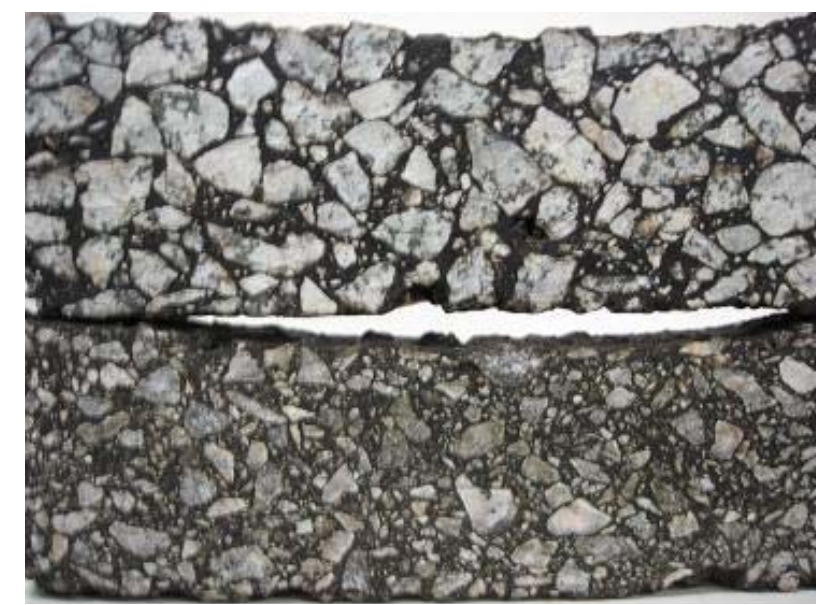

Figura 2.4.1.6 Diferença de graduação entre um SMA (corpo-de-prova superior) e um concreto asfáltico (corpo-de-prova inferior), (Bernucci, 2001)

A mancha de areia depende da graduação do SMA. Quanto maior o diâmetro máximo, a altura da mancha de areia será maior.

Outro tipo de revestimento asfáltico de graduação descontínua introduzido em 2005 no Brasil pela Concessionária Via Oeste na Rodovia Castelo Branco foi o BBTM na especificação francesa 0/10 - Béton Bitumineux Très Mince ou concreto asfáltico delgado. A Figura 2.4.1.7 mostra um aspecto geral deste revestimento asfáltico de aplicações funcionais logo após sua execução, realçando a macrotextura peculiar desta solução asfáltica. Os valores de altura média de mancha de areia dependem das dimensões dos agregados graúdos e variam em geral entre 0,7 a 1,2 mm.

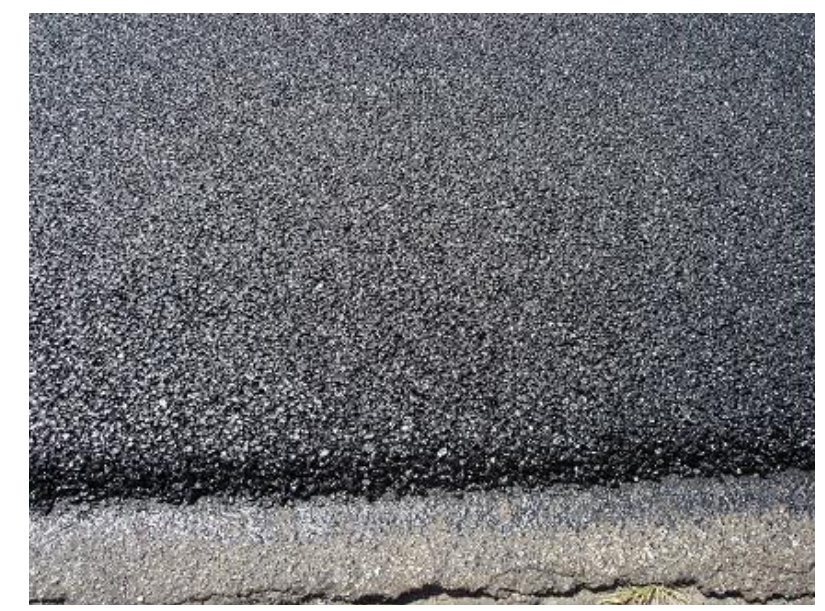

Figura 2.4.1.7 Aspecto final de um $B B T M$ logo após sua execução na Rodovia Castelo Branco em setembro de 2005, (Bernucci, 2005) 


\subsubsection{Tratamentos Superficiais Asfálticos}

Os tratamentos superficiais são executados por aplicações sucessivas de camada de ligante asfáltico (a quente com CAP ou a frio com emulsão asfáltica) e camada de agregados de dimensões similares. A Figura 2.4.2.1 mostra um desenho esquemático de um tratamento superficial simples, ou seja, uma camada de ligante seguida da aplicação de apenas uma camada de agregados.

A Figura 2.4.2.2 mostra por sua vez um tratamento superficial duplo com a aplicação de duas camadas de ligante asfáltico e duas camadas de agregados, sendo a primeira de agregados graúdos e a segunda de agregados miúdos. A textura superficial resultante é em geral aberta a muito aberta dependendo da dimensão dos agregados empregados. Nos tratamento superficiais duplos, a macrotextura medida na mancha de areia excede facilmente $1 \mathrm{~mm}$.

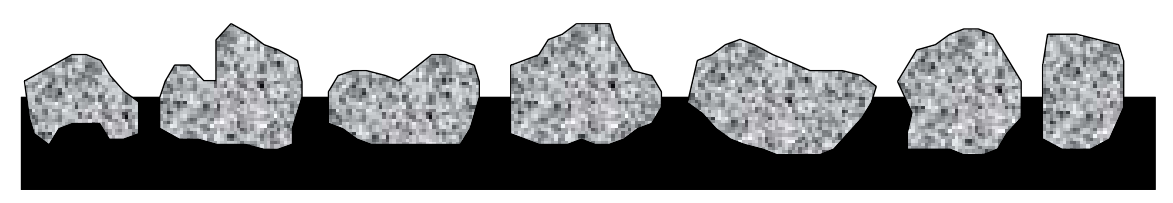

Figura 2 4.2.1 Desenho esquemático de um tratamento superficial simples (modificado de Nascimento, 2003)

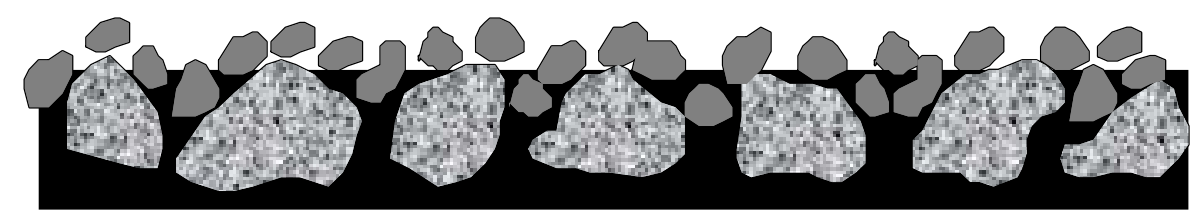

Figura 2.4.2.2 Desenho esquemático de um tratamento superficial duplo (modificado de Nascimento, 2003)

A Figura 2.4.2.3 mostra um aspecto de um tratamento antipó, constituído de uma camada de emulsão recoberta por uma areia ou pó-de-pedra, correspondendo a um tratamento superficial simples. A Figura 2.4.2.4 mostra por sua vez um aspecto da superfície aberta de um tratamento superficial duplo. 


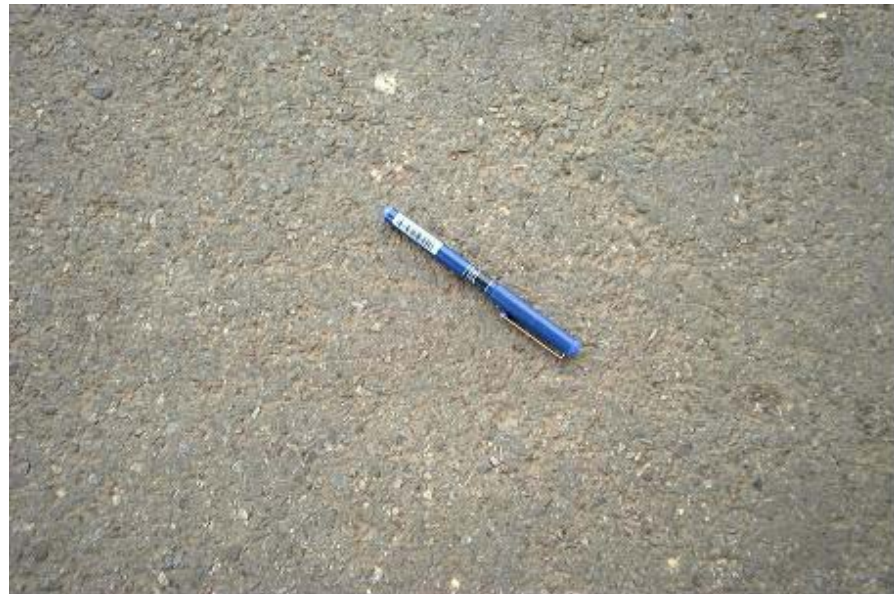

Figura 2.4.2.3 Aspecto da textura de um tratamento superficial tipo antipó, (Bernucci, 2005)

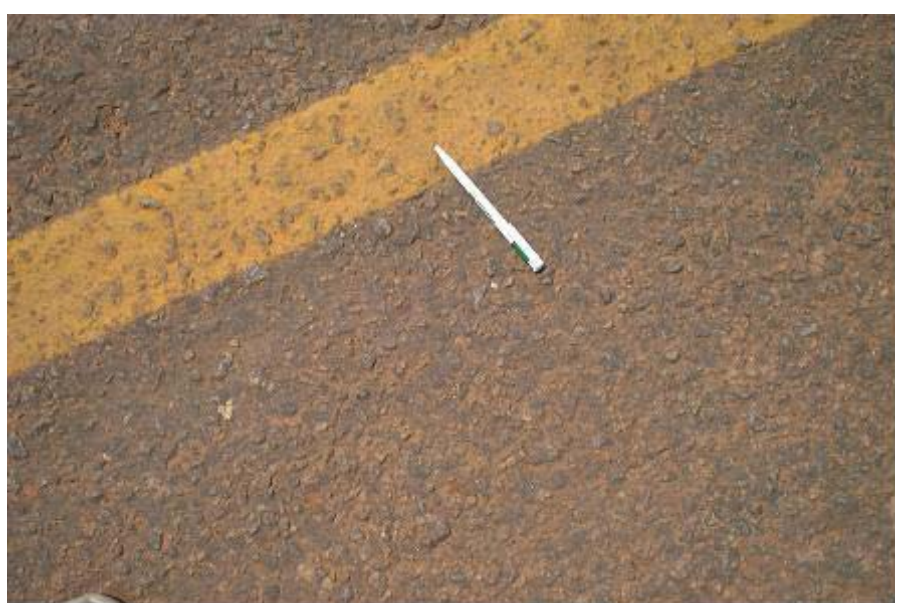

Figura 2.4.2.4 Aspecto da textura de um tratamento superficial duplo, (Bernucci, 2005)

\subsubsection{Microrrevestimentos e Lamas Asfálticas}

As lamas asfálticas são empregadas há mais de 40 anos no Brasil e utilizam emulsão asfáltica. Os microrrevestimentos asfálticos são produtos mais recentes, introduzidos no Brasil no início da década de 90 e utilizam emulsão asfáltica modificada por polímero SBS ou ainda SBR. A textura superficial do microrrevestimento depende do tipo e dimensões dos agregados miúdos empregados. Em geral são aplicados em duas camadas sucessivas para restaurações funcionais. A Figura 2.4.3.1 mostra uma comparação de duas manchas de areia executadas em trechos contíguos da Rodovia 
Castelo Branco em 1998, oportunidade na qual a Concessionária aplicou microrrevestimento sobre o concreto asfáltico para, dentre outras melhorias, a redução de acidentes em pista molhada. A altura média de mancha de areia nos microrrevestimentos asfálticos varia entre 0,8 a 1,2mm em geral.
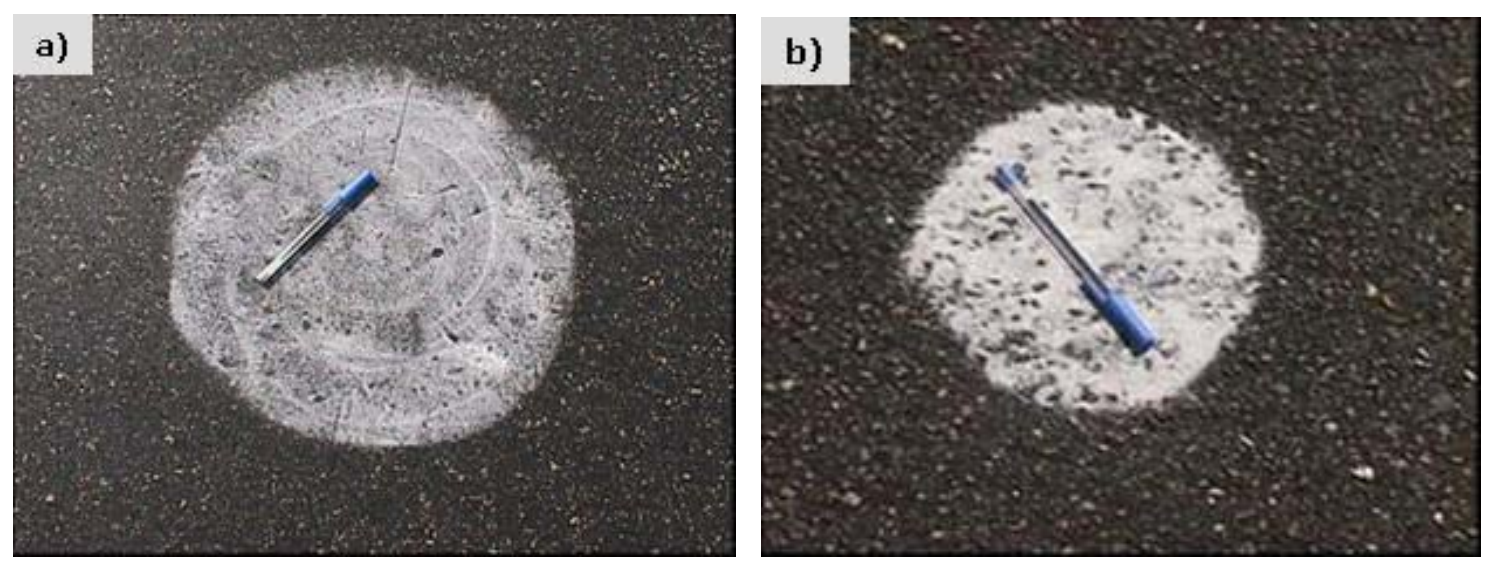

Figura 2.4.3.1 Aspectos comparativos de mancha de areia em um concreto asfáltico (foto à esquerda) e em um microrrevestimento asfáltico a frio (foto à direita), (Moura, 1998)

\subsubsection{Agregados}

A rugosidade superficial dos agregados pode ser avaliada pelo atrito obtido por meio do Pêndulo Britânico. Apesar de alguns agregados apresentarem-se inicialmente com valores de atrito dentro das especificações, >47 para o DNIT (2005) e ARTESP (desde 1998), com a remoção das películas asfálticas com a operação dos veículos e ação abrasiva dos pneus, a rugosidade dos agregados pode ser drasticamente alterada, principalmente nos casos em que o agregado apresenta baixa resistência ao polimento.

É importante ressaltar que uma boa textura (macrotextura e microtextura), é função da resistência ao polimento/desgaste do agregado (Pottinger, 1986), nos seus mais diversos aspectos. 
As principais características dos agregados que freqüentemente estão relacionadas com a resistência ao deslizamento são: resistência ao polimento e ao desgaste, a textura, a forma e o tamanho das partículas, como segue:

a) Resistência ao polimento e ao desgaste - Estas são as características mais importantes dos agregados em relação ao atrito. Rochas ricas em sílica são as que apresentam melhor comportamento. Geralmente, rochas com alto teor de carbonatos não apresentam bom desempenho. Rochas do tipo quartzito, diorito e granito apresentam excelente comportamento;

b) Textura - As texturas superficiais dos agregados individuais são governadas pelo tamanho dos grãos dos minerais individualmente e da matriz na qual eles estão cimentados. Para que um agregado exiba resistência satisfatória ao deslizamento, é necessário que ele tenha dois constituintes minerais de diferentes durezas, cimentados numa matriz que se desgastará diferencialmente, permitindo uma constante exposição de novas superfícies;

c) Forma - O processo de britagem determina a forma da partícula dos agregados, que por sua vez afeta as propriedades de resistência ao deslizamento. A forma dos agregados depende de muitos dos fatores que influenciam a textura. Um dos aspectos mais importantes é a angularidade dos agregados. Partículas alongadas e chatas apresentam péssimo desempenho (FAA, 1986);

d) Tamanho do Agregado e Graduação - Quanto maior o tamanho do agregado, melhores são as características de resistência ao deslizamento e melhor macrotextura. No caso de pavimentos de concreto cimento, o agregado miúdo (areia) dá melhores características de resistência à derrapagem.

A Figura 2.4.4.1 mostra agregados já polidos na superfície de um concreto asfáltico. 


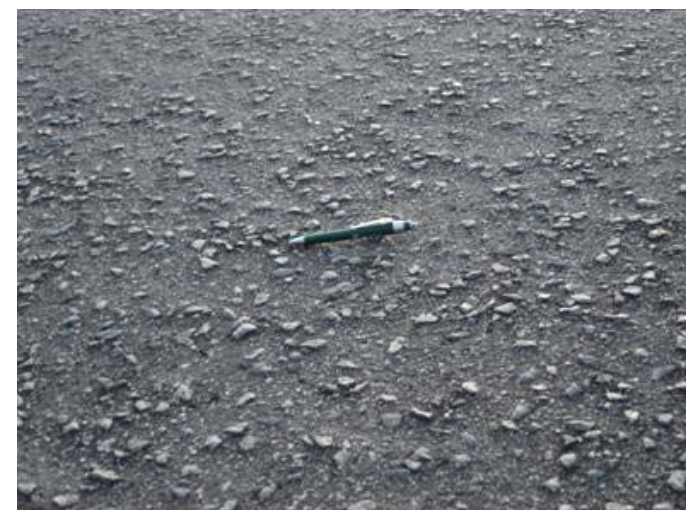

Figura 2.4.4.1 Agregados já polidos na superfície de um concreto asfáltico,

(Bernucci, 2005)

\subsubsection{Efeito do Tipo de Revestimento Asfáltico no Coeficiente de Atrito}

Os franceses têm realizado diversas comparações entre os coeficientes de atrito longitudinais, CAL, medido com equipamento de roda bloqueada tipo LCPC Skid Trailler, em diferentes revestimentos asfálticos. A Figura 2.4.5.1 mostra resultados de CAL em função da velocidade de medida, em três diferentes tipos de revestimentos asfálticos em estado molhado: um Drenante (BBDr - Béton Bitumineux Drainants), um Tratamento Superficial (ECF - Enrobés Coulés à Froid) e um concreto asfáltico (BBSG - Béton Bitumineux Semi-Grenus).

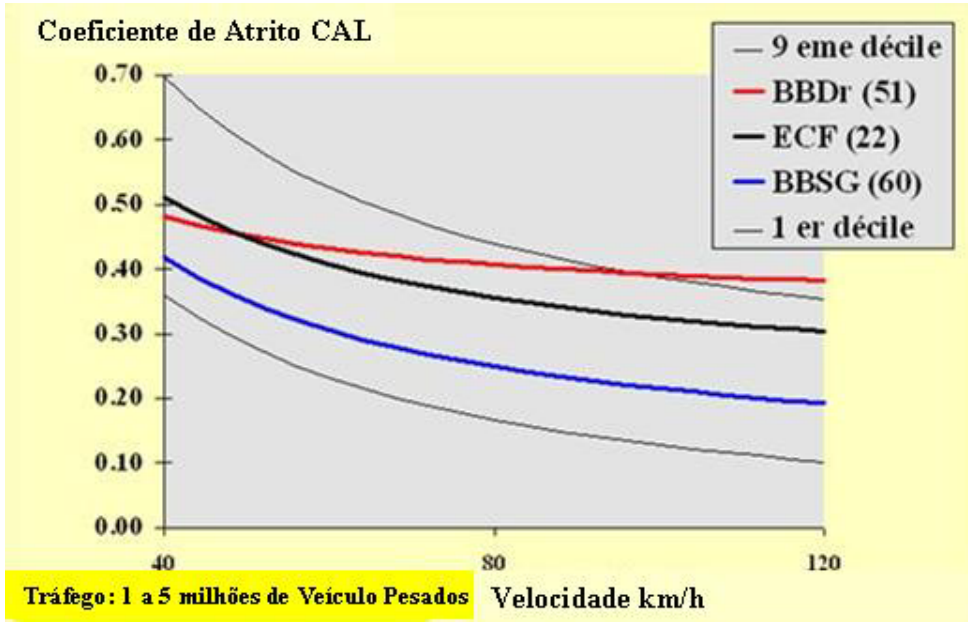

Figura 2.4.5.1 Valores de CAL em função da velocidade em três diferentes revestimentos asfálticos (Brosseaud, 2002) ${ }^{1}$

\footnotetext{
${ }^{1}$ Extraído de palestra preparada por Yves Brosseaud (2005), LCPC, e disponível no site: http://www.lcpc.fr/fr/sources/seminaires/secu_2005/19-7.pdf
} 
Observa-se a superioridade do revestimento drenante sobre os demais tipos, e a manutenção do CAL com a velocidade, devido o efeito de retirada da água superficial pelos vazios interconectados. O concreto asfáltico é, por sua vez, o mais propenso a sofrer redução do CAL com o aumento da velocidade.

Por meio de pesquisa, realizada nos Estados Unidos, de acordo com Corey-Lay (1998), pode-se observar a variação da textura com o coeficiente de atrito medido por meio do Pêndulo Britânico em 14 trechos de superfícies compostas de mistura betuminosa de 7 diferentes tipos, dos quais destacam-se 6 na Figura 2.4.5.2. Observa-se nesta figura que o tipo de mistura asfáltica tem forte influência na textura (Mancha de Areia - HS) e no coeficiente de atrito (BPN), pela variação na faixa de 0,5 a $1,0 \mathrm{~mm}$ e 56 a 67 , respectivamente.

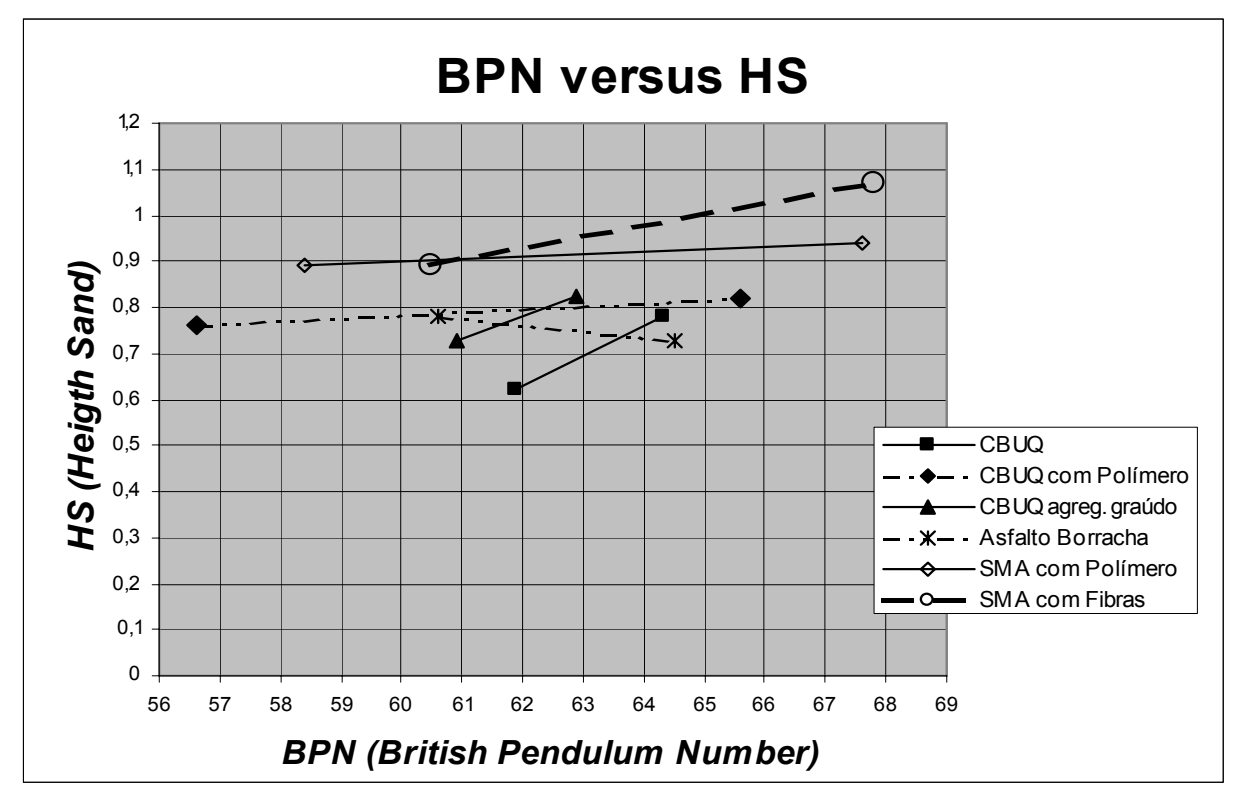

Figura 2.4.5.2 Variação da textura com o coeficiente de atrito para diversos tipos de misturas asfálticas

Para o pavimento proporcionar boa aderência na interação com o pneu, principalmente em presença de água, é necessário que a camada de rolamento que o compõe, apresente textura capaz de fornecer o adequado potencial de drenagem, eliminando a água pelos micros canais formados pela macrotextura, além de conter em sua composição agregados que apresentem rugosidade suficiente para romper a 
lâmina de água, ou seja, boa microtextura. Ou seja, é ideal que a camada de rolamento apresente textura rugosa e aberta, admitindo-se dependendo da situação, textura rugosa e fechada ou polida e aberta e, devendo ser evitada textura polida e fechada.

\subsubsection{Efeito do Tipo de Revestimento Asfáltico na Geração de Ruído}

O som é o resultado de pequenas perturbações de pressão em um meio fluido, quando gerado na interação pneu-pavimento este meio é o ar; qualquer evento resultante da interação pneu-pavimento que crie uma perturbação de pressão no ar irá criar um som. A ciência que estuda a geração, propagação e recepção do som em todos os aspectos é a acústica, e o ruído é definido como um som indesejável (Bernhard e Wayson, 2005).

A intensidade do som está diretamente relacionada às flutuações de pressão transmitidas através do ar e que chegam aos ouvidos; estas pequenas flutuações na pressão barométrica viajam como ondas no ar e flexionam o tímpano, criando a sensação do som cujo volume é uma determinação subjetiva de cada indivíduo. A interação pneu-pavimento e as vibrações do veículo criam flutuações facilmente detectadas pelo ouvido humano (NCHRP Synthesis 268, 1998). Um ouvido saudável pode sentir variações de pressão pequenas, da ordem de $2 \times 10-5 \mathrm{~N} / \mathrm{m}^{2}$, até grandes $\left(63 \mathrm{~N} / \mathrm{m}^{2}\right.$ patamar considerado como em que se inicia a sensação de dor).

A resposta do ouvido humano não é linear, portanto, o som é expresso em termos de seu nível de pressão (SPL - Sound Pressure Leve) utilizando-se uma escala logarítmica em decibel (dB) em lugar de pascal ( $\mathrm{Pa}$ ) (Bernhard e Wayson, 2005; NCHRP Synthesis 268, 1998). Pelo fato de não ser linear, quando a fonte de som dobra sua força, ocorrerá somente um acréscimo de $3 \mathrm{~dB}$, ou seja, se existirem duas fontes de tráfego, cada uma com $60 \mathrm{~dB}$, o total audível é de $63 \mathrm{~dB}$ e não $120 \mathrm{~dB}$ (NCHRP Synthesis 268, 1998). A Figura 2.4.6.1 apresenta exemplos dos níveis de ruído de várias fontes presentes no dia-a-dia das pessoas. 
O ruído gerado em rodovia é um problema ambiental que afeta tanto as áreas urbanas quanto as áreas rurais e apenas recentemente vem sendo tratado com maior atenção no Brasil. O seu principal impacto está associado ao incômodo e seus efeitos negativos causados às pessoas e às suas vidas, podendo afetar a saúde, dificultar a comunicação, desvalorizar propriedades, entre outros (Bernhard e Wayson, 2005).

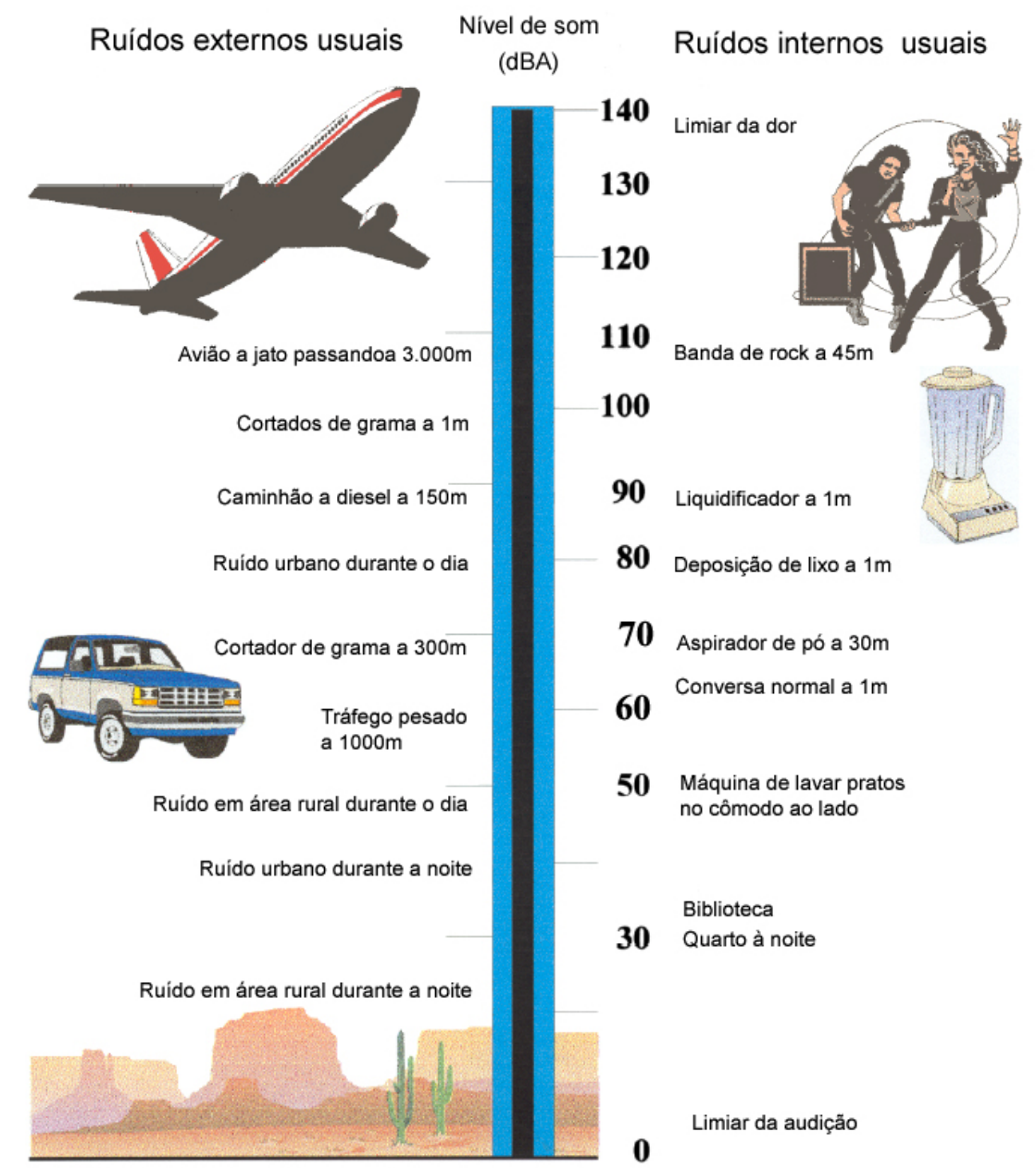

Figura 2.4.6.1 Nível de som para fontes típicas de ruído (Bernhard e Wayson, 2005)

O ruído de tráfego em rodovias é proveniente de três fontes distintas: sistema automotor dos veículos, ruído aerodinâmico e a interação pneu-pavimento (Bernhard e Wayson, 2005). Conforme é possível observar na Figura 2.4.6.2, a principal fonte do ruído gerado em rodovias é proveniente da interação pneu-pavimento e, portanto, pavimentos com baixo nível de ruído se apresentam como uma solução estratégica para a mitigação do problema. A textura do pavimento é um fator de importância significativa no nível de ruído gerado. 


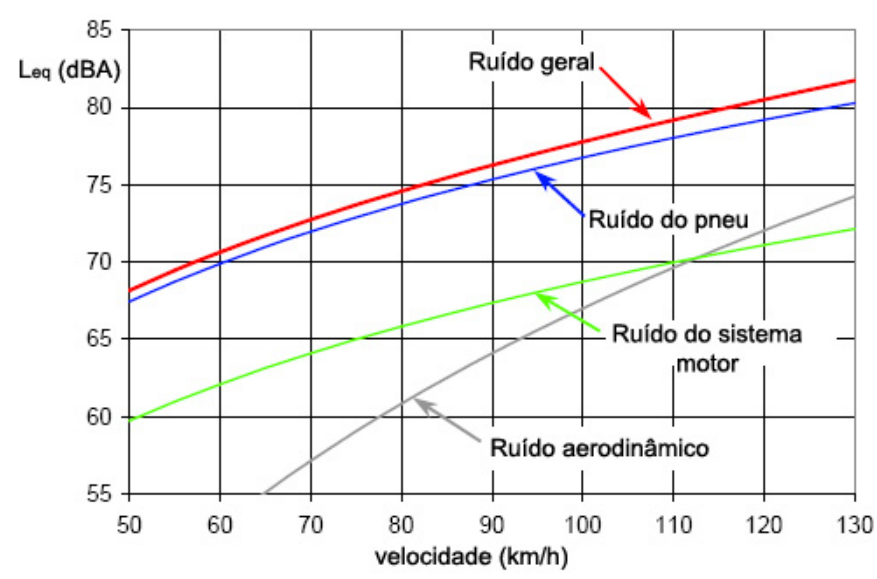

Figura 2 4.6.2 Principais fontes do ruído gerado pelo tráfego de veículos (Donavan, 2004 apud Bernhard e Wayson, 2005)

A Figura 2.4.6.3 exemplifica a diferença da propagação do ruído de uma mesma fonte através de um pavimento de concreto asfáltico e de um terreno simplesmente gramado indicando a importância do tipo de superfície e textura na propagação do ruído.
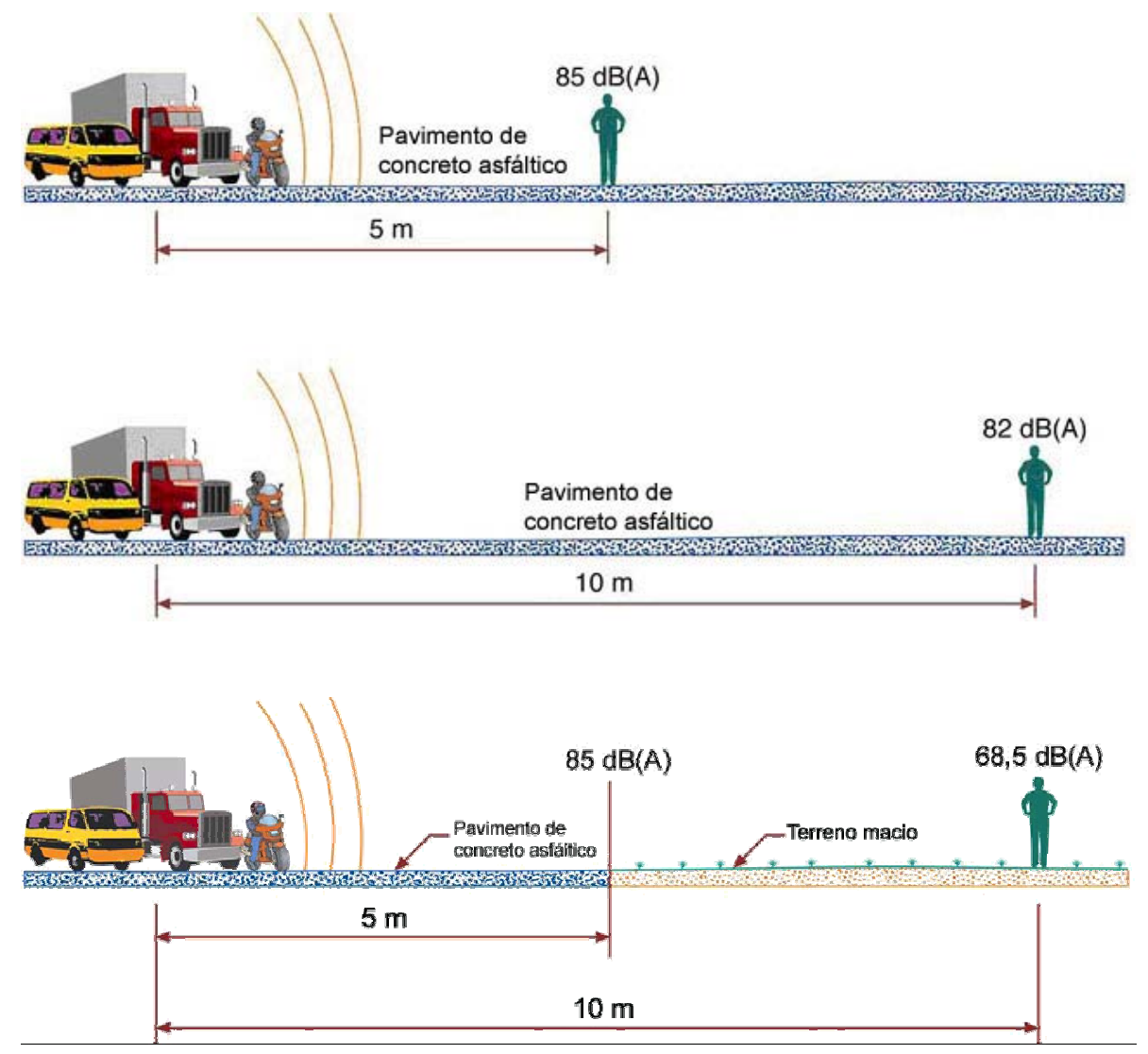

Figura 2:4.6.3 Variação da propagação de ruído em superfícies de diferentes texturas (Hanson e James, 2004) 
Em geral, superfícies mais porosas são mais silenciosas que superfícies mais densas (NCHRP Synthesis 268, 1998); a redução do ruído ponderado pode ser de 4,2 dB(A) para o asfalto poroso (NCHRP Synthesis 284, 2000) em relação aos concretos asfálticos densas. Além disso, as misturas mais abertas na presença de água de chuva diminuem o potencial de hidroplanagem, reduzem o fenômeno do spray (borrifo), o ofuscamento causado pelos faróis e ainda são mais resistentes à deformação permanente (NCHRP Synthesis 284, 2000).

\subsection{Experimento Internacional de Comparação e Harmonização das Medidas de Textura e Atrito e por meio do IFI - International Friction Index}

Com o objetivo de harmonizar as medidas de atrito e de textura foi desenvolvido um índice, assim como o que ocorreu com o IRI - International Roughness Index, aceito internacionalmente para avaliação da irregularidade do pavimento, cujo desenvolvimento inicial teve como origem pesquisas realizadas no Brasil com apoio do Banco Mundial na década de 80 .

Os métodos e equipamentos de medidas de textura e resistência ao deslizamento variam consideravelmente de um país para outro. O objetivo do experimento internacional foi proporcionar um meio de comparação entre as medidas realizadas. Os resultados obtidos são importantes para unificar as políticas de gerência de pavimentos em diferentes países, para harmonizar os métodos de medida e para se obter especificações e recomendações dos materiais utilizados em pavimentação.

Os valores de aderência, ou seja, macrotextura e microtextura podem ser quantificados por meio de um índice composto denominado IFI (International Friction Index). Esse índice foi desenvolvido a partir de uma experiência internacional de comparação e harmonização de métodos de medidas de textura e atrito dos pavimentos que foi conduzida no outono de 1992 sob a responsabilidade do Comitê de Características de Superfície (C1) da PIARC (Permanent International Association of 
Road Congress, atualmente denominada de World Road Association) ou AIPCR (Association International Permanente des Congrèss de la Route). 0 experimento contou com a participação de 47 equipamentos de medição procedentes de 16 países, como segue: Alemanha, Áustria, Bélgica, Canadá, Dinamarca, Espanha, Estados Unidos, França, Itália, Japão, Noruega, Países Baixos, Polônia, Reino Unido, Suécia e Suíça. Por meio destes equipamentos foram medidos 67 parâmetros diferentes, sendo 33 de textura e 34 de atrito.

O experimento internacional da PIARC selecionou 54 locais 28 situados na Bélgica, (sendo 22 em diversas rodovias, 2 no aeroporto de Beauvechain e 4 no circuito de provas de corrida de Zolder) e 26 na Espanha (sendo $18 \mathrm{em}$ diversas rodovias, 1 no aeroporto de Alicante, 4 na base aérea de Morón e 3 na base aérea de Rota), (Wanbold et al.,1995, TRB, 2000).

Não foram utilizadas pistas experimentais, porque em estudos anteriores foi comprovada a necessidade dos pavimentos serem submetidos ao tráfego real e apresentarem as variáveis verdadeiras. As pistas experimentais são aptas para a calibração de equipamentos, mas não refletem as condições das rodovias, além de apresentarem poucos tipos de superfícies de pavimentos, aproximadamente dez (Wambold et al., 1995). Foram utilizadas rodovias em serviço por possuírem diferentes tipos de materiais, de graus de desgaste e polimento, com uma ampla escala de textura e atrito. Foram escolhidos locais na Espanha e na Bélgica com o objetivo de realizar os ensaios em clima seco e também em clima úmido.

Cada um dos ensaios para medição de atrito foi realizado em três velocidades diferentes, 30, 60 e $90 \mathrm{~km} / \mathrm{h}$, e repetido duas vezes para cada uma das velocidades. Todas as medidas de textura foram executadas com o pavimento seco, antes da aplicação de água para os ensaios de atrito. Como grupo de controle, medidas de microtextura foram realizadas com o Pêndulo Britânico, antes e depois dos ensaios, com os equipamentos de medição de atrito. Estes dados foram usados para comprovar que não ocorreram variações estatísticas significativas durante a realização do ensaio. 
Os trechos de ensaio selecionados atenderam aos seguintes requisitos:
a) Comprimento mínimo de 150 metros;
b) Retas com inclinação máxima de $\pm 2 \%$;
c) Textura homogênea, sem interseç̧ões e sem defeitos importantes como fissuras, panelas e outros;
d) Trechos com megatextura (irregularidade) diferente, porém com macrotextura e microtextura iguais;
e) Áreas com espaço suficiente para os equipamentos realizarem as manobras ao término da primeira avaliação, facilitando a repetição do ensaio no trecho;
f) Áreas para estacionamento dos equipamentos participantes no evento;
g) Pontos para abastecimento de água ou caminhão pipa disponível;
h) $75 \%$ dos locais em pavimentos asfálticos e $25 \%$ em pavimentos de concreto de cimento Portland.

Os locais foram selecionados de modo que os ensaios pudessem ser realizados com segurança, por isso foram escolhidos locais com baixo volume de tráfego ou com tráfego controlado.

Foram registrados os resultados numéricos obtidos nos ensaios de atrito e textura, a descrição dos equipamentos, as características dos locais e as informações climáticas (Wambold et al., 1995; TRB, 2000).

O programa resultou em um banco de dados com mais de 15000 valores numéricos, para diferentes tipos de superfícies, que foram utilizados para criar uma escala comum que quantificasse a aderência no pavimento molhado. Esta escala comum, baseada em medidas de atrito $\left(\mathrm{F}_{60}\right)$ e textura $(\mathrm{Sp})$, foi denominada IFI - International Friction Index, cujo procedimento está descrito na ASTM E-1960 (ASTM, 2001; Wambold et al., 1995; Gothié, 1998). 
Anteriormente, vários estudos foram realizados buscando relacionar as medidas de atrito dos diferentes equipamentos; correlações boas foram alcançadas quando as superfícies dos pavimentos eram constantes; quando variavam, não se obtiveram boas correlações.

Foi admitido que para relacionar as medidas de atrito realizadas com equipamentos distintos como roda bloqueada, roda parcialmente bloqueada ou roda oblíqua em relação ao sentido do rolamento, era necessário incluir os efeitos da textura da camada de rolamento.

O objetivo geral do experimento foi harmonizar os vários métodos com que se mede o atrito e a textura dos pavimentos em diferentes países, buscando o seguinte resultado:

1. Desenvolver e estimar as relações existentes entre as medidas de atrito e de textura executadas com diferentes equipamentos, variando as condições físicas dos ensaios como a textura e os materiais que compõe a camada superficial do pavimento, a velocidade de ensaio, o ângulo de deriva das rodas, o pneu do equipamento e o clima;

2. Quantificar as relações existentes entre as medidas de atrito e as medidas de textura, proporcionadas pelos diversos equipamentos em determinadas condições;

3. Quantificar a repetibilidade e os erros de medições dos diversos equipamentos. Avaliar o método e o tamanho de seleção das amostras que são necessárias, para cada um dos equipamentos atingir a exatidão aceitável;

4. Estabelecer uma escala internacional de atrito que seja possível fazer referência a todos os equipamentos e avaliar a amplitude para determinar valores nesta escala. 
O modelo da PIARC para a obtenção do índice internacional de atrito, IFI, de acordo com Wambold e Andresen (1998), foi baseado em um modelo desenvolvido pela Universidade do Estado da Pensilvânia que descreve o comportamento da resistência ao deslizamento do pneu-pavimento considerando às variações de velocidade e diferentes tipos de pneus dos equipamentos de medição de atrito.

\subsubsection{Penn State Mode/ ou Modelo da Pensilvânia}

O Penn State Model ou Modelo da Pensilvânia é uma função exponencial que pressupõe a velocidade de deslizamento como variável independente. O modelo foi desenvolvido para pavimentos molhados com objetivo de monitorar a macrotextura (Wambold, 1998).

Este modelo associa o atrito $F(S)$ em um ensaio executado com um determinado equipamento com a velocidade correspondente de medição (S), conforme mostra a Equação 2.5.1.1 (Valdés et al., 2002; NCHRP 2001).

$$
\mathrm{F}(\mathrm{S})=\mathrm{F}_{0}{ }^{\left(-\mathrm{S} / \mathrm{S}_{0}\right)}
$$

Onde:

$F(S)$ = atrito medido com um determinado equipamento;

$S=$ velocidade de deslizamento do pneu;

$S_{0}=$ velocidade do veículo em função do tipo de pneu;

$F_{0}=$ valor do atrito a uma velocidade de deslizamento zero, ou seja, quando o equipamento se encontra parado.

O modelo traduz matematicamente o observado experimentalmente de que quanto maior a velocidade, menor é o valor do atrito medido. Foram observadas muitas dispersões nos resultados e o modelo foi modificado passando a velocidade de referência de $0 \mathrm{~km} / \mathrm{h}$ para $10 \mathrm{~km} / \mathrm{h}$, de acordo com a Equação 2.5.1.2.

$$
\mathrm{F}(\mathrm{S})=\mathrm{F}_{1}{ }^{\left(10-\mathrm{S} / \mathrm{S}_{1}\right)}
$$


Onde:

$F_{1}=$ valor do atrito obtido para uma velocidade de deslizamento a 10 $\mathrm{km} / \mathrm{h}$;

$S_{1}=$ velocidade do veículo em função do tipo de pneu.

O modelo da PIARC adotou o princípio do Penn State Model, porém para a velocidade de referência de $60 \mathrm{~km} / \mathrm{h}$.

\subsubsection{Modelo da PIARC}

As primeiras análises dos dados obtidos em campo no experimento internacional da PIARC foram correlações lineares entre os equipamentos de medição de atrito, do mesmo tipo e com os outros tipos, independente do princípio de medida ou do tipo do pneu do equipamento. Essas correlações foram consideradas aceitáveis nas condições de realização do ensaio, os valores obtidos para o coeficiente de correlação nas regressões lineares entre os pares de equipamentos de medição de atrito estão apresentados na Tabela 2.5.2.1.

Tabela 2.5.2.1 Coeficiente de correlação das regressões lineares dos equipamentos de medição de atrito

\begin{tabular}{c|c|c|c|c}
\hline $\begin{array}{c}\text { Tipo de } \\
\text { Equipamento }\end{array}$ & $\begin{array}{c}\text { Roda } \\
\text { oblíqua }\end{array}$ & $\begin{array}{c}\text { Roda parcialmente } \\
\text { bloqueada }\end{array}$ & $\begin{array}{c}\text { Roda } \\
\text { bloqueada }\end{array}$ & $\begin{array}{c}\text { Pêndulo } \\
\text { Britânico }\end{array}$ \\
\hline Roda oblíqua & 0,863 & 0,819 & 0,795 & 0,665 \\
\hline $\begin{array}{c}\text { Roda parcialmente } \\
\text { bloqueada }\end{array}$ & 0,819 & 0,834 & 0,783 & 0,732 \\
\hline Roda bloqueada & 0,795 & 0,783 & 0,843 & 0,670 \\
\hline Pêndulo Britânico & 0,665 & 0,732 & 0,670 & 0,830 \\
\hline \hline
\end{tabular}

Os parâmetros de macrotextura foram classificados no experimento em três tipos: 
1. MDP-Mean Profile Depth ou profundidade média do perfil;

2. RMS - Root Mean Square of Texture Profile ou raiz média quadrática do perfil da textura;

3. Tempo de drenagem obtido por meio de um drenômetro.

A Tabela 2.5.2.2 apresenta os limites máximos e mínimos dos coeficientes de correlação obtidos com os três tipos de equipamentos utilizados para obtenção da macrotextura e também o número de equipamentos utilizados. Alguns equipamentos de medição de textura apresentam mais de um parâmetro de textura; nestes casos, foi considerado o melhor parâmetro de cada tipo para esses valores de coeficiente de correlação apresentados.

Tabela 2.5.2.2 Coeficiente de correlação das regressões lineares dos equipamentos de medição de textura

\begin{tabular}{c|c|c|c}
\hline \hline \multirow{2}{*}{$\begin{array}{c}\text { Parâmetro de } \\
\text { Textura }\end{array}$} & $\begin{array}{c}\text { Número de } \\
\text { Equipamentos }\end{array}$ & \multicolumn{2}{|c}{ Coeficiente de Correlação } \\
\cline { 3 - 4 } & 5 & 0,940 & Mínimo \\
\hline MDP & 10 & 0,854 & 0,966 \\
\hline RMS & 2 & 0,880 & 0,953 \\
\hline $\begin{array}{c}\text { Tempo de } \\
\text { drenagem }\end{array}$ & & 0,940 \\
\hline \hline
\end{tabular}

Foi verificada a repetibilidade das medidas de atrito, tendo visto que com cada um dos equipamentos foram realizadas duas medições, a cada uma das três velocidades, 30, 60 e $90 \mathrm{~km} / \mathrm{h}$. Foi determinado o valor absoluto da diferença entre a primeira e segunda avaliação, e o desvio padrão desses valores forneceu as medidas de repetibilidade.

As medidas de repetibilidade foram avaliadas para as três velocidades (baixa, média e alta), para os três níveis dos valores de atrito (baixo, médio e alto) em função dos três tipos de equipamentos (roda oblíqua, roda parcialmente bloqueada e roda bloqueada), os resultados estão apresentados na Tabela 2.5.2.3. 
Tabela 2.5.2.3 Repetibilidade das medidas realizadas no experimento internacional com os equipamentos de medição de atrito

\begin{tabular}{c|c|c|c}
\hline \hline & Roda Oblíqua & $\begin{array}{c}\text { Roda } \\
\text { Parcialmente } \\
\text { Bloqueada }\end{array}$ & Roda Bloqueada \\
\hline Velocidade baixa & 0,034 & 0,033 & 0,028 \\
\hline Velocidade média & 0,029 & 0,032 & 0,024 \\
\hline Velocidade alta & 0,028 & 0,031 & 0,027 \\
\hline Atrito baixo & 0,027 & 0,023 & 0,015 \\
\hline Atrito médio & 0,031 & 0,031 & 0,023 \\
\hline Atrito alto & 0,028 & 0,026 & 0,029 \\
\hline \hline
\end{tabular}

O IFI é uma escala de referência baseada no modelo da PIARC, que relaciona o atrito com a velocidade de deslizamento; este modelo pode estimar a constante de referência da velocidade $(S p)$ e o atrito a $60 \mathrm{~km} / \mathrm{h}\left(F_{60}\right)$ de um determinado pavimento. $O$ par de valores, $S p$ e $F_{60}$, expressam o valor de IFI de um pavimento e permite calcular o valor do atrito, $F(S)$, a qualquer velocidade de deslizamento $S$.

Para se obter o valor de IFI é preciso realizar, com qualquer equipamento ou técnica homologada ou homologável a partir de critérios estabelecidos no experimento internacional, dois tipos de medidas sobre o pavimento, uma de atrito $(F R)$ e outra de textura $(T x)$.

Para encontrar um índice válido para todos os equipamentos, foi necessário fixar um valor real de atrito; como não existe esse valor, foi estabelecida uma combinação das medidas realizadas pelos diferentes equipamentos a várias velocidades de deslizamento, para traçar uma curva de atrito versus velocidade para cada seção do ensaio. Essas curvas foram denominadas de "Curvas de Referência" ou "Golden Curves" e caracterizam-se pelos parâmetros, $G F_{60}$ e $G S$, conforme pode ser visto na Equação 2.5.2.1.

$$
G F(s)=G F_{60}{ }^{[60-S) / G S]}
$$


Onde:

$S=$ velocidade de deslizamento em $\mathrm{km} / \mathrm{h}$;

$G F_{(s)}=$ valor do atrito da "Curva de Referência", a velocidade de deslizamento S;

$G F_{60}=$ valor do atrito na "Curva de Referência", na velocidade de deslizamento de $60 \mathrm{~km} / \mathrm{h}$;

$G S=$ parâmetro que representa a influência da velocidade na "Curva de Referência" em km/h.

O parâmetro GS está associado a valores de macrotextura que podem ser obtidos por meio dos equipamentos utilizados no experimento internacional. Por meio de uma regressão linear se obtém o valor estimado de Sp do parâmetro GS. A constante que representa a influência da velocidade na "Curva de Referência" pode ser obtida por meio da Equação 2.5.2.2.

$$
S_{p}=a+b . T x
$$

Onde:

$T_{x}=$ parâmetro de textura, determinado a partir de valores obtidos para a determinação da macrotextura em função do equipamento utilizado; $a$ e $b=$ constantes determinadas em função do equipamento utilizado.

Os equipamentos de medida de atrito possuem uma velocidade de deslizamento relativa $(S)$ que depende da configuração do equipamento e da velocidade do ensaio, onde:

$S$ = velocidade do veículo $\mathrm{V}$, para equipamentos de roda bloqueada;

$S=$ V para equipamentos com roda parcialmente bloqueada;

$S=$ V.sen $\alpha$ para equipamentos com roda oblíqua onde $\alpha=$ ângulo de deriva da roda.

O primeiro passo para estimar o valor do atrito na "Curva de Referência", à velocidade de $60 \mathrm{~km} / \mathrm{h}\left(G F_{60}\right)$, a partir de uma medida de FRS obtida por meio de um 
equipamento de medição de atrito a uma velocidade de deslizamento $S$, consiste em ajustar o valor do atrito a uma velocidade comum de $60 \mathrm{~km} / \mathrm{h}$, utilizando o parâmetro de velocidade $\mathrm{Sp}$ e a Equação 2.5.2.3.

$$
F R_{60}=F R S^{\left\lfloor(S-60) / S_{p}\right\rfloor}
$$

Onde:

$F R_{60}=$ valor do atrito do equipamento convertido à velocidade de $60 \mathrm{~km} / \mathrm{h}$;

$F R S=$ atrito medido pelo equipamento a velocidade de deslizamento $\mathrm{S}$;

$S=$ velocidade de deslizamento do equipamento.

O último passo da harmonização consiste na previsão de $G F_{60}$ por meio de uma regressão linear a partir de $F R_{60}$ e $T X$, de acordo com a Equação 2.5.2.4.

$$
\mathrm{F}_{60}=\mathrm{A}+\mathrm{B} \cdot \mathrm{FR}_{60}+\mathrm{C} \cdot \mathrm{Tx}
$$

A, B e C são as constantes de calibração próprias para um determinado equipamento; em muitos casos a constante $C$ é praticamente nula. Combinando os resultados anteriores, pode-se expressar $F_{60}$ em função das medidas de $F R S$ (atrito) e $T x$ (textura), conforme pode ser visto na Equação 2.5.2.5.

$$
\mathrm{FR}_{60}=\mathrm{A}+\mathrm{B} \cdot \mathrm{FRS}^{[(\mathrm{S}-60) /(\mathrm{a}+\mathrm{b} \cdot \mathrm{Tx})]}+\mathrm{C} \cdot \mathrm{Tx}
$$

$F_{60}$ é o valor estimado de $G F_{60}$, ou seja, o valor do atrito na "Curva de Referência" a 60 $\mathrm{km} / \mathrm{h}$. Sp é o valor estimado do parâmetro $G S$, que representa a influência da velocidade na "Curva de Referência". Os pares de valores $\mathrm{F}_{60}$ e Sp formam o Index International de Friction de referência (GIFI) utilizado, conforme pode ser visto na Figura 2.5.2.1.

O resultado mais importante do experimento internacional foi à obtenção de uma escala universal de atrito IFI $\left(\mathrm{F}_{60}, \mathrm{Sp}\right)$ bem definida. Esses valores podem ser utilizados em estudos de acidentes, avaliações para sistemas de gerência de pavimentos, de manutenção, operações aeroportuárias entre outras aplicações. Com os valores de IFI é possível também, estabelecer níveis de intervenções em função de $F_{60}$ e $\mathrm{Sp}$, determinando a estratégia de reabilitação mais adequada, conforme pode ser visto na 
Figura 2.5.2.2. Esses níveis podem ser estabelecidos pelos órgãos fiscalizadores e/ou administradores de rodovias em função da classe da via.

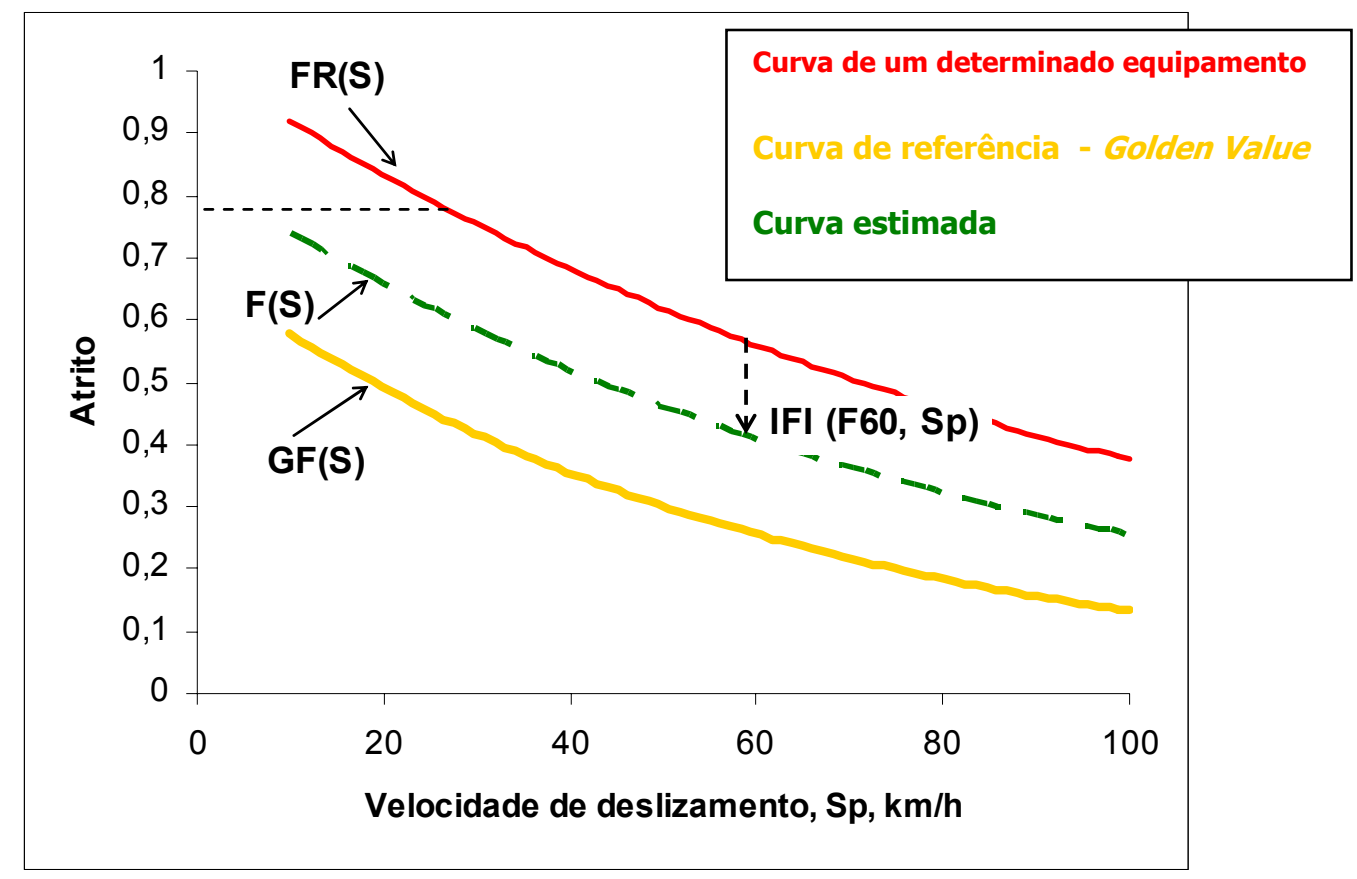

Figura 2.5.2.1 Processo de harmonização da curva de atrito versus velocidade de deslizamento

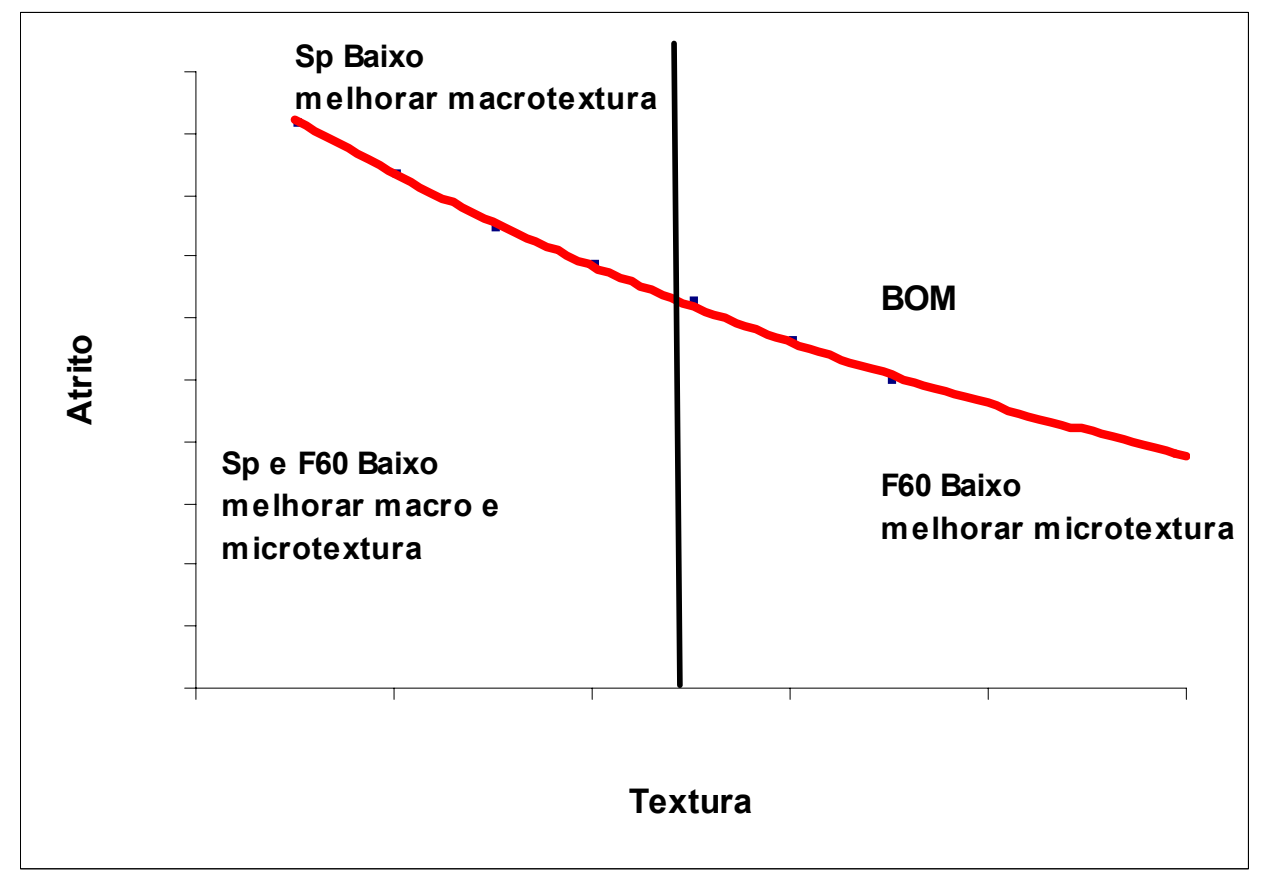

Figura 2.5.2.2 Significado das distintas zonas de um diagrama de atrito - textura 
O IFI pode ser utilizado por órgãos viários e aeroportuários sem necessidade de trocar os métodos em vigor (equipamentos e procedimentos) e sem perda do histórico do banco de dados.

Como os materiais para pavimentação, influem nos valores de atrito e de textura, seus fornecedores podem ampliar o seu campo de distribuição a países com especificações harmonizadas.

Os consultores podem trabalhar em países estrangeiros adaptando as especificações baseadas nos métodos de controle local. Os fabricantes de equipamentos de atrito e textura poderão aumentar seus mercados de distribuição.

O meio técnico tende a melhorar o conhecimento sobre o fenômeno do deslizamento e dos efeitos da textura.

Os usuários de vias, rodovias e aeroportos podem receber informações de aderência em uma escala idêntica em todos os países, o que pode contribuir para melhorar a segurança (Wambold et al., 1995).

\subsubsection{Cálculo do Valor de IFI de Acordo com o procedimento ASTM}

Para o cálculo do valor numérico de IFI é necessário que se obtenham duas informações sobre a superfície de rolamento do pavimento, uma sobre a textura (altura de areia) ( $T x$ em $\mathrm{mm}$ e outra sobre o atrito ( $F R S$ ); esses valores podem ser obtidos por meio de quaisquer dos equipamentos contemplados na norma ASTM E1960 (2001) e descritos da Tabela 2.5.3.2. Com o valor obtido da textura, por meio de ensaio apropriado como a mancha de areia ou perfilômetro laser, em mm, calcula-se (Sp) constante de velocidade. Durante a elaboração do modelo, e a partir dos dados do experimento, foi comprovado que a constante (Sp) da velocidade de referência, pode ser determinada mediante uma regressão linear, com uma medida de macrotextura $(T x)$, como segue na equação 2.5.3.1.

$$
S_{p}=a+B \cdot T x
$$


Os valores a e b estão expressos na Tabela 2.5.3.1.

Tabela 2.5.3.1 Valores de a e b para cálculo de Sp

\begin{tabular}{l|l|r|c}
\hline \hline \multicolumn{1}{c|}{ Norma } & \multicolumn{1}{c|}{ Ensaio } & \multicolumn{1}{c}{ a } & \multicolumn{1}{c}{ b } \\
\hline \hline ASTM E-1845 & Perfilômetro Laser & 14,2 & 89,7 \\
\hline ASTM-965 & Mancha de Areia & $-11,6$ & 113,6 \\
\hline \hline
\end{tabular}

A seguir com o valor obtido de atrito (FRS), por meio de um dos equipamentos contemplados na norma, procede-se o cálculo de (FR60), que é uma constante referente à velocidade de deslizamento de $60 \mathrm{~km} / \mathrm{h}$, e pode ser obtida pela Equação 2.5.3.2 do tipo exponencial.

$$
\mathrm{FR}_{6 \mathrm{o}}=\mathrm{FRS}^{\left\lfloor(\mathrm{S}-60) / \mathrm{s}_{\mathrm{p}}\right\rfloor}
$$

A Equação 2.5.3.2 permite converter a medida de atrito $(F R S)$, realizada a qualquer velocidade (S), a uma medida de atrito a $60 \mathrm{~km} / \mathrm{h}$ (FR60). Definido o equipamento a ser utilizado, determina-se a constante da velocidade do equipamento $(S)$ por meio da Tabela 2.5.3.2.

Mede-se o atrito com um equipamento e velocidade determinada ( $F R S$ ), depois se estima o atrito medido a $60 \mathrm{~km} / \mathrm{h}$ ( $F R 60$ ), por meio do modelo PIARC, e por último, estima-se 0 atrito harmonizado de referência $\left(F_{60}\right)$, por meio da Equação 2.5.3.3 onde A e B foram determinados no Experimento Internacional para os diferentes equipamentos utilizados para medir $\mathrm{O}$ atrito.

$$
\mathrm{FR}_{60}=\mathrm{A}+\mathrm{B} \cdot \mathrm{FR}_{60}+\mathrm{C} \cdot \mathrm{Tx}
$$

Por definição, os pares de valores $\left(\mathrm{F}_{60}, \mathrm{Sp}\right)$ designam-se como sendo o IFI de um pavimento. Seu conhecimento permite traçar a curva de referência estimada de atrito versus velocidade de deslizamento conforme mostra a Figura 2.5.3.1.

O Anexo X2 da ASTM E-1960 (2001) especifica como utilizar outro equipamento ou técnica que não esteja contemplado na Tabela 2.5.3.2. 
Tabela 2.5.3.2 Relação de equipamentos que foram calibrados para obtenção de $F_{60}$

\begin{tabular}{|c|c|c|c|c|c|}
\hline Características & Equipamento & $\mathbf{s}$ & A & B & C \\
\hline \multicolumn{6}{|c|}{ Pneus lisos } \\
\hline \multirow{2}{*}{$\begin{array}{l}\text { Roda } \\
\text { bloqueada }\end{array}$} & ASTM E-274 (USA) & 65 & 0,045 & 0,925 & 0 \\
\hline & LCPC Skid Trailer (F) & 60 & 0,002 & 1,008 & 0 \\
\hline \multirow{5}{*}{$\begin{array}{c}\text { Roda } \\
\text { Parcialmente } \\
\text { Bloqueada }\end{array}$} & OSCAR at $86 \%(\mathrm{~N})$ & 52 & $-0,03$ & 0,864 & 0 \\
\hline & OSCAR at $20 \%(\mathrm{~N})$ & 12 & 0,119 & 0,643 & 0 \\
\hline & Komatsu Skis Trailer (J) & 10 & 0,042 & 0,849 & 0 \\
\hline & DWW Trailer (NL) & 43 & 0,019 & 0,868 & 0 \\
\hline & Griptesyer (UK) & 9,4 & 0,082 & 0,91 & 0 \\
\hline \multirow{11}{*}{ Roda Obliqua } & Stradograph (DK) & 12,5 & 0,054 & 0,77 & 0 \\
\hline & Odoliograph Wallon (B) & 12,9 & 0,113 & 0,729 & 0 \\
\hline & Odoliograph CRR (B) & 20,5 & 0,113 & 0,746 & 0 \\
\hline & SCRIM Flemish (B) & 20,5 & 0,049 & 0,967 & 0 \\
\hline & SCRIM CEDEX (E) & 20,5 & 0,019 & 0,813 & 0 \\
\hline & SCRIM MOPT (E) & 20,5 & 0,032 & 0,873 & 0 \\
\hline & SCRIM SRM (D) & 20,5 & 0,017 & 0,85 & 0 \\
\hline & SCRIM GEOCISA (E) & 20,5 & 0,021 & 0,928 & 0 \\
\hline & SCRIM (F) & 20,5 & $-0,006$ & 0,862 & 0 \\
\hline & SUMMS (I) & 20,5 & 0,002 & 0,987 & 0 \\
\hline & SCRIMTEX (UK) & 17,1 & 0,033 & 0,872 & 0 \\
\hline \multicolumn{6}{|c|}{$\begin{array}{c}\text { Pneus com ranhuras } \\
\end{array}$} \\
\hline \multirow{5}{*}{$\begin{array}{c}\text { Roda } \\
\text { bloqueada }\end{array}$} & $\begin{array}{l}\begin{array}{l}\text { Stuttgarter Reibungsmesser } \\
(\mathrm{CH})\end{array} \\
\end{array}$ & 60 & 0,022 & 0,05 & 0,082 \\
\hline & Skiddometer $(\mathrm{CH})$ & 60 & 0,026 & 0,504 & 0,099 \\
\hline & Stuttgarter Reibungmesser (A) & 60 & $-0,072$ & 0,767 & 0,086 \\
\hline & ASTM E-274 (USA) & 65 & $-0,023$ & 0,607 & 0,098 \\
\hline & Friction Tester (PL) & 60 & $-0,025$ & 0,807 & 0,068 \\
\hline \multirow{4}{*}{$\begin{array}{c}\text { Roda } \\
\text { Parcialmente } \\
\text { Bloqueada }\end{array}$} & Stuttgarter Reibungmesser $(\mathrm{CH})$ & 12 & 0,141 & 0,323 & 0,074 \\
\hline & Skiddometer & 12 & 0,03 & 0,918 & $-0,014$ \\
\hline & BV-11 (S) & 12 & 0,04 & 0,856 & $-0,016$ \\
\hline & Stuttgarter Reibungmesser (A) & 12 & 0,02 & 0,867 & $-0,006$ \\
\hline \multicolumn{6}{|c|}{ Equipamentos com sapatas } \\
\hline \multirow{4}{*}{ Estáticos } & DF Tester at $60 \mathrm{~km} / \mathrm{h}(\mathrm{J})$ & 60 & $-0,034$ & 0,771 & 0 \\
\hline & DF Tester at $20 \mathrm{~km} / \mathrm{h}(\mathrm{J})$ & 20 & 0,081 & 0,732 & 0 \\
\hline & Pendulum Tester BPT (USA) & 10 & 0,056 & 0,008 & 0 \\
\hline & Pendulum Tester SRT $(\mathrm{CH})$ & 10 & 0,044 & 0,01 & 0 \\
\hline
\end{tabular}




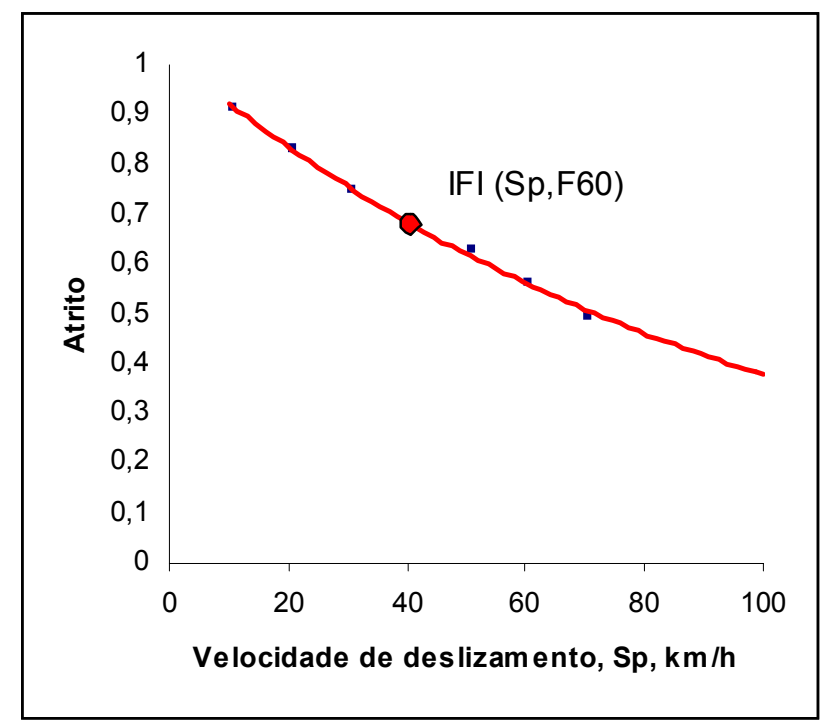

Figura 2.5.3.1 Modelo do IFI

\subsection{Políticas e Recomendações de Aderência Quanto à Segurança}

Políticas de aderência podem ser apresentadas em forma de normas ou de recomendações, cujo objetivo é quantificar e qualificar, por meio dos diversos ensaios e metodologias existentes, os valores admissíveis visando à segurança. Estudos dos valores de atrito e textura vêm sendo desenvolvidos rotineiramente, na maioria dos países, para estabelecimento de políticas para pavimentos. No caso aeroportuário, as políticas são mais exigentes e verificações rotineiras são adotadas pelos órgãos responsáveis; para o caso rodoviário, alguns países são mais exigentes que outros e, finalmente, no sistema viário urbano, pouco se têm realizado.

Os países que adotam políticas de aderência para pavimentos rodoviários, geralmente as classificam em dois casos:

1. Para recebimento de obras novas; ou

2. Para recomendações de reabilitação para vias em serviço quando necessário.

A seguir serão apresentados alguns desses parâmetros no Brasil, na Oceania, na Europa, na Ásia e na América. Alguns países adotam valores de atrito, outros de 
textura, ou ambos. Para os países que adotam valores de atrito e textura, foi calculado o IFI, com o objetivo de comparação com os valores obtidos no desenvolvimento desse trabalho no Capítulo 4, onde estão apresentadas às análises dos dados.

\subsubsection{Brasil}

O Brasil dispõe de recomendações e diretrizes de valores de atrito e textura para o caso rodoviário e urbano; exigências restritivas necessitam ser implantadas de acordo com a complexidade exigida no local de sua aplicação.

\subsubsection{DNIT - Departamento Nacional de Infra-Estrutura de Transporte}

O DNIT (DNER, 2000), em seus diversos editais, apenas recomenda padrões de exigências como condição de segurança e especifica, em caráter provisório, até a oficialização de normas nacionais sobre o tema, valores mínimos para a camada de rolamento, composta de misturas asfálticas, como segue: macrotextura verificada por meio da altura de areia (HS) deve estar no intervalo de 0,60 a 1,20 mm; e a condição de atrito obtida por meio do Pêndulo Britânico, expressa em valor de resistência à derrapagem, deve estar no intervalo de 47 a 75 . Esses valores deverão ser verificados três meses após a execução de novos pavimentos e/ou da primeira restauração, e a cada ano por meio de equipamentos de grande produtividade.

A Norma do DNIT 031/2004 denominada Pavimentos Flexíveis - Concreto Asfáltico (DNIT, 2004), que tem por objetivo especificar a sistemática a ser utilizada na execução de misturas asfálticas a quente, no seu item 7.3, Verificação do Produto, na alínea d) Condições de Segurança, específica que o revestimento deverá apresentar Valores de Resistência a Derrapagem, obtidos por meio do Pêndulo Britânico (ASTM E 303), VDR $\geq 45$; quanto a textura especifica valores de altura de areia (NF P-98-216-7), 1,20mm $\geq \mathrm{HS} \geq 0,60 \mathrm{~mm}$. 
O Manual de Restauração de Pavimentos Asfálticos (DNIT, 2006) recentemente publicado, recomenda uma textura superficial de média a grosseira $(1,20 \mathrm{~mm} \geq \mathrm{HS} \geq$ $0,60 \mathrm{~mm}$ ) e sugere microtextura rugosa com o limite de BPN $\geq 55$.

O Manual de Reabilitação de Pavimentos Asfálticos (DNER, 1998), o DNIT apresenta faixas de valores de atrito e textura; a Tabela 2.6.1.1.1 apresenta os conceitos para macrotextura para o ensaio Mancha de Areia e a Tabela 2.6.1.1.2 mostra os valores limites de CAT e VRD, propostos pelo Comitê Marshall.

Tabela 2.6.1.1.1 Classificação da macrotextura superficial do revestimento (DNER, 1998)

\begin{tabular}{l|c}
\hline \hline \multicolumn{2}{c}{ Mancha de Areia } \\
CLASSIFICAÇÃO & LIMITES \\
\hline MUITO FINA & HS $\leq 0,20$ \\
\hline FINA & $0,20<\mathrm{HS} \leq 0,40$ \\
\hline MÉDIA & $0,40<\mathrm{HS} \leq 0,80$ \\
\hline GROSSA & $0,80<\mathrm{HS} \leq 1,20$ \\
\hline MUITO GROSSA & $\mathrm{HS}>1,20$ \\
\hline \hline
\end{tabular}

Tabela 2.6.1.1.2 Valores limites de CAT e VRD propostos pelo Comitê Marshall, (DNER, 1998)

\begin{tabular}{c|l|c|c|c}
\hline \multirow{2}{*}{ Categoria } & \multirow{2}{*}{ Tipos de segmento } & \multicolumn{2}{|c}{ Valores Limites } \\
\cline { 3 - 5 } & \multicolumn{2}{|c|}{ Coeficiente de Atrito } & $\begin{array}{c}\text { Valor de } \\
\text { Resistência a } \\
\text { Derrapagem }\end{array}$ \\
\cline { 3 - 5 } & $\begin{array}{c}\text { Velocidade de } \\
\text { ensaio (km/h) }\end{array}$ & CAT & VRD \\
\hline \multirow{2}{*}{$\mathrm{A}$} & $\begin{array}{l}\text { Cruzamento em nível; } \\
\text { Curvas com raio <150m; } \\
\text { Rampas >5\% extensão 100m; } \\
\text { Semáforos transversais urbanas }\end{array}$ & 50 & 0,55 & 58 \\
\hline \multirow{2}{*}{$\mathrm{B}$} & $\begin{array}{l}\text { Rodovias com velocidade } \\
\text { diretriz > 80km/h; } \\
\text { Rodovias em perímetro urbano } \\
\text { com VDM > 200 }\end{array}$ & 50 & 0,50 & 53 \\
\hline $\mathrm{C}$ & $\begin{array}{l}\text { Rodovias sem sinuosidade e } \\
\text { planas, sem tráfego expressivo } \\
\text { e sem intersecções perigosas. }\end{array}$ & 50 & 0,45 & 47 \\
\hline \hline
\end{tabular}


O Manual de Restauração de Pavimentos Asfálticos (DNIT, 2006) que foi recentemente publicado, cita e recomenda as faixas de valores para IFI, apresentados por Aps et al. (2004-b), na época em sua segunda tentativa, de acordo com a Tabela 2.6.1.1.3; hoje o presente trabalho encontra-se na quarta tentativa.

Tabela 2.6.1.1.3 Faixas de Classificação de $I F I-2^{\underline{a}}$ Tentativa

\begin{tabular}{l|c|c}
\hline \hline \multicolumn{3}{c}{ Limites IFI (IBP,2004) } \\
\hline Péssimo & \multicolumn{2}{c}{$<0,06$} \\
\hline Ruim & 0,06 & 0,12 \\
\hline Regular & 0,13 & 0,16 \\
\hline Bom & 0,17 & 0,30 \\
\hline Ótimo & \multicolumn{2}{|c}{$>0,30$} \\
\hline \hline
\end{tabular}

\subsubsection{ARTESP (Agência de Transportes do Estado de São Paulo)}

A ARTESP em seus diversos editais de concessão de rodovias estaduais, no Anexo 6, item 3.2.1 Pavimentos - Padrões, d) Condições de Segurança, estabelece o atendimento as Normas Britânicas HD 15/87 e HD 36/87 do Departamento de Trânsito de Londres. Como parâmetro mínimo exigidos estabelece:

a) Macrotextura - expressa pelo ensaio de Mancha de Areia, referente a textura superficial classificada de media a grosseira: 0,60mm $<\mathrm{HS}<1,2 \mathrm{~mm}$, conforme visto na Tabela 2.6.1.1.1;

b) Coeficiente de Atrito - expresso pelos valores obtidos com o Pêndulo Britânico nas classes de médio a muito rugoso: VRD $>47$, conforme pode ser visto na Tabela 2.6.1.2.1.

Estabelece que o referido controle seja realizado a cada 4 anos. 
Tabela 2.6.1.2.1 Classificação da microtextura com o Pêndulo Britânico (ABPv, 1998)

\begin{tabular}{l|c}
\hline \multicolumn{2}{c}{ CLASSIFICAÇÃo } \\
\hline PERIGOSA & LIMITES \\
\hline MUITO LISA & $25-31$ \\
\hline LISA & $32-39$ \\
\hline INSUFICIENTEMENTE RUGOSA & $40-46$ \\
\hline MEDIANAMENTE RUGOSA & $47-54$ \\
\hline RUGOSA & $55-75$ \\
\hline MUITO RUGOSA & $>75$ \\
\hline \hline
\end{tabular}

\subsubsection{Oceania}

\subsubsection{Nova Zelândia}

Na Nova Zelândia os valores de atrito, definidos para o equipamento SCRIM, e valores de textura são especificados em duas categorias, valores para investigação do local e valores limites ou críticos; esses valores estão apresentados na Tabela 2.6.2.1.1 e Tabela 2.6.2.1.2, respectivamente, SM020 (2000).

Tabela 2.6.2.1.1 Níveis para investigação do atrito

\begin{tabular}{|c|c|c|c|}
\hline Categoria & Tipo & $\begin{array}{c}\text { Valor para } \\
\text { Investigação }\end{array}$ & $\begin{array}{l}\text { Valor } \\
\text { Limite }\end{array}$ \\
\hline 1 & $\begin{array}{l}\text { Aproximações a: } \\
\text { Cruzamento ferroviário em nível } \\
\text { Semáforos } \\
\text { Cruzamento de pedestres } \\
\text { Rotatórias } \\
\text { Intersecções controladas de "Pare e Dê a Preferência" } \\
\text { Ponte de pista simples }\end{array}$ & 0,55 & 0,45 \\
\hline 2 & $\begin{array}{l}\text { Curvas de raio }<250 \mathrm{~m} \\
\text { Declives com gradientes }>10 \%\end{array}$ & 0,50 & 0,40 \\
\hline 3 & $\begin{array}{l}\text { Aproximação à junção de rodovias } \\
\text { Declives com gradientes } 5-10 \% \\
\text { Área de intersecções de rodovias especiais, incluindo rampas } \\
\text { de entrada e saída } \\
\text { Rampas }\end{array}$ & 0,45 & 0,35 \\
\hline 4 & Rodovias sem divisão de pista (sem interferências)* & 0,40 & 0,30 \\
\hline 5 & Rodovias com pistas divididas (sem interferências)* & 0,35 & 0,25 \\
\hline
\end{tabular}

* sem interferências: onde nenhuma outra restrição geométrica ou situações nas quais veículos podem precisar frear subitamente podem influenciar os requisitos da resistência ao deslizamento 
Tabela 2 6.2.1.2 Níveis para investigação da textura

\begin{tabular}{c|c|c}
\hline \hline Categoria & Valor para Investigação & Valor Limite \\
\hline Velocidade $\geq 70 \mathrm{~km} / \mathrm{h}$ & $0,9 \mathrm{~mm}$ & $0,7 \mathrm{~mm}$ \\
\hline Velocidade $<70 \mathrm{~km} / \mathrm{h}$ & $0,7 \mathrm{~mm}$ & $0,5 \mathrm{~mm}$ \\
\hline \hline
\end{tabular}

A partir da combinação dos valores apresentados nas Tabelas 2.6.2.1.1 e 2.6.2.1.2 foram calculados valores de IFI para todas as possíveis situações conforme pode ser vista na Tabela 2.6.2.1.3. Não foram apresentados valores de IFI para o caso $1 \mathrm{com}$ velocidades maiores que $70 \mathrm{~km} / \mathrm{h}$, porque naquele país, essas velocidades não são praticadas nesta situação.

Tabela 2.6.2.1.3 Níveis para investigação em termos de IFI $\left(\mathrm{Sp} ; \mathrm{F}_{60}\right)$

\begin{tabular}{|c|c|c|c|c|c|}
\hline \multirow{2}{*}{\multicolumn{2}{|c|}{ Tipo }} & $\begin{array}{c}\text { Valor para } \\
\text { Investigação }\end{array}$ & $\begin{array}{l}\text { Valor } \\
\text { Limite }\end{array}$ & $\begin{array}{c}\text { Valor para } \\
\text { Investigação }\end{array}$ & $\begin{array}{c}\text { Valor } \\
\text { Limite mínimo }\end{array}$ \\
\hline & & \multicolumn{2}{|c|}{ Velocidades maiores-70km/h } & \multicolumn{2}{|c|}{ Velocidades menores-70km/h } \\
\hline 1 & $\begin{array}{l}\text { Aproximações a: } \\
\text { Cruzamento ferroviário em } \\
\text { nível } \\
\text { Semáforos } \\
\text { Cruzamento de pedestres } \\
\text { Rotatórias } \\
\text { Intersecções controladas de } \\
\text { "Pare e Dê a Preferência" } \\
\text { Ponte de pista simples }\end{array}$ & - & - & $(0,30 ; 75)$ & $(0,26 ; 60)$ \\
\hline 2 & $\begin{array}{l}\text { Curvas de raio }<250 \mathrm{~m} \\
\text { Declives com gradientes }> \\
10 \%\end{array}$ & $(0,32 ; 95)$ & $(0,23 ; 75)$ & $(0,32 ; 75)$ & $(0,23 ; 60)$ \\
\hline 3 & $\begin{array}{l}\text { Aproximação à junção de } \\
\text { rodovias } \\
\text { Declives com gradientes } 5 \text { - } \\
10 \% \\
\text { Área de intersecções de } \\
\text { rodovias especiais, } \\
\text { incluindo rampas de } \\
\text { entrada e saída } \\
\text { Rampas }\end{array}$ & $(0,30 ; 95)$ & $(0,20 ; 75)$ & $(0,30 ; 75)$ & $(0,20 ; 60)$ \\
\hline 4 & $\begin{array}{l}\text { Rodovias sem divisão de } \\
\text { pista (sem interferências)* }\end{array}$ & $(0,25 ; 90)$ & $(0,17 ; 75)$ & $(0,25 ; 75)$ & $(0,17 ; 60)$ \\
\hline 5 & $\begin{array}{l}\text { Rodovias com pistas } \\
\text { divididas (sem } \\
\text { interferências)* }\end{array}$ & $(0,22 ; 95)$ & $(0,17 ; 75)$ & $(0,22 ; 75)$ & $(0,15 ; 60)$ \\
\hline
\end{tabular}




\subsubsection{Austrália}

A Austrália define valores de intervenção para a textura e o atrito conforme pode ser visto na Tabela 2.6.2.2.1 e Tabela 2.6.2.2.2, respectivamente (NCHRP, 2000).

Tabela 2.6.2.2.1 Valores estabelecidos para a textura

\begin{tabular}{c|c|c}
\hline \hline \multicolumn{3}{|c}{ Rodovias } \\
\hline Especiais & Primárias & Secundárias \\
\hline $0,4<\mathrm{MTD}<0,8 \mathrm{~mm}$ & $0,2<\mathrm{MTD}<0,4 \mathrm{~mm}$ & $0,2<\mathrm{MTD}<0,4 \mathrm{~mm}$ \\
\hline \hline
\end{tabular}

Tabela 2.6.2.2.2 Valores estabelecidos para o atrito

\begin{tabular}{c|c}
\hline \hline \multicolumn{2}{c}{ Rodovias } \\
\hline Especiais, Primárias e Secundárias & Locais \\
\hline BPN $>45$ & BPN $>40$ \\
\hline \hline
\end{tabular}

\subsubsection{Europa}

\subsubsection{Suíça}

A Suíça utiliza para medidas de macrotextura o equipamento OFT - Outflow Time (s) e para medidas de microtextura o Pêndulo Britânico e recomenda valores pra níveis de intervenção, conforme pode ser visto na Tabela 2.6.3.1.1 (NCHRP, 2000).

Tabela 2.6.3.1.1 Níveis de intervenção para textura

\begin{tabular}{c|c|c}
\hline \hline Limite de Velocidade (km/h) & BPN & OFT \\
\hline \hline$\leq 60$ & 65 & 150 \\
\hline$>60$ e $\leq 100$ & 65 & 100 \\
\hline$>100$ & 65 & 50 \\
\hline \hline
\end{tabular}

Recomenda também níveis de atrito para nova construção de pavimentos e para restauração, de acordo com a Tabela 2.6.3.1.2; os equipamentos utilizados neste 
país para obtenção dos valores de atrito são o Skiddometer BV-8 ou o equipamento Stuttgarter Reibungsmesser (NCHRP, 2000).

Tabela 2.6.3.1.2 Níveis de intervenção para atrito

\begin{tabular}{|c|c|c|}
\hline Limite de Velocidade $(\mathrm{km} / \mathrm{h})$ & Velocidade & $\mu$ (roda bloqueada) \\
\hline$\leq 60$ & 40 & 0,48 \\
\hline$>60$ e $\leq 100$ & 60 & 0,39 \\
\hline$>100$ & 80 & 0,32 \\
\hline
\end{tabular}

\subsubsection{Espanha}

Na Espanha são recomendados valores de microtextura e macrotextura para recebimento de obras novas (Poncino, 2002), conforme pode ser vista na Tabela 2.6.3.2.1.

Tabela 2.6.3.2.1 Valores de microtextura e macrotextura para recebimento de obras novas

\begin{tabular}{|c|c|c|c|}
\hline \multicolumn{2}{|c|}{ Tipo de Revestimento } & \multirow{2}{*}{$\begin{array}{c}\begin{array}{c}\text { Altura de Areia } \\
(\mathbf{m m})\end{array} \\
0,7\end{array}$} & \multirow{2}{*}{$\begin{array}{c}\text { Atrito com o } \\
\text { Pendulo Britânico } \\
0,65\end{array}$} \\
\hline Mistura Asfáltica & - & & \\
\hline \multirow{2}{*}{$\begin{array}{l}\text { Mistura asfáltica a } \\
\text { quente delgada }\end{array}$} & M 8 & 0,9 & \multirow{2}{*}{0,65} \\
\hline & $\mathrm{F} 10$ & 1,1 & \\
\hline \multirow{4}{*}{ Lamas Asfálticas } & LB 1 & 1,1 & \multirow{2}{*}{0,65} \\
\hline & LB 2 & 0,9 & \\
\hline & LB 3 & 0,7 & 0,60 \\
\hline & LB 4 & 0,5 & 0,55 \\
\hline \multirow{3}{*}{$\begin{array}{l}\text { Tratamento } \\
\text { Superficial }\end{array}$} & Textura fina & 0,6 & 0,55 \\
\hline & Textura média & 0,8 & 0,60 \\
\hline & Textura grossa & $>1$ & 0,65 \\
\hline $\begin{array}{c}\text { Concreto de } \\
\text { Cimento Portland }\end{array}$ & 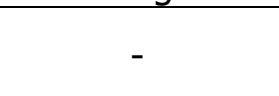 & 0,7 a 1 & - \\
\hline
\end{tabular}

Para pavimentos em uso existem apenas recomendações de atrito para serviços de manutenção, conforme pode ser vista na Tabela 2.6.3.2.2. Os valores de atrito são 
obtidos por meio do equipamento SCRIM, roda oblíqua, e ensaio realizado a 60 $\mathrm{km} / \mathrm{h}$.

Tabela 2 6.3.2.2 Valores de microtextura para intervenções

\begin{tabular}{c|l}
\hline \hline Valor de Atrito (CAT) & \multicolumn{1}{c}{ Ação de Manutenção } \\
\hline CAT $>50$ & Nenhuma, bom estado \\
\hline $50>$ CAT $>40$ & $\begin{array}{l}\text { Acompanhamento da evolução e } \\
\text { intervenção assim que possível }\end{array}$ \\
\hline $40>$ CAT & Atuação imediata \\
\hline \hline
\end{tabular}

\subsubsection{América}

\subsubsection{Estados Unidos da América}

De acordo com a NCHRP (2000), uma pesquisa realizada com os 41 estados do Estados Unidos da América, pode-se extrair as seguintes informações:

a) Para avaliar o atrito, grande parte dos estados utiliza o trailer ASTM E-274 (1997), com pneus ranhurados;

b) Apenas 5 estados medem a textura e desses só 3 com regularidade;

c) As avaliações de atrito são realizadas para programas de gerência de pavimentos com várias finalidades;

d) As avaliações de atrito são usadas para estabelecer critérios de recebimento de obras novas ou para adoção de medidas em pavimentos em serviço, por 20 estados;

e) Estratégias de intervenção para pavimentos em serviços em função do atrito são utilizadas por 11 estados;

f) Investigações de acidentes;

g) Estudos para as condições aeroportuárias;

h) Estudos de casos especiais.

A Tabela 2.6.4.1.1 apresenta uma síntese das informações obtidas. 
Tabela 2.6.4.1.1 Valores limites para atrito

\begin{tabular}{|c|c|c|c|c|c|}
\hline \multirow{2}{*}{ Agência } & \multicolumn{4}{|c|}{ Valor Limite de Intervenção } & \multirow{2}{*}{$\begin{array}{c}\text { Valor Limite Obras } \\
\text { Novas }\end{array}$} \\
\hline & Especial & Primária & Secundária & Local & \\
\hline Arizona & $\begin{array}{l}34 \mathrm{Mu-} \\
\text { meter }\end{array}$ & 34Mumeter & 34Mumeter & - & 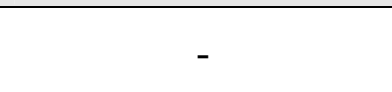 \\
\hline Idaho & SN40S $>30$ & SN40S $>30$ & SN40S $>30$ & - & - \\
\hline Illinois & $\mathrm{SN} 40 \mathrm{R}>30$ & SN40R $>30$ & $\mathrm{SN} 40 \mathrm{R}>30$ & - & - \\
\hline Kentucky & $\mathrm{SN} 40 \mathrm{R}>28$ & SN40R $>25$ & $\mathrm{SN} 40 \mathrm{R}>25$ & $\mathrm{SN} 40 \mathrm{R}>25$ & - \\
\hline New York & $\mathrm{SN} 40 \mathrm{R}>32$ & $\mathrm{SN} 40 \mathrm{R}>32$ & $\mathrm{SN} 40 \mathrm{R}>32$ & $\mathrm{SN} 40 \mathrm{R}>32$ & - \\
\hline $\begin{array}{l}\text { South } \\
\text { Carolina }\end{array}$ & $\mathrm{SN} 40 \mathrm{R}>41$ & $\mathrm{SN} 40 \mathrm{R}>37$ & $\mathrm{SN} 40 \mathrm{R}>37$ & 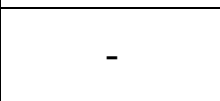 & - \\
\hline Texas & SN40R $>30$ & SN40R $>26$ & SN40R $>22$ & - & - \\
\hline Utah & $\begin{array}{c}\mathrm{SN} 40 \mathrm{R}>30- \\
35\end{array}$ & $\mathrm{SN} 40 \mathrm{R}>35$ & SN40R $>35$ & - & - \\
\hline Washington & $\mathrm{SN} 40 \mathrm{R}>30$ & $\mathrm{SN} 40 \mathrm{R}>30$ & $\mathrm{SN} 40 \mathrm{R}>30$ & $\mathrm{SN} 40 \mathrm{R}>30$ & $\mathrm{SN} 40 \mathrm{R}>30$ \\
\hline Wyoming & $\mathrm{SN} 40 \mathrm{R}>35$ & $\mathrm{SN} 40 \mathrm{R}>35$ & $\mathrm{SN} 40 \mathrm{R}>35$ & - & - \\
\hline Puerto Rico & $\mathrm{SN} 40 \mathrm{R}>40$ & $\mathrm{SN} 40 \mathrm{R}>40$ & - & - & - \\
\hline Maine & - & - & - & - & $\mathrm{SN} 40 \mathrm{R}>35$ \\
\hline Minnesota & - & - & - & - & SN40R $>45 ;$ SN40S $>37$ \\
\hline Wisconsin & - & - & - & - & $\mathrm{SN} 40 \mathrm{R}>38$ \\
\hline
\end{tabular}

Poucos são os trabalhos práticos publicados com de valores de IFI; entre os encontrados na literatura, cita-se McDaniel et al. (2004) que apresentou valores médios para Concreto Asfáltico convencional, SMA - Stone Matrix Asphalt e PFC Porous Friction Course cujos valores de IFI $\left(\mathrm{F}_{60}\right)$ estão apresentados na Tabela 2.6.4.1.2 e corroboram com os valores apresentados por Aps et al. (2003).

Tabela 2.6.4.1.2 Valores de $I F I\left(\mathrm{~F}_{60}\right)$

\begin{tabular}{c|c}
\hline \hline & IFI ( $\left.\mathbf{F}_{\mathbf{6 0}}\right)$ \\
\hline \hline Concreto Asfáltico Convencional & 0,19 \\
\hline Stone Matrix Asphalt - SMA & 0,28 \\
\hline Porous Friction Course - PFC & 0,36 \\
\hline \hline
\end{tabular}




\section{Capítulo 3 Pesquisa de Campo}

O Objetivo central desta pesquisa é avaliar a aplicabilidade do IFI (International Friction Index) como indicador de aderência para pavimentos brasileiros e estabelecer faixas de classificação de valores para o IFI de tal sorte que os órgãos gestores viários poderão avaliar as condições de aderência em pista molhada de suas vias ou de locais específicos de suas vias.

Para alcançar esta finalidade os ensaios foram realizados em locais definidos nos trabalhos de escritório por meio de um plano formal denominado Delineamento de Experimento. $O$ objetivo do delineamento de experimento é a execução de uma série de testes para descobrir o que ocorre em um processo ou sistema. O processo aqui referido, estatisticamente é definido como um conjunto de causas que produzem um ou mais efeitos. Para esta pesquisa os ensaios de campo foram realizados em superfícies compostas de diferentes tipos de misturas asfálticas e expostas a diferentes tipos de veículos ou tráfego; foi elaborado um banco de dados a partir de resultados extraídos de aeroportos, rodovias, vias urbanas, do autódromo de Interlagos e da pista de prova da Pirelli. A metodologia utilizada para os trabalhos de campo consistiu nas seguintes etapas:

a) Revisão dos procedimentos dos ensaios dos equipamentos de medição de características de superfície disponíveis para realização desta pesquisa:

i) Mancha de Areia de acordo com a ASTM E 965-96 (2001);

ii) Pêndulo Britânico conforme preconiza a ASTM E-303-93 (1998);

iii) Drenabilidade em conformidade com as instruções do LTP-EPUSP;

iv) Mu-meter segundo a ASTM E-670, 2000;

v) Cálculos dos valores de IFI de acordo com a ASTM E-1960-98, 2001.

b) Seleção dos locais para a realização dos ensaios de campo buscando-se trechos: 
i) Com diferentes tipos de revestimentos asfálticos, idades, solicitações de tráfego e geometria;

ii) Revestimentos asfálticos com textura superficial sem defeitos como fissuras, panelas, afundamentos e outros.

c) Elaboração do banco de dados a partir de valores obtidos no campo de macrotextura, microtextura, drenabilidade e valores de IFI (Sp; F60) calculados.

O Banco de Dados, com os valores de ensaio de campo, ao término dos trabalhos ficou constituído por 417 valores, sendo 178 referentes a textura, 166 ao atrito e 73 a drenabilidade, distribuídos em doze tipos de revestimentos asfálticos diferentes, e esses com características de textura e atrito diferentes entre si. A Figura 3.1 mostra a distribuição dos dados coletados para estes doze tipos estudados que compõem o banco de dados.

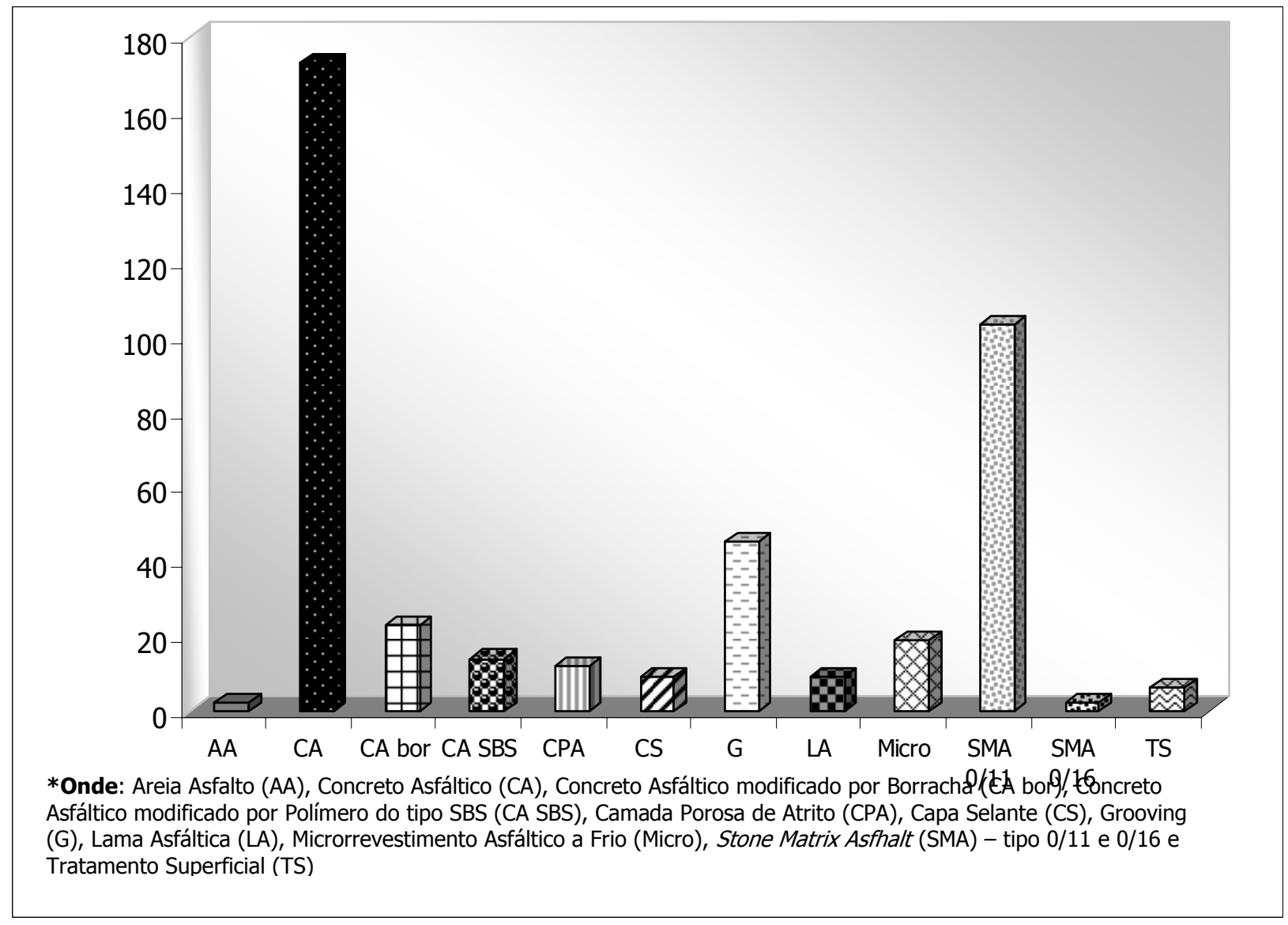

Figura 3.1 Distribuição dos valores pelos diferentes tipos de revestimentos asfálticos 
A seguir serão apresentados os resultados obtidos, em forma de tabela, por meio das avaliações de campo realizadas ou de valores obtidos juntos aos órgãos, concessionárias ou teses do LTP/EPUSP e os valores calculados de IFI (Sp; F60). Para todas as tabelas apresentadas é válida a seguinte legenda:

\begin{tabular}{l|l}
\hline \hline & $\begin{array}{l}\text { Mancha de Areia } \\
\text { CLASSIFICAÇÃo }\end{array}$ \\
\hline MF & MUITO FINA \\
\hline$F$ & FINA \\
\hline$M$ & MÉDIA \\
\hline$G$ & GROSSEIRA \\
\hline$M G$ & MUITO GROSSEIRA \\
\hline \hline
\end{tabular}

\begin{tabular}{l|l}
\hline \multicolumn{2}{c}{$\begin{array}{c}\text { Pêndulo Britânico } \\
\text { CLASSIFICAÇÃo }\end{array}$} \\
\hline $\mathrm{P}$ & PERIGOSA \\
\hline $\mathrm{ML}$ & MUITO LISA \\
\hline $\mathrm{L}$ & LISA \\
\hline $\mathrm{IR}$ & INSUFICIENTEMENTE RUGOSA \\
\hline $\mathrm{MR}$ & MÉDIANAMENTE RUGOSA \\
\hline $\mathrm{R}$ & RUGOSA \\
\hline MUR & MUITO RUGOSA \\
\hline \hline
\end{tabular}

Empregam-se ainda, termos de forma resumida que se referem a:

a) Mancha de Areia = altura média da mancha ou da profundidade média de areia em $\mathrm{mm}$;

b) Drenabilidade $=$ volume por tempo de escoamento;

c) Pêndulo = média de 5 leituras corrigidas (dividido por 100);

d) Mu-meter $=$ atrito medido pelo equipamento, sendo considerada a média do trecho.

\subsection{Aeroportos}

\subsubsection{Aeroporto Internacional de São Paulo/Guarulhos}

O Aeroporto Internacional de São Paulo/Guarulhos (SBGR) possui duas pistas de pouso e decolagem designadas 09R/27L e 09L/27R contando com $3.500 \mathrm{~m}$ e $3.700 \mathrm{~m}$ de extensão respectivamente. Os revestimentos dos pavimentos de ambas as pistas é de Concreto Asfáltico com a aplicação de grooving (ranhuras transversais obtidas por fresagem). 
As pistas foram abertas ao tráfego aéreo em janeiro de 1985 e acumularam até o final do ano de 2002 um movimento da ordem de 1.500 .000 pousos e decolagens de aeronaves comerciais. Os valores obtidos estão apresentados na Tabela 3.1.1.1, cujos ensaios foram realizados em junho de 2003 (Aps et al., 2003-a).

Tabela 3.1.1.1 Valores obtidos para o Aeroporto Internacional de São Paulo/Guarulhos

\begin{tabular}{|c|c|c|c|c|c|c|c|c|c|c|}
\hline \multirow{2}{*}{\multicolumn{2}{|c|}{$\begin{array}{c}\text { Unidade } \\
\text { Amostragem }\end{array}$}} & \multirow{2}{*}{\multicolumn{3}{|c|}{$\begin{array}{c}\text { Macrotextura } \\
\text { Altura de Areia Hs }(\mathbf{m m})\end{array}$}} & \multirow{3}{*}{$\begin{array}{c}\begin{array}{c}\text { Drena- } \\
\text { bilidade }\end{array} \\
\text { I/s }\end{array}$} & \multicolumn{3}{|c|}{ Microtextura (atrito) } & \multirow{2}{*}{\multicolumn{2}{|c|}{$\boldsymbol{I F I}$}} \\
\hline & & & & & & \multicolumn{2}{|c|}{ Pend. Britânico } & \multirow[b]{2}{*}{$\begin{array}{l}\text { Mu- } \\
\text { meter }\end{array}$} & & \\
\hline $\begin{array}{l}\mathbf{N} \\
\mathbf{0}\end{array}$ & Tipo & $\begin{array}{c}\text { Diâm. } \\
\text { Méd. } \\
\text { cm }\end{array}$ & $\begin{array}{c}\text { Hs } \\
(\mathbf{m m})\end{array}$ & $\begin{array}{l}\text { Classi- } \\
\text { ficação }\end{array}$ & & $\begin{array}{l}\text { Média } \\
\text { FRS }\end{array}$ & $\begin{array}{l}\text { Classi- } \\
\text { ficação }\end{array}$ & & $\mathbf{S p}$ & F60 \\
\hline 1 & Grooving & 31 & 1,55 & MG & 0,32 & 67 & $\mathrm{R}$ & \multirow{6}{*}{$68^{*}$} & 164,48 & 0,45 \\
\hline 2 & Grooving & 29,3 & 1,32 & MG & 0,26 & 67 & $\mathrm{R}$ & & 138,35 & 0,43 \\
\hline 3 & Grooving & 25,8 & 1,41 & MG & - & 73 & $\mathrm{R}$ & & 148,58 & 0,47 \\
\hline 4 & Grooving & 29,2 & 1,02 & $\mathrm{G}$ & 0,21 & 68 & $\mathrm{R}$ & & 104,27 & 0,39 \\
\hline 5 & Grooving & 31 & 1,55 & MG & 0,27 & 80 & MuR & & 164,48 & 0,53 \\
\hline 6 & C. Asfáltico & 24,7 & 0,52 & $M$ & 0,12 & 60 & $\mathrm{R}$ & & 47,47 & 0,22 \\
\hline
\end{tabular}

*A ASTM 1960-98 não faz referência ao equipamento mu-meter, para o cálculo do IFI, empregou-se os valores obtidos com o Pêndulo Britânico.

\subsubsection{Aeroporto Internacional de São Paulo/Congonhas}

O Aeroporto Internacional de São Paulo/Congonhas (SBSP) possui duas pistas de pouso e decolagem paralelas, designadas 17R/35L e 17L/35R contando com 1.940 m e $1.435 \mathrm{~m}$ de extensão respectivamente. Os revestimentos dos pavimentos de ambas as pistas é de Concreto Asfáltico de textura fechada, com a aplicação de grooving (ranhuras transversais serradas), na época da avaliação.

Nos últimos anos de operação registrou um tráfego de aeronaves da ordem de 80.000 movimentos/ano. Os valores obtidos em campo estão apresentados na Tabela 3.1.2.1 e foram realizados em outubro de 2003 (Aps et al., 2003-b). 
Tabela 3.1.2.1 Valores obtidos para o Aeroporto - Congonhas

\begin{tabular}{|c|c|c|c|c|c|c|c|c|c|}
\hline \multicolumn{2}{|c|}{ Unidade Amostragem } & \multicolumn{3}{|c|}{$\begin{array}{c}\text { Macrotextura } \\
\text { Altura de Areia Hs }(\mathbf{m m})\end{array}$} & \multirow{2}{*}{$\begin{array}{c}\begin{array}{c}\text { Drena- } \\
\text { bilidade }\end{array} \\
\text { I/s }\end{array}$} & \multicolumn{2}{|c|}{$\begin{array}{l}\text { Microtextura } \\
\text { Pend. Britânico }\end{array}$} & \multicolumn{2}{|c|}{ IFI } \\
\hline No & Tipo & $\begin{array}{l}\text { Diâm. } \\
\text { Méd. } \\
\text { cm }\end{array}$ & $\underset{(\mathbf{m m})}{\text { Hs }}$ & $\begin{array}{l}\text { Classi- } \\
\text { ficação }\end{array}$ & & $\begin{array}{c}\text { Média } \\
\text { FRS }\end{array}$ & $\begin{array}{l}\text { Classi- } \\
\text { ficação }\end{array}$ & $\mathbf{S p}$ & F60 \\
\hline 1 & Concreto Asfáltico & 27,7 & 0,41 & M & 0,02 & 89 & MuR & 34,98 & 0,23 \\
\hline 2 & Grooving & 17,3 & 1,06 & G & 0,44 & 82 & MuR & 108,82 & 0,47 \\
\hline 3 & Grooving & 18,8 & 0,90 & G & 0,41 & 72 & $\mathrm{R}$ & 90,64 & 0,39 \\
\hline 4 & Grooving & 14 & 1,62 & MG & 0,29 & 90 & MuR & 172,43 & 0,59 \\
\hline 5 & Grooving & 15,9 & 1,27 & MG & 0,25 & 95 & MuR & 132,67 & 0,58 \\
\hline 6 & Grooving S/E & 17,3 & 1,06 & G & 0,29 & 70 & $\mathrm{R}$ & 108,82 & 0,41 \\
\hline 7 & Grooving $S / E$ & 15 & 1,41 & MG & 0,32 & 70 & $\mathrm{R}$ & 148,58 & 0,46 \\
\hline 8 & Grooving/E & 21,3 & 0,70 & M & 0,35 & 67 & $\mathrm{R}$ & 67,92 & 0,31 \\
\hline 9 & Grooving/E & 19 & 0,88 & G & 0,27 & 69 & $\mathrm{R}$ & 88,37 & 0,37 \\
\hline 10 & Grooving/E & 16,1 & 1,22 & MG & 0,3 & 65 & $\mathrm{R}$ & 126,99 & 0,41 \\
\hline 11 & Grooving/E & 16 & 1,24 & MG & 0,46 & 68 & $\mathrm{R}$ & 129,26 & 0,43 \\
\hline
\end{tabular}

\subsubsection{Campo de Marte}

Embora o aeroporto não possua linhas aéreas regulares, é o quinto em movimento operacional no Brasil; voltado essencialmente para aviação executiva, escolas de pilotagem como o Aeroclube de São Paulo, e serviço aerotático das Polícias Civil e Militar do Estado de São Paulo. Possui uma pista de $1.600 \mathrm{~m}$ de extensão com revestimento em Concreto Asfáltico, textura fechada. Apresenta um movimento da ordem de 100.000 pousos e decolagens anuais com a particularidade de que cerca de $70 \%$ desse movimento refere-se a helicópteros. Os valores obtidos estão apresentados na Tabela 3.1.3.1, cujos ensaios foram realizados em junho de 2003 (Aps et al., 2003-a).

Tabela 3.1.3.1 Valores obtidos para o Campo de Marte

\begin{tabular}{|c|c|c|c|c|c|c|c|c|c|}
\hline \multicolumn{2}{|c|}{ Unidade Amostragem } & \multicolumn{3}{|c|}{$\begin{array}{c}\text { Macrotextura } \\
\text { Altura de Areia Hs (mm) }\end{array}$} & \multirow{2}{*}{$\begin{array}{c}\begin{array}{c}\text { Drena- } \\
\text { bilidade }\end{array} \\
\text { I/s }\end{array}$} & \multicolumn{2}{|c|}{$\begin{array}{l}\text { Microtextura } \\
\text { Pend. Britânico }\end{array}$} & \multicolumn{2}{|c|}{ IFI } \\
\hline No & Tipo & $\begin{array}{c}\text { Diâm. } \\
\text { Méd. } \\
\text { cm }\end{array}$ & $\begin{array}{c}\mathrm{Hs} \\
(\mathbf{m m})\end{array}$ & $\begin{array}{l}\text { Classi- } \\
\text { ficação }\end{array}$ & & $\begin{array}{l}\text { Média } \\
\text { FRS }\end{array}$ & $\begin{array}{l}\text { Classi- } \\
\text { ficação }\end{array}$ & $\mathbf{S p}$ & F60 \\
\hline 1 & Concreto Asfáltico & 26,2 & 0,46 & M & 0,040 & 59 & $\mathrm{R}$ & 40,66 & 0,19 \\
\hline 2 & Concreto Asfáltico & 30 & 0,35 & $\mathrm{~F}$ & 0,040 & 59 & $\mathrm{R}$ & 28,16 & 0,14 \\
\hline 3 & Concreto Asfáltico & 30,4 & 0,34 & $\mathrm{~F}$ & 0,050 & 64 & $\mathrm{R}$ & 27,02 & 0,14 \\
\hline 4 & CA /Pintura & 30,9 & 0,33 & $\mathrm{~F}$ & 0,020 & 58 & $\mathrm{R}$ & 25,89 & 0,12 \\
\hline
\end{tabular}




\subsection{Rodovias}

Foram realizadas medições em trechos de rodovias do Estado de São Paulo e em trechos de rodovia do Estado do Rio Grande do Sul que possuem segmentos executados com revestimento asfáltico não convencional, e que serviram de subsídios para outras pesquisas, além dos revestimentos convencionais para comparação dos valores verificados.

\subsubsection{Via Anchieta - SP 150}

As avaliações de campo foram realizadas em três seções-teste na Via Anchieta, seção-teste de revestimento do tipo SMA (Stone Matrix Asphalt), Concreto Asfáltico convencional na faixa III da DERSA (CAP 20) e Concreto Asfáltico faixa IV-b do Instituto do Asfalto norte-americano com asfalto-borracha. Os resultados obtidos por meio de ensaios de campo, na Via Anchieta, foram realizados em março de 2002 por Reis (2002) e em novembro de 2002 e março de 2003 por Aps et al. (2003-c, 2003d, 2003f) e em maio de 2006 por técnicos do IPT - Instituto de Pesquisa Tecnológica do Estado de São Paulo. Estes dados estão apresentados nas Tabelas 3.2.1.1, 3.2.1.2, 3.2.1.3 e 3.2.1.4.

Tabela 3.2.1.1 Resultados coletados de macrotextura e microtextura de Reis (2002) e valores calculados de $I F I-$ SP 150

\begin{tabular}{|c|c|c|c|c|c|c|c|c|}
\hline \multicolumn{2}{|r|}{ Unidade Amostragem } & \multicolumn{3}{|c|}{$\begin{array}{c}\text { Macrotextura } \\
\text { Altura de Areia Hs }(\mathrm{mm})\end{array}$} & \multicolumn{2}{|c|}{$\begin{array}{c}\text { Microtextura } \\
\text { Pend. Britânico }\end{array}$} & \multicolumn{2}{|c|}{$\boldsymbol{I F I}$} \\
\hline No & Tipo & $\begin{array}{l}\text { Diâm. } \\
\text { Méd. } \\
\text { cm }\end{array}$ & $\begin{array}{c}\text { Hs } \\
(\mathrm{mm})\end{array}$ & $\begin{array}{l}\text { Classi- } \\
\text { ficação }\end{array}$ & $\begin{array}{l}\text { Média } \\
\text { FRS }\end{array}$ & $\begin{array}{l}\text { Classi- } \\
\text { ficação }\end{array}$ & $\mathbf{S p}$ & F60 \\
\hline 1 & SMA faixa alemã D0-11S & 17,30 & 1,06 & G & 54 & MR & 109,17 & 0,33 \\
\hline 2 & SMA faixa alemã D0-11S & 17,25 & 1,07 & $\mathrm{G}$ & 47 & MR & 109,87 & 0,29 \\
\hline 3 & SMA faixa alemã D0-11S & 18,70 & 0,91 & $\mathrm{G}$ & 49 & MR & 91,77 & 0,28 \\
\hline 4 & SMA faixa alemã D0-11S & 16,25 & 1,20 & MG & 50 & MR & 125,28 & 0,32 \\
\hline 5 & SMA faixa alemã D0-11S & 18,10 & 0,97 & $\mathrm{G}$ & 52 & MR & 98,73 & 0,31 \\
\hline
\end{tabular}


Tabela 3.2.1.2 Resultados obtidos em 11/11/ 2002 - SP 150

\begin{tabular}{c|l|c|c|c}
\hline \hline \multicolumn{2}{c|}{ Unidade Amostragem } & \multicolumn{3}{c}{ Macrotextura } \\
Altura de Areia Hs (mm) \\
\hline \multirow{2}{*}{$N$} & \multicolumn{1}{|c|}{ Tipo } & $\begin{array}{c}\text { Diâm. } \\
\text { Méd. } \\
\text { cm }\end{array}$ & Hs (mm) & $\begin{array}{c}\text { Classi- } \\
\text { ficação }\end{array}$ \\
\hline 1 & Concreto Asfáltico mod bor & 30 & 0,35 & $\mathrm{~F}$ \\
\hline 2 & Concreto Asfáltico mod bor & 36,9 & 0,23 & $\mathrm{~F}$ \\
\hline 3 & Concreto Asfáltico mod bor & 29,2 & 0,37 & $\mathrm{~F}$ \\
\hline 4 & Concreto Asfáltico mod bor & 26,2 & 0,46 & $\mathrm{M}$ \\
\hline 5 & Concreto Asfáltico mod bor & 28,1 & 0,4 & $\mathrm{M}$ \\
\hline 6 & SMA faixa alemã D0-11S & 26,5 & 0,45 & $\mathrm{M}$ \\
\hline 7 & SMA faixa alemã D0-11S & 23,2 & 0,59 & $\mathrm{M}$ \\
\hline 8 & SMA faixa alemã D0-11S & 19,7 & 0,82 & $\mathrm{G}$ \\
\hline 9 & SMA faixa alemã D0-11S & 20,2 & 0,78 & $\mathrm{M}$ \\
\hline 10 & SMA faixa alemã D0-11S & 19,3 & 0,85 & $\mathrm{G}$ \\
\hline 11 & SMA faixa alemã D0-11S & 20,3 & 0,77 & $\mathrm{M}$ \\
\hline 12 & Concreto Asfáltico & 20,2 & 0,78 & $\mathrm{M}$ \\
\hline 13 & Concreto Asfáltico & 21,5 & 0,69 & $\mathrm{M}$ \\
\hline \hline
\end{tabular}

Tabela 3.2.1.3 Resultados obtidos em 11/06/ 2003 e valores de IFI-SP 150

\begin{tabular}{|c|c|c|c|c|c|c|c|c|c|}
\hline \multicolumn{2}{|r|}{ Unidade Amostragem } & \multicolumn{3}{|c|}{$\begin{array}{c}\text { Macrotextura } \\
\text { Altura de Areia Hs (mm) }\end{array}$} & \multirow{2}{*}{$\begin{array}{c}\begin{array}{c}\text { Drena- } \\
\text { bilidade }\end{array} \\
\text { I/s }\end{array}$} & \multicolumn{2}{|c|}{$\begin{array}{l}\text { Microtextura } \\
\text { Pend. Britânico }\end{array}$} & \multicolumn{2}{|c|}{$\boldsymbol{I F I}$} \\
\hline No & Tipo & $\begin{array}{l}\text { Diâm. } \\
\text { Méd. } \\
\text { cm }\end{array}$ & $\begin{array}{l}\text { Hs } \\
(\mathbf{m m})\end{array}$ & $\begin{array}{l}\text { Classi- } \\
\text { ficação }\end{array}$ & & $\begin{array}{c}\text { Média } \\
\text { FRS }\end{array}$ & $\begin{array}{l}\text { Classi- } \\
\text { ficação }\end{array}$ & $\mathbf{S p}$ & F60 \\
\hline 1 & Concreto Asfáltico mod bor & 31 & 0,331 & $\mathrm{~F}$ & 0,119 & 30 & ML & 26,01 & 0,09 \\
\hline 2 & Concreto Asfáltico mod bor & 29,2 & 0,373 & $\mathrm{~F}$ & 0,063 & 40 & IR & 30,79 & 0,12 \\
\hline 3 & Concreto Asfáltico mod bor & 29,3 & 0,371 & $\mathrm{~F}$ & 0,097 & 31 & $\mathrm{ML}$ & 30,50 & 0,10 \\
\hline 4 & Concreto Asfáltico mod bor & 25,8 & 0,478 & M & 0,072 & 39 & LISA & 42,70 & 0,15 \\
\hline 5 & Concreto Asfáltico mod bor & 27,8 & 0,412 & $M$ & 0,058 & 48 & $\mathrm{MR}$ & 35,17 & 0,15 \\
\hline 6 & Concreto Asfáltico mod bor & 26,7 & 0,446 & $M$ & 0,093 & 36 & LISA & 39,10 & 0,14 \\
\hline 7 & SMA faixa alemã D0-11S & 24,8 & 0,517 & M & 0,110 & 23 & $\mathrm{P}$ & 47,17 & 0,12 \\
\hline 8 & SMA faixa alemã D0-11S & 22,3 & 0,64 & $M$ & - & 44 & IR & 61,09 & 0,21 \\
\hline 9 & SMA faixa alemã D0-11S & 23,8 & 0,562 & $M$ & - & 44 & IR & 52,21 & 0,19 \\
\hline 10 & SMA faixa alemã D0-11S & 20,2 & 0,78 & M & 0,140 & 41 & IR & 76,98 & 0,23 \\
\hline 11 & SMA faixa alemã D0-11S & 20 & 0,795 & $M$ & - & 45 & IR & 78,77 & 0,25 \\
\hline 12 & SMA faixa alemã D0-11S & 19,3 & 0,854 & G & - & 42 & IR & 85,44 & 0,24 \\
\hline 13 & SMA faixa alemã D0-11S & 19,3 & 0,854 & G & 0,208 & 41 & IR & 85,44 & 0,24 \\
\hline 14 & SMA faixa alemã D0-11S & 20,3 & 0,772 & M & 0,198 & 35 & LISA & 76,11 & 0,20 \\
\hline 15 & SMA faixa alemã D0-11S & 20,2 & 0,78 & $M$ & - & 42 & IR & 76,98 & 0,23 \\
\hline 16 & SMA faixa alemã D0-11S & 21,5 & 0,688 & $M$ & - & 35 & LISA & 66,60 & 0,19 \\
\hline 17 & Concreto Asfáltico & 21,2 & 0,708 & M & 0,150 & 48 & MR & 68,82 & 0,24 \\
\hline 18 & Concreto Asfáltico & 23,5 & 0,576 & M & 0,057 & 51 & MR & 53,85 & 0,22 \\
\hline 19 & Concreto Asfáltico & 19,8 & 0,812 & G & 0,140 & 46 & IR & 80,60 & 0,25 \\
\hline 20 & Concreto Asfáltico & 24,3 & 0,539 & $M$ & 0,097 & 44,2 & IR & 49,61 & 0,19 \\
\hline 21 & Concreto Asfáltico & 25,2 & 0,501 & M & 0,085 & 47 & MR & 45,32 & 0,18 \\
\hline
\end{tabular}


Tabela 3.2.1.4 Resultados obtidos de macrotextura, microtextura, drenabilidade, em maio de 2006 e valores de IFI calculados - SP 150

\begin{tabular}{|c|c|c|c|c|c|c|c|c|}
\hline \multicolumn{2}{|r|}{ Unidade Amostragem } & \multicolumn{3}{|c|}{$\begin{array}{c}\text { Macrotextura } \\
\text { Altura de Areia Hs (mm) }\end{array}$} & \multicolumn{2}{|c|}{$\begin{array}{l}\text { Microtextura } \\
\text { Pend. Britânico }\end{array}$} & \multicolumn{2}{|c|}{$\boldsymbol{I F I}$} \\
\hline No & Tipo & $\begin{array}{l}\text { Diâm. } \\
\text { Méd. } \\
\text { cm }\end{array}$ & $\begin{array}{l}\text { Hs } \\
(\mathbf{m m})\end{array}$ & $\begin{array}{l}\text { Classi- } \\
\text { ficação }\end{array}$ & $\begin{array}{l}\text { Média } \\
\text { FRS }\end{array}$ & $\begin{array}{l}\text { Classi- } \\
\text { ficação }\end{array}$ & $\mathbf{S p}$ & F60 \\
\hline 1 & SMA faixa alemã D0-11S & 18,50 & 0,93 & G & 50,4 & MR & 94,01 & 0,29 \\
\hline 2 & SMA faixa alemã D0-11S & 18,38 & 0,94 & G & 47,8 & MR & 95,45 & 0,28 \\
\hline 3 & SMA faixa alemã D0-11S & 18,38 & 0,94 & G & 52,6 & MR & 95,45 & 0,31 \\
\hline 4 & SMA faixa alemã D0-11S & 17,95 & 0,99 & G & 52,8 & MR & 100,58 & 0,31 \\
\hline 5 & SMA faixa alemã D0-11S & 18,68 & 0,91 & G & 55,6 & MR & 92,04 & 0,31 \\
\hline 6 & SMA faixa alemã D0-11S & 17,83 & 1,00 & G & 45,4 & MR & 102,16 & 0,28 \\
\hline 7 & SMA faixa alemã D0-11S & 20,68 & 0,74 & G & 47,6 & MR & 72,96 & 0,25 \\
\hline 8 & SMA faixa alemã D0-11S & 18,50 & 0,93 & G & 47,6 & MR & 94,01 & 0,28 \\
\hline 9 & SMA faixa alemã D0-11S & 21,73 & 0,67 & G & 49,4 & MR & 64,98 & 0,24 \\
\hline 10 & SMA faixa alemã D0-11S & 19,03 & 0,88 & G & 47,6 & MR & 88,26 & 0,27 \\
\hline 11 & SMA faixa alemã D0-11S & 18,98 & 0,88 & G & 45,2 & MR & 88,79 & 0,26 \\
\hline
\end{tabular}

\subsubsection{Rodovia Santos Dumont - SP 75}

Foram realizados os ensaios de campo, de macrotextura e microtextura, na Rodovia Santos Dumont - SP-75, sob concessão da empresa Colinas, em 21/3/2005; os ensaios foram realizados em 4 trechos com revestimentos distintos, SMA, Tratamento Superficial Duplo, Microrrevestimento Asfáltico a Frio e Concreto Asfáltico na faixa III da DERSA. A Tabela 3.2.2.1 apresenta os valores obtidos em campo de ensaios realizados por técnicos do LTP.

\subsubsection{Rodovia dos Bandeirantes - SP 348}

Foram realizados os ensaios de campo, de macrotextura, drenabilidade e microtextura na Rodovia dos Bandeirantes SP-348 antes da execução dos serviços de manutenção com reposição da camada de rolamento com Microrrevestimento Asfáltico a Frio, em junho de 2003. A Tabela 3.2.3.1 apresenta os valores obtidos em campo. 
Tabela 3.2.2.1 Valores obtidos em campo e valores de IFI calculados - SP 75

\begin{tabular}{|c|c|c|c|c|c|c|c|c|}
\hline \multicolumn{2}{|r|}{ Unidade Amostragem } & \multicolumn{3}{|c|}{$\begin{array}{c}\text { Macrotextura } \\
\text { Altura de Areia Hs }(\mathrm{mm})\end{array}$} & \multicolumn{2}{|c|}{$\begin{array}{c}\text { Microtextura } \\
\text { Pend. Britânico }\end{array}$} & \multicolumn{2}{|c|}{$\boldsymbol{I F I}$} \\
\hline No & Tipo & $\begin{array}{c}\text { Diâm. } \\
\text { Méd. } \\
\text { cm }\end{array}$ & $\begin{array}{c}\text { Hs } \\
(\mathbf{m m})\end{array}$ & $\begin{array}{l}\text { Classi- } \\
\text { ficação }\end{array}$ & $\begin{array}{l}\text { Média } \\
\text { FRS }\end{array}$ & $\begin{array}{l}\text { Classi- } \\
\text { ficação }\end{array}$ & $\mathbf{S p}$ & F60 \\
\hline 1 & SMA faixa alemã D0-11S & 23 & 0,60 & $M$ & 30 & $M L$ & 56,76 & 0,16 \\
\hline 2 & SMA faixa alemã D0-11S & 25 & 0,50 & $M$ & 40 & IR & 44,75 & 0,16 \\
\hline 3 & SMA faixa alemã D0-11S & 26 & 0,46 & $M$ & 35 & $\mathrm{~L}$ & 41,21 & 0,14 \\
\hline 4 & SMA faixa alemã D0-11S & 25 & 0,52 & $M$ & 35 & $\mathrm{~L}$ & 47,83 & 0,15 \\
\hline 5 & SMA faixa alemã D0-11S & 25 & 0,52 & $M$ & 35 & $\mathrm{~L}$ & 47,83 & 0,15 \\
\hline 6 & SMA faixa alemã D0-11S & 24 & 0,54 & $M$ & 35 & $\mathrm{~L}$ & 49,47 & 0,16 \\
\hline 7 & Tratamento Superficial & 14,7 & 1,48 & MA & 62,8 & $\mathrm{R}$ & 156,53 & 0,42 \\
\hline 8 & Tratamento Superficial & 14,3 & 1,55 & MA & 58,4 & $\mathrm{R}$ & 164,48 & 0,40 \\
\hline 9 & Microrrevestimento & 21,8 & 0,67 & $M$ & 54,2 & MR & 64,26 & 0,26 \\
\hline 10 & Microrrevestimento & 21,7 & 0,68 & $M$ & 53,2 & MR & 65,43 & 0,25 \\
\hline 11 & Microrrevestimento & 19,8 & 0,81 & $\mathrm{G}$ & 53,7 & MR & 80,33 & 0,29 \\
\hline 12 & Microrrevestimento & 20,5 & 0,76 & $M$ & 53,7 & MR & 74,45 & 0,28 \\
\hline 13 & Microrrevestimento & 20,8 & 0,73 & $M$ & 53,7 & MR & 71,72 & 0,27 \\
\hline 14 & CA Faixa 2 DERSA & 36,8 & 0,23 & $\mathrm{~F}$ & 52 & $\mathrm{R}$ & 15,05 & 0,07 \\
\hline 15 & CA Faixa 2 DERSA & 39,5 & 0,20 & $\mathrm{~F}$ & 49,6 & MR & 11,58 & 0,06 \\
\hline 16 & CA Faixa 2 DERSA & 40,0 & 0,20 & $\mathrm{~F}$ & 50,8 & MR & 11,00 & 0,06 \\
\hline 17 & CA Faixa 2 DERSA & 38,8 & 0,21 & $\mathrm{~F}$ & 50,8 & MR & 12,38 & 0,06 \\
\hline 18 & CA Faixa 2 DERSA & 39,5 & 0,20 & $\mathrm{~F}$ & 50,8 & MR & 11,58 & 0,06 \\
\hline 19 & CA Faixa 2 DERSA & 39,8 & 0,20 & $\mathrm{~F}$ & 50,8 & MR & 11,19 & 0,06 \\
\hline
\end{tabular}

Tabela 3.2.3.1 Valores obtidos em campo e valores de IFI calculados - SP 348

\begin{tabular}{c|c|c|c|c|c|c|c|c|c}
\hline \hline \multicolumn{2}{c|}{ Unidade Amostragem } & \multicolumn{2}{|c|}{ Macrotextura } & \multicolumn{2}{c|}{$\begin{array}{c}\text { Drena- } \\
\text { bilidade }\end{array}$} & \multicolumn{2}{c|}{$\begin{array}{c}\text { Microtextura } \\
\text { Pend. Britânico }\end{array}$} & \multicolumn{2}{c}{ IFI } \\
\hline No & Tipo & $\begin{array}{c}\text { Diâm. } \\
\text { Méd. } \\
\text { cm }\end{array}$ & $\begin{array}{c}\text { Hs } \\
(\mathbf{m m})\end{array}$ & $\begin{array}{c}\text { Classi- } \\
\text { ficação }\end{array}$ & I/s & $\begin{array}{c}\text { Média } \\
\text { FRS }\end{array}$ & $\begin{array}{c}\text { Classi- } \\
\text { ficação }\end{array}$ & Sp & F60 \\
\hline 1 & Concreto Asfáltico & 31,5 & 0,32 & $\mathrm{~F}$ & 0,016 & 49,8 & $\mathrm{R}$ & 24,75 & 0,11 \\
\hline 2 & Concreto Asfáltico & 25,33 & 0,50 & $\mathrm{M}$ & 0,044 & 47,6 & $\mathrm{MR}$ & 45,20 & 0,18 \\
\hline 3 & Concreto Asfáltico & 31,17 & 0,33 & $\mathrm{~F}$ & 0,039 & 56,8 & $\mathrm{R}$ & 25,89 & 0,12 \\
\hline \hline
\end{tabular}

\subsubsection{Rodovia Presidente Dutra - BR 116}

Foram realizados os ensaios de campo, de macrotextura e microtextura na Rodovia

Presidente Dutra BR-116 (Nova Dutra, 2000) após dois anos de construção da Camada Porosa de Atrito (CPA) modificada por polímero do tipo SBS. A Tabela 3.2.4.1 apresenta os valores obtidos em campo. 
Tabela 3.2.4.1 Resultados obtidos em julho de 2000 e valores de IFI calculados BR 116

\begin{tabular}{|c|c|c|c|c|c|c|c|c|}
\hline \multicolumn{2}{|r|}{ Unidade Amostragem } & \multicolumn{3}{|c|}{$\begin{array}{c}\text { Macrotextura } \\
\text { Altura de Areia } \mathrm{Hs}(\mathrm{mm})\end{array}$} & \multicolumn{2}{|c|}{$\begin{array}{l}\text { Microtextura } \\
\text { Pend. Britânico }\end{array}$} & \multicolumn{2}{|c|}{ IFI } \\
\hline No & Tipo & $\begin{array}{l}\text { Diâm. } \\
\text { Méd. } \\
\text { cm }\end{array}$ & $\begin{array}{l}\text { Hs } \\
(\mathbf{m m})\end{array}$ & $\begin{array}{l}\text { Classi- } \\
\text { ficação }\end{array}$ & $\begin{array}{l}\text { Média } \\
\text { FRS }\end{array}$ & $\begin{array}{l}\text { Classi- } \\
\text { ficação }\end{array}$ & $\mathbf{S p}$ & F60 \\
\hline 1 & CPA mod SBS & 16,35 & 1,19 & G & 55 & $\mathrm{R}$ & 123,58 & 0,35 \\
\hline 2 & CPA mod SBS & 14,5 & 1,51 & MG & 53 & MR & 159,94 & 0,37 \\
\hline 3 & CPA mod SBS & 15,25 & 1,37 & MG & 49 & MR & 144,03 & 0,33 \\
\hline 4 & CPA mod SBS & 16,8 & 1,13 & G & 49 & MR & 116,77 & 0,31 \\
\hline 5 & CPA mod SBS & 16,35 & 1,19 & G & 58 & $\mathrm{R}$ & 123,58 & 0,37 \\
\hline
\end{tabular}

\subsection{5- Rodovia Capivari - Osório RST 101}

Foram realizados os ensaios de campo, de macrotextura, microtextura e drenabilidade na Rodovia RST/101 por Oliveira et al. (2004); os ensaios foram realizados em três trechos com revestimentos distintos: o primeiro com Tratamento Superficial Duplo (TSD) com Capa Selante (CS), o segundo e o terceiro com revestimento do tipo Cape Seal, ou seja, Tratamento Superficial Simples (TSS) mais uma aplicação de Lama Asfáltica (Cape Seal) ou Tratamento Superficial Simples (TSS) mais uma camada de Microrrevestimento Asfáltico a Frio. As Tabelas 3.2.5.1, 3.2.5.2 e 3.2.5.3 apresentam os valores obtidos em agosto de 2002, abril de 2004 e setembro de 2004, respectivamente.

Tabela 3.2.5.1 Resultados obtidos em agosto de 2002 (Oliveira et al., 2004) e valores de IFI calculados - RST 101

\begin{tabular}{|c|c|c|c|c|c|c|c|c|c|}
\hline \multicolumn{2}{|c|}{ Unidade Amostragem } & \multicolumn{3}{|c|}{$\begin{array}{c}\text { Macrotextura } \\
\text { Altura de Areia } \mathrm{Hs}(\mathrm{mm})\end{array}$} & \multirow{2}{*}{$\begin{array}{c}\begin{array}{c}\text { Drena- } \\
\text { bilidade }\end{array} \\
\text { I/s }\end{array}$} & \multicolumn{2}{|c|}{$\begin{array}{l}\text { Microtextura } \\
\text { Pend. Britânico }\end{array}$} & \multicolumn{2}{|c|}{ IFI } \\
\hline No & Tipo & $\begin{array}{l}\text { Diâm. } \\
\text { Méd. } \\
\text { cm }\end{array}$ & $\begin{array}{l}\text { Hs } \\
(\mathbf{m m})\end{array}$ & $\begin{array}{l}\text { Classi- } \\
\text { ficação }\end{array}$ & & $\begin{array}{c}\text { Média } \\
\text { FRS }\end{array}$ & $\begin{array}{l}\text { Classi- } \\
\text { ficação }\end{array}$ & $\mathbf{S p}$ & F60 \\
\hline 1 & TSD + Capa Selante & 12,8 & 1,93 & MuG & 0,473 & 56 & $\mathrm{R}$ & 207,65 & 0,41 \\
\hline 2 & $\begin{array}{l}\text { TSS + Lama } \\
\text { (Cape Seal) }\end{array}$ & 22,9 & 0,61 & $M$ & 0,154 & 58 & $\mathrm{R}$ & 57,70 & 0,25 \\
\hline 3 & $\begin{array}{l}\text { TSS + Micro Lama } \\
\text { (Cape Seal) }\end{array}$ & 21,1 & 0,71 & M & 0,149 & 60 & $\mathrm{R}$ & 69,06 & 0,29 \\
\hline
\end{tabular}


Tabela 3.2.5.2 Resultados obtidos em abril de 2004 (Oliveira et al., 2004) e valores de IFI calculados - RST 101

\begin{tabular}{|c|c|c|c|c|c|c|c|c|c|}
\hline \multirow{2}{*}{\multicolumn{2}{|c|}{ Unidade Amostragem }} & \multirow{2}{*}{\multicolumn{3}{|c|}{$\begin{array}{c}\text { Macrotextura } \\
\text { Altura de Areia } \mathrm{Hs}(\mathrm{mm})\end{array}$}} & \multirow{4}{*}{$\begin{array}{c}\begin{array}{c}\text { Drena- } \\
\text { bilidade }\end{array} \\
1 / s\end{array}$} & \multirow{2}{*}{\multicolumn{2}{|c|}{\begin{tabular}{|c|} 
Microtextura \\
Pend. Britânico
\end{tabular}}} & \multirow{2}{*}{\multicolumn{2}{|c|}{$\boldsymbol{I F I}$}} \\
\hline & & & & & & & & & \\
\hline \multirow[b]{2}{*}{ No } & \multirow[b]{2}{*}{ Tipo } & \multirow{2}{*}{$\begin{array}{c}\text { Diâm. } \\
\text { Méd. } \\
\text { cm }\end{array}$} & \multirow{2}{*}{$\begin{array}{c}\text { Hs } \\
(\mathbf{m m})\end{array}$} & \multirow{2}{*}{$\begin{array}{l}\text { Classi- } \\
\text { ficação }\end{array}$} & & Média & Classi- & & \\
\hline & & & & & & FRS & ficação & Sp & F60 \\
\hline 1 & $\mathrm{TSD}+\mathrm{CS}$ & 12,1 & 2,18 & MuG & 0,609 & 56 & $R$ & 236,05 & 0,42 \\
\hline 2 & TSS + Lama & 17,7 & 1,01 & $G$ & 0,239 & 58 & $\mathrm{R}$ & 103,14 & 0,34 \\
\hline 3 & TSS + Micro & 21,8 & 0,67 & M & 0,168 & 60 & $\mathrm{R}$ & 64,51 & 0,28 \\
\hline
\end{tabular}

Tabela 3.2.5.3 Resultados obtidos em setembro de 2004 (Oliveira et al., 2004) e valores de IFI calculados - RST 101

\begin{tabular}{c|c|c|c|c|c|c|c|c|c}
\hline \hline \multicolumn{2}{c|}{ Unidade Amostragem } & \multicolumn{3}{c|}{ Macrotextura } & $\begin{array}{c}\text { Drena- } \\
\text { bilidade }\end{array}$ & \multicolumn{2}{c|}{$\begin{array}{c}\text { Microtextura } \\
\text { Pend. Britânico }\end{array}$} & \multicolumn{2}{c}{ IFI } \\
\hline No & Tipo & $\begin{array}{c}\text { Diâm. } \\
\text { Méd. } \\
\text { Cm }\end{array}$ & $\begin{array}{c}\text { Hs } \\
(\mathbf{m m})\end{array}$ & $\begin{array}{c}\text { Classi- } \\
\text { ficação }\end{array}$ & I/s & $\begin{array}{c}\text { Média } \\
\text { FRS }\end{array}$ & $\begin{array}{c}\text { Classi- } \\
\text { ficação }\end{array}$ & Sp & F60 \\
\hline 1 & TSD + CS & 13,7 & 1,7 & MuG & 0,556 & 56 & $\mathrm{R}$ & 181,52 & 0,40 \\
\hline 2 & TSS + Lama & 18,2 & 0,96 & $\mathrm{G}$ & 0,237 & 58 & $\mathrm{R}$ & 97,46 & 0,33 \\
\hline 3 & TSS + Micro & 19,1 & 0,87 & $\mathrm{G}$ & 0,141 & 60 & $\mathrm{R}$ & 87,23 & 0,33 \\
\hline \hline
\end{tabular}

Vale ressaltar que o revestimento asfáltico do tipo Cape Seal, Tratamento Superficial Simples com aplicação de camada de Microrrevestimento Asfáltico a Frio, foi considerado para efeito de análise, nesta pesquisa, em função de sua característica final de acabamento, ou seja, como Microrrevestimento Asfáltico a Frio (Micro).

\subsubsection{Valores de Pavimentos Rodoviários Obtidos no LTP - EPUSP}

Com o objetivo de complementar o Banco de Dados foram realizados ensaios no Laboratório de Tecnologia de Pavimentação em placa de Areia Asfalto extraída da pista e em placas de revestimento asfáltico do tipo SMA na faixa 0/16 e Camada Porosa de Atrito (CPA) moldadas em laboratório, em 07 de agosto de 2006. A Tabela 3.2.6.1 apresenta os valores obtidos. 
Tabela 3.2.6.1 Resultados obtidos em agosto de 2006 e valores de IFI calculados LTP - EPUSP

\begin{tabular}{c|l|c|c|c|c|c|c|c}
\hline \hline \multicolumn{2}{c|}{ Unidade Amostragem } & \multicolumn{2}{c|}{ Macrotextura } & \multicolumn{2}{c|}{ Microtextura } & \multicolumn{2}{c}{ IFI } \\
Altura de Areia Hs (mm) & Pend. Britânico & \multicolumn{2}{c}{} \\
\hline No & Tipo & $\begin{array}{c}\text { Diâm. } \\
\text { Méd. } \\
\text { cm }\end{array}$ & $\begin{array}{c}\text { Hs } \\
\text { (mm) }\end{array}$ & $\begin{array}{c}\text { Classi- } \\
\text { ficação }\end{array}$ & $\begin{array}{c}\text { Média } \\
\text { FRS }\end{array}$ & $\begin{array}{c}\text { Classi- } \\
\text { ficação }\end{array}$ & Sp & F60 \\
\hline 1 & SMA 0/16 & 15,35 & 1,35 & MG & 64,4 & R & 141,76 & 0,42 \\
\hline 2 & Areia Asfalto & 42,30 & 0,18 & MF & 55 & R & 8,85 & 0,06 \\
\hline 3 & CPA & 12,68 & 1,98 & MG & 71 & R & 213,33 & 0,51 \\
\hline \hline
\end{tabular}

\subsection{Vias Urbanas}

\subsubsection{Corredor Tecnológico}

Via idealizada por meio de convênio realizado entre a Escola Politécnica da Universidade de São Paulo, a empresa Serveng-Civilsan SA, a empresa Ipiranga Asfaltos SA e com o apoio da Prefeitura do Município de Barueri - SP. O Corredor Tecnológico é uma via municipal, sujeita ao tráfego pesado de caminhões, no município de Barueri, SP. Possui cerca de 2500 metros de extensão e 9,9 metros de largura, com três faixas, sendo uma descendente, de maior carga e, duas ascendentes. Foram projetadas e executadas cinco diferentes soluções de revestimento asfáltico: Concreto Asfáltico convencional na faixa III da Prefeitura do Município de São Paulo (CAP 20), Concreto Asfáltico convencional na faixa B do DERSA (CAP 20), Concreto Asfáltico convencional na faixa IV-b do Instituto do Asfalto norte-americano (CAP 20), Concreto Asfáltico com asfalto modificado por polímero na faixa IV-b do Instituto do Asfalto norte-americano (CAP modificado com SBS) e SMA com asfalto modificado por polímero na faixa alemã D 0-11(CAP modificado com SBS). A Tabela 3.3.1.1 apresenta os resultados obtidos em 2004 (Nascimento, 2004) e cálculos dos valores de IFI (Aps, 2004-b) e as Tabelas 3.3.1.2 apresentam os valores obtidos em campo em 24/03/06, por técnicos do IPT Instituto de Pesquisas Tecnológicas. 
Tabela 3.3.1.1 Resultados obtidos dos ensaios e valores de IFI calculados

\begin{tabular}{|c|c|c|c|c|c|c|c|c|}
\hline \multicolumn{2}{|r|}{ Unidade Amostragem } & \multicolumn{3}{|c|}{$\begin{array}{c}\text { Macrotextura } \\
\text { Altura de Areia Hs }(\mathrm{mm})\end{array}$} & \multicolumn{2}{|c|}{$\begin{array}{l}\text { Microtextura } \\
\text { Pend. Britânico }\end{array}$} & \multicolumn{2}{|c|}{ IFI } \\
\hline No & Tipo & $\begin{array}{l}\text { Diâm. } \\
\text { Méd. } \\
\text { cm }\end{array}$ & $\underset{(\mathrm{mm})}{\mathrm{Hs}}$ & $\begin{array}{l}\text { Classi- } \\
\text { ficação }\end{array}$ & $\begin{array}{l}\text { Média } \\
\text { FRS }\end{array}$ & $\begin{array}{l}\text { Classi- } \\
\text { ficação }\end{array}$ & $\mathbf{S p}$ & F60 \\
\hline 1 & CA faixa III - PMSP CAP 20 & 24,2 & 0,54 & $\mathrm{M}$ & 66,6 & $\mathrm{R}$ & 50,12 & 0,25 \\
\hline 2 & CA faixa III - PMSP CAP 20 & 21 & 0,72 & $M$ & 68 & $\mathrm{R}$ & 70,36 & 0,32 \\
\hline 3 & CA faixa III - PMSP CAP 20 & 23,4 & 0,58 & M & 67 & $\mathrm{R}$ & 54,41 & 0,27 \\
\hline 4 & CA faixa III - DERSA CAP 20 & 32,6 & 0,30 & $\mathrm{~F}$ & 62,4 & $\mathrm{R}$ & 22,41 & 0,11 \\
\hline 5 & CA faixa III - DERSA CAP 20 & 29,3 & 0,37 & $\mathrm{~F}$ & 60,2 & $\mathrm{R}$ & 30,50 & 0,15 \\
\hline 6 & CA faixa III - DERSA CAP 20 & 28,4 & 0,39 & $\mathrm{~F}$ & 57,6 & $\mathrm{R}$ & 33,22 & 0,16 \\
\hline 7 & CA IA faixa IV-b CAP 20 & 31,1 & 0,33 & $\mathrm{~F}$ & 46,6 & MR & 25,77 & 0,11 \\
\hline 8 & CA IA faixa IV-b CAP 20 & 28,1 & 0,40 & $M$ & 47 & MR & 34,18 & 0,14 \\
\hline 9 & CA IA faixa IV-b CAP 20 & 30,2 & 0,35 & $\mathrm{~F}$ & 45,8 & MR & 28,03 & 0,12 \\
\hline 10 & CA IA faixa IV-b mod SBS & 33,5 & 0,28 & $\mathrm{~F}$ & 47,2 & MR & 20,61 & 0,09 \\
\hline 11 & CA IA faixa IV-b mod SBS & 33,3 & 0,29 & $\mathrm{~F}$ & 47,6 & MR & 21,00 & 0,09 \\
\hline 12 & CA IA faixa IV-b mod SBS & 32 & 0,31 & $\mathrm{~F}$ & 52 & MR & 23,70 & 0,11 \\
\hline 13 & SMA faixa alemã D0-11S & 21 & 0,72 & $M$ & 66,6 & $\mathrm{R}$ & 70,36 & 0,32 \\
\hline 14 & SMA faixa alemã D0-11S & 22 & 0,66 & M & 68 & $\mathrm{R}$ & 63,08 & 0,30 \\
\hline 15 & SMA faixa alemã D0-11S & 22,1 & 0,65 & $M$ & 67 & $\mathrm{R}$ & 62,41 & 0,30 \\
\hline
\end{tabular}

Tabela 3.3.1.2 Resultados obtidos em 24/03/06 e valores de IFI calculados

\begin{tabular}{|c|c|c|c|c|c|c|c|c|}
\hline \multicolumn{2}{|r|}{ Unidade Amostragem } & \multicolumn{3}{|c|}{$\begin{array}{c}\text { Macrotextura } \\
\text { Altura de Areia Hs (mm) }\end{array}$} & \multicolumn{2}{|c|}{$\begin{array}{l}\text { Microtextura } \\
\text { Pend. Britânico }\end{array}$} & \multicolumn{2}{|c|}{$\boldsymbol{I F I}$} \\
\hline No & Tipo & $\begin{array}{l}\text { Diâm. } \\
\text { Méd. } \\
\text { cm }\end{array}$ & $\begin{array}{c}\text { Hs } \\
(\mathbf{m m})\end{array}$ & $\begin{array}{l}\text { Classi- } \\
\text { ficação }\end{array}$ & $\begin{array}{c}\text { Média } \\
\text { FRS }\end{array}$ & $\begin{array}{l}\text { Classi- } \\
\text { ficação }\end{array}$ & $\mathbf{S p}$ & F60 \\
\hline 1 & CA faixa III - PMSP CAP 20 & 25,2 & 0,50 & M & 56,2 & $\mathrm{R}$ & 45,34 & 0,21 \\
\hline 2 & CA faixa III - PMSP CAP 20 & 23,2 & 0,59 & $M$ & 59,6 & $\mathrm{R}$ & 55,58 & 0,25 \\
\hline 3 & CA faixa III - PMSP CAP 20 & 24,1 & 0,55 & M & 55,4 & $\mathrm{R}$ & 50,53 & 0,22 \\
\hline 4 & CA faixa III - PMSP CAP 20 & 20,8 & 0,74 & $M$ & 57 & $\mathrm{R}$ & 72,38 & 0,28 \\
\hline 5 & CA faixa III - PMSP CAP 20 & 25,3 & 0,50 & $M$ & 57 & $\mathrm{R}$ & 45,12 & 0,21 \\
\hline 6 & CA faixa III - DERSA CAP 20 & 22,1 & 0,65 & M & 57 & $\mathrm{R}$ & 62,27 & 0,26 \\
\hline 7 & CA faixa III - DERSA CAP 20 & 22,9 & 0,61 & $M$ & 57,2 & $\mathrm{R}$ & 57,35 & 0,25 \\
\hline 8 & CA faixa III - DERSA CAP 20 & 23,5 & 0,58 & $M$ & 58,8 & $\mathrm{R}$ & 53,88 & 0,24 \\
\hline 9 & CA faixa III - DERSA CAP 20 & 26,6 & 0,45 & M & 57,7 & $\mathrm{R}$ & 39,60 & 0,19 \\
\hline 10 & CA faixa III - DERSA CAP 20 & 23,9 & 0,56 & $M$ & 57,7 & $\mathrm{R}$ & 51,70 & 0,23 \\
\hline 11 & CA IA faixa IV-b CAP 20 & 28,4 & 0,40 & $\mathrm{~F}$ & 45 & $\mathrm{R}$ & 33,39 & 0,14 \\
\hline 12 & CA IA faixa IV-b CAP 20 & 27,6 & 0,42 & M & 59,8 & $\mathrm{R}$ & 35,87 & 0,17 \\
\hline 13 & CA IA faixa IV-b CAP 20 & 28,2 & 0,40 & M & 51,4 & $\mathrm{R}$ & 33,87 & 0,15 \\
\hline 14 & CA IA faixa IV-b CAP 20 & 30,8 & 0,34 & $\mathrm{~F}$ & 52 & $\mathrm{R}$ & 26,64 & 0,12 \\
\hline 15 & CA IA faixa IV-b mod SBS & 27,5 & 0,42 & M & 50 & $\mathrm{R}$ & 36,30 & 0,16 \\
\hline 16 & CA IA faixa IV-b mod SBS & 27,9 & 0,41 & M & 49,2 & $\mathrm{R}$ & 34,85 & 0,15 \\
\hline 17 & CA IA faixa IV-b mod SBS & 26,9 & 0,44 & M & 48,4 & $\mathrm{R}$ & 38,56 & 0,16 \\
\hline 18 & CA IA faixa IV-b mod SBS & 28,1 & 0,40 & M & 49,2 & $\mathrm{R}$ & 34,11 & 0,15 \\
\hline 19 & SMA faixa alemã D0-11S & 21,3 & 0,70 & M & 48,6 & $\mathrm{R}$ & 68,48 & 0,24 \\
\hline 20 & SMA faixa alemã D0-11S & 20,8 & 0,74 & M & 55 & $\mathrm{R}$ & 72,38 & 0,28 \\
\hline 21 & SMA faixa alemã D0-11S & 19,3 & 0,85 & G & 48,6 & $\mathrm{R}$ & 85,48 & 0,27 \\
\hline 22 & SMA faixa alemã D0-11S & 19,4 & 0,85 & G & 50,7 & $\mathrm{R}$ & 84,73 & 0,28 \\
\hline
\end{tabular}




\subsubsection{Ruas da Cidade de Santos}

Para o caso urbano foram selecionadas vias da Cidade de Santos, litoral do Estado de São Paulo, que possui uma área de $271 \mathrm{~km}^{2}$, sendo $231,6 \mathrm{~km}^{2}$ na área continental e $39,4 \mathrm{~km}^{2}$ situados na área insular. A população estimada é de 417.100 habitantes sendo 415.602 concentrados na área insular e 1498 habitantes no continente, ou seja, 99,64\% da população da Cidade de Santos se concentram em apenas 14,54\% da área total do Município, de acordo com a Prefeitura Municipal (PMS, 1994). A cidade de Santos possui aproximadamente $530 \mathrm{~km}$ de vias asfaltadas e é considerada uma cidade de médio porte, sendo que apresenta um elevado número de veículos registrados para uma extensão de vias pequena em comparação com outros municípios da região. A Tabela 3.3.2.1 apresenta os valores obtidos em campo em 18/03/06.

Tabela 3.3.2.1 Resultados obtidos e valores de IFI calculados (Aps et al., 2003-e)

\begin{tabular}{|c|c|c|c|c|c|c|c|c|c|}
\hline \multicolumn{2}{|c|}{ Unidade Amostragem } & \multicolumn{3}{|c|}{$\begin{array}{c}\text { Macrotextura } \\
\text { Altura de Areia Hs }(\mathrm{mm})\end{array}$} & \multirow{2}{*}{$\begin{array}{c}\begin{array}{c}\text { Drena- } \\
\text { bilidade }\end{array} \\
\text { I/s }\end{array}$} & \multicolumn{2}{|c|}{$\begin{array}{c}\text { Microtextura } \\
\text { Pend. Britânico }\end{array}$} & \multicolumn{2}{|c|}{$\boldsymbol{I F I}$} \\
\hline No & Tipo & $\begin{array}{c}\text { Diâm. } \\
\text { Méd. } \\
\text { cm }\end{array}$ & $\begin{array}{c}\text { Hs } \\
(\mathbf{m m})\end{array}$ & $\begin{array}{l}\text { Classi- } \\
\text { ficação }\end{array}$ & & $\begin{array}{c}\text { Média } \\
\text { FRS }\end{array}$ & $\begin{array}{l}\text { Classi- } \\
\text { ficação }\end{array}$ & $\mathbf{S p}$ & F60 \\
\hline 1 & CA convencional F III & 31,3 & 0,32 & $\mathrm{~F}$ & 0,028 & 54 & MR & 24,75 & 0,11 \\
\hline 2 & CA convencional F III & 26,8 & 0,44 & $M$ & 0,058 & 49 & MR & 38,38 & 0,16 \\
\hline 3 & CA convencional F III & 24,7 & 0,52 & $M$ & 0,164 & 60 & $\mathrm{R}$ & 47,47 & 0,22 \\
\hline 4 & CA convencional F III & 18,5 & 0,93 & $\mathrm{G}$ & 0,241 & 57 & $\mathrm{R}$ & 94,05 & 0,32 \\
\hline 5 & CA convencional F III & 32,4 & 0,3 & $\mathrm{~F}$ & 0,055 & 58 & $\mathrm{R}$ & 22,48 & 0,11 \\
\hline 6 & CA convencional F III & 30,4 & 0,34 & $\mathrm{~F}$ & 0,047 & 49 & MR & 27,02 & 0,12 \\
\hline 7 & CA convencional F III & 28,8 & 0,38 & $\mathrm{~F}$ & 0,031 & 56 & $\mathrm{R}$ & 31,57 & 0,15 \\
\hline 8 & CA convencional F III & 26,2 & 0,46 & $M$ & 0,062 & 58 & $\mathrm{R}$ & 40,66 & 0,19 \\
\hline 9 & CA convencional F III & 26,2 & 0,46 & $M$ & 0,038 & 58 & $\mathrm{R}$ & 40,66 & 0,19 \\
\hline 10 & CA convencional F III & 16 & 1,24 & MG & 0,297 & 58 & $\mathrm{R}$ & 129,26 & 0,37 \\
\hline 11 & CA convencional F III & 18 & 0,98 & G & 0,108 & 59 & $\mathrm{R}$ & 99,73 & 0,34 \\
\hline 12 & CA convencional F III & 24,9 & 0,51 & $M$ & 0,052 & 48 & MR & 46,34 & 0,19 \\
\hline 13 & CA convencional F III & 24,9 & 0,51 & $M$ & 0,089 & 54 & $\mathrm{R}$ & 46,34 & 0,20 \\
\hline 14 & CA convencional F III & 25,7 & 0,48 & $M$ & 0,036 & 60 & $\mathrm{R}$ & 42,93 & 0,21 \\
\hline 15 & CA convencional F III & 26,5 & 0,45 & $M$ & 0,021 & 57 & $\mathrm{R}$ & 39,52 & 0,18 \\
\hline 16 & CA convencional F III & 27,7 & 0,41 & $M$ & 0,004 & 54 & $\mathrm{R}$ & 34,98 & 0,16 \\
\hline 17 & CA convencional F III & 28,1 & 0,4 & $M$ & 0,019 & 54 & $\mathrm{R}$ & 33,84 & 0,15 \\
\hline 18 & CA convencional F III & 28,4 & 0,39 & $\mathrm{~F}$ & 0,003 & 63 & $\mathrm{R}$ & 32,70 & 0,17 \\
\hline 19 & CA convencional F III & 33,5 & 0,28 & $\mathrm{~F}$ & 0,005 & 59 & $\mathrm{R}$ & 20,21 & 0,10 \\
\hline 20 & CA convencional F III & 25,4 & 0,49 & $M$ & 0,034 & 58 & $\mathrm{R}$ & 44,06 & 0,21 \\
\hline 21 & CA convencional F III & 25,7 & 0,48 & $M$ & 0,013 & 53 & $\mathrm{R}$ & 42,93 & 0,19 \\
\hline 22 & CA convencional F III & 34,7 & 0,26 & $\mathrm{~F}$ & 0,012 & 54 & $\mathrm{R}$ & 17,94 & 0,08 \\
\hline
\end{tabular}




\subsection{Circuitos de Provas}

\subsubsection{Autódromo de Interlagos - José Carlos Pace}

Foram realizados ensaios na pista do Autódromo de Interlagos, "José Carlos Pace", que é o único da América Latina a fazer parte do circuito internacional de Fórmula 1, e um dos poucos circuitos de automobilismo, fora dos Estados Unidos, a ter sentido anti-horário; o que de acordo com especialistas, dificulta a prova.

Em 1990, quando o autódromo completava 50 anos, a pista foi reformada, passando de 7.823 metros de circuito para os atuais 4.309 metros de extensão, com curvas novas como a "Curva do S", "Bico do Pato", "Mergulho", "Curva do Sol" que se tornaram mundialmente populares. Além do Grande Prêmio de Fórmula 1, acontecem outras importantes provas nacionais como Stock Car, Fórmula Truck, Fórmula 3 , Fórmula Ford, provas de motovelocidade, aulas de pilotagem e direção defensiva.

Para o Grande Prêmio do Brasil de Fórmula I de 2000, por exigência da FIA Federação Internacional de Automobilismo, o autódromo sofreu intervenções nas pistas com a aplicação do revestimento do tipo SMA, para melhorar a resistência à aderência em condições de pista molhada. A Tabela 3.4.1.1 apresenta os valores obtidos em campo em 11/03/2003 por Aps et al. (2004-a).

Tabela 3.4.1.1 Resultados obtidos por meio do ensaio de Mancha de Areia e Pêndulo Britânico em março de 2003 e valores de IFI calculados

\begin{tabular}{c|c|c|c|c|c|c|c|c}
\hline \hline \multicolumn{2}{c|}{ Unidade Amostragem } & \multicolumn{3}{c|}{ Macrotextura } & \multicolumn{2}{c}{ Microtextura } & \multicolumn{2}{c}{ IFI } \\
Altura de Areia Hs (mm) & Pend. Britânico & \multicolumn{2}{c}{} \\
\hline \multirow{2}{*}{ No } & Tipo & $\begin{array}{c}\text { Diâm. } \\
\text { Méd. } \\
\text { cm }\end{array}$ & $\begin{array}{c}\text { Hs } \\
\text { (mm) }\end{array}$ & $\begin{array}{c}\text { Classi- } \\
\text { ficação }\end{array}$ & $\begin{array}{c}\text { Média } \\
\text { FRS }\end{array}$ & $\begin{array}{c}\text { Classi- } \\
\text { ficação }\end{array}$ & Sp & F60 \\
\hline 1 & SMA faixa alemã D0-11S & 16,8 & 1,13 & G & 59 & R & 116,52 & 0,36 \\
\hline 2 & SMA faixa alemã D0-11S & 19,9 & 0,80 & G & 59,5 & R & 79,71 & 0,31 \\
\hline 3 & SMA faixa alemã D0-11S & 20,3 & 0,77 & M & 61 & R & 76,15 & 0,31 \\
\hline 4 & SMA faixa alemã D0-11S & 17,2 & 1,08 & G & 52,8 & MR & 110,63 & 0,32 \\
\hline 5 & SMA faixa alemã D0-11S & 20 & 0,80 & G & 50,4 & MR & 78,80 & 0,27 \\
\hline \hline
\end{tabular}




\subsubsection{Campo de Prova da Pirelli}

Localizado na cidade de Sumaré, SP, inaugurado em 1988, o campo de prova da Pirelli é constituído de pistas para realização de testes de pneus e veículos; possui uma extensão de $30000 \mathrm{~m}^{2}$ de pavimentos asfálticos, textura fechada, dos quais $17000 \mathrm{~m}^{2}$ simulam a condição de pistas molhadas. A Tabela 3.4.2.1 apresenta os valores obtidos em campo em 19/03/2003 e valores de IFI calculados (Aps et al., 2003-f).

Tabela 3.4.2.1 Resultados obtidos por meio do ensaio Mancha de Areia, Pêndulo Britânico e Drenabilidade em 19/03/2003 e valores de IFI calculados

\begin{tabular}{|c|c|c|c|c|c|c|c|c|c|}
\hline \multicolumn{2}{|c|}{ Unidade Amostragem } & \multicolumn{3}{|c|}{$\begin{array}{c}\text { Macrotextura } \\
\text { Altura de Areia } \mathrm{Hs}(\mathrm{mm})\end{array}$} & \multirow{2}{*}{$\begin{array}{c}\begin{array}{c}\text { Drena- } \\
\text { bilidade }\end{array} \\
\mathrm{I} / \mathrm{s}\end{array}$} & \multicolumn{2}{|c|}{$\begin{array}{c}\text { Microtextura } \\
\text { Pend. Britânico }\end{array}$} & \multicolumn{2}{|c|}{ IFI } \\
\hline No & Tipo & $\begin{array}{l}\text { Diam. } \\
\text { Méd. } \\
\text { cm }\end{array}$ & $\begin{array}{l}\text { Hs } \\
(\mathbf{m m})\end{array}$ & $\begin{array}{l}\text { Classi- } \\
\text { ficação }\end{array}$ & & $\begin{array}{c}\text { Média } \\
\text { FRS }\end{array}$ & $\begin{array}{l}\text { Classi- } \\
\text { ficação }\end{array}$ & $\mathbf{S p}$ & F60 \\
\hline 1 & Concreto Asfáltico & 24,5 & 0,53 & M & 0,034 & 47,8 & MR & 48,64 & 0,19 \\
\hline 2 & Concreto Asfáltico & 23 & 0,60 & $M$ & 0,063 & 51,2 & MR & 56,76 & 0,23 \\
\hline 3 & Concreto Asfáltico & 27 & 0,44 & M & 0,013 & 55,4 & $\mathrm{R}$ & 38,00 & 0,17 \\
\hline 4 & Concreto Asfáltico & 23,5 & 0,58 & $M$ & 0,087 & 61 & $\mathrm{R}$ & 53,88 & 0,25 \\
\hline
\end{tabular}

Com o objetivo de entender os fenômenos evolvidos na frenagem, foram iniciadas algumas medidas reais, empregando um ônibus rodoviário que foi especialmente monitorado para executar as provas de frenagem em piso seco e molhado. No decorrer da prova foram medidas as seguintes variáveis: a velocidade linear do veículo com o "Correvit" e as velocidades angulares das rodas com "Encoders". Além disso, foram instalados acelerômetros no eixo dianteiro para adquirir os sinais de vibração e sensores de altura laser, ligados ao cubo da roda, para medir de modo indireto a carga atuante em cada pneumático no eixo dianteiro. O sistema de freio traseiro foi desativado para garantir o controle do veículo durante as frenagens Costa et al. (2003).

A Tabela 3.4.2.2 apresenta dois valores obtidos por meio de prova realizada com ônibus rodoviário monitorado em pavimento seco e molhado, com uma velocidade de 
$60 \mathrm{~km} / \mathrm{h}$, selecionada por ser referência para qual o IFI converte todos os equipamentos de medida de aderência em pista molhada, ou seja, é uma estimativa da aderência de um veículo de passeio com pneus lisos e roda travada a $60 \mathrm{~km} / \mathrm{h}$, (Aps et al., 2003-f).

Tabela 3.4.2.2 Atrito obtido por meio de ônibus rodoviário monitorado, março 2003

\begin{tabular}{c|c|c|c|c}
\hline \hline \multirow{2}{*}{ Unidade Amostragem } & \multirow{2}{*}{ Condição } & \multicolumn{2}{c}{$\begin{array}{c}\text { Micro Textura } \\
\text { Pend. Britânico }\end{array}$} \\
\cline { 5 - 6 } No & \multirow{2}{*}{ Tipo } & & $\begin{array}{c}\text { Média } \\
\text { FRS }\end{array}$ & $\begin{array}{c}\text { Classi- } \\
\text { ficação }\end{array}$ \\
\hline 1 & Concreto Asfáltico & molhado & 0,17 & $\mathrm{P}$ \\
\hline 2 & Concreto Asfáltico & seco & 0,33 & $\mathrm{~L}$ \\
\hline \hline
\end{tabular}

Ressalta-se que veículos comerciais apresentam uma aderência menor que os veículos de passeio; este fato deve ser considerado no dimensionamento dos freios e no cálculo da distância mínima de parada. Lembra-se que o valor comumente encontrado, nas referências bibliográficas, está em torno de 0.8 para veículos de passeio em pista seca (Clark, 1981). Em uma referência mais recente, Yamazaki (2003), chegou a valores em torno de 0.9 para pneus de carro e 0.5 para pneus de caminhões no seco a $60 \mathrm{~km} / \mathrm{h}$, estes valores caem para valores próximos a 0.5 e 0.4 , respectivamente, em pistas molhadas (Costa et al., 2003). 


\section{Capítulo 4 Análise de Dados}

Este capítulo apresenta as análises e discussões dos resultados obtidos por meio de confrontos, tentativas de correlação e de observações de como esses dados refletem as condições observadas em campo em função dos valores apresentados no Capítulo 3. As referências bibliográficas sobre valores de $\operatorname{IFI}\left(\mathrm{Sp} ; \mathrm{F}_{60}\right)$ ainda são poucas e as faixas de classificação por meio desse índice combinado são praticamente inexistentes.

Os objetivos iniciais do Experimento Internacional da PIARC foram atingidos conforme visto no Capítulo 2 e Wambold et al. (1995) sugere que organizações como a ASTM (American Society for Testing and Materials), o CEN (Comité Européen de Normalisation) e a ISO (International Organization for Standardization) elaborem normas incorporando o modelo da PIARC de cálculo de valores de $\left.\operatorname{IFI~(Sp;~} \mathrm{F}_{60}\right)$; isso em parte já ocorreu com a publicação da norma ASTM E 1960-98 Standard Practice for Calculating International Friction Index of a Pavement Surface. Wambold et al. (1995) recomenda também que os órgãos e as concessionárias que administram rodovias aceitem e utilizem essas normas.

Como próximo passo sugere Wambold et al. (1995) que grupos de trabalhos internacionais fixem faixas de valores aceitáveis para a realização de intervenções que possam ser utilizadas em gerência de pavimentos em todo o mundo, escopo desta tese. Segundo Wambold et al., deve-se trabalhar com a expressão "valores aceitáveis" porque é necessário que sejam valores distintos de acordo com o tipo de classe da rodovia.

Para alcançar tal objetivo, buscou-se adotar um procedimento para criação do Banco de Dados, pois não se dispunha de série histórica de dados confiáveis, cuja metodologia utilizada consistiu em: 
a) Definição dos objetivos do experimento: avaliar a aplicabilidade do IFI como indicador para pavimentos brasileiros e estabelecer faixas de valores para o IFI de tal sorte que os órgãos gestores viários poderão avaliar as condições de aderência em pista molhada de suas vias ou de locais específicos de suas vias;

b) Definição de parâmetros do experimento: esta fase envolveu a coleta de informações técnicas do processo, no qual, foram listados todos os fatores de controle, fatores de ruído, os níveis de ajustagem e as variáveis de resposta. As informações técnicas são os resultados da combinação entre o conhecimento prático (experiência) e a compreensão teórica do objeto de estudo;

c) Seleção dos fatores de controle e das variáveis de resposta: nesta fase foram selecionados os fatores de controle (variáveis independentes), as faixas de variação dos níveis de ajustagem desses fatores e as respostas do experimento (variáveis dependentes), assim como, definidos os métodos de medição dos fatores de controle e a escala numérica que será utilizada para se avaliar as respostas do experimento definidas nas fases anteriores. Conforme pode ser observado na Figura 4.1;

d) Realização do experimento: nesta etapa foi importante que o processo tenha sido acompanhado e realizado pela equipe técnica responsável, para assegurar-se que todos os procedimentos foram executados conforme 0 plano;

e) Elaboração do banco de dados: foram organizados os dados coletados e obtidos no campo de macrotextura, microtextura, e drenabilidade, e os respectivos valores de $\operatorname{IFI}\left(\mathrm{Sp} ; \mathrm{F}_{60}\right)$ calculados;

f) Análise dos dados por meio de conceitos estatísticos: com o objetivo de descrever o comportamento das variáveis, foi realizada a relação entre elas e a estimativa dos efeitos produzidos nas respostas observadas; 
g) Interpretação dos resultados: com base nas respostas das aplicações estatísticas, foram analisados os dados e tecidas as conclusões práticas dos resultados, qual seja a delimitação em faixas de classificação de IFI (Sp; $\left.\mathrm{F}_{60}\right)$.

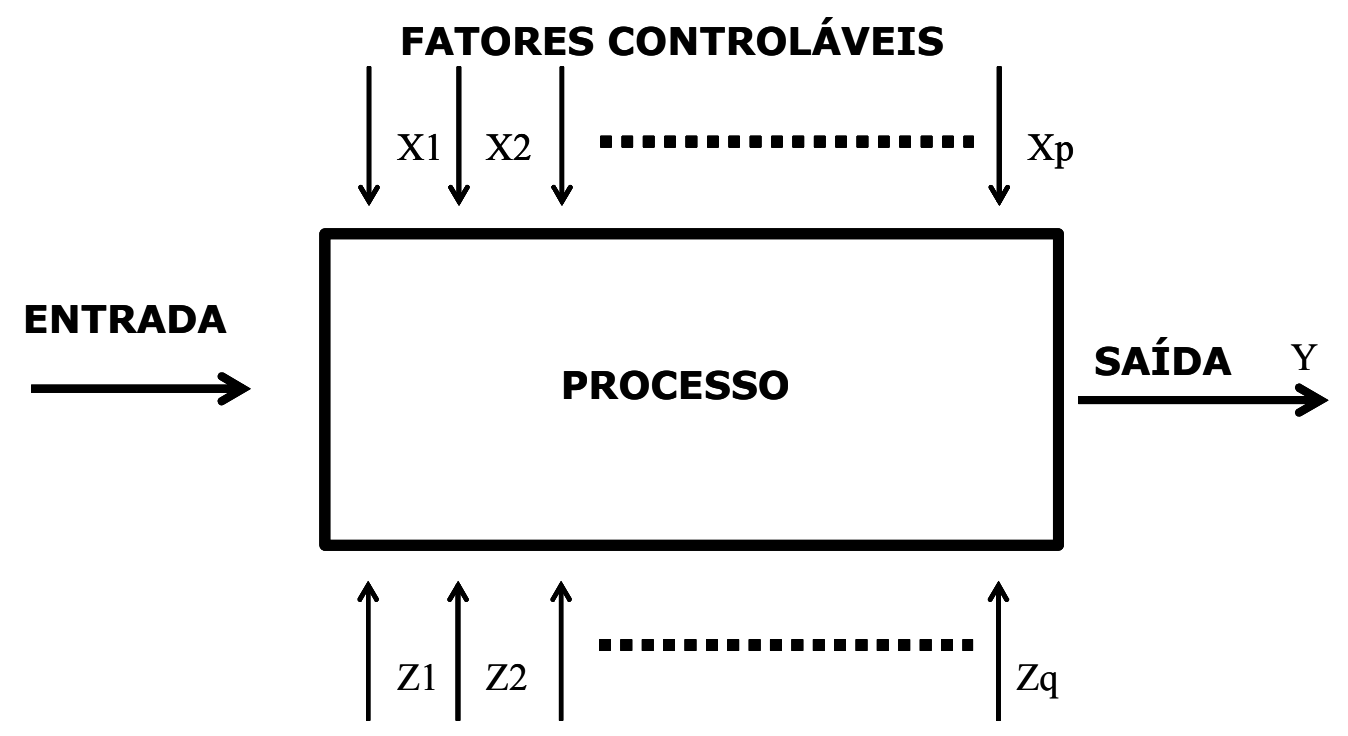

FATORES NÃO CONTROLÁVEIS

Figura 4.1 Modelo geral de um processo para o delineamento de experimento (Calegare, 2001)

\subsection{Banco de Dados e Grupo de Controle}

Ao término dos trabalhos de campo e coleta de dados confiáveis disponíveis, obtevese o Banco de Dados para as análises estatísticas composto por 417 valores, sendo 178 referentes à textura, 166 ao atrito e 73 à drenabilidade, distribuídos em doze tipos de revestimentos asfálticos diferentes, e esses com características de textura e atrito diferentes entre si, conforme apresentado na Figura 3.1 do Capítulo 3; além de 330 valores calculados de $I F I$, divididos em dois grupos de 165 valores referentes ao parâmetro $\mathrm{Sp}$ e $\mathrm{F}_{60}$.

Com o objetivo de verificar o que ocorre neste processo, ou seja, estatisticamente o conjunto de causas que produzem efeitos, foi estabelecido no Delineamento de Experimento que seria extraída uma amostra do Banco de Dados (universo da 
pesquisa), sem perda das características essenciais, com a finalidade de ser usada como Grupo de Controle (amostra). O grupo de controle nesta pesquisa é o Estudo de Caso Controle (amostra) que será apresentado no Capítulo 5, onde será comparado com o Banco de Dados resultante (amostra treinamento), conforme pode ser visto na Tabela 4.1.1, cujo objetivo é verificar se o experimento está validado ou se ocorrem diferenças significantes entre os grupos.

O grupo de controle são três trechos da Via Anchieta, compostos pelos revestimentos: SMA (Stone Matrix Asphalt), Concreto Asfáltico convencional na faixa III da DERSA, usinado com CAP 20, e Concreto Asfáltico na faixa IV-b do Instituto do Asfalto norte-americano, porém empregando asfalto modificado por borracha. Estes três trechos foram eleitos para o grupo de controle pela participação direta do LTPEPUSP na concepção dos trechos e pelos testes dos revestimentos terem sido monitorados periodicamente, assegurando confiabilidade nos resultados obtidos nestes locais.

Primeiramente foram usadas ferramentas da estatística descritiva para analisar o conjunto de dados expressos em termos numéricos, sumarizando e descrevendo o comportamento e as características da amostra e a seguir foram realizadas análises inferenciais acerca do universo da qual a amostra foi retirada.

Tabela 4.1.1 Resumo dos dados da pesquisa

\begin{tabular}{c|c|c|c}
\hline \hline Ensaio & $\begin{array}{c}\text { Banco de Dados } \\
\text { (universo) }\end{array}$ & $\begin{array}{c}\text { Grupo de Controle } \\
\text { (amostra) }\end{array}$ & $\begin{array}{c}\text { Banco de Dados sem } \\
\text { Grupo de Controle } \\
\text { (amostra treinamento) }\end{array}$ \\
\hline \hline Macrotextura & 178 & 50 & 128 \\
\hline Microtextura & 166 & 37 & 129 \\
\hline Drenabilidade & 73 & 15 & 58 \\
\hline Total & $\mathbf{4 1 7}$ & 102 & 315 \\
\hline \hline
\end{tabular}




\subsection{Consistência do Banco de Dados da Amostra Treinamento por meio da Ferramenta Estatística Boxplot para valores de $\mathbf{F}_{60}$}

Os valores dos ensaios de campo foram agrupados em função das características do revestimento asfáltico, em doze grupos como segue: Areia Asfalto (AA), Concreto Asfáltico usinado com asfalto convencional (CA), Concreto Asfáltico modificado por Borracha (CA bor), Concreto Asfáltico modificado por Polímero do tipo SBS (CA SBS), Camada Porosa de Atrito (CPA), Tratamento Superficial Duplo com aplicação de Capa Selante (CS), Concreto Asfáltico com Grooving (G), Cape Seal - Tratamento Superficial Simples com aplicação de Lama Asfáltica (LA), Microrrevestimento Asfáltico a Frio (Micro), Stone Matrix Asfhalt (SMA) - tipo 0/11 e 0/16, e Tratamento Superficial (TS). Vale ressaltar que o revestimento do tipo Concreto Asfáltico modificado por Borracha (CA bor) não faz parte da Amostra Treinamento, portanto os valores referentes a este tipo serão analisados na Amostra Estudo de Caso (grupo de controle).

Primeiramente foi verificada a consistência do Banco de Dados da Amostra Treinamento por meio da ferramenta estatística Boxplot para os valores de $F_{60}$, pois a partir desses valores é que poderão ser construídas as faixas de classificação. A ferramenta estatística Boxplot ${ }^{1}$ é a forma resumida de apresentar uma distribuição onde é ressaltada a tendência central ou a média e a dispersão dos dados.

O Boxplot é uma maneira de realizar a análise exploratória de dados descrevendo as principais características como média, desvio padrão, valores mínimo e máximo, mediana, primeiro e terceiro quartis, ou seja, mostra a dispersão de um grupo de dados e as diferenças existentes entre grupos. A Figura 4.2.1, apresenta esquematicamente um exemplo de BoxPlot.

Os valores de máximo e mínimo são representados graficamente desde que não sejam observações discrepantes; o critério para decidir se uma observação é

\footnotetext{
${ }^{1}$ Boxplot cujo nome completo é Box and Whisker Plot na tradução para o português (Brasil) é conhecido como o gráfico de caixa ou desenho esquemático e no português de Portugal é denominado como gráfico de caixa e bigode.
} 
discrepante pode variar, como por exemplo, os pontos soltos ou dados suspeitos (outliers), valores maiores ou iguais a valores extremos entre outros.

Solto (outliers) $=$ Extremo $+1,5(\mathrm{Q} 1-\mathrm{Q} 3)$

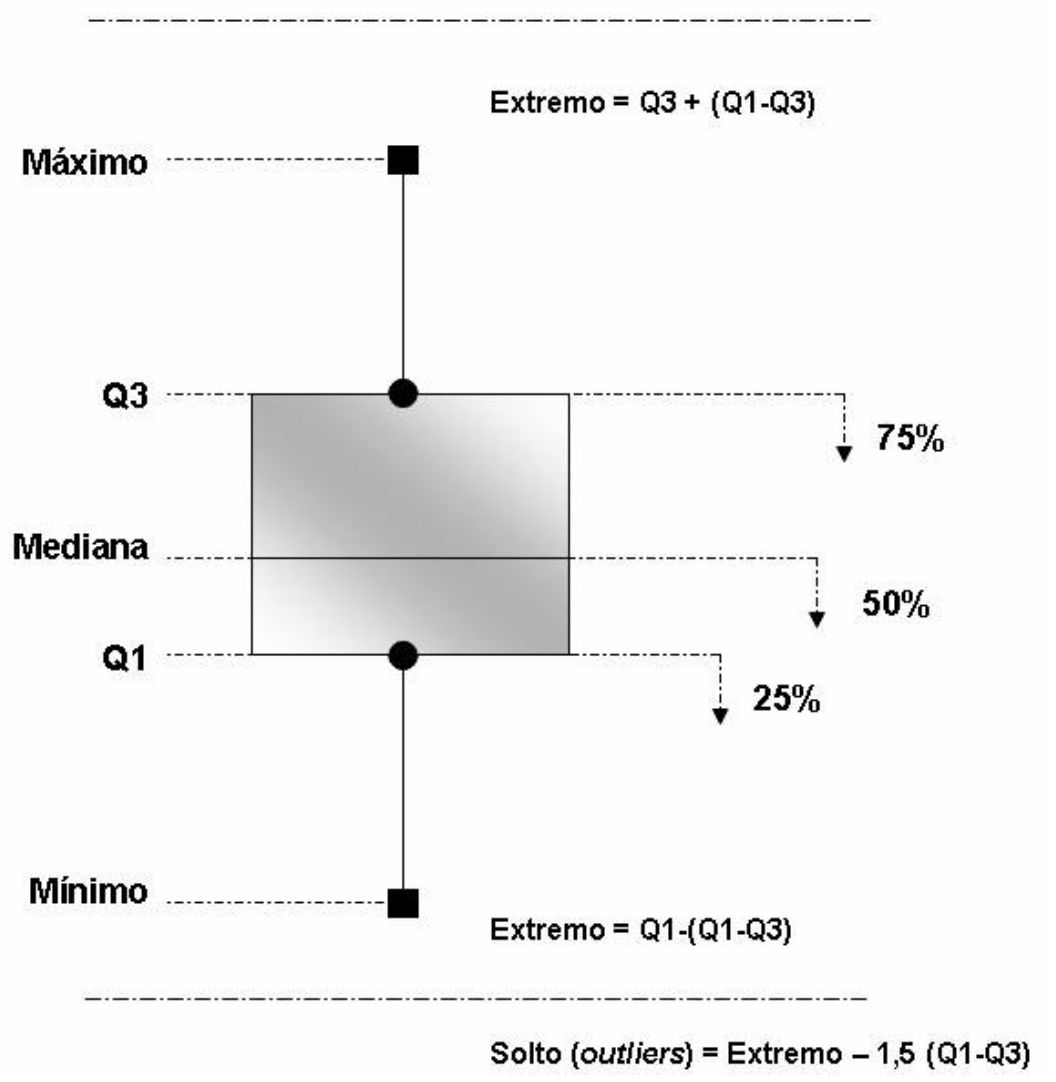

Figura 4.2.1 Esquema da ferramenta estatística Boxplot

Nesta pesquisa, primeiramente a amostra foi testada, para os valores de $F_{60}$, para os pontos soltos, equações 1 e 2, e verificou-se que todos os valores estavam dentro da faixa de tolerância; após esta verificação foi repetido o mesmo teste sendo aceitos os valores iguais ou inferiores aos pontos extremos de acordo com as equações 3 e 4 .

$$
\begin{array}{ll}
\text { pontos_soltos_máx } \geq Q 3+|Q 1-Q 3|+1,5|Q 1-Q 3| & \text { equação } 1 \\
\text { pontos_soltos_mín } \geq Q 1-|Q 1-Q 3|-1,5|Q 1-Q 3| & \text { equação } 2 \\
\text { pontos_externos_máx } \geq Q 3+|Q 1-Q 3| & \text { equação } 3 \\
\text { pontos_externos_mín } \geq Q 1-|Q 1-Q 3| & \text { equação } 4
\end{array}
$$

onde:

$$
\begin{aligned}
& Q 1=\text { primeiro_quartil } \\
& Q 3=\text { terceiro_quartil }
\end{aligned}
$$


Essa verificação foi realizada nas amostras de revestimentos que possuem mais de três observações e após esse procedimento nove valores foram excluídos conforme pode ser visto na Tabela 4.2.1 e a Amostra Treinamento final está apresentado na Figura 4.2.2. Estatisticamente esses pontos, considerados discrepantes nesta pesquisa, podem representar um erro de observação ou de arredondamento (Bussab e Morretin, 2006).

Tabela 4.2.1 Banco de dados da amostra treinamento para valores de $F_{60}$

\begin{tabular}{l|c|c|c|c|c|c|c|c|c}
\hline \hline $\begin{array}{c}\text { Tipo de } \\
\text { Revestimento } \\
\text { Asfáltico }\end{array}$ & \multicolumn{4}{c|}{ Parâmetros Estatísticos } & \multicolumn{3}{c}{ Valores Discrepantes - F60 } \\
\cline { 2 - 11 } & Mínimo & $\mathbf{Q 1}$ & Mediana & Q3 & Máximo & \multicolumn{4}{c}{ (descartados) } \\
\hline CA & 0,06 & 0,12 & 0,17 & 0,21 & 0,28 & 0,32 & 0,32 & 0,34 & 0,37 \\
\hline CA mod SBS & 0,09 & 0,12 & 0,15 & 0,16 & 0,16 & & & & \\
\hline CPA & 0,31 & 0,33 & 0,35 & 0,37 & 0,37 & & & & \\
\hline G & 0,37 & 0,40 & 0,43 & 0,45 & 0,47 & 0,31 & 0,53 & 0,58 & 0,59 \\
\hline Micro & 0,25 & 0,26 & 0,28 & 0,28 & 0,29 & 0,33 & & & \\
\hline SMA D0-11S & 0,14 & 0,16 & 0,27 & 0,31 & 0,36 & & & & \\
\hline TSS com CS & 0,40 & 0,40 & 0,41 & 0,41 & 0,42 & & & & \\
\hline LA & 0,25 & 0,29 & 0,33 & 0,34 & 0,34 & & & & \\
\hline TS & 0,40 & & 0,41 & & 0,42 & & & & \\
\hline SMA D0-16 & & & 0,42 & & & & & & \\
\hline AA & & & 0,06 & & & & & & \\
\hline \hline
\end{tabular}

As análises descritas acima (verificação de pontos soltos e extremos) não puderam ser realizadas para os revestimentos do tipo Tratamento Superficial, SMA na faixa 0/16 e Areia Asfalto, pois os mesmos apresentam observações reduzidas, duas, uma e uma respectivamente; porém esses valores foram apresentados na Tabela 4.2.1.

Observa-se a grande variação dos valores de Concreto Asfáltico e SMA conforme pode ser visto na Figura 4.2.2, isto pode ser explicado, pois além de serem as amostras com maiores números de dados (amostras pequenas podem parecer mais homogêneas), os valores de CA e SMA variam de revestimentos novos a revestimentos com mais de seis anos ou mais de quatro anos, respectivamente. Embora alguns grupos apresentem valores de máximo ou de mínimo mais distante que outros ressalta-se que todos os valores estão dentro do critério estabelecido de aceitação. 


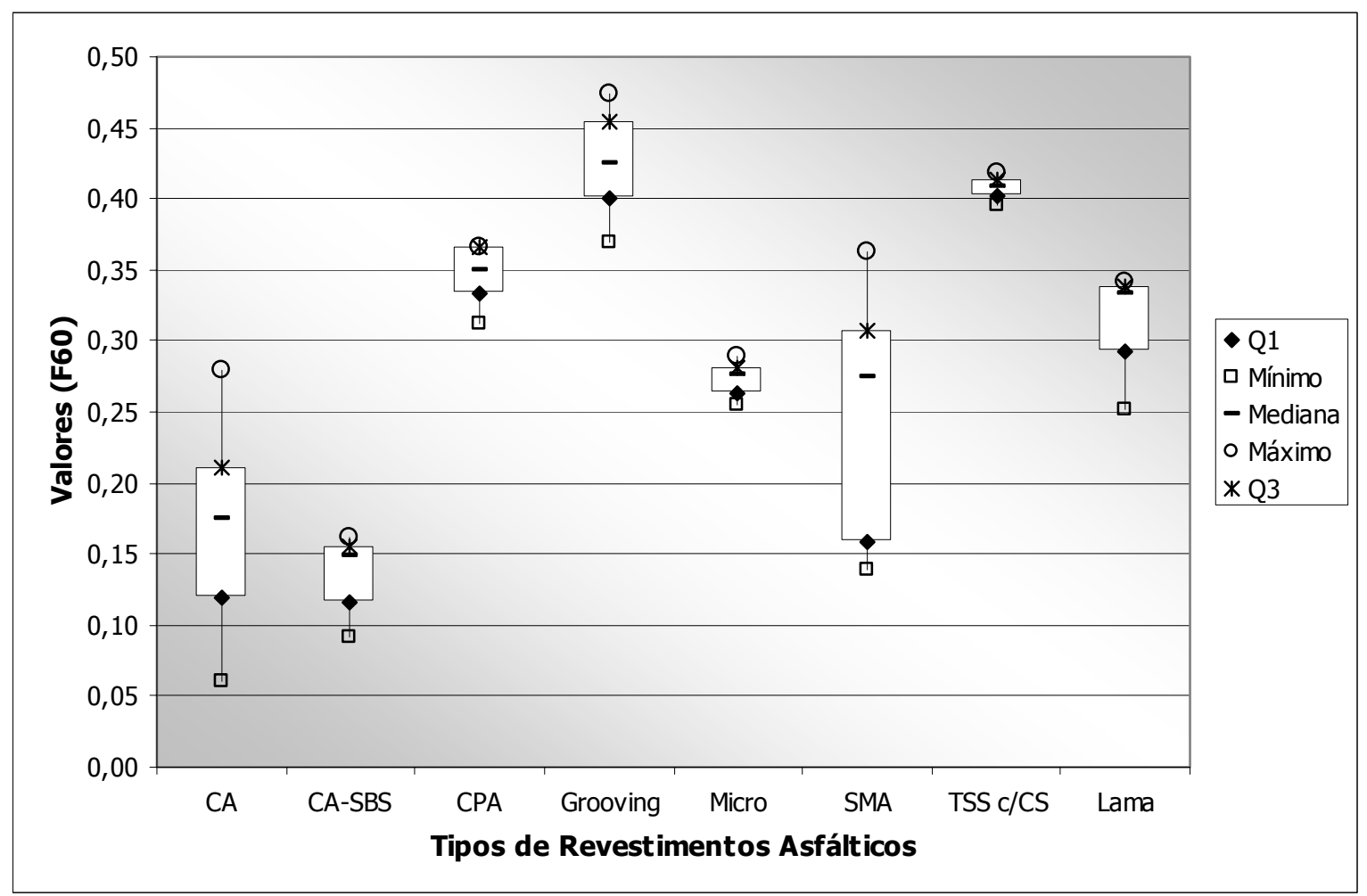

Figura 4.2.2 Boxplot dos valores de $\mathrm{F}_{60}$ para amostra treinamento

\subsection{Matrizes de Correlação e de Covariância}

Os pares de valores $\left(\mathrm{Sp}, \mathrm{F}_{60}\right)$ designam-se como sendo o IFI de um pavimento, porém as análises apresentadas a seguir serão realizadas em função do parâmetro $F_{60}$, isto porque os valores de $F_{60}$ são obtidos por meio de equação, conforme visto no Capítulo 2, que possui dependência com os valores de Sp.

Para analisar o comportamento entre os valores de campo de macrotextura (HS, $\mathrm{mm})$, de drenabilidade $(\mathrm{l} / \mathrm{s})$, de microtextura $(B P N)$ e o valor calculado de $\operatorname{IFI}\left(\mathrm{F}_{60}\right)$, foram construídas as Matrizes de Correlação Linear (Pearson), onde se pode observar a correlação das variáveis $X_{i}$ e $X_{j}$ em cada interseção linha (i) coluna (j). Para melhor entendimento desses valores foram construídas as Matrizes de Covariância cuja diagonal contém a variância da variável e cada interseção linha (i) coluna (j) a covariância das variáveis $X_{i}$ e $X_{j}$. As Tabelas de 4.3.1 a 4.3.16, apresentam os valores obtidos para essas matrizes. 
Tabela 4.3.1 Matriz de correlação linear para Concreto Asfáltico

\begin{tabular}{c|c|c|c|c}
\hline \hline Fator & $\begin{array}{c}\text { HS } \\
\mathbf{( m m )}\end{array}$ & $\begin{array}{c}\text { Drenabilidade } \\
\mathbf{( I / s )}\end{array}$ & BPN & $\mathbf{F}_{\mathbf{6 0}}$ \\
\hline HS (mm) & 1 & 0,511 & 0,251 & 0,971 \\
\hline $\begin{array}{c}\text { Drenabilidade } \\
(\mathbf{I} / \mathbf{s})\end{array}$ & 0,511 & 1 & 0,002 & 0,497 \\
\hline BPN & 0,251 & 0,002 & 1 & 0,454 \\
\hline $\mathbf{F}_{\mathbf{6 0}}$ & 0,971 & 0,497 & 0,454 & 1 \\
\hline \hline
\end{tabular}

Tabela 4.3.2 Matriz de covariância para Concreto Asfáltico

\begin{tabular}{c|c|c|c|c}
\hline Fator & $\begin{array}{c}\text { HS } \\
(\mathbf{m m})\end{array}$ & $\begin{array}{c}\text { Drenabilidade } \\
(\mathbf{I} / \mathbf{s})\end{array}$ & BPN & $\mathbf{F}_{\mathbf{6 0}}$ \\
\hline HS (mm) & 0,015 & 0,002 & 0,002 & 0,007 \\
\hline $\begin{array}{c}\text { Drenabilidade } \\
(\mathbf{I} / \mathbf{s})\end{array}$ & 0,002 & 0,001 & 0,000 & 0,001 \\
\hline BPN & 0,002 & 0,000 & 0,004 & 0,002 \\
\hline F60 & 0,007 & 0,001 & 0,002 & 0,004 \\
\hline \hline
\end{tabular}

Tabela 4.3.3 Matriz de Correlação linear para Concreto Asfáltico modificado por SBS

\begin{tabular}{c|c|c|c}
\hline Fator & HS (mm) & BPN & $\mathbf{F}_{\mathbf{6 0}}$ \\
\hline HS (mm) & 1 & $-0,123$ & 0,998 \\
\hline BPN & $-0,123$ & 1 & $-0,065$ \\
\hline $\mathbf{F}_{\mathbf{6 0}}$ & 0,998 & $-0,065$ & 1 \\
\hline \hline
\end{tabular}

Tabela 4.3.4 Matriz de covariância para Concreto Asfáltico modificado SBS

\begin{tabular}{c|c|c|c}
\hline Fator & HS (mm) & BPN & $\mathbf{F}_{60}$ \\
\hline HS (mm) & 0,003 & 0,000 & 0,002 \\
\hline BPN & 0,000 & 0,000 & 0,000 \\
\hline $\mathbf{F}_{60}$ & 0,002 & 0,000 & 0,001 \\
\hline \hline
\end{tabular}


Tabela 4.3.5 Matriz de correlação linear para Camada Porosa de Atrito

\begin{tabular}{c|c|c|c}
\hline \hline Fator & HS (mm) & BPN & $\mathbf{F}_{\mathbf{6 0}}$ \\
\hline HS (mm) & 1 & $-0,159$ & 0,447 \\
\hline BPN & $-0,159$ & 1 & 0,812 \\
\hline $\mathbf{F}_{\mathbf{6 0}}$ & 0,447 & 0,812 & 1 \\
\hline \hline
\end{tabular}

Tabela 4.3.6 Matriz de covariância para Camada Porosa de Atrito

\begin{tabular}{c|c|c|c}
\hline \hline Fator & HS (mm) & BPN & $\mathbf{F}_{\mathbf{6 0}}$ \\
\hline HS (mm) & 0,020 & $-0,001$ & 0,001 \\
\hline BPN & $-0,001$ & 0,001 & 0,001 \\
\hline $\mathbf{F}_{\mathbf{6 0}}$ & 0,001 & 0,001 & 0,000 \\
\hline \hline
\end{tabular}

Tabela 4.3.7 Matriz de correlação linear para Grooving

\begin{tabular}{c|c|c|c|c}
\hline \hline Fator & HS (mm) & $\begin{array}{c}\text { Drenabilidade } \\
\mathbf{( I / s )}\end{array}$ & BPN & $\mathbf{F}_{\mathbf{6 0}}$ \\
\hline HS (mm) & 1 & $-0,057$ & $-0,252$ & 0,734 \\
\hline $\begin{array}{c}\text { Drenabilidade } \\
\mathbf{( I / s )}\end{array}$ & $-0,019$ & 1 & 0,546 & 0,391 \\
\hline BPN & $-0,252$ & 0,546 & 1 & 0,460 \\
\hline $\mathbf{F}_{\mathbf{6 0}}$ & 0,734 & 0,391 & 0,460 & 1 \\
\hline \hline
\end{tabular}

Tabela 4.3.8 Matriz de covariância para Grooving

\begin{tabular}{c|c|c|c|c}
\hline \hline Fator & HS (mm) & $\begin{array}{c}\text { Drenabilidade } \\
(\mathbf{I} / \mathbf{s})\end{array}$ & BPN & $\mathbf{F}_{\mathbf{6 0}}$ \\
\hline HS (mm) & 0,045 & 0,000 & $-0,002$ & 0,005 \\
\hline $\begin{array}{c}\text { Drenabilidade } \\
(\mathbf{I} / \mathbf{s})\end{array}$ & 0,000 & 0,006 & 0,002 & 0,001 \\
\hline BPN & $-0,002$ & 0,002 & 0,002 & 0,001 \\
\hline $\mathbf{F}_{\mathbf{6 0}}$ & 0,005 & 0,001 & 0,001 & 0,001 \\
\hline \hline
\end{tabular}


Tabela 4.3.9 Matriz de correlação linear para Microrrevestimento Asfáltico a Frio

\begin{tabular}{c|c|c|c}
\hline Fator & HS (mm) & BPN & $\mathbf{F}_{\mathbf{6 0}}$ \\
\hline HS (mm) & 1 & $-0,369$ & 0,602 \\
\hline BPN & $-0,369$ & 1 & 0,518 \\
\hline $\mathbf{F}_{60}$ & 0,602 & 0,518 & 1 \\
\hline \hline
\end{tabular}

Tabela 4.3.10 Matriz de covariância para Microrrevestimento Asfáltico a Frio

\begin{tabular}{c|c|c|c}
\hline Fator & HS (mm) & BPN & $\mathbf{F}_{\mathbf{6 0}}$ \\
\hline HS (mm) & 0,002 & $-0,001$ & 0,000 \\
\hline BPN & $-0,001$ & 0,001 & 0,000 \\
\hline $\mathbf{F}_{60}$ & 0,000 & 0,000 & 0,000 \\
\hline \hline
\end{tabular}

Tabela 4.3.11 Matriz de correlação linear para Stone Matrix Asfhalt (SMA) - 0/11

\begin{tabular}{c|c|c|c}
\hline Fator & HS (mm) & BPN & $\mathbf{F}_{\mathbf{6 0}}$ \\
\hline HS (mm) & 1 & 0,531 & 0,839 \\
\hline BPN & 0,531 & 1 & 0,903 \\
\hline $\mathbf{F}_{60}$ & 0,839 & 0,903 & 1 \\
\hline \hline
\end{tabular}

Tabela 4.3.12 Matriz de covariância para Stone Matrix Asfhalt (SMA) - 0/11

\begin{tabular}{c|c|c|c}
\hline Fator & HS (mm) & BPN & $\mathbf{F}_{\mathbf{6 0}}$ \\
\hline HS (mm) & 0,033 & 0,012 & 0,011 \\
\hline BPN & 0,012 & 0,015 & 0,008 \\
\hline $\mathbf{F}_{60}$ & 0,011 & 0,008 & 0,005 \\
\hline \hline
\end{tabular}


Tabela 4.3.13 Matriz de correlação linear para TSD com aplicação de Capa Selante

\begin{tabular}{c|c|c|c|c}
\hline \hline Fator & $\begin{array}{c}\text { HS } \\
(\mathbf{m m})\end{array}$ & $\begin{array}{c}\text { Drenabilidade } \\
(\mathbf{I} / \mathbf{s})\end{array}$ & $\mathbf{B P N}$ & $\mathbf{F}_{\mathbf{6 0}}$ \\
\hline $\mathbf{H S}(\mathbf{m m})$ & 1 & 0,411 & 0,878 & 0,998 \\
\hline $\begin{array}{c}\text { Drenabilidade } \\
\mathbf{( I / s )}\end{array}$ & 0,411 & 1 & 0,797 & 0,349 \\
\hline $\mathbf{B P N}$ & 0,878 & 0,797 & 1 & 0,844 \\
\hline $\mathbf{F}_{\mathbf{6 0}}$ & 0,998 & 0,349 & 0,844 & 1 \\
\hline \hline
\end{tabular}

Tabela 4.3.14 Matriz de covariância para TSD com aplicação de Capa Selante

\begin{tabular}{c|c|c|c|c}
\hline \hline Fator & $\begin{array}{c}\text { HS } \\
(\mathbf{m m})\end{array}$ & $\begin{array}{c}\text { Drenabilidade } \\
(\mathbf{I} / \mathbf{s})\end{array}$ & $\mathbf{B P N}$ & $\mathbf{F 6 0} \mathbf{F}_{\mathbf{6 0}}$ \\
\hline $\mathbf{H S}(\mathbf{m m})$ & 0,038 & 0,004 & 0,000 & 0,002 \\
\hline $\begin{array}{c}\text { Drenabilidade } \\
\mathbf{( I / s )}\end{array}$ & 0,004 & 0,003 & 0,000 & 0,000 \\
\hline $\mathbf{B P N}$ & 0,000 & 0,000 & 0,000 & 0,000 \\
\hline $\mathbf{F}_{\mathbf{6 0}}$ & 0,002 & 0,000 & 0,000 & 0,000 \\
\hline \hline
\end{tabular}

Tabela 4.3.15 Matriz de correlação linear para TSS com Lama Asfáltica

\begin{tabular}{c|c|c|c|c}
\hline \hline Fator & $\begin{array}{c}\text { HS } \\
(\mathbf{m m})\end{array}$ & $\begin{array}{c}\text { Drenabilidade } \\
\mathbf{( \mathbf { s } )}\end{array}$ & $\mathbf{B P N}$ & $\mathbf{F}_{\mathbf{6 0}}$ \\
\hline HS (mm) & 1 & 0,995 & 0,596 & 0,999 \\
\hline $\begin{array}{c}\text { Drenabilidade } \\
\mathbf{( I / s )}\end{array}$ & 0,995 & 1 & 0,514 & 0,998 \\
\hline $\mathbf{B P N}$ & 0,596 & 0,514 & 1 & 0,567 \\
\hline $\mathbf{F}_{\mathbf{6 0}}$ & 0,999 & 0,998 & 0,567 & 1 \\
\hline \hline
\end{tabular}


Tabela 4.3.16 Matriz de covariância para TSS com Lama Asfáltica

\begin{tabular}{c|c|c|c|c}
\hline \hline Fator & $\begin{array}{c}\text { HS } \\
\mathbf{( m m})\end{array}$ & $\begin{array}{c}\text { Drenabilidade } \\
(\mathbf{I} / \mathbf{s})\end{array}$ & $\mathbf{B P N}$ & $\mathbf{F}_{\mathbf{6 0}}$ \\
\hline $\mathbf{H S} \mathbf{( m m )}$ & 0,032 & 0,007 & 0,000 & 0,007 \\
\hline $\begin{array}{c}\text { Drenabilidade } \\
(\mathbf{I} / \mathbf{s})\end{array}$ & 0,007 & 0,002 & 0,000 & 0,002 \\
\hline $\mathbf{B P N}$ & 0,000 & 0,000 & 0,000 & 0,000 \\
\hline $\mathbf{F}_{\mathbf{6 0}}$ & 0,007 & 0,002 & 0,000 & 0,002 \\
\hline \hline
\end{tabular}

Não foram construídas as Matrizes de Correlação Linear (Pearson) e de Covariância para os revestimentos do tipo Areia Asfalto (AA), Stone Matrix Asfhalt (SMA) - 0/16 e Tratamento Superficial (TS), pois o primeiro apresenta duas observações e outros dois tipos apenas uma observação cada. Vale ressaltar que o revestimento do tipo Concreto Asfáltico modificado por Borracha (CA bor) não faz parte da Amostra Treinamento, portanto os valores referentes a este tipo serão analisados na Amostra Estudo de Caso, no Capítulo 5.

Analisando-se os coeficientes de correlação encontrados entre os ensaios de Mancha de Areia (HS, mm) e Drenabilidade (I/s) extraídos das matrizes apresentadas anteriormente observou-se dispersão entre os valores. Essa dispersão pode indicar limitações no ensaio de Drenabilidade para alguns tipos de textura.

Conforme observado na Tabela 4.3.17 o ensaio de Drenabilidade nesta pesquisa, é válido para pavimentos asfálticos que apresentem textura variando entre fina e grossa, estando a grande maioria dos valores na classe média. A correlação pode não ser válida para revestimentos cujas texturas são muito grossas (abertas), como mostra a Tabela 4.3.17; isto ocorre da mesma forma para as texturas muito fechadas ou muito finas, como será visto no Capítulo 5. Estes resultados corroboram com aqueles encontrados por Ferreira (2002), que constatou em sua pesquisa de Mestrado que esse ensaio não é indicado para pavimentos asfálticos cujas texturas são fechadas ou muito abertas. 
Tabela 4.3.17 Correlação linear entre o ensaio de Mancha de Areia e Drenabilidade

\begin{tabular}{l|c|l|l}
\hline \multicolumn{1}{c|}{ Tipo } & \multicolumn{2}{|c|}{ Correlação Linear } & \multicolumn{1}{c}{ Classificação } \\
\hline Grooving & $-0,019$ & negativa de fraca a inexistente & grossa a muito grossa \\
\hline TSS com CS & 0,411 & positiva de fraca a média & muito grossa \\
\hline Concreto Asfáltico & 0,511 & positiva média & média a fina \\
\hline Lama Asfáltica & 0,995 & positiva forte & média a grossa \\
\hline \hline
\end{tabular}

Na Tabela 4.3.18 são apresentados os coeficientes de correlação encontrados entre os ensaios de Mancha Areia (HS, mm) e os ensaios de atrito por meio do Pêndulo Britânico (BPN) em função do parâmetro IFI $\left(\mathrm{F}_{60}\right)$ extraídos das matrizes apresentadas anteriormente.

Observa-se que a correlação entre o ensaio de Mancha de Areia com o valor de IFI $\left(F_{60}\right)$ calculado é positiva e forte e a correlação existente entre os valores obtidos de atrito por meio do Pêndulo Britânico e os valores calculados de IFI $\left(\mathrm{F}_{60}\right)$ são inferiores variando de fraca a média, na maioria dos casos; sabendo-se que os valores de IFI $\left(\mathrm{Sp} ; \mathrm{F}_{60}\right)$ são obtidos a partir de dados de textura e de atrito, pode-se inferir, para estes dados, que o valor de IFI está mais afetado pela variação dos valores de textura do que pelos valores de atrito medido pelos equipamentos padronizados nessa norma.

Tabela 4.3.18 Correlação linear entre os valores de $F_{60}$ (calculados) e os valores obtidos em campo de HS ( $\mathrm{mm}$ ) e BPN

\begin{tabular}{l|l|l|c|l}
\hline \multirow{2}{*}{\begin{tabular}{c}
\multirow{2}{*}{ Tipo de } \\
Revestimento
\end{tabular}} & \multicolumn{2}{c|}{ HS (mm) } & \multicolumn{2}{c}{ BPN } \\
\cline { 2 - 5 } & \multicolumn{2}{c|}{ Correlação Linear } & \multicolumn{2}{c}{ Correlação Linear } \\
\hline Lama Asfáltica & 0,999 & positiva forte & 0,567 & positiva média \\
\hline CA mod SBS & 0,998 & positiva forte & $-0,065$ & negativa fraca a inexistente \\
\hline TSS com CS & 0,998 & positiva forte & 0,844 & positiva forte \\
\hline Concreto Asfáltico & 0,971 & positiva forte & 0,454 & positiva fraca a média \\
\hline SMA faixa alemã D0-16 & 0,839 & positiva forte & 0,903 & positiva forte \\
\hline Grooving & 0,734 & positiva média a forte & 0,460 & positiva de fraca a média \\
\hline Microrrevestimento & 0,602 & positiva média & 0,518 & positiva média \\
\hline Camada Porosa Atrito & 0,447 & positiva fraca a média & 0,812 & positiva forte \\
\hline \hline
\end{tabular}


Observa-se na tabela 4.3.18 a correlação de média a forte para todos os tipos de revestimentos asfálticos estudados, exceto para o tipo CPA que apresentou uma correlação fraca; os resultados do ensaio de mancha de areia em revestimentos drenantes são distorcidos devido à penetração excessiva dos grãos da areia nos poros vazios resultando em manchas de diâmetro menores e maximizando a altura da areia, diferentes dos canais de drenagem superficiais. De acordo com o exposto neste item está verificada a correlação entre os valores de macrotextura (HS) e os valores de microtextura (BPN) com os valores de $\operatorname{IFI}\left(\mathrm{F}_{60}\right)$.

De um modo geral, analisando-se as diagonais das Matrizes de Covariância onde são apresentadas as variâncias das variáveis, pode-se observar a homogeneidade entre os valores de cada variável. Por sua vez observando-se os valores das covariâncias, verifica-se a variabilidade baixa entre as variáveis.

\subsection{Faixas de Classificação de Valores de $\operatorname{IFI}\left(\mathrm{F}_{60}\right)$}

Conforme observado anteriormente, por meio da interpretação das matrizes de correlação e covariância, foi verificada a existência de correlação entre os valores de macrotextura (HS) e os valores de microtextura (BPN) com os valores de IFI ( $\left.\mathrm{F}_{60}\right)$ calculados. Este trabalho propõe faixas de classificação para os valores de IFI (Sp; $\mathrm{F}_{60}$ ) com base nas propriedades estudadas de macrotextura e microtextura, na interpretação dos resultados obtidos e coletados de valores reais de campo, e na experiência pratica da avaliação de pavimentos.

Para a definição das faixas de classificação deste índice, inicialmente foram consideradas cinco faixas de classificação, péssimo, ruim, regular, bom e ótimo, conforme pode ser observado na Tabela 4.4.1 e 4.4.2 Faixas Propostas $1^{\text {a }}$ e $2^{\underline{a}}$ Tentativa. 
Tabela 4.4.1 Faixas propostas $1^{\underline{a}}$ Tentativa (Aps et al.,2004-a)

\begin{tabular}{l|c|c}
\hline \hline \multicolumn{2}{c}{ Limites IFI(Enacor, 2004) } \\
\hline Péssimo & \multicolumn{2}{|c}{$<0,06$} \\
\hline Ruim & 0,06 & 0,10 \\
\hline Regular & 0,11 & 0,16 \\
\hline Bom & 0,17 & 0,30 \\
\hline Ótimo & \multicolumn{2}{|c}{$>0,30$} \\
\hline \hline
\end{tabular}

Tabela 4.4.2 Faixas propostas $2^{\underline{a}}$ Tentativa (Aps et al.,2004-b)

\begin{tabular}{l|c|c}
\hline \multicolumn{3}{c}{ Limites IFI (IBP, 2004) } \\
\hline Péssimo & \multicolumn{2}{c}{$<0,06$} \\
\hline Ruim & 0,06 & 0,12 \\
\hline Regular & 0,13 & 0,16 \\
\hline Bom & 0,17 & 0,30 \\
\hline Ótimo & \multicolumn{2}{|c}{$>0,30$} \\
\hline \hline
\end{tabular}

Posteriormente, decidiu-se adotar sete faixas, péssimo, muito ruim, ruim, regular, bom, muito bom e ótimo, consideradas adequadas ${ }^{2}$ para o caso brasileiro, conforme pode ser visto na Tabela 4.4.3 Faixas Propostas $3^{\mathrm{a}}$ Tentativa.

Tabela 4.4.3 Faixas propostas $3^{\text {a }}$ Tentativa (Aps et al.,2005)

\begin{tabular}{l|c|c}
\hline \multicolumn{3}{c}{ Limites IFI (ARTESP, 2005) } \\
\hline Péssimo & \multicolumn{2}{c}{$<0,06$} \\
\hline Muito Ruim & 0,06 & 0,07 \\
\hline Ruim & 0,08 & 0,10 \\
\hline Regular & 0,11 & 0,14 \\
\hline Bom & 0,15 & 0,23 \\
\hline Muito Bom & 0,24 & 0,34 \\
\hline Ótimo & \multicolumn{2}{|c}{$>0,34$} \\
\hline \hline
\end{tabular}

As Faixas de classificação dos valores de $\operatorname{IFI}\left(\mathrm{F}_{60}\right)$, sugeridas nesta pesquisa estão na 4- Tentativa; as alterações foram ocorrendo consequentemente com o crescimento do Banco de Dados e com o refinamento das análises estatísticas, de modo a atender a necessidade de aumento para sete categorias de classificação. Inicialmente, para a elaboração dessas faixas foram calculados valores teóricos de $\mathrm{Sp}$ e $F_{60}$, com base na classificação de valores de macrotextura por meio do ensaio de

\footnotetext{
${ }^{2}$ Sugestão Dr. Octávio de Souza Campos da Agência de Transportes do Estado de São Paulo ARTESP.
} 
Mancha de Areia e de microtextura realizado com o Pendulo Britânico, conforme Tabela 2.6.1.1.1 e 2.6.1.2.1, respectivamente apresentadas no Capítulo 2.

Para melhor ajuste foi necessária a incorporação de mais duas faixas na classificação da Mancha de Areia para tornar compatível o número de faixas para o Pêndulo Britânico, conforme pode ser observado na Tabela 4.4.4. O valor de 0,6mm criado além de ser o valor médio entre 0,40 e 0,80 mm, que corresponde à faixa média de macrotextura, é o limite mínimo da faixa de mancha de areia recomendada pela ARTESP para os pavimentos da rede concessionada estadual paulista.

Tabela 4.4.4 Classificação da macrotextura com ampliação para sete categorias

\begin{tabular}{l|c}
\hline \multicolumn{2}{c}{ Mancha de Areia } \\
CLASSIFICAÇÃO & LIMITES \\
\hline MUITO FINA & $<0,20$ \\
\hline FINA & $0,20<\mathrm{HS} \leq 0,40$ \\
\hline MEDIANAMENTE FINA & $\mathbf{0 , 4 0}<\mathrm{HS} \leq \mathbf{0 , 6 0}$ \\
\hline MÉDIA & $0,60<\mathrm{HS} \leq 0,80$ \\
\hline MEDIANAMENTE GROSSA & $\mathbf{0 , 8 0}<\mathbf{H S ~} \leq \mathbf{1 , 0}$ \\
\hline GROSSA & $1,00<\mathrm{HS} \leq 1,2$ \\
\hline MUITO GROSSA & $>1,20$ \\
\hline \hline
\end{tabular}

Posteriormente foram recalculados os valores de IFI $\left(\mathrm{Sp} ; \mathrm{F}_{60}\right)$ para os limites das faixas de macrotextura (Tabela 4.4.4) e microtextura (Tabela 2.6.1.2.1), e verificouse que esses valores não resultaram em faixas apropriadas. Os valores foram ajustados com base na experiência de campo resultando na $1^{\underline{a}}$ Tentativa. Com a ampliação de valores do Banco de Dados, os procedimentos foram repetidos, conforme apresentado na $2^{\mathrm{a}}$ Tentativa e $3^{\mathrm{a}}$ Tentativa, cujos valores sugeridos se enquadram para a maioria dos casos, conforme visto na Figura 4.4.1.

A Figura 4.4.1 apresenta as retas da regressão linear, as equações, os coeficientes de correlação de cada reta para a amostra treinamento e os valores da $3^{\text {a }}$ Tentativa (Limites aceitáveis), respectivamente; embora esses coeficientes indiquem forte correlação as duas retas não estão paralelas. 


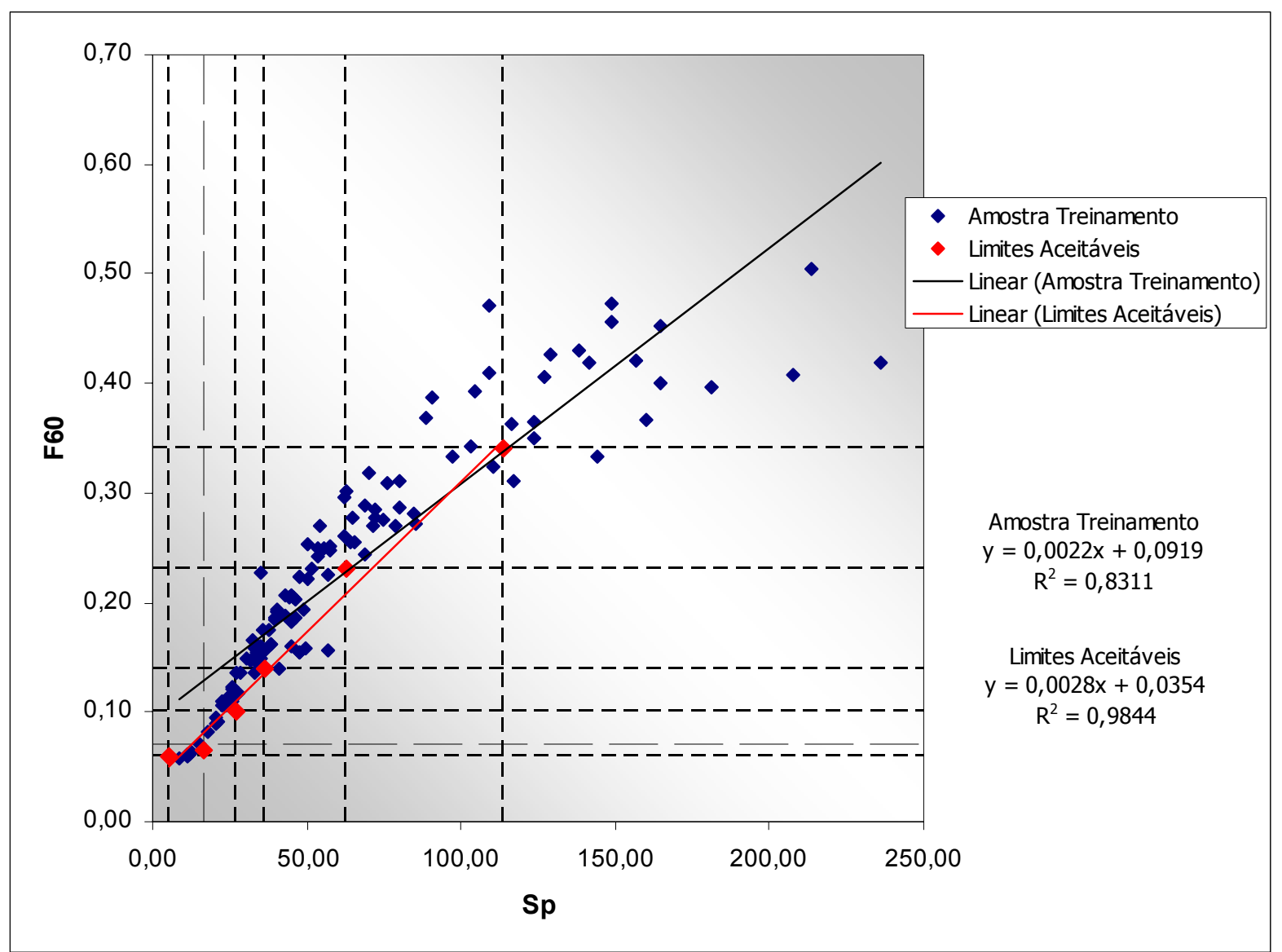

Figura 4.4.1 Valores da amostra treinamento e faixas de classificação da $3^{\text {a }}$ Tentativa (Limites aceitáveis)

A Figura 4.4.2 apresenta os coeficientes de regressão das duas retas, uma obtida a partir dos dados de campo (amostra treinamento), excluindo-se os valores de $F_{60}$ superiores a 0,34 para refinar a análise, e a outra reta construída com a faixa de valores aceitáveis ${ }^{3}$ propostos na $3^{\mathrm{a}}$ Tentativa. Este tipo de comparação serviu para verificar estatisticamente se a inclinação das duas retas e o coeficiente de correlação correspondente apresentam a mesma tendência.

O coeficiente de correlação avalia o grau de relacionamento entre causa e efeito de um fenômeno qualquer (Campos 2006); portanto, os dois coeficientes de correlação comprovam a forte correlação entre Sp e F60. A inclinação das retas é idêntica,

\footnotetext{
3 De acordo com Wambold et al., (2005) deve-se trabalhar com a expressão "valores aceitáveis" porque é necessário que sejam valores distintos de acordo com o tipo de classe da rodovia.
} 
mostrando que a tendência de variação da amostra treinamento é a mesma dos limites aceitáveis.

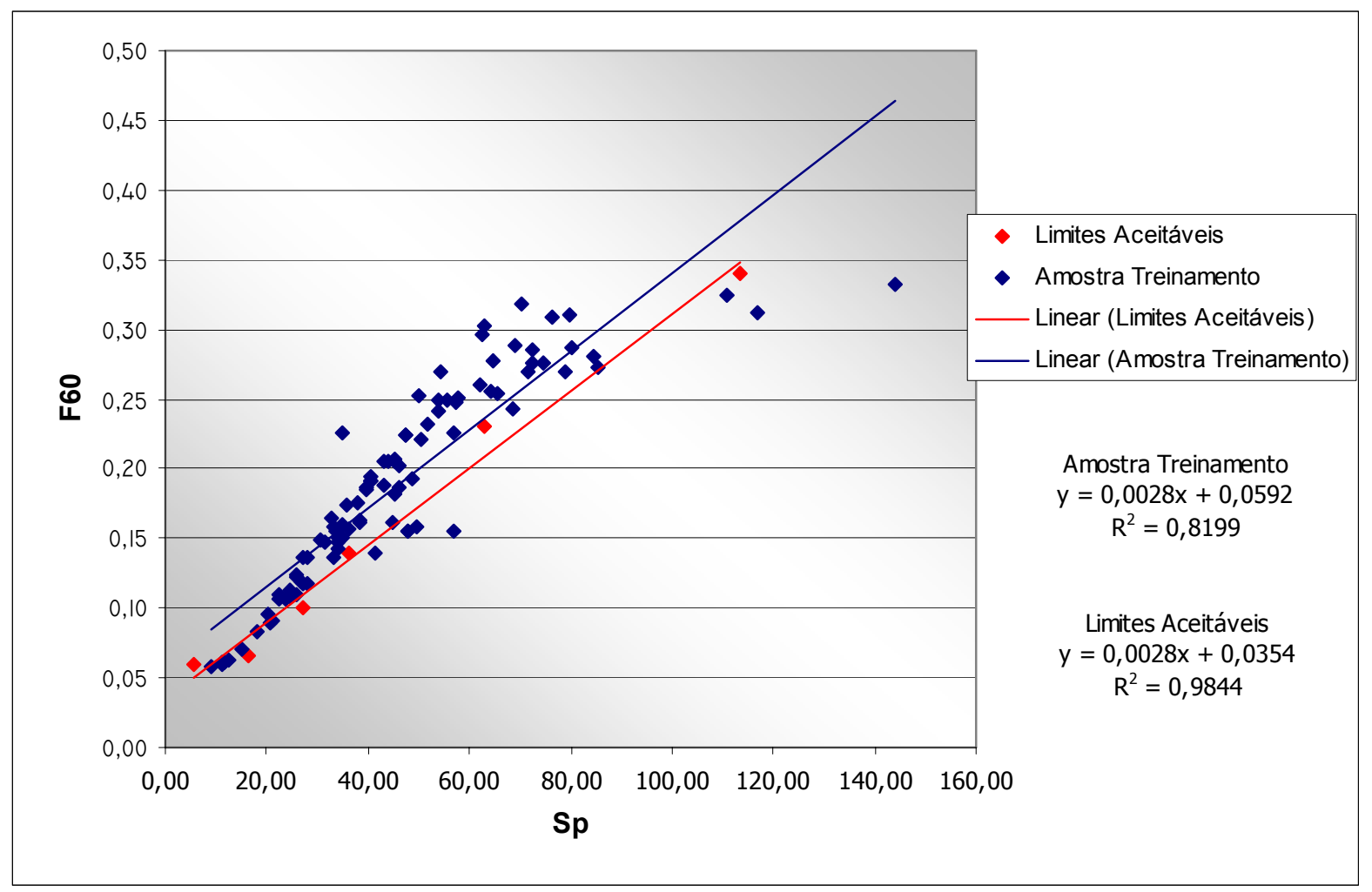

Figura 4.4.2 Amostra treinamento com valores $F_{60}$ até 0,34

Buscando-se a equação linear que descreve a amostra e comparando com a equação que descreve os valores das faixas de classificação pode-se observar a similaridade entre elas; usando a equação dos valores das faixas de classificação e recalculando os valores de $F_{60}$, para os mesmos valores de $S p$ (Anexo 1 ), ajusta-se a faixa de classificação apresentada na Tabela 4.4.5, denominada $4^{\text {a }}$ Tentativa.

Tabela 4.4.5 Faixas propostas $4^{\mathrm{a}}$ Tentativa

\begin{tabular}{l|c|c}
\hline \hline \multicolumn{3}{c}{ Limites IFI } \\
\hline Péssimo & \multicolumn{2}{c}{$<0,05$} \\
\hline Muito Ruim & 0,06 & 0,08 \\
\hline Ruim & 0,09 & 0,11 \\
\hline Regular & 0,12 & 0,14 \\
\hline Bom & 0,15 & 0,21 \\
\hline Muito Bom & 0,22 & 0,35 \\
\hline Ótimo & \multicolumn{2}{|c}{$>0,35$} \\
\hline \hline
\end{tabular}


A Figura 4.4.3 apresenta os limites da 4 $4^{\text {a }}$ Tentativa (limites aceitáveis) e todos os valores da amostra treinamento. Comparando as faixas de variação de cada tipo de revestimento asfáltico que compõem esta amostra (treinamento), observa-se que estes valores estão bem inseridos e refletem a realidade nesta classificação proposta. Resumidamente a Tabela 4.4.6 apresenta os valores mínimos, máximos e as medianas para cada tipo de revestimento asfáltico.

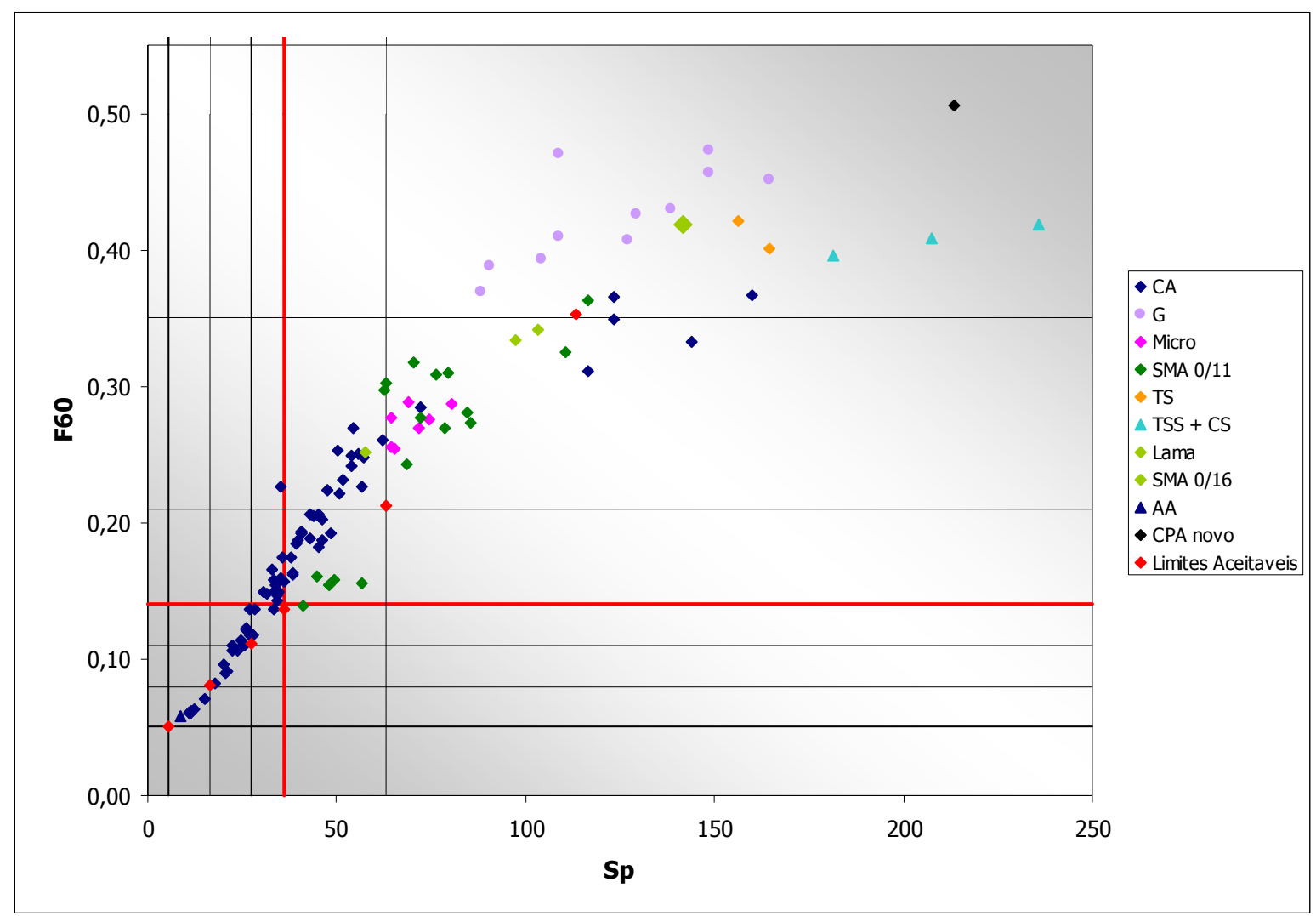

Figura 4.4.3 Amostra treinamento e limites aceitáveis

Tabela 4.4.6 Faixas de variação $\left(F_{60}\right)$ para a amostra treinamento

\begin{tabular}{|c|c|c|c|}
\hline \multirow{2}{*}{$\begin{array}{c}\text { Tipo } \\
\text { Revestimento Asfáltico }\end{array}$} & \multicolumn{3}{|c|}{ Valores } \\
\hline & Mínimo & Mediana & Máximo \\
\hline Areia Asfalto & \multicolumn{3}{|c|}{$0,06 *$} \\
\hline Concreto Asfáltico & 0,06 & 0,17 & 0,28 \\
\hline CA mod SBS & 0,09 & 0,15 & 0,16 \\
\hline SMA faixa alemã D0-11S & 0,14 & 0,27 & 0,36 \\
\hline Lama Asfáltica & 0,25 & 0,33 & 0,34 \\
\hline Microrrevestimento Asfáltico a Frio & 0,25 & 0,28 & 0,29 \\
\hline Camada Porosa de Atrito & 0,31 & 0,35 & 0,37 \\
\hline Grooving & 0,37 & 0,43 & 0,47 \\
\hline TSS com CS & 0,40 & 0,41 & 0,42 \\
\hline Tratamento Superficial & 0,40 & 0,41 & 0,42 \\
\hline SMA faixa alemã D0-16 & \multicolumn{3}{|c|}{$0,42^{*}$} \\
\hline
\end{tabular}

*Observação unitária 
Pode-se observar que os revestimentos que apresentam valores mais elevados de $F_{60}$ são os revestimentos tipo Grooving, Tratamento Superficial, Tratamento Superficial com Capa Selante, SMA faixa alemã D0-16 e Camada Porosa de Atrito; os valores das medianas, para esses revestimentos, variaram entre 0,35 e 0,42, o que corrobora com as Faixas Propostas na 4ํㅜTentativa onde estes pavimentos estariam dentro da classificação ótima e com a experiência prática na avaliação de pavimentos asfálticos.

O revestimento asfáltico a quente convencionalmente mais adotado no Brasil, o Concreto Asfáltico, cujos valores de $F_{60}$ variam entre 0,06 e 0,28, também correspondem ao observado em campo, onde foram avaliadas superfícies logo após a execução, com um, dois e até 10 anos de vida de serviço. Incluem-se concretos asfálticos executados por prefeituras que trabalham normalmente com a curva granulométrica mais fechada, até por órgãos que procuram graduações com tendência mais aberta, como os aeroviários. Repetindo-se a análise para este tipo de revestimento, verificou-se que todos permanecem enquadrados nesta classificação.

Em função da variedade de locais e de vida de serviço destes revestimentos, foi elaborada a Figura 4.4.4 que apresenta estes dados, a procedência e o tempo de serviço, com a classificação variando de muito ruim a muito bom.

Observa-se que há uma leve tendência de revestimentos mais antigos apresentarem uma macrotextura mais aberta que os mais novos. Embora estas características dependam intrinsecamente da graduação e da dosagem do teor de ligante, com a ação do tráfego e das intempéries, ocorre a remoção do mástique asfáltico deixando os agregados mais expostos e aumentando, consequentemente, a macrotextura. De forma similar, a perda de agregados ou desagregação torna a superfície mais rugosa ou mais aberta. Esta constatação de variação das características de macrotextura com o tempo somente pode ser afirmada com um monitoramento constante desde o início de uma obra até o momento de sua restauração. 


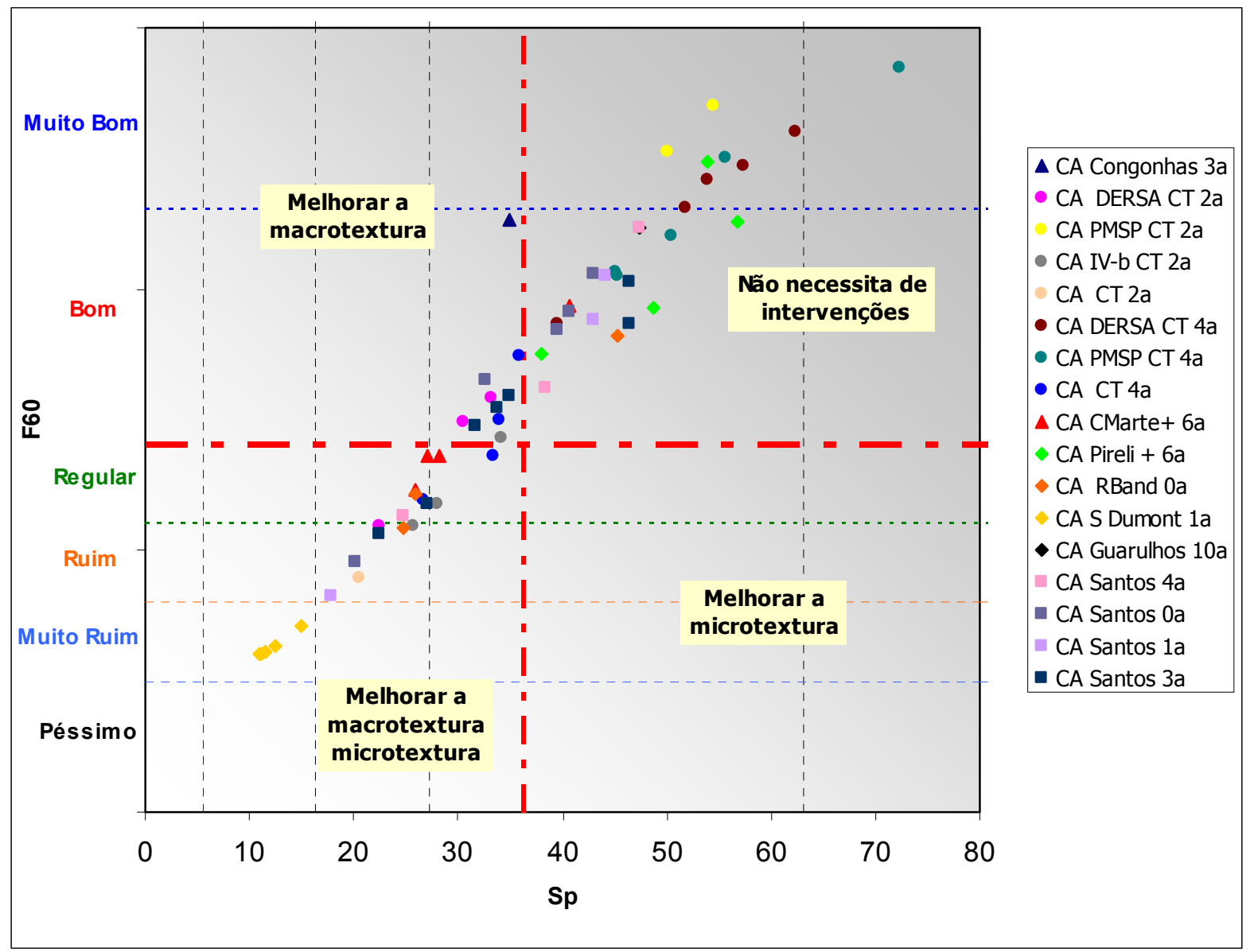

Figura 4.4.4 Dados referentes a valores de Concreto Asfáltico convencional

A Tabela 4.4.7 apresenta os valores calculados de IFI $\left(\mathrm{Sp} ; \mathrm{F}_{60}\right)$ para as políticas existentes no país de aderência que foram apresentadas em forma de normas ou de recomendações no Capítulo 2 e que têm por objetivo quantificar e qualificar, por meio dos diversos ensaios e metodologias existentes, os valores admissíveis visando à segurança. Esses cálculos permitem observar o nível de exigência desses órgãos. As recomendações para os valores de $\mathrm{Hs}(\mathrm{mm})$ são coincidentes, ou seja, variação entre 0,60 e 1,20mm, e para os valores de microtextura variam de 45 a 75 .

No Manual de Restauração de Pavimentos Asfálticos, recentemente publicado (DNIT, 2006), recomenda-se o uso de microtextura rugosa com o limite mínimo de BPN de 55 , o que representa um ganho em relação à segurança, pois esses revestimentos quando combinados com o valor máximo recomendado para a macrotextura $(1,20 \mathrm{~mm})$ já estão classificados como ótimos $(0,35)$. Esta recomendação do DNIT foi escolhida como sendo o limite da $4^{a}$ Tentativa para a classe ótima. 
Tabela 4.4.7 Valores de IFI (Sp; $\left.F_{60}\right)$ para recomendações do DNIT e da ARTESP

\begin{tabular}{|c|c|c|c|c|c|c|}
\hline \multirow{2}{*}{ Órgão } & \multirow{2}{*}{ Publicação } & \multirow{2}{*}{$H s=T x$} & Media & \multirow{2}{*}{ Sp } & \multirow{2}{*}{ FR-60 } & \multirow{2}{*}{ Conceito } \\
\hline & & & FRS & & & \\
\hline DNIT & 2000 & 0,60 (mín) & 47 (mín) & 56,56 & 0,21 & мUIто вом \\
\hline DNIT & 2000 & 1,20 (máx) & 47 (mín) & 124,72 & 0,31 & мUIто вом \\
\hline DNIT & 2000 & 0,60 (mín) & 75 (máx) & 56,56 & 0,30 & мUIто вом \\
\hline DNIT & 2000 & 1,20 (máx) & 75 (máx) & 124,72 & 0,46 & ÓтIм0 \\
\hline DNIT & 2004 & 0,60 (mín) & 45 (mín) & 56,56 & 0,20 & BOM \\
\hline DNIT & 2004 & 1,20 (máx) & 45 (mín) & 124,72 & 0,30 & мUIто вом \\
\hline DNIT & 2006 & 0,60 (mín) & 55 (mín) & 56,56 & 0,24 & MUITO вом \\
\hline DNIT & 2006 & 1,20 (máx) & 55 (mín) & 124,72 & 0,35 & о́тім0 \\
\hline ARTESP & diversas & 0,60 (mín) & 47 & 56,56 & 0,21 & MUIто вом \\
\hline ARTESP & diversas & 1,20 (máx) & 47 & 124,72 & 0,31 & мUIто вом \\
\hline
\end{tabular}

Para validar esta $4^{\mathfrak{a}}$ Tentativa as mesmas análises anteriormente realizadas foram repetidas para a amostra denominada nesta pesquisa de Grupo de Controle, que estão apresentadas no Capítulo 5. A classificação para todos os tipos de superfícies asfálticas apresentadas no Capitulo 3, baseada na $4^{\mathrm{a}}$ Tentativa, está demonstrada no Anexo 2.

O item 4.5 a seguir apresenta-se um estudo sobre o efeito da variação da forma, natureza e granulometria do material na realização do ensaio de Mancha de Areia, pois os valores de IFI $\left(\mathrm{Sp} ; \mathrm{F}_{60}\right)$ têm forte dependência deste ensaio.

\subsection{Efeito da Variação da Granulometria da Areia ou Micro Esfera de Vidro na Determinação da Macrotextura por meio do Ensaio ASTM E 965-96}

Após a verificação da granulometria de micros esferas de vidro, originada de diversos fabricantes, foi observada que as mesmas não atendiam a curva estabelecida pela Norma ASTM E 965-96 (2001) e era necessário realizar o peneiramento para ajustar a curva desejada. $\mathrm{O}$ objetivo dessa pesquisa foi verificar se a Areia Normal Brasileira 
pode ser uma alternativa pela sua facilidade de obtenção atendo aos requisitos especificados em norma. De acordo com a especificação da norma ASTM E 965-96 (2001) Standard Test Method for Measuring Surface Macro Texture Depth Using a Volumetric Technique, foram realizados ensaios com o objetivo de verificar a validade da utilização de outro tipo de areia distinta daquela recomendada pela norma.

A ASTM E 965-96 (2001) recomenda que seja utilizado como material micro esferas de vidro de acordo com o procedimento ASTM D1155 (mínimo 90\% de esfericidade) com 90\% de material passando na peneira de abertura 0,25 mm (\# n-60) e ficando retido na peneira de abertura $0,177 \mathrm{~mm}$ ( \# $\mathrm{n}^{0} 80$ ). Nesta pesquisa foram utilizados três tipos distintos de material:

1) Micro esferas de vidro de acordo com a recomendação da ASTM;

2) Areia Normal Brasileira de acordo com a granulometria recomendada pela ASTM;

3) Areia Normal Brasileira em uma das granulometrias produzidas comercialmente, ou seja, areia passando na peneira de abertura $0,3 \mathrm{~mm}$ (\# $\mathrm{n}^{\circ} 50$ ) e ficando retido na peneira de abertura 0,149 mm (\# $\mathrm{n}$-100).

A característica da forma dos grãos observada em microscópio eletrônico pode ser observada na Figura 4.5.1.

A Areia Normal Brasileira, produzida há aproximadamente 30 anos pelo IPT, é uma areia padrão para execução de ensaio de resistência à compressão de cimento Portland, conforme preconiza a norma NBR 7215/96 Cimento Portland Determinação da resistência à compressão; é regulamentada pela norma NBR 7214 "Areia Normal para ensaio de cimento", que fixa as características necessárias da matéria-prima, sua origem, procedimentos de produção, ensaios de caracterização e o controle do produto, por meio de análises diárias e semanais tais como amostragem, granulometria, índice de matéria orgânica, índice de materiais pulverulento, análise petrográfica, entre outros. 


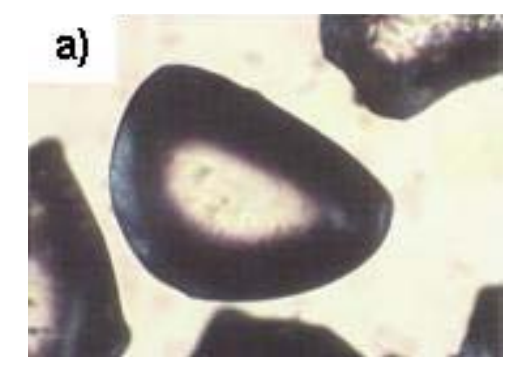

b)

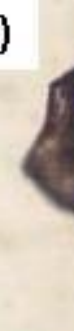

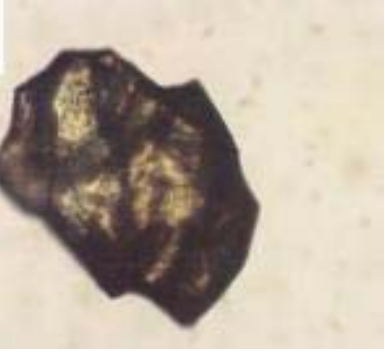

c)

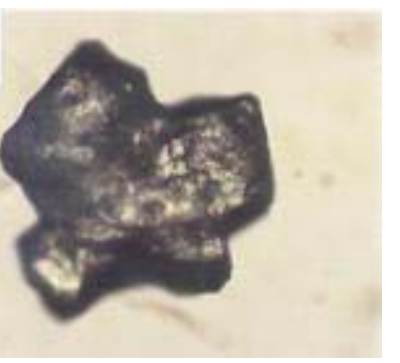

Figura 4.5.1 Características da forma dos grãos: a) Micro esfera de vidro; b) Areia Normal Brasileira; c) Areia comum

O local selecionado para a pesquisa foi o Corredor Tecnológico, cujos detalhes estão apresentados no Capítulo 3, que possui cinco tipos de revestimentos asfáltico: Concreto Asfáltico convencional na faixa III da Prefeitura do Município de São Paulo (CAP 20), Concreto Asfáltico convencional na faixa B do DERSA (CAP 20), Concreto Asfáltico convencional na faixa IV-b do Instituto do Asfalto norte-americano (CAP 20), Concreto Asfáltico com asfalto modificado por polímero na faixa IV-b do Instituto do Asfalto norte-americano (CAP modificado com $S B S$ ) e $S M A$ com asfalto modificado por polímero na faixa alemã D 0-11 (CAP modificado com SBS).

No Delineamento do Experimento foi estabelecido: que os ensaios seriam realizados por único operador, em cinco diferentes tipos de superfícies, quatro repetições por tipo de superfície e três tipos diferentes de areia.

Primeiramente foram selecionados visualmente trechos homogêneos para cada seção de pavimento, e estas áreas foram marcados com giz para que todos os ensaios fossem realizados no mesmo local. Após a realização do procedimento para um tipo de areia, a superfície era cuidadosamente limpa e o procedimento repetido exatamente no mesmo local, conforme pode ser visto na Figura 4.5.2. Os resultados obtidos com os valores dos diâmetros e as alturas médias calculadas estão apresentados nas Tabelas 4.5.1 e 4.5.2. 

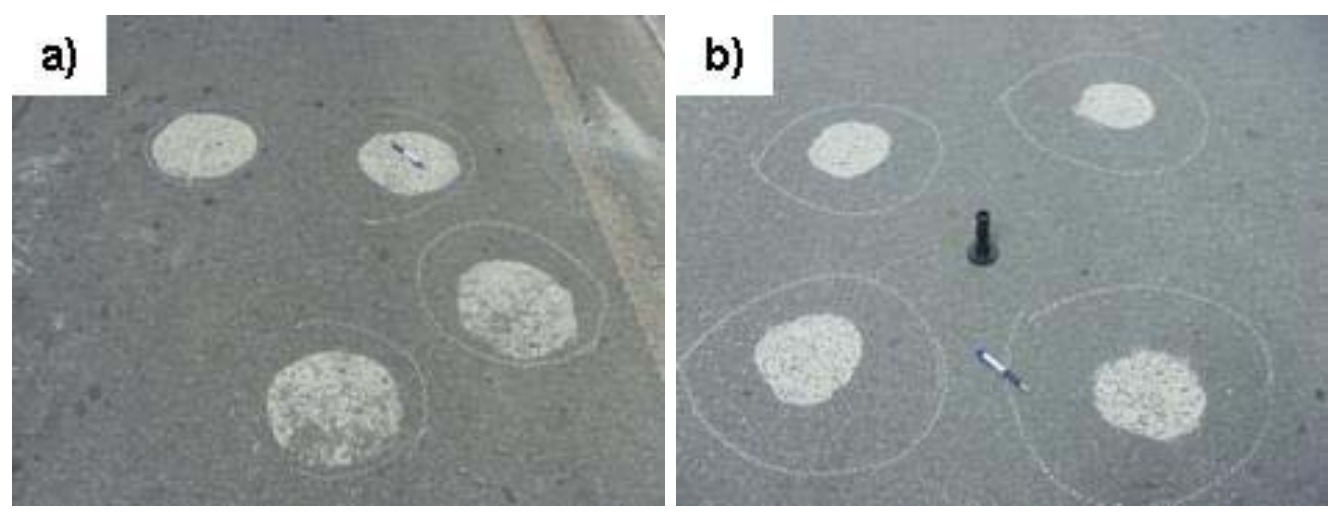

Figura 4.5.2 Seleção de trechos homogêneos

Tabela 4.5.1 Resultados obtidos para micro esferas de vidro

\begin{tabular}{|c|c|c|c|c|c|c|c|}
\hline \multirow{2}{*}{\multicolumn{2}{|c|}{$\begin{array}{l}\text { Tipos de } \\
\text { revestimentos }\end{array}$}} & \multicolumn{6}{|c|}{ Microesfera \# 60-80 } \\
\hline & & D1 & D2 & D3 & D4 & Dm & HS \\
\hline \multirow{5}{*}{1} & \multirow{5}{*}{$\begin{array}{l}\text { CA convencional na } \\
\text { faixa III da PMSP }\end{array}$} & 255 & 258 & 242 & 253 & 252,0 & 0,50 \\
\hline & & 226 & 222 & 230 & 250 & 232,0 & 0,59 \\
\hline & & 250 & 243 & 247 & 225 & 241,3 & 0,55 \\
\hline & & 200 & 215 & 210 & 205 & 207,5 & 0,74 \\
\hline & & 240 & 265 & 245 & 260 & 252,5 & 0,50 \\
\hline \multirow{5}{*}{2} & \multirow{5}{*}{$\begin{array}{l}\text { CA convencional na } \\
\text { faixa } B \text { do DERSA }\end{array}$} & 220 & 223 & 222 & 220 & 221,3 & 0,65 \\
\hline & & 225 & 241 & 228 & 222 & 229,0 & 0,61 \\
\hline & & 230 & 240 & 225 & 245 & 235,0 & 0,58 \\
\hline & & 265 & 270 & 260 & 268 & 265,8 & 0,45 \\
\hline & & 225 & 245 & 246 & 240 & 239,0 & 0,56 \\
\hline \multirow{4}{*}{3} & CA com asfalto & 300 & 270 & 274 & 290 & 283,5 & 0,40 \\
\hline & convencional na & 290 & 280 & 264 & 270 & 276,0 & 0,42 \\
\hline & faixa IV-b do & 305 & 275 & 288 & 260 & 282,0 & 0,40 \\
\hline & Instituto do Asfalto & 333 & 300 & 310 & 287 & 307,5 & 0,34 \\
\hline \multirow{4}{*}{4} & CA com asfalto & 280 & 265 & 280 & 274 & 274,8 & 0,42 \\
\hline & mod por polímero & 291 & 285 & 265 & 275 & 279,0 & 0,41 \\
\hline & na faixa IV-b do & 266 & 278 & 264 & 266 & 268,5 & 0,44 \\
\hline & Instituto do Asfalto & 294 & 266 & 275 & 290 & 281,3 & 0,40 \\
\hline \multirow{4}{*}{5} & \multirow{4}{*}{$\begin{array}{l}\text { SMA modificado } \\
\text { por polímero na } \\
\text { faixa alemã D 0-11 }\end{array}$} & 210 & 215 & 220 & 205 & 212,5 & 0,70 \\
\hline & & 220 & 200 & 205 & 205 & 207,5 & 0,74 \\
\hline & & 190 & 195 & 195 & 192 & 193,0 & 0,85 \\
\hline & & 200 & 195 & 180 & 200 & 193,8 & 0,85 \\
\hline
\end{tabular}


Tabela 4.5.2 Resultados obtidos para Areia Normal Brasileira em duas granulometrias

\begin{tabular}{|c|c|c|c|c|c|c|c|c|c|c|c|c|c|}
\hline & \multirow{2}{*}{$\begin{array}{c}\text { Tipos de } \\
\text { revestimentos }\end{array}$} & \multicolumn{6}{|c|}{ Areia \# $60-80$} & \multicolumn{6}{|c|}{ Areia Normal \# 50-100 } \\
\hline & & D1 & D2 & D3 & D4 & Dm & HS & D1 & D2 & D3 & D4 & Dm & HS \\
\hline \multirow{5}{*}{1} & \multirow{5}{*}{$\begin{array}{l}\text { CA convencional } \\
\text { na faixa III da } \\
\text { PMSP }\end{array}$} & 250 & 234 & 254 & 255 & 248,3 & 0,52 & 250 & 267 & 250 & 254 & 255,3 & 0,49 \\
\hline & & 232 & 225 & 237 & 230 & 231,0 & 0,60 & 240 & 242 & 245 & 223 & 237,5 & 0,56 \\
\hline & & 260 & 252 & 230 & 250 & 248,0 & 0,52 & 257 & 242 & 245 & 260 & 251,0 & 0,51 \\
\hline & & 200 & 205 & 205 & 200 & 202,5 & 0,78 & 175 & 210 & 180 & 195 & 190,0 & 0,88 \\
\hline & & 255 & 262 & 260 & 245 & 255,5 & 0,49 & 260 & 230 & 252 & 248 & 247,5 & 0,52 \\
\hline \multirow{5}{*}{2} & & 240 & 215 & 210 & 230 & 223,8 & 0,64 & 215 & 225 & 230 & 225 & 223,8 & 0,64 \\
\hline & CA convencional & 237 & 215 & 235 & 234 & 230,3 & 0,60 & 228 & 225 & 224 & 235 & 228,0 & 0,61 \\
\hline & na fai & 245 & 228 & 252 & 242 & 241,8 & 0,54 & 208 & 235 & 230 & 230 & 225,8 & 0,62 \\
\hline & DERSA & 270 & 228 & 252 & 242 & 248,0 & 0,52 & 260 & 270 & 262 & 255 & 261,8 & 0,46 \\
\hline & & 240 & 237 & 245 & 235 & 239,3 & 0,56 & 241 & 235 & 255 & 225 & 239,0 & 0,56 \\
\hline \multirow{4}{*}{3} & & 290 & 290 & 270 & 275 & 281,3 & 0,40 & 294 & 284 & 275 & 290 & 285,8 & 0,39 \\
\hline & convencional na & 280 & 290 & 293 & 287 & 287,5 & 0,39 & 270 & 271 & 277 & 278 & 274,0 & 0,42 \\
\hline & faixa IV-b do & 273 & 264 & 276 & 280 & 273,3 & 0,43 & 260 & 262 & 272 & 270 & 266,0 & 0,45 \\
\hline & Institutc & 323 & 290 & 300 & 305 & 304,5 & 0,34 & 295 & 295 & 280 & 280 & 287,5 & 0,39 \\
\hline \multirow{4}{*}{4} & CA con & 275 & 294 & 297 & 290 & 289,0 & 0,38 & 270 & 273 & 273 & 264 & 270,0 & 0,44 \\
\hline & mod por polímero & 280 & 287 & 284 & 270 & 280,3 & 0,41 & 292 & 260 & 295 & 270 & 279,3 & 0,41 \\
\hline & na faixa IV-b do & 270 & 283 & 272 & 266 & 272,8 & 0,43 & 270 & 275 & 280 & 280 & 276,3 & 0,42 \\
\hline & & 280 & 286 & 294 & 280 & 285,0 & 0,39 & 288 & 288 & 300 & 292 & 292,0 & 0,37 \\
\hline \multirow{4}{*}{5} & \multirow{4}{*}{$\begin{array}{l}\text { SMA modificado } \\
\text { por polímero na } \\
\text { faixa alemã D 0-11 }\end{array}$} & 210 & 215 & 205 & 206 & 209,0 & 0,73 & 195 & 220 & 200 & 200 & 203,8 & 0,77 \\
\hline & & 220 & 205 & 204 & 210 & 209,8 & 0,72 & 215 & 210 & 220 & 210 & 213,8 & 0,70 \\
\hline & & 202 & 200 & 195 & 200 & 199,3 & 0,80 & 205 & 210 & 195 & 210 & 205,0 & 0,76 \\
\hline & & 210 & 195 & 200 & 200 & 201,3 & 0,79 & 200 & 212 & 190 & 205 & 201,8 & 0,78 \\
\hline
\end{tabular}

Os cinco trechos avaliados se enquadram na classificação média para a textura, mas pode-se observar, por meio da Figura 4.5.3, a homogeneidade existente entre os trechos 1 e 2, e também 3 e 4; para este caso, pode-se inferir que o trecho 1 e 2 apresentam textura media (HS médio entre 0,58 e 0,57mm), o trecho 2 e 3 mediamente fina (HS médio entre 0,40 e $0,41 \mathrm{~mm}$ ) e o trecho 5 medianamente grossa $(\mathrm{Hs}=0,77 \mathrm{~mm})$.

Analisando o desvio padrão das médias por trecho entre os materiais, conforme apresentado na Tabela 4.5.3, observa-se que o trecho 5 cuja textura é mais aberta apresentou maior dispersão entre os resultados. 


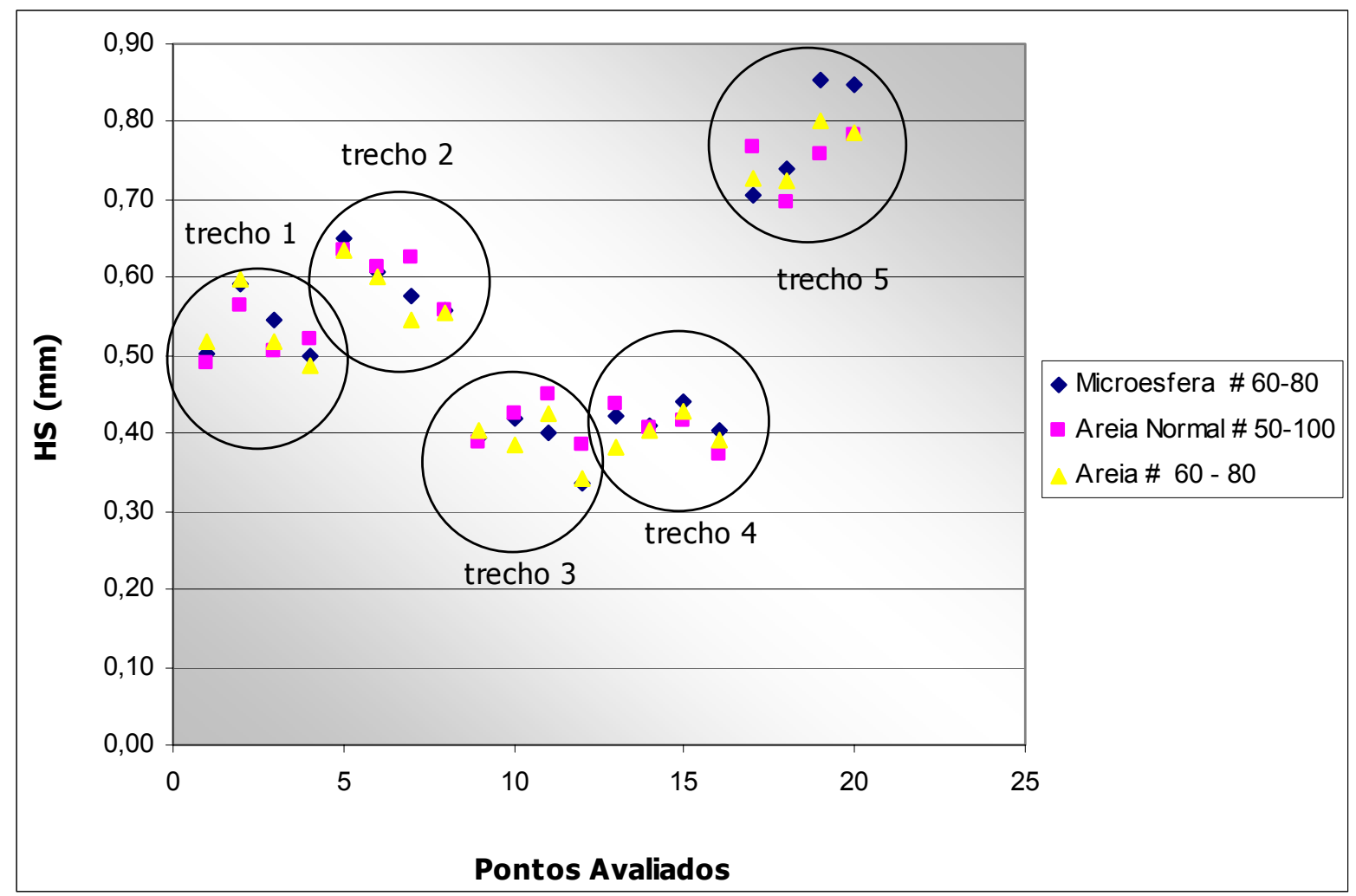

Figura 4.5.3 Homogeneidade existente entre os trechos

Tabela 4.5.3 Valores médios por trechos e tipo de material

\begin{tabular}{l|c|c|c|c|c}
\hline \hline \multicolumn{1}{c|}{ Tipo } & Trecho & Trecho & Trecho & Trecho & Trecho \\
& $\mathbf{1}$ & $\mathbf{2}$ & $\mathbf{3}$ & $\mathbf{4}$ & $\mathbf{5}$ \\
\hline Média - Microesfera \# 60-80 & 0,58 & 0,57 & 0,39 & 0,42 & 0,79 \\
\hline Média - Areia \# 60 - 80 & 0,58 & 0,57 & 0,39 & 0,40 & 0,76 \\
\hline Média - Areia Normal \# 50-100 & 0,59 & 0,58 & 0,41 & 0,41 & 0,75 \\
\hline Média & 0,58 & 0,57 & 0,40 & 0,41 & 0,77 \\
\hline Desvio Padrão & 0,009 & 0,006 & 0,014 & 0,009 & 0,019 \\
\hline \hline
\end{tabular}

A ASTM E 965-96 (2001) comenta que esse ensaio realizado em superfícies homogêneas em campo comparando trecho a trecho, pode apresentar um desvio padrão de até $27 \%(0,27)$. O maior desvio padrão encontrado foi de $16 \%(0,16)$, conforme pode ser visto na Tabela 4.5.4. 
Tabela 4.5.4 Desvio padrão por trechos e tipo de material

\begin{tabular}{c|c|c|c|c|c}
\hline \multirow{2}{*}{ Tipo } & \multicolumn{5}{|c}{ Desvio Padrão } \\
\cline { 2 - 7 } & Trecho & Trecho & Trecho & Trecho & Trecho \\
& $\mathbf{1}$ & $\mathbf{2}$ & $\mathbf{3}$ & $\mathbf{4}$ & $\mathbf{5}$ \\
\hline Microesfera \# 60-80 & 0,10 & 0,07 & 0,04 & 0,02 & 0,08 \\
\hline Areia \# 60 - 80 & 0,12 & 0,05 & 0,04 & 0,02 & 0,04 \\
\hline Areia Normal \# 50-100 & 0,16 & 0,07 & 0,03 & 0,03 & 0,04 \\
\hline \hline
\end{tabular}

Observa-se que a correlação existente entre a micro esfera de vidro e os dois tipos de areia é positiva e forte $(0,99$ e 0,96); a correlação entre as areia também é positiva e forte $(0,95)$; isto pode ser visto observando a Figura 4.54 e a Tabela 4.5.5.

Tabela 4.5.5 Matriz de correlação linear (Pearson)

\begin{tabular}{c|c|c|c}
\hline \hline Fator & $\begin{array}{c}\text { Microesfera } \\
\text { \# 60-80 }\end{array}$ & $\begin{array}{c}\text { Areia } \\
\text { 60-80 }\end{array}$ & $\begin{array}{c}\text { Areia Normal } \\
\text { \# 50-100 }\end{array}$ \\
\hline $\begin{array}{c}\text { Microesfera } \\
\text { \# 60-80 }\end{array}$ & 1 & 0,99 & 0,96 \\
\hline $\begin{array}{c}\text { Areia } \\
\text { \# 60 - 80 }\end{array}$ & 0,99 & 1 & 0,95 \\
\hline $\begin{array}{c}\text { Areia Normal } \\
\text { \# 50-100 }\end{array}$ & 0,96 & 0,95 & 1 \\
\hline \hline
\end{tabular}

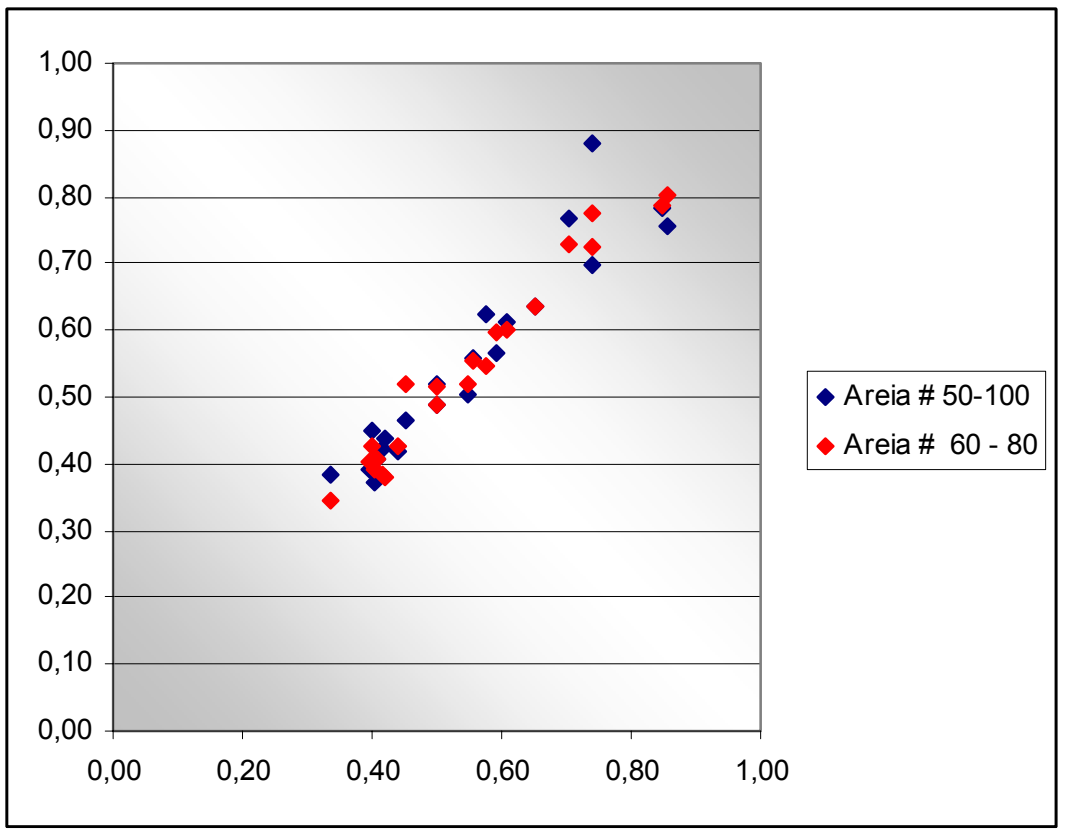

Figura 4.5.4 Dispersão da micro esfera de vidro com a Areia Normal Brasileira 
Analisando os resultados anteriores é possível inferir, para estes dados, que os dois tipos de areia possuem características e comportamentos similares, podendo ser utilizado em substituição da micro esfera de vidro na realização do ensaio ASTM E 965-96 (2001). 


\section{Capítulo 5 Estudo de Caso - Seção Teste na Via Anchieta}

Para validar a $4^{\mathrm{a}}$ Tentativa de faixas classificatórias das superfícies quanto à aderência pneu-pavimento por meio do índice combinado IFI (International Friction Index), apresentadas no Capítulo 4, as mesmas análises estatísticas foram repetidas para a amostra denominada nesta pesquisa de Grupo de Controle apresentadas neste capítulo.

Este capítulo apresenta a avaliação do revestimento do tipo SMA (Stone Matrix Asphalt), executado em seção teste e comparado com dois trechos contíguos, um de Concreto Asfáltico convencional na faixa III da DERSA, usinado com CAP 20, e outro também com Concreto Asfáltico na faixa IV-b do Instituto do Asfalto norteamericano, porém empregando asfalto modificado por borracha. O SMA foi selecionado para Grupo de Controle por ser uma seção teste onde se tem um conhecimento detalhado do projeto de mistura asfáltica, dos procedimentos construtivos e de controle. Além disso, monitoramentos foram realizados neste trecho periodicamente para o estudo das características de textura e sua evolução. Este Banco de Dados é composto por 102 valores, sendo 50 referentes à macrotextura, 37 à microtextura, 15 à drenabilidade, e 38 pares de valores $\left(S p ; F_{60}\right)$.

\subsection{A Seção-Teste na Via Anchieta}

As avaliações de campo foram realizadas em seção-teste na Via Anchieta, sentido descendente, cujo tráfego diário médio desta rodovia é de aproximadamente 40.000 veículos, com 50\% de caminhões pesados; a estrada liga a cidade de São Paulo a Santos, por onde escoa as cargas para o principal Porto do país. A rodovia foi construída no final da década de 40, em CCP (Concreto de Cimento de Portland) e 
recebeu sucessivos recapeamentos em Concreto Asfáltico sobre a superfície que apresentava fissuras provenientes da reflexão das trincas das placas de CCP (Figura 5.1.1).

A seção-teste de revestimento do tipo SMA (Stone Matrix Asphalt) foi concebida com o projeto de dosagem segundo a normalização alemã com a faixa $0 / 11 \mathrm{~S}$, destinada ao tráfego pesado, empregando asfalto modificado por polímero SBS, no teor de projeto de $6,1 \%$, com agregados pétreos do tipo gnaisse, fíler calcáreo e cal hidratada, e $0,45 \%$ de fibras de celulose impregnadas com emulsão na forma de pellets. A descrição mais detalhada do projeto encontra-se em Reis (2002). A Figura 5.1.2(a) mostra um aspecto do $S M A$ com sua particularidade de textura superficial.
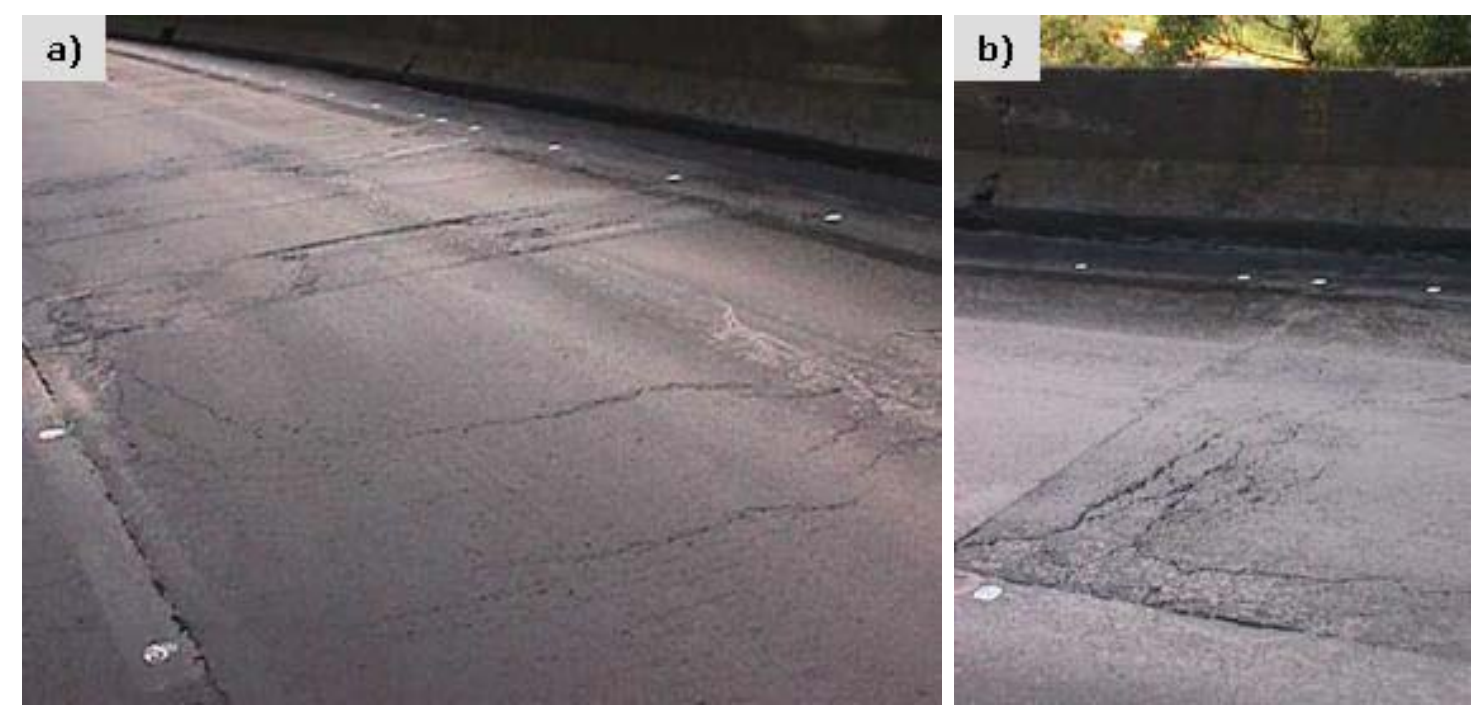

Figura 5.1.1 Trincamento no Concreto Asfáltico devido à reflexão de trincas das placas de Concreto de Cimento Portland (Bernucci, 2002)

A seção-teste foi construída em agosto de 2001 em um local muito peculiar, considerado pela concessionária Ecovias, responsável pela rodovia, como um dos locais de solicitação mecânica mais severa - Figura 5.1.2(b), com um potencial elevado para acidentes, devido a uma curva perigosa, acentuada, conhecida por "curva da onça", em declive e com um índice pluviométrico anual médio elevado, de cerca de 3500 a $4000 \mathrm{~mm} / \mathrm{ano}$. 

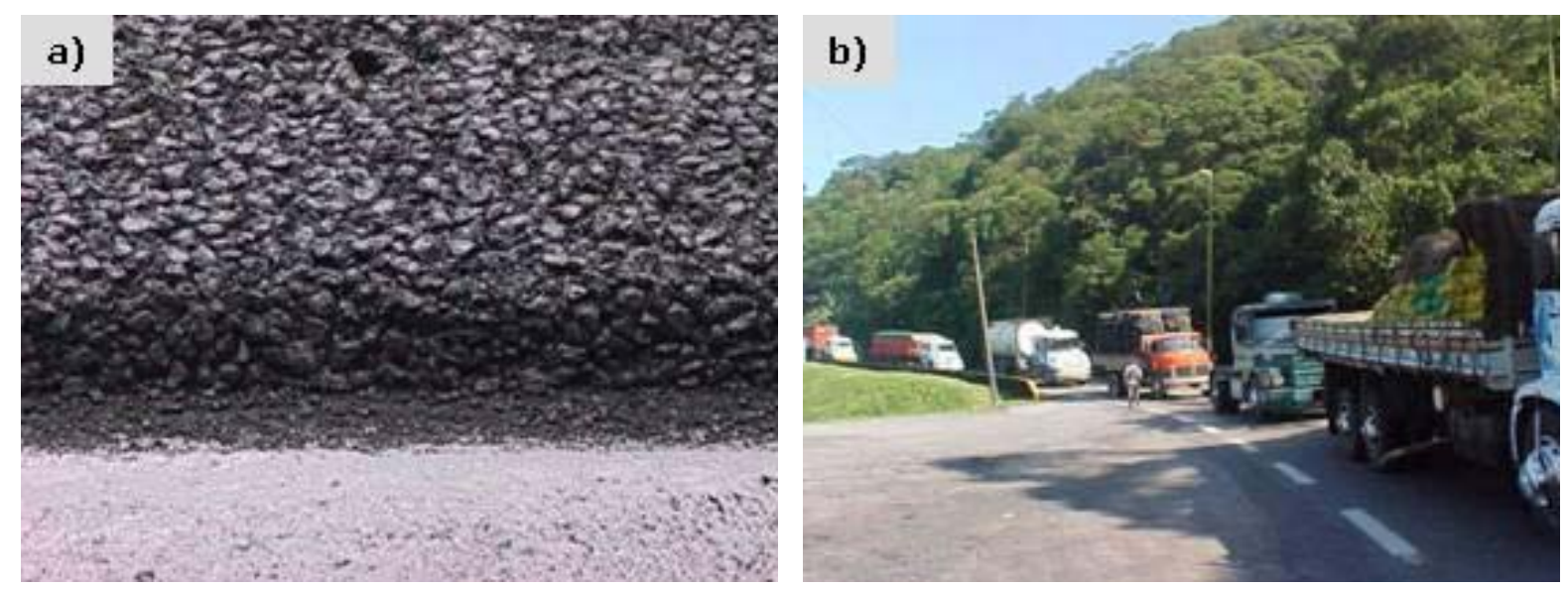

Figura 5.1.2 (a) Aspecto da textura superficial de revestimento asfáltico tipo SMA (Bernucci, 2002), e (b) vista geral da curva onde foi executado o trecho experimental com SMA na Via Anchieta

O trecho em curva e declive foi construído na década de 40 quando, provavelmente, a definição do perfil vertical do traçado da rodovia foi conseqüência da topografia do terreno e do nível de segurança e das técnicas disponíveis àquela época.

A forte declividade e o comprimento são os principais fatores que afetam a ocorrência de acidentes em rampas, aliados à presença de veículos pesados que combinados, tendem a registrar maior número de acidentes devido às diferenças de velocidades que se acentuam nessas condições de operação. 0 número de acidentes em rampas descendentes é $63 \%$ maior que em rampas ascendentes. Acidentes em declives também resultam maior percentual de feridos e mortes quando comparados aos acidentes em aclives (FHWA, 1992 apud Nodari 2003).

Sabe-se por meio da revisão da literatura que o aumento da textura superficial do revestimento asfáltico reduz a ocorrência de acidentes; buscava-se neste estudo de caso a comparação dos dados de acidentes, antes e depois da construção dos trechos experimentais com objetivo de realizar essa verificação. Porém, a metodologia de coleta de dados dos acidentes em todo o Estado de São Paulo é baseada nas informações dos BOATRv (Boletins de Acidentes de Trânsito Rodoviário da Polícia Rodoviária) que foram insuficientes para esse tipo de análise. 
Por meio da análise dos dados de acidentes podem-se cometer muitos erros; as pesquisas de acidentes para diagnóstico do resultado obtido por meio de intervenção nos pavimentos devem ser realizadas antes e depois, no local selecionado e em outro para grupo de controle com o objetivo de garantir que fatores exógenos não ocorreram, como por exemplo, instalação de placas de sinalização, campanhas educativas, desvios em outras rodovias aumentando o volume de tráfego entre outros.

O estado de São Paulo recebe $53 \%$ do volume de tráfego pedagiado do país de aproximadamente 643.000 .000 veículos; conforme pode ser visto na Figura 5.1.3, estima-se que $8 \%$ façam uso da Via Anchieta, o que mostra a necessidade de se trabalhar com pavimentos mais aderentes, com boa macrotextura devido aos altos índices pluviométricos, e adequada microtextura devido à baixa velocidade em curvas descendentes, freqüentes ocorrências de frenagens emergenciais e elevado volume de tráfego. A Figura 5.2(b) ilustra esta situação.

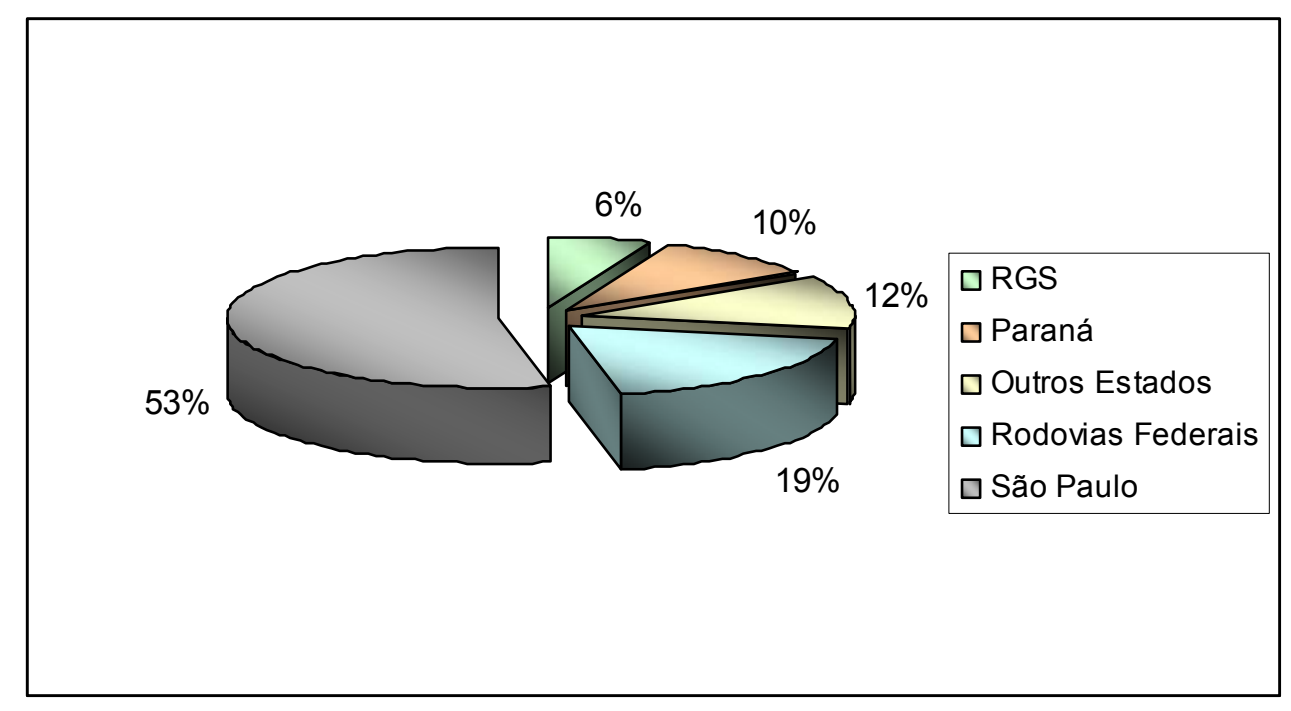

Figura 5.1.3 Tráfego total pedagiado em 2005 (ABCR, 2005)

Vale ressaltar a dificuldade para obtenção de dados junto às concessionárias, seja em relação ao VDM ou coleta de acidentes para a realização de um estudo mais aprofundado. A Figura 5.1.4 mostra os dados obtidos sobre acidentes, que infelizmente não fornecem informações suficientes para que se possa obter 
quaisquer relação das intervenções realizadas com a ocorrência de acidentes ou fatores exógenos nestes anos em questão.

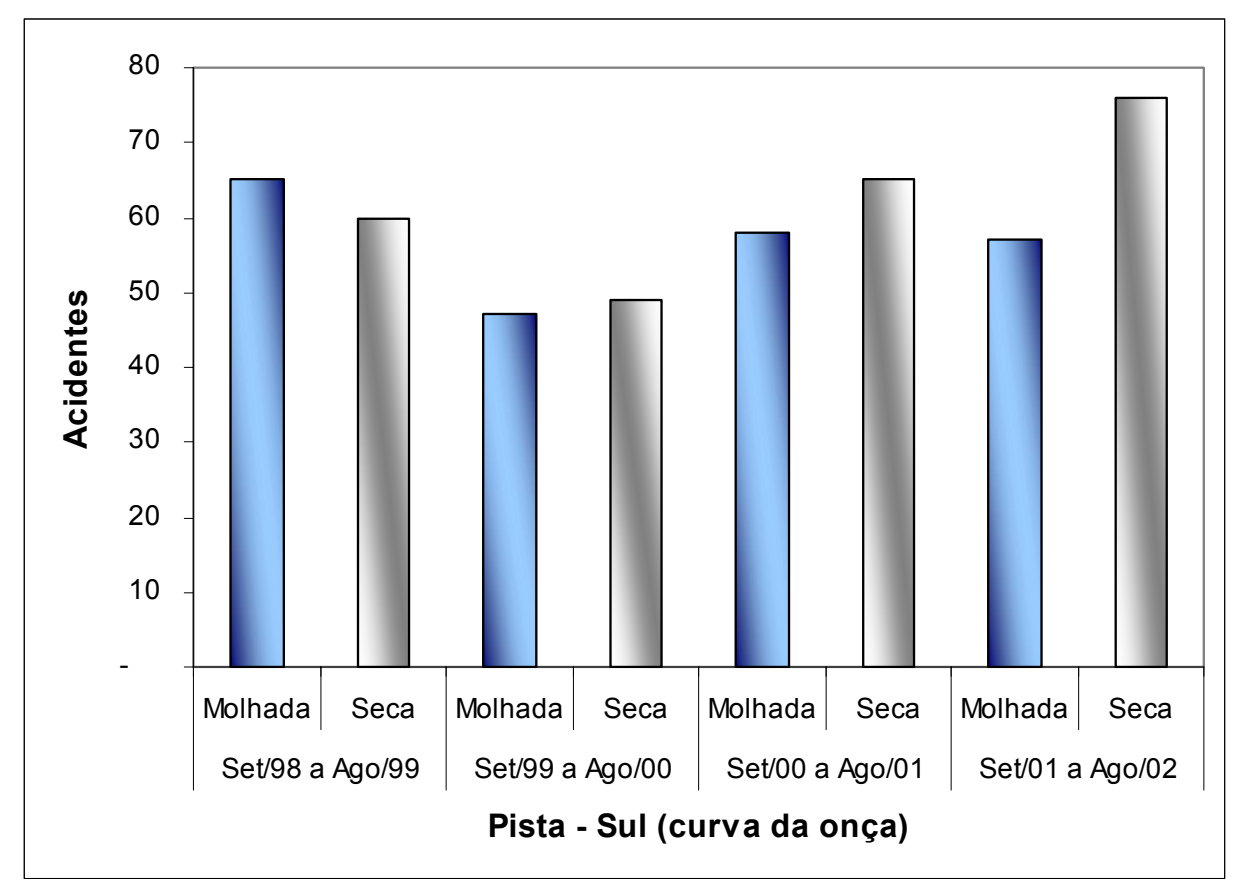

Figura 5.1.4: Acidentes ocorridos na Via Anchieta de 1998 a 2002

\subsection{Ensaios Realizados e Resultados Obtidos}

Para obtenção dos valores apresentados neste capítulo foram realizados ensaios e/ou coletados, dados de macrotextura, microtextura, drenabilidade e calculados os valores de IFI, International Friction Index. Os valores de macrotextura foram obtidos por meio do ensaio de Mancha de Areia, conforme preconizado pela ASTM E 965-96 e comparados com os valores resultantes do ensaio de Drenabilidade com objetivo de verificar o comportamento da textura do pavimento frente a chuvas visto que o local apresenta alto índice pluviométrico.

Os valores de microtextura foram obtidos por meio de avaliações com o Pêndulo Britânico, cuja utilização é especificada pelo método da ASTM E-303-93. Deve-se realçar que a medida de microtextura é um importante fator nas operações a baixa velocidade. Além do potencial intrínseco de polimento dos agregados pela natureza, 
deve-se ressaltar que em declives os pneus de caminhões e as forças tangenciais tendem a agir como veículos de aceleração do polimento dos agregados.

Em 2002 foram realizadas as primeiras medidas de atrito e de textura da superfície usando o Pêndulo Britânico e o ensaio de Mancha de Areia, outras avaliações foram realizadas posteriormente, em novembro de 2002. Em junho de 2003 além de novos ensaios, com a finalidade de comparação, foram realizadas também medições em outras curvas com características semelhantes onde foram executados recapeamentos em Concreto Asfáltico convencional na faixa III da DERSA (CAP 20) e outro na faixa IV-b do Instituto do Asfalto norte-americano, porém com asfalto modificado por borracha.

Em maio de 2006 foram realizadas medidas de textura e de atrito na seção de SMA. Nesta data a via estava sofrendo intervenções por meio da remoção do revestimento antigo e reposição com SMA com asfalto modificado por borracha e os ensaios foram realizados no trecho que não necessitou de intervenção; porém, não foi possível a realização desses ensaios na seção de Concreto Asfáltico convencional e Concreto Asfáltico modificado por borracha, pois as mesmas não foram preservadas por apresentarem necessidade de manutenção.

Após a realização dos ensaios de campo para complementação dos resultados, foram calculados valores de IFI (International Friction Index), conforme a ASTM E-1960-98. A descrição dos ensaios de campo realizados e o procedimento para a determinação dos valores de IFI estão descritos no Capítulo 2.

Os resultados obtidos por meio de ensaios de campo, na Via Anchieta, foram realizados em março de 2002 por Reis (2002) e em novembro de 2002 e março de 2003 por Aps et al. (2003) e em maio de 2006 por técnicos do IPT- Instituto de Pesquisa Tecnológica do Estado de São Paulo. Estes dados estão apresentados nas Tabelas 5.2.1, 5.2.2, 5.2.3 e 5.2.4. 
Tabela 5.2.1 Resultados coletados de macrotextura e microtextura de Reis (2002) e cálculo de IFI em março de 2002

\begin{tabular}{|c|c|c|c|c|c|c|c|c|}
\hline \multicolumn{2}{|r|}{ Unidade Amostragem } & \multicolumn{3}{|c|}{$\begin{array}{c}\text { Macrotextura } \\
\text { Altura de Areia Hs (mm) }\end{array}$} & \multicolumn{2}{|c|}{$\begin{array}{l}\text { Microtextura } \\
\text { Pend. Britânico }\end{array}$} & \multicolumn{2}{|c|}{$\boldsymbol{I F I}$} \\
\hline No & Tipo & $\begin{array}{l}\text { Diam. } \\
\text { Méd. } \\
(\mathrm{cm})\end{array}$ & $H s=T x$ & $\begin{array}{l}\text { Classi- } \\
\text { ficação }\end{array}$ & $\begin{array}{l}\text { Média } \\
\text { FRS }\end{array}$ & $\begin{array}{l}\text { Classi- } \\
\text { ficação }\end{array}$ & $\mathbf{S p}$ & F60 \\
\hline 1 & SMA faixa alemã D0-11S & 17,30 & 1,06 & G & 54 & MR & 109,17 & 0,33 \\
\hline 2 & SMA faixa alemã D0-11S & 17,25 & 1,07 & G & 47 & MR & 109,87 & 0,29 \\
\hline 3 & SMA faixa alemã D0-11S & 18,70 & 0,91 & $\mathrm{G}$ & 49 & MR & 91,77 & 0,28 \\
\hline 4 & SMA faixa alemã D0-11S & 16,25 & 1,20 & MG & 50 & MR & 125,28 & 0,32 \\
\hline 5 & $S M A$ faixa alemã D0-11S & 18,10 & 0,97 & $\mathrm{G}$ & 52 & MR & 98,73 & 0,31 \\
\hline
\end{tabular}

Para as Tabelas 5.2.1, 5.2.2, 5.2.3 e 5.2.4 é válida a seguinte legenda:

\begin{tabular}{|c|c|}
\hline \multicolumn{2}{|r|}{$\begin{array}{l}\text { Mancha de Areia } \\
\text { CLASSIFICAÇÃO }\end{array}$} \\
\hline MF & MUITO FINA \\
\hline $\mathrm{F}$ & FINA \\
\hline$M$ & MÉDIA \\
\hline$G$ & GROSSEIRA \\
\hline MG & MUITO GROSSEIRA \\
\hline \multicolumn{2}{|r|}{$\begin{array}{l}\text { Pêndulo Britânico } \\
\text { CLASSIFICAÇÃo }\end{array}$} \\
\hline$P$ & PERIGOSA \\
\hline ML & MUITO LISA \\
\hline $\mathrm{L}$ & LISA \\
\hline IR & INSUFICIENTEMENTE RUGOSA \\
\hline $\mathrm{MR}$ & MEDIANAMENTE RUGOSA \\
\hline $\mathrm{R}$ & RUGOSA \\
\hline MuR & MUITO RUGOSA \\
\hline
\end{tabular}

Onde:

Mancha de Areia = média da profundidade de areia em mm;

Drenabilidade $=$ volume por tempo de escoamento;

Pêndulo = média de 5 leituras corrigidas (dividido por 100);

IFI = valor calculado de acordo com a ASTM E-1960-98. 
Tabela 5.2.2 Resultados obtidos do ensaio de macrotextura para a Via Anchieta em novembro de 2002 (Aps et al., 2003)

\begin{tabular}{c|c|c|c|c}
\hline \hline \multicolumn{2}{c|}{ Unidade Amostragem } & \multicolumn{3}{c}{ Macrotextura } \\
Altura de Areia Hs (mm)
\end{tabular}

A Figura 5.2.1 apresenta a Mancha de Areia realizada em trecho em Concreto Asfáltico e trecho em SMA contíguos da SP-150 realizados em 21/11/02.

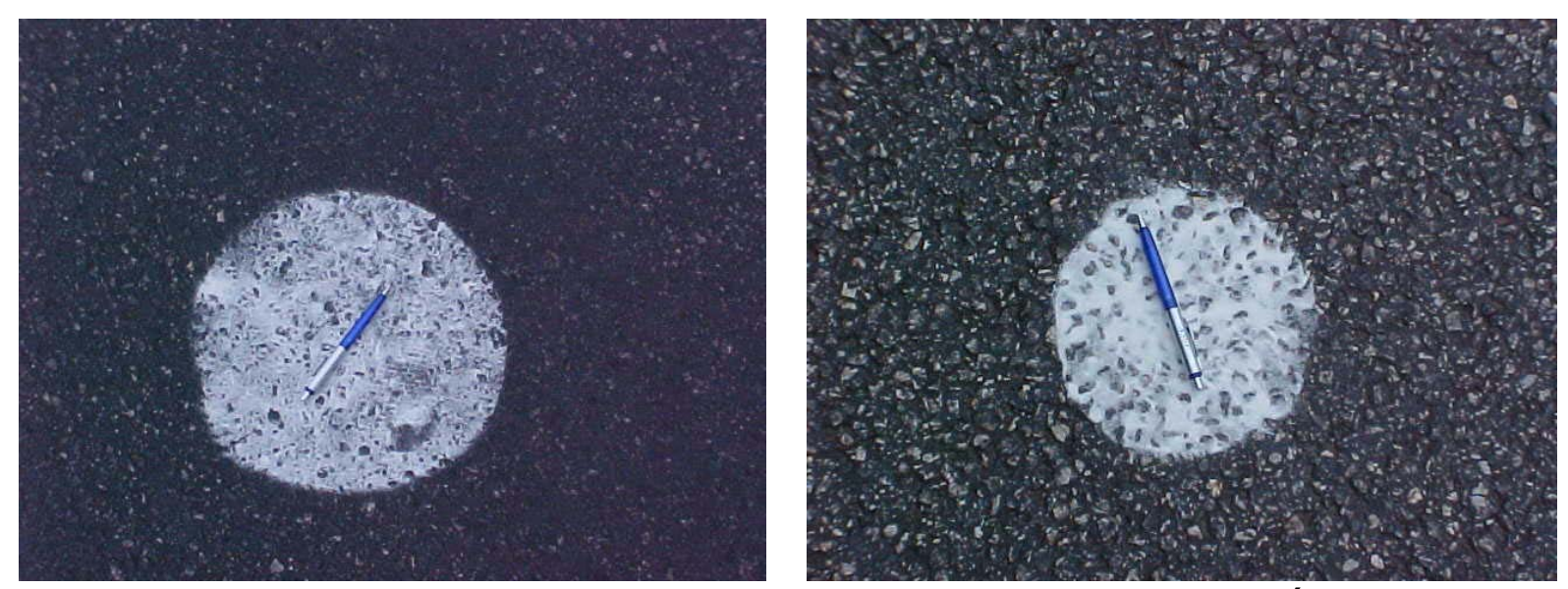

Figura 5.2.1 Mancha de Areia realizada em trecho em Concreto Asfáltico e trecho em SMA contíguos da SP-150 (ensaios realizados em 21/11/02) 
Tabela 5.2.3 Resultados obtidos de macrotextura, microtextura, drenabilidade e cálculo de valores de IFI para a Via Anchieta em junho de 2003 (Aps et al., 2003b)

\begin{tabular}{|c|c|c|c|c|c|c|c|c|c|}
\hline \multicolumn{2}{|r|}{ Unidade Amostragem } & \multicolumn{3}{|c|}{$\begin{array}{l}\text { Macrotextura } \\
\text { Altura de Areia Hs }(\mathbf{m m})\end{array}$} & \multirow{2}{*}{$\begin{array}{c}\text { Drena- } \\
\text { bilidade } \\
(1 / s)\end{array}$} & \multicolumn{2}{|c|}{$\begin{array}{c}\text { Microtextura } \\
\text { Pend. Britânico }\end{array}$} & \multicolumn{2}{|c|}{$\boldsymbol{I F I}$} \\
\hline No & Tipo & $\begin{array}{l}\text { Diam. } \\
\text { Méd. } \\
\text { (cm) }\end{array}$ & $H s=T x$ & $\begin{array}{l}\text { Classi- } \\
\text { ficação }\end{array}$ & & $\begin{array}{l}\text { Média } \\
\text { FRS }\end{array}$ & $\begin{array}{l}\text { Classi- } \\
\text { ficação }\end{array}$ & $\mathbf{S p}$ & F60 \\
\hline 1 & Concreto Asfáltico mod & 31 & 0,331 & $\mathrm{~F}$ & 0,119 & 30 & $M L$ & 26,01 & 0,09 \\
\hline 2 & Concreto Asfáltico mod & 29,2 & 0,373 & $\mathrm{~F}$ & 0,063 & 40 & IR & 30,79 & 0,12 \\
\hline 3 & Concreto Asfáltico mod & 29,3 & 0,371 & $\mathrm{~F}$ & 0,097 & 31 & ML & 30,50 & 0,10 \\
\hline 4 & Concreto Asfáltico mod & 25,8 & 0,478 & $M$ & 0,072 & 39 & LISA & 42,70 & 0,15 \\
\hline 5 & Concreto Asfáltico mod & 27,8 & 0,412 & $M$ & 0,058 & 48 & MR & 35,17 & 0,15 \\
\hline 6 & Concreto Asfáltico mod & 26,7 & 0,446 & $M$ & 0,093 & 36 & LISA & 39,10 & 0,14 \\
\hline 7 & SMA faixa alemã D0-11S & 24,8 & 0,517 & $M$ & 0,110 & 23 & $\mathrm{P}$ & 47,17 & 0,12 \\
\hline 8 & SMA faixa alemã D0-11S & 22,3 & 0,64 & $M$ & - & 44 & IR & 61,09 & 0,21 \\
\hline 9 & $S M A$ faixa alemã D0-11S & 23,8 & 0,562 & $M$ & - & 44 & IR & 52,21 & 0,19 \\
\hline 10 & SMA faixa alemã D0-11S & 20,2 & 0,78 & M & 0,140 & 41 & IR & 76,98 & 0,23 \\
\hline 11 & SMA faixa alemã D0-11S & 20 & 0,795 & $M$ & - & 45 & IR & 78,77 & 0,25 \\
\hline 12 & SMA faixa alemã D0-11S & 19,3 & 0,854 & $\mathrm{G}$ & - & 42 & IR & 85,44 & 0,24 \\
\hline 13 & SMA faixa alemã D0-11S & 19,3 & 0,854 & $\mathrm{G}$ & 0,208 & 41 & IR & 85,44 & 0,24 \\
\hline 14 & SMA faixa alemã D0-11S & 20,3 & 0,772 & $M$ & 0,198 & 35 & LISA & 76,11 & 0,20 \\
\hline 15 & SMA faixa alemã D0-11S & 20,2 & 0,78 & $M$ & - & 42 & IR & 76,98 & 0,23 \\
\hline 16 & SMA faixa alemã D0-11S & 21,5 & 0,688 & $M$ & - & 35 & LISA & 66,60 & 0,19 \\
\hline 17 & Concreto Asfáltico & 21,2 & 0,708 & $M$ & 0,150 & 48 & MR & 68,82 & 0,24 \\
\hline 18 & Concreto Asfáltico & 23,5 & 0,576 & $M$ & 0,057 & 51 & MR & 53,85 & 0,22 \\
\hline 19 & Concreto Asfáltico & 19,8 & 0,812 & G & 0,140 & 46 & IR & 80,60 & 0,25 \\
\hline 20 & Concreto Asfáltico & 24,3 & 0,539 & $M$ & 0,097 & 44,2 & IR & 49,61 & 0,19 \\
\hline 21 & Concreto Asfáltico & 25,2 & 0,501 & $M$ & 0,085 & 47 & MR & 45,32 & 0,18 \\
\hline
\end{tabular}

Tabela 5.2.4 Resultados obtidos do ensaio de macrotextura, microtextura e cálculo de valores de IFI em maio de 2006 realizados por técnicos do IPT

\begin{tabular}{|c|c|c|c|c|c|c|c|c|}
\hline \multirow{2}{*}{\multicolumn{2}{|c|}{ Unidade Amostragem }} & \multirow{2}{*}{\multicolumn{3}{|c|}{$\begin{array}{c}\text { Macrotextura } \\
\text { Altura de Areia Hs (mm) }\end{array}$}} & \multirow{2}{*}{\multicolumn{2}{|c|}{$\begin{array}{c}\text { Microtextura } \\
\text { Pend. Britânico }\end{array}$}} & \multirow{2}{*}{\multicolumn{2}{|c|}{$\boldsymbol{I} \boldsymbol{F I}$}} \\
\hline & & & & & & & & \\
\hline \multirow[b]{2}{*}{ No } & \multirow[b]{2}{*}{ Tipo } & \multirow{2}{*}{$\begin{array}{l}\text { Diam. } \\
\text { Méd. } \\
\text { (cm) }\end{array}$} & \multirow[b]{2}{*}{$H s=T x$} & \multirow{2}{*}{$\begin{array}{l}\text { Classi- } \\
\text { ficação }\end{array}$} & Média & Clacci- & \multirow[b]{2}{*}{$\mathbf{S p}$} & \multirow[b]{2}{*}{ F60 } \\
\hline & & & & & FRS & ficação & & \\
\hline 2 & SMA faixa alemã D0-11S & 18,50 & 0,93 & G & 50,4 & MR & 94,01 & 0,29 \\
\hline 3 & SMA faixa alemã D0-11S & 18,38 & 0,94 & $\mathrm{G}$ & 47,8 & MR & 95,45 & 0,28 \\
\hline 4 & SMA faixa alemã D0-11S & 18,38 & 0,94 & G & 52,6 & MR & 95,45 & 0,31 \\
\hline 5 & SMA faixa alemã D0-11S & 17,95 & 0,99 & G & 52,8 & MR & 100,58 & 0,31 \\
\hline 6 & SMA faixa alemã D0-11S & 18,68 & 0,91 & G & 55,6 & MR & 92,04 & 0,31 \\
\hline 7 & SMA faixa alemã D0-11S & 17,83 & 1,00 & $\mathrm{G}$ & 45,4 & MR & 102,16 & 0,28 \\
\hline 8 & SMA faixa alemã D0-11S & 20,68 & 0,74 & G & 47,6 & MR & 72,96 & 0,25 \\
\hline 9 & SMA faixa alemã D0-11S & 18,50 & 0,93 & $\mathrm{G}$ & 47,6 & MR & 94,01 & 0,28 \\
\hline 10 & SMA faixa alemã D0-11S & 21,73 & 0,67 & $\mathrm{G}$ & 49,4 & MR & 64,98 & 0,24 \\
\hline 11 & SMA faixa alemã D0-11S & 19,03 & 0,88 & $\mathrm{G}$ & 47,6 & MR & 88,26 & 0,27 \\
\hline 12 & SMA faixa alemã D0-11S & 18,98 & 0,88 & $\mathrm{G}$ & 45,2 & MR & 88,79 & 0,26 \\
\hline
\end{tabular}




\subsection{Análise dos Resultados Parciais}

A partir dos valores contidos nas Tabelas 5.2.1, 5.2.2, 5.2 .3 e 5.2 .4 serão apresentadas as análises e discussões dos resultados obtidos por meio de confrontos, tentativas de correlação e de observações de como esses dados refletem as condições observadas em campo. Os dados foram divididos em três grupos distintos de pavimentos asfálticos: Concreto Asfáltico convencional, Concreto Asfáltico modificado por borracha e SMA, e tratados separadamente.

\subsubsection{Concreto Asfáltico Convencional (faixa III da DERSA - CAP 20)}

Foi construída a Matriz de Correlação Linear (Pearson) apresentada na Tabela 5.3.1.1, onde se pode observar a correlação das variáveis $X_{i}$ e $X_{j}$ em cada interseção linha (i) coluna (j).

Observa-se a forte correlação positiva existente entre o ensaio de Mancha de Areia e de Drenabilidade com o valor de IFI $\left(\mathrm{F}_{60}\right)$ calculado e a correlação fraca existente entre os valores obtidos de atrito por meio do Pêndulo Britânico e os valores calculados de IFI $\left(\mathrm{F}_{60}\right)$; sabendo-se que os valores de IFI $\left(\mathrm{Sp} ; \mathrm{F}_{60}\right)$ são obtidos a partir de dados de textura e de atrito, pode-se inferir, para estes dados, que o valor de IFI está mais afetado pela variação do índice de textura do que pelo índice de atrito medido pelos equipamentos padronizados nessa norma.

Para melhor entendimento dos valores foi construída a Matriz de Covariância, Tabela 5.3.1.2, cuja diagonal contém a variância da variável e cada interseção linha (i) coluna (j) a covariância das variáveis $X_{i}$ e $X_{j}$.

Analisando a diagonal da Tabela 5.3.1.2, onde são apresentadas as variâncias das variáveis, pode-se observar a homogeneidade entre os valores de cada variável. Por sua vez observando-se os valores das covariâncias, verifica-se a variabilidade baixa entre as variáveis. 
Tabela 5.3.1.1 Matriz de correlação linear para Concreto Asfáltico

\begin{tabular}{c|c|c|c|c}
\hline \hline Fator & $\begin{array}{c}\text { HS } \\
\mathbf{( m m )}\end{array}$ & $\begin{array}{c}\text { Drenabilidade } \\
\mathbf{( I / s )}\end{array}$ & BPN & F60 \\
\hline $\begin{array}{c}\text { HS } \\
\mathbf{( m m})\end{array}$ & 1 & 0,787 & $-0,046$ & 0,955 \\
\hline $\begin{array}{c}\text { Drenabilidade } \\
(\mathbf{I} / \mathbf{s})\end{array}$ & 0,787 & 1 & $-0,413$ & 0,665 \\
\hline BPN & $-0,046$ & $-0,413$ & 1 & 0,240 \\
\hline F60 & 0,955 & 0,665 & 0,240 & 1 \\
\hline \hline
\end{tabular}

Tabela 5.3.1.2 Matriz de covariância para Concreto Asfáltico

\begin{tabular}{c|c|c|c|c}
\hline \hline Fator & $\begin{array}{c}\text { HS } \\
(\mathbf{m m})\end{array}$ & $\begin{array}{c}\text { Drenabilidade } \\
\mathbf{( \mathbf { l } / \mathbf { s } )}\end{array}$ & $\mathbf{B P N}$ & $\mathbf{F 6 0}$ \\
\hline $\begin{array}{c}\text { HS } \\
\mathbf{( m m )}\end{array}$ & 0,013 & 0,003 & 0,000 & 0,003 \\
\hline $\begin{array}{c}\text { Drenabilidade } \\
\mathbf{( I / s )}\end{array}$ & 0,003 & 0,001 & 0,000 & 0,001 \\
\hline $\mathbf{B P N}$ & 0,000 & 0,000 & 0,001 & 0,000 \\
\hline $\mathbf{F 6 0}$ & 0,003 & 0,001 & 0,000 & 0,001 \\
\hline \hline
\end{tabular}

\subsubsection{Concreto Asfáltico Modificado (faixa IV-b do Instituto do Asfalto Norte-americano Modificado por Borracha)}

Analisando os dados da matriz de correlação e de covariância apresentadas nas Tabelas 5.3.2.1 e 5.3.2.2, pode-se observar que para este pavimento cuja textura pode ser classificada entre média a fina, a correlação entre os valores obtidos pelos ensaios de mancha de areia e de atrito, apresenta forte correlação com o IFI $\left(\mathrm{F}_{60}\right)$; conforme era de se esperar, pois para texturas mais fechadas o atrito começa a exercer maior influência.

O ensaio de Drenabilidade quando correlacionado com o valor de $\operatorname{IFI}\left(\mathrm{F}_{60}\right)$ calculado apresenta correlação negativa forte, ou seja, inversamente proporcional ao até agora 
observado; isso leva à reflexão se esse ensaio é válido para pavimentos cuja textura é fechada.

Tabela 5.3.2.1 Matriz de correlação linear para Concreto Asfáltico modificado

\begin{tabular}{|c|c|c|c|c|}
\hline Fator & $\begin{array}{c}\text { HS } \\
(\mathrm{mm})\end{array}$ & $\begin{array}{c}\text { Drenabilidade } \\
(1 / \mathrm{s})\end{array}$ & BPN & F60 \\
\hline HS (mm) & 1 & $-0,469$ & 0,453 & 0,903 \\
\hline $\begin{array}{c}\text { Drenabilidade } \\
(1 / s)\end{array}$ & $\begin{array}{c}- \\
0,469\end{array}$ & 1 & $-0,909$ & $-0,744$ \\
\hline BPN & 0,453 & $-0,909$ & 1 & 0,790 \\
\hline F60 & 0,903 & $-0,744$ & 0,790 & 1 \\
\hline
\end{tabular}

Tabela 5.3.2.2 Matriz de covariância para Concreto Asfáltico modificado

\begin{tabular}{c|c|c|c|c}
\hline Fator & $\begin{array}{c}\text { HS } \\
\mathbf{( m m )}\end{array}$ & $\begin{array}{c}\text { Drenabilidade } \\
\mathbf{( I / s )}\end{array}$ & BPN & F60 \\
\hline HS (mm) & 0,002 & 0,000 & 0,001 & 0,001 \\
\hline $\begin{array}{c}\text { Drenabilidade } \\
\mathbf{( I / s )}\end{array}$ & 0,000 & 0,000 & $-0,001$ & 0,000 \\
\hline BPN & 0,001 & $-0,001$ & 0,004 & 0,001 \\
\hline F60 & 0,001 & 0,000 & 0,001 & 0,001 \\
\hline \hline
\end{tabular}

A dispersão dos valores obtidos por meio do ensaio de Mancha de Areia e Drenabilidade podem indicar limitações, deste último ensaio, para texturas fechadas e muito abertas de pavimentos em Concreto Asfáltico, conforme constatou Ferreira (2002) em sua pesquisa de Mestrado.

\subsubsection{SMA (Stone Matrix Asphalt) de Acordo com a Normalização Alemã com a Faixa $0 / 11 \mathrm{~S}$}

Para o caso do revestimento do tipo SMA a análise será apresentada em quatro etapas. As três primeiras por meio de matriz de correlação e covariância referentes as avaliações de campo realizadas em março de 2002, junho de 2003 e maio de 
2006 e a quarta por meio do boxplot incluindo também a avaliação realizada em novembro de 2002.

\subsubsection{Dados Obtidos em Março de 2002}

As Tabelas 5.3.3.1.1 e 5.3.3.1.2 apresentam valores de ensaio em pavimentos tipo $S M A$, logo após a sua construção, ou seja, quando esses pavimentos ainda estão com a textura mais aberta e os agregados recobertos ainda com uma película de asfalto no início da operação da pista recapeada, inibindo a microtextura. Apesar desta particularidade, analisando os dados da matriz de correlação e de covariância observa-se que há forte correlação positiva entre o ensaio de Mancha de Areia e de Pêndulo Britânico e com o valor de IFI $\left(\mathrm{F}_{60}\right)$ calculado. Possivelmente a película de ligante sobre os agregados foi arrancada rapidamente devido às condições de elevados esforços tangenciais na curva com SMA.

A correlação entre o ensaio de Mancha de Areia e o valor de Pêndulo Britânico é negativa fraca a inexistente, assim como já observado que o mesmo ensaio pode não ser válido para pavimentos de textura muito grossa como aqueles com grooving (Aps et al., 2003).

Tabela 5.3.3.1.1 Matriz de correlação linear (Pearson) para SMA- março de 2002

\begin{tabular}{c|c|c|c}
\hline \hline Fator & HS (mm) & BPN & F60 \\
\hline $\begin{array}{c}\text { HS } \\
(\mathbf{m m})\end{array}$ & 1 & $-0,008$ & 0,701 \\
\hline $\mathbf{B P N}$ & $-0,008$ & 1 & 0,706 \\
\hline $\mathbf{F 6 0}$ & 0,701 & 0,706 & 1 \\
\hline \hline
\end{tabular}


Tabela 5.3.3.1.2 Matriz de covariância para SMA - março de 2002

\begin{tabular}{c|c|c|c}
\hline Fator & HS (mm) & BPN & F60 \\
\hline $\begin{array}{c}\text { HS } \\
(\mathbf{m m})\end{array}$ & 0,0100 & 0,0000 & 0,0012 \\
\hline BPN & 0,0000 & 0,0006 & 0,0003 \\
\hline F60 & 0,0012 & 0,0003 & 0,0003 \\
\hline \hline
\end{tabular}

\subsubsection{Dados Obtidos em Junho de 2003}

Analisando os dados da matriz de correlação e de covariância apresentadas nas Tabelas 5.3.3.2.1 e 5.3.3.2.1, observa-se que há forte correlação positiva entre o ensaio de Mancha de Areia, Pêndulo Britânico e de Drenabilidade com o valor de IFI $\left(F_{60}\right)$ calculado.

Tabela 5.3.3.2.1 Matriz de correlação linear para SMA - junho de 2003

\begin{tabular}{c|c|c|c|c}
\hline Fator & $\begin{array}{c}\text { HS } \\
\mathbf{( m m})\end{array}$ & $\begin{array}{c}\text { Drenabilidade } \\
\mathbf{( I / s )}\end{array}$ & BPN & F60 \\
\hline $\begin{array}{c}\text { HS } \\
\mathbf{( m m})\end{array}$ & 1 & 0,832 & 0,475 & 0,858 \\
\hline $\begin{array}{c}\text { Drenabilidade } \\
(\mathbf{I} / \mathbf{s})\end{array}$ & 0,832 & 1 & 0,645 & 0,719 \\
\hline BPN & 0,475 & 0,645 & 1 & 0,855 \\
\hline F60 & 0,858 & 0,719 & 0,855 & 1 \\
\hline \hline
\end{tabular}

Tabela 5.3.3.2.2 Matriz de covariância para SMA - junho de 2003

\begin{tabular}{c|c|c|c|c}
\hline Fator & $\begin{array}{c}\text { HS } \\
(\mathbf{m m})\end{array}$ & $\begin{array}{c}\text { Drenabilidade } \\
\mathbf{( I / s )}\end{array}$ & BPN & F60 \\
\hline $\begin{array}{c}\text { HS } \\
\mathbf{( m m )}\end{array}$ & 0,012 & 0,004 & 0,003 & 0,003 \\
\hline $\begin{array}{c}\text { Drenabilidade } \\
\mathbf{( I / s )}\end{array}$ & 0,004 & 0,002 & 0,002 & 0,001 \\
\hline BPN & 0,003 & 0,002 & 0,004 & 0,002 \\
\hline F60 & 0,003 & 0,001 & 0,002 & 0,001 \\
\hline \hline
\end{tabular}




\subsubsection{Dados Obtidos em Maio de 2006}

Analisando os dados da matriz de correlação e de covariância apresentadas nas Tabelas 5.3.3.3.1 e 5.3.3.3.2, observa-se que a forte correlação positiva entre o ensaio de Mancha de Areia e Pêndulo Britânico com o valor de IFI (F60) calculado continua mantida.

Tabela 5.3.3.3.1 Matriz de correlação linear (Pearson) para SMA - maio de 2006

\begin{tabular}{c|c|c|c}
\hline \hline Fator & HS (mm) & BPN & F60 \\
\hline $\begin{array}{c}\text { HS } \\
(\mathbf{m m})\end{array}$ & 1 & 0,175 & 0,784 \\
\hline BPN & 0,175 & 1 & 0,744 \\
\hline F60 & 0,784 & 0,744 & 1 \\
\hline \hline
\end{tabular}

Tabela 5.3.3.3.2 Matriz de covariância para SMA - maio de 2006

\begin{tabular}{c|c|c|c}
\hline \hline Fator & HS (mm) & BPN & F60 \\
\hline $\begin{array}{c}\text { HS } \\
(\mathbf{m m})\end{array}$ & 0,0085 & 0,0005 & 0,0017 \\
\hline BPN & 0,0005 & 0,0011 & 0,0006 \\
\hline F60 & 0,0017 & 0,0006 & 0,0006 \\
\hline \hline
\end{tabular}

\subsubsection{Comparação das Quatro Avaliações Realizadas}

As Figuras 5.3.3.4.1 e 5.3.3.4.2 mostram a evolução da textura superficial do pavimento SMA, por meio das quatro avaliações de campo apresentadas anteriormente, de março de 2002 a maio de 2006 em função da textura e do atrito respectivamente, por meio dos boxplots. 


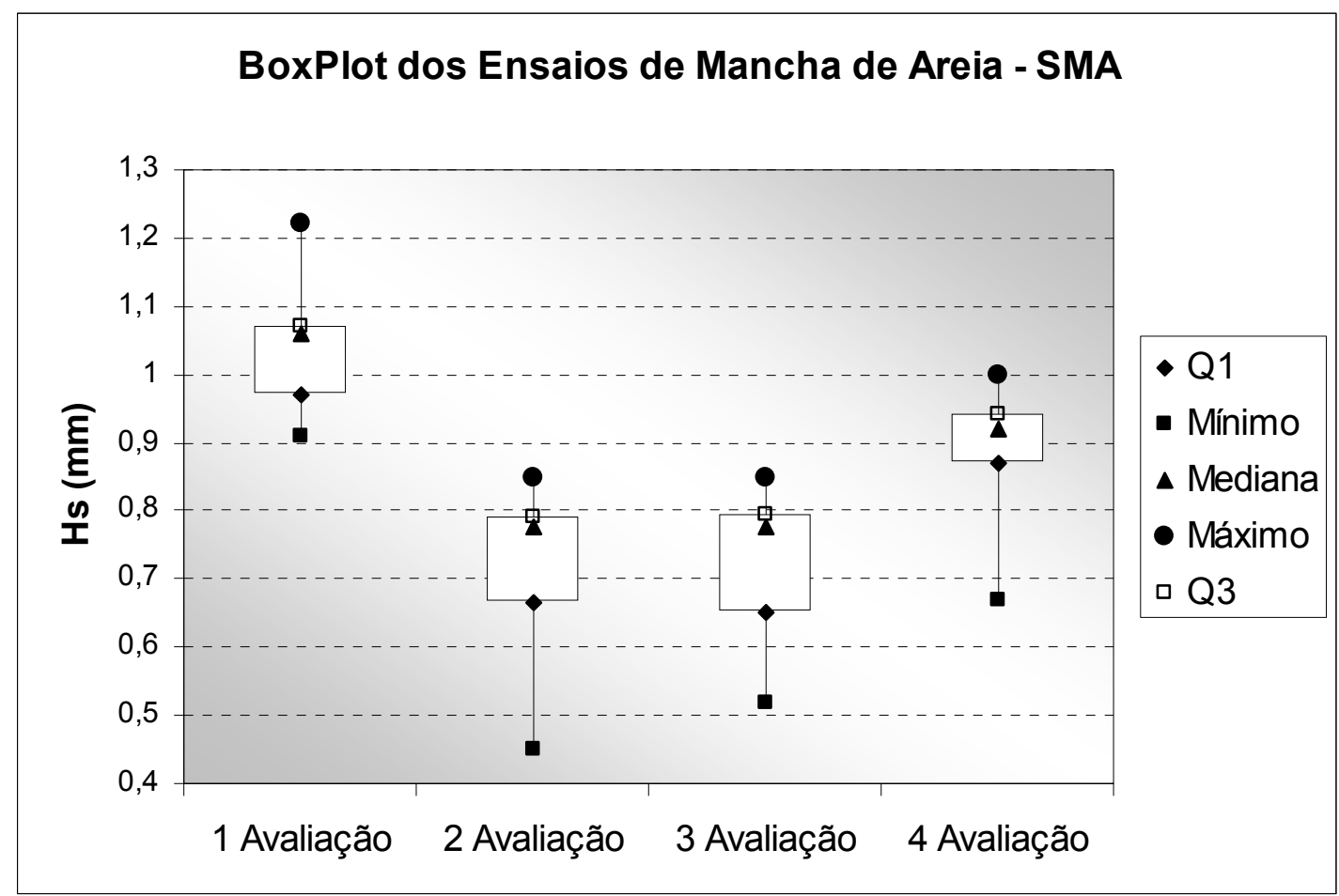

Figura 5.3.3.4.1 Boxplots dos ensaios de Mancha de Areia realizados em diversas datas para pavimentos asfálticos tipo SMA

Observa-se uma grande variação inicial da textura do pavimento tendendo a se fechar sob a ação do tráfego, porém após essa alteração há uma tendência em se manter constante; além disso, observa-se também que com o passar do tempo os valores ficam menos dispersos como visto na Figura 4.3.3.4.1 por meio da variação do intervalo entre quartis. Valores extremos mínimos encontrados, na segunda e terceira avaliação, podem ser explicados devido ao gráfico contemplar as avaliações realizadas nas faixas 1 e 2 de tipo e volume de tráfego distintos. Após decorridos quatro anos do revestimento estar sujeito às ações do tráfego pesado, nota-se a tendência da textura ficar mais aberta; isso pode ser explicado devido ao desgaste do mástique da mistura ou ao possível início do processo de desagregação.

A Figura 5.3.3.4.2 apresenta três medições realizadas com o Pêndulo Britânico, comparando a primeira e a segunda medição, cujo intervalo é de aproximadamente um ano e três meses, pode-se observar a variação do grau de polimento do agregado com o passar do tempo. A primeira avaliação possui maior homogeneidade; a dispersão do valor mínimo da segunda avaliação pode receber a 
mesma interpretação da textura, ou seja, avaliações realizadas nas faixas 1 e 2 . Observando-se a terceira avaliação, decorridos quatro anos, em comparação com as duas anteriores nota-se que o coeficiente de atrito apresenta uma elevação, assim como na análise da textura, isso pode ser explicado devido ao desgaste do mástique da mistura, expondo agregados que na avaliação anterior encontravam-se revestidos.

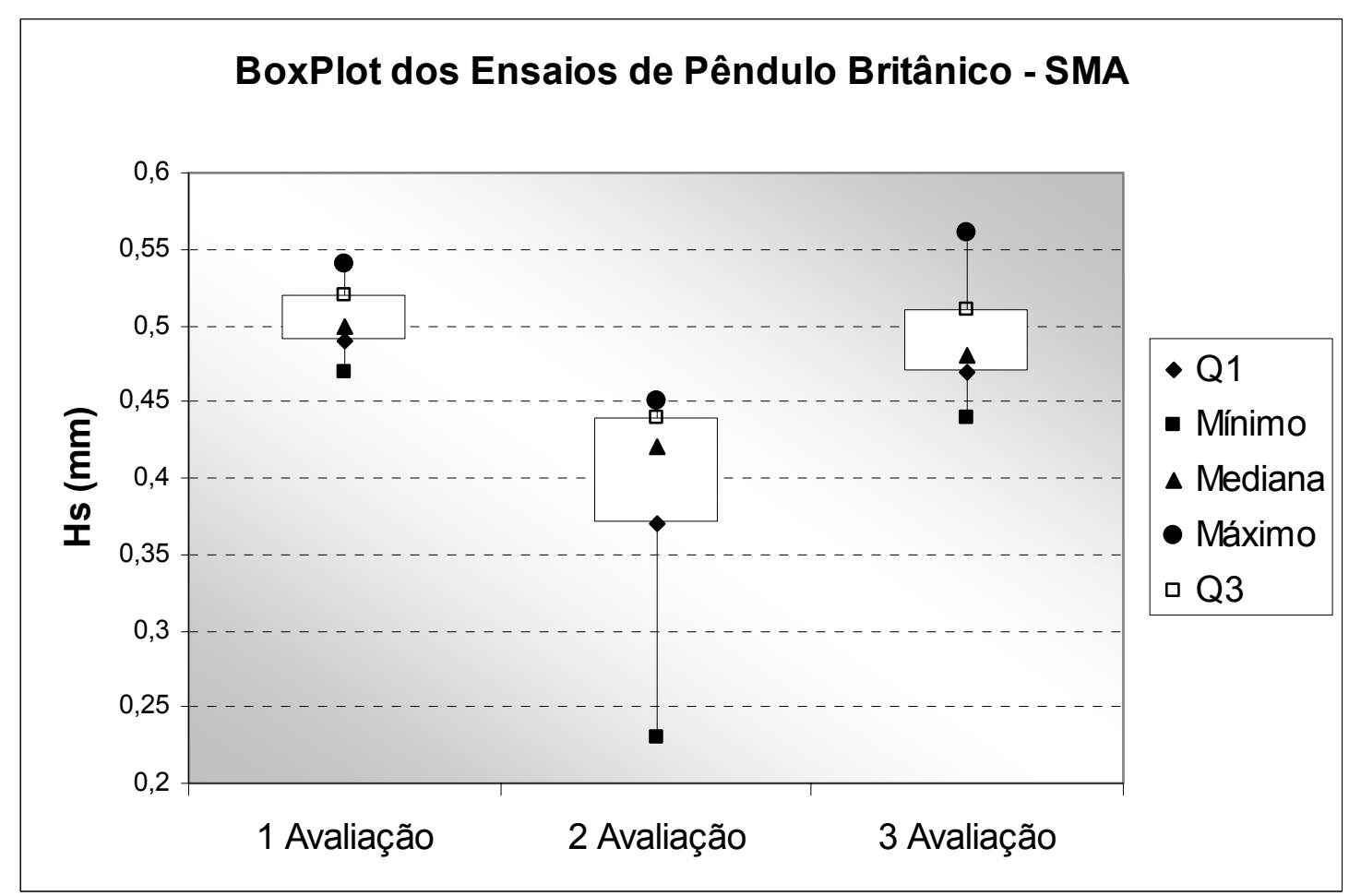

Figura 5.3.3.4.2 Boxplots dos ensaios de Atrito realizados em três datas distintas para pavimentos asfálticos SMA

\subsection{Análise dos Valores Calculados de IFI (Sp; $\mathrm{F}_{60}$ ) Visando às Necessidades de Intervenção}

Com os valores obtidos por meio dos ensaios e dos cálculos realizados, apresentados na Tabela 5.2.1, 5.2.3 e 5.2.4, a Figura 5.4.1 apresenta os valores obtidos em ensaio de campo com o Pêndulo Britânico e a Mancha de Areia, bem como os valores limites recomendados pelo DNIT, conforme visto no Capítulo 2. Observa-se que o revestimento do tipo SMA novo (2002) é o único que não necessita de correções; o 
revestimento do tipo SMA depois de decorrido um ano de operação, de acordo com a figura, precisaria receber intervenções para melhorar a microtextura; possivelmente o agregado já não apresentava de partida uma elevada resistência ao polimento. Ensaios desta natureza não são previstos nas normas brasileiras, ao contrário da prática francesa e européia em geral. Nota-se também, que o SMA na avaliação de maio de 2006 necessita de intervenção para melhoria da microtextura, porém sem necessidade de urgência.

O Concreto Asfáltico modificado por borracha necessitaria de intervenções visando à melhora da macrotextura e da microtextura; sobre o Concreto Asfáltico convencional não é possível tecer conclusões devido à heterogeneidade de situações apresentadas.

A Figura 5.4.2 apresenta os valores calculados de IFI $\left(\mathrm{Sp} ; \mathrm{F}_{60}\right)$ e valores limites sugeridos na 4a. Tentativa. Conforme pode ser observado nesta figura, somente 0 revestimento de Concreto Asfáltico modificado com borracha necessitaria receber intervenções para melhorar a macrotextura e a microtextura. Essa situação é bem diferente da apresentada pela Figura 5.4.1, sendo que pela experiência adquirida em avaliação superficial de pavimentos asfálticos, pode-se afirmar que o apresentado na Figura 5.4.2 é o correspondente ao real observado em campo. Portanto, o índice combinado está mais adequado para a avaliação de estratégias de intervenção do que a análise simplista dos resultados de ensaios.

As faixas de classificação dos valores calculados de IFI $\left(\mathrm{F}_{60}\right)$, sugeridas na $4^{\mathrm{a}}$. Tentativa estão expressas na Tabela 5.4.1; essas faixas deverão ser atendidas além daqueles valores obtidos nos ensaios de determinação da macrotextura e da microtextura. Para pavimentos novos os valores deverão estar compreendidos na classificação BOA; pavimentos em serviços serão tolerados valores na faixa REGULAR; pavimentos com classificação inferior a REGULAR deverão sofrer estratégias de manutenção a fim de garantir a segurança viária. 


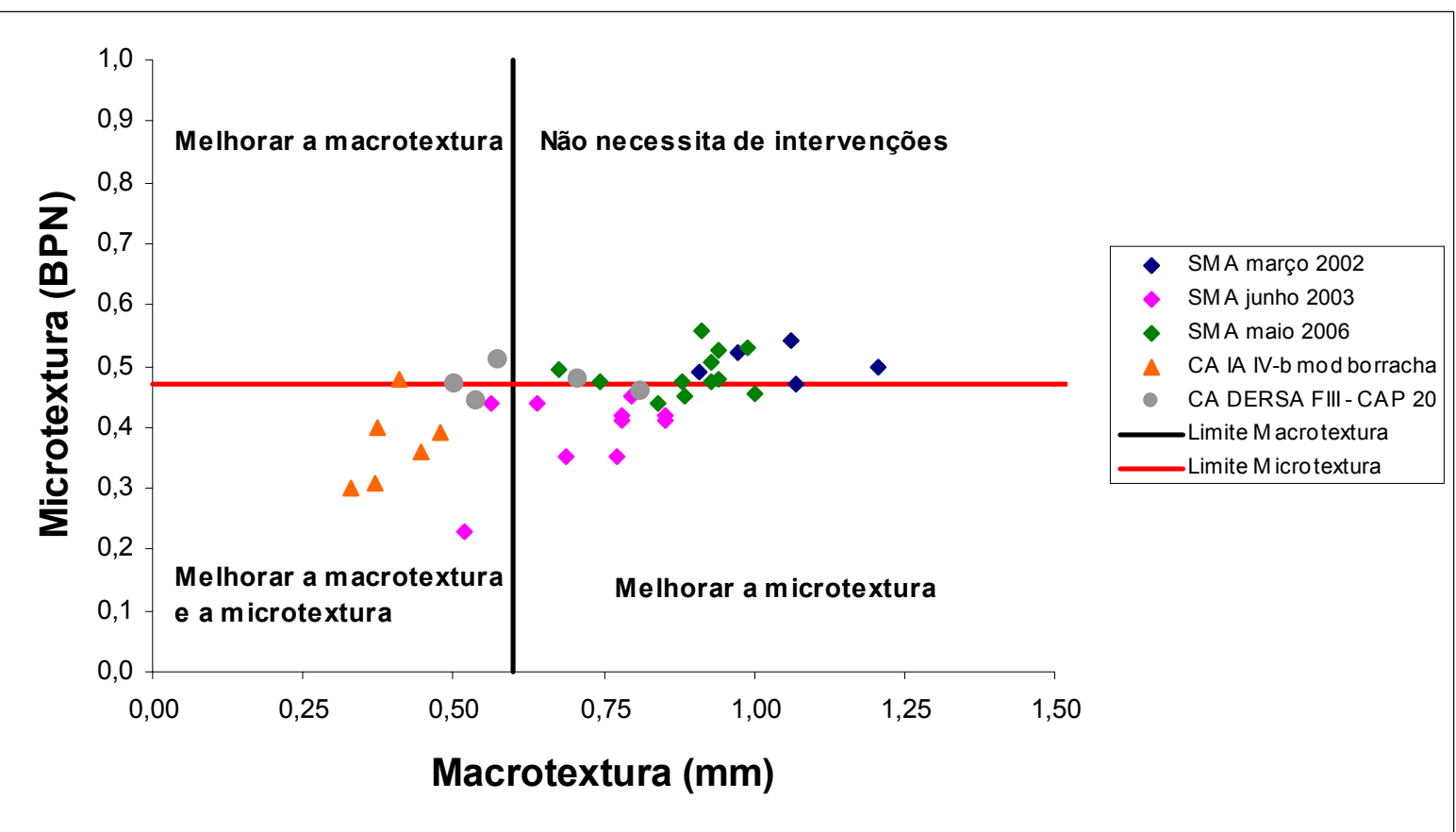

Figura 5.4.1 Valores de atrito versus valores de textura em função de limites sugeridos pelo DNIT 2000

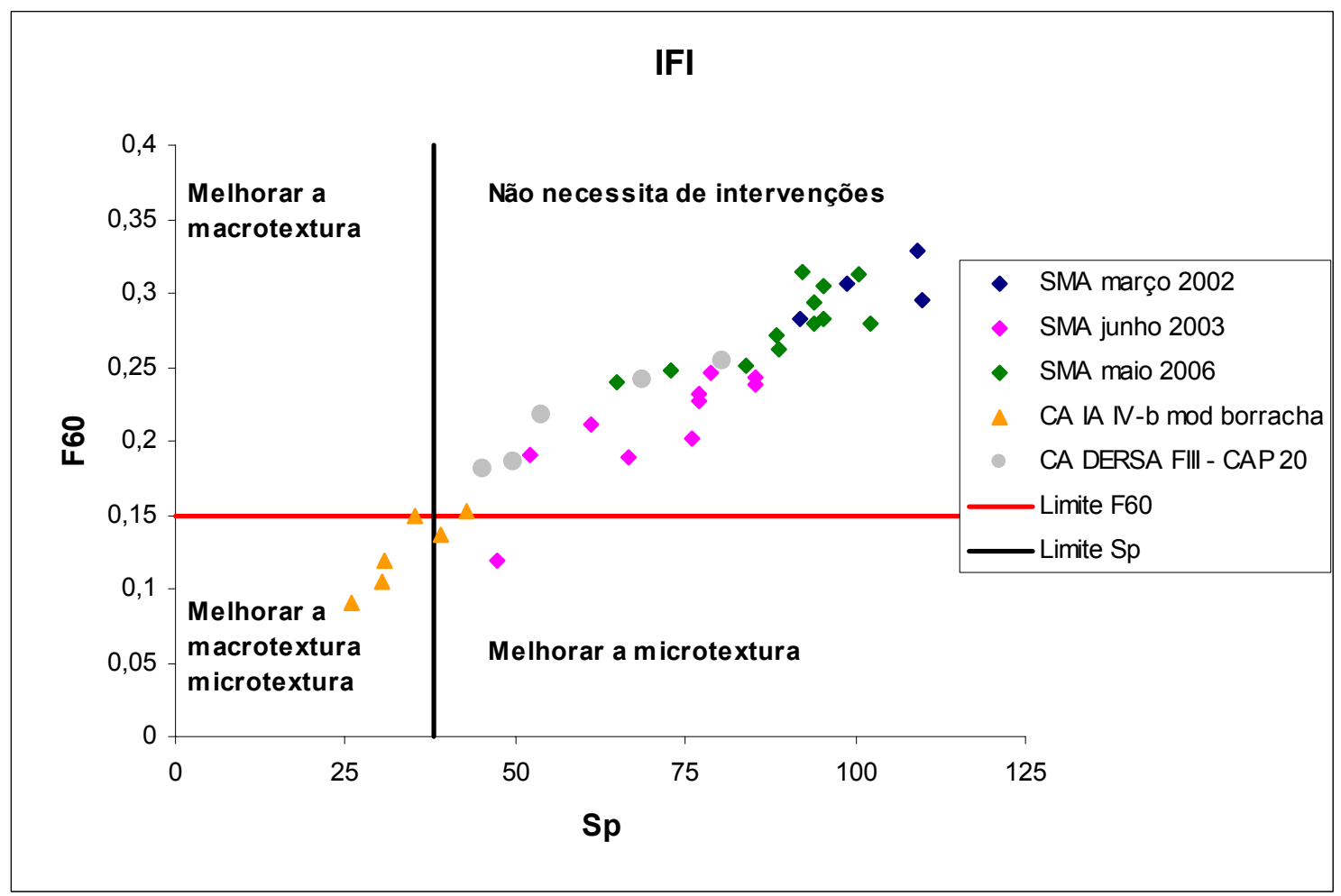

Figura 5.4.2 Valores de $I F I,(S p)$ versus $\left(F_{60}\right)$ em função de limites sugeridos na $4^{a}$. 
Tabela 5.4.1 Faixas limites de valores de $\operatorname{IFI}\left(\mathrm{F}_{60}\right) 4^{\mathrm{a}}$ Tentativa

\begin{tabular}{l|c|c}
\hline \hline \multicolumn{3}{|c}{ Limites IFI } \\
\hline Péssimo & \multicolumn{2}{|c}{$<0,05$} \\
\hline Muito Ruim & 0,06 & 0,08 \\
\hline Ruim & 0,09 & 0,11 \\
\hline Regular & 0,12 & 0,14 \\
\hline Bom & 0,15 & 0,21 \\
\hline Muito Bom & 0,22 & 0,35 \\
\hline Ótimo & \multicolumn{2}{|c}{$>0,35$} \\
\hline \hline
\end{tabular}

Outra aplicação para esse índice (IFI) é a possibilidade de estimar valores de atrito FRS, para qualquer velocidade (S). Isso na prática se torna muito interessante, como visto neste estudo, os valores de IFI $\left(\mathrm{Sp} ; \mathrm{F}_{60}\right)$ estão indicando a necessidade de intervenções urgentes, no trecho de Concreto Asfáltico modificado, visando a segurança dos usuários; sabe-se que tais atividades requerem estudos, programação, contratação e interdição do tráfego local, o que nem sempre é possível no momento. Recalculando os valores de $F_{60}$ para outras velocidades, conforme pode ser visto na Tabela 5.4.2, pode-se optar pela redução da velocidade local até que tais intervenções sejam realizadas.

Neste caso, se no referido trecho for recomendada uma velocidade de $60 \mathrm{~km} / \mathrm{h}$, pode-se reduzir a velocidade para $40 \mathrm{~km} / \mathrm{h}$, garantindo melhores condições de segurança até que as intervenções sejam feitas. Esta conclusão é decorrente da análise dos dados da Tabela 5.4.2 que mostram valores de $F(60)$ de 0,09 e 0,10, classificados como ruins. Observe-se que reduzindo-se a velocidade, o $F(40)$ passa para 0,13 e 0,15 respectivamente, classificados como regular e bom.

Tabela 5.4.2 Valores de $F_{60}$ recalculados para outras velocidades.

\begin{tabular}{c|c|c|c|c|c|c|c|c|c}
\hline \hline \multirow{2}{*}{ Sp } & \multirow{2}{*}{ FRS } & \multicolumn{7}{|c}{ Valores de F(S), km/h } \\
\cline { 3 - 11 } & & FR(0) & $\mathbf{F ( 0 )}$ & $\mathbf{F R ( 2 0 )}$ & $\mathbf{F ( 2 0 )}$ & $\mathbf{F R ( 4 0 )}$ & $\mathbf{F ( 4 0 )}$ & $\mathbf{F R ( 6 0 )}$ & $\mathbf{F ( 6 0 )}$ \\
\hline 26,01 & 30,00 & 44,06 & 0,41 & 20,43 & 0,22 & 9,47 & 0,13 & 4,39 & 0,09 \\
\hline 30,79 & 40,00 & 55,35 & 0,50 & 28,91 & 0,29 & 15,10 & 0,18 & 7,89 & 0,12 \\
\hline 30,50 & 31,00 & 43,03 & 0,40 & 22,34 & 0,23 & 11,59 & 0,15 & 6,02 & 0,10 \\
\hline 42,70 & 39,00 & 49,29 & 0,45 & 30,86 & 0,30 & 19,32 & 0,21 & 12,09 & 0,15 \\
\hline 35,17 & 48,00 & 63,79 & 0,57 & 36,12 & 0,34 & 20,45 & 0,22 & 11,58 & 0,15 \\
\hline 39,10 & 36,00 & 46,49 & 0,43 & 27,88 & 0,28 & 16,72 & 0,19 & 10,02 & 0,14 \\
\hline \hline
\end{tabular}




\subsection{Considerações Finais sobre as Análises da Amostra do Grupo de Controle}

Pode-se inferir, neste trabalho, que o ensaio de Mancha de Areia e o de Drenabilidade para os pavimentos asfálticos de Concreto Asfáltico e SMA apresentam boa correlação; sendo $\mathrm{R}=0,79$ (correlação forte) para Concreto Asfáltico e $\mathrm{R}=0,83$ (correlação forte) para o SMA.

Os valores de IFI obtidos por meio da ASTM E-1960-98 (2001), para pavimentos em Concreto Asfáltico, são mais afetados pela variação do índice de textura do pavimento do que pelo índice de atrito medido por equipamentos padronizados por essa norma.

O ensaio de Drenabilidade, quando realizado em revestimento asfáltico Concreto Asfáltico modificado por borracha e correlacionado com o valor de IFI $\left(\mathrm{F}_{60}\right)$ calculado, apresenta correlação negativa forte, ou seja, inversamente proporcional ao até agora observado, isso leva à reflexão se esse ensaio é válido para pavimentos cuja textura é fechada. Dispersões observadas nos valores obtidos por meio do ensaio de Drenabilidade indicam limitações deste ensaio para texturas fechadas e muito abertas de pavimentos asfálticos.

De maneira geral, pôde-se observar que o SMA promove uma melhor macrotextura que o Concreto Asfáltico, como era de se esperar para os projetos de mistura asfáltica executados. Quanto ao IFI, observa-se a superioridade do SMA e Concreto Asfáltico convencional sobre o Concreto Asfáltico modificado.

Embora análises de dados de acidentes não tenham sido realizadas, pode-se afirmar por meio de entrevistas realizadas com a Polícia Rodoviária local que o número de acidentes foi reduzido significativamente após a execução do SMA na "curva da onça".

Os valores de IFI $\left(\mathrm{Sp} ; \mathrm{F}_{60}\right)$ podem ser utilizados para estratégias de intervenção visando à segurança do usuário. 


\section{Conclusões}

As conclusões desta pesquisa estão tecidas em função do objetivo central e metas associadas que estão apresentados no Capítulo 1, como segue:

\section{a) Verificar a aplicabilidade da norma da ASTM E-1960-98 que define valores de IFI International Friction Index:}

O IFI pode ser utilizado por órgãos viários e aeroportuários sem necessidade de alterar os métodos de avaliação de textura e atrito em vigor (equipamentos e procedimentos), sem qualquer perda do histórico do banco de dados.

Os valores de IFI $\left(\mathrm{Sp} ; \mathrm{F}_{60}\right)$ podem ser utilizados para estratégias de intervenção visando a segurança do usuário.

Esses valores podem ser utilizados em estudos de acidentes, avaliações para sistemas de gerência de pavimentos, de manutenção, operações aeroportuárias entre outras aplicações.

b) Demonstrar que valores de macrotextura e microtextura obtidos por meio de aparelhagem portátil podem ser empregados para o cálculo dos valores de IFI:

Demonstrou-se que valores de macrotextura e microtextura obtidos por meio de aparelhagem portátil (Mancha de Areia e Pêndulo Britânico) podem ser empregados para o cálculo dos valores de IFI; 


\section{c) Estimar as relações existentes entre as medidas de atrito, textura e drenabilidade variando as superfícies ensaiadas:}

Pode-se inferir que o ensaio de Drenabilidade, nesta pesquisa, é válido para pavimentos asfálticos que apresentem textura média, variando de fina a grossa.

Dispersões observadas nos valores obtidos por meio do ensaio de Drenabilidade em comparação com o ensaio de Mancha de Areia de acordo com a ASTM E 965-96 (2001) indicaram limitações deste ensaio para revestimentos cujas texturas são muito fechadas ou muito abertas. $O$ ensaio de Drenabilidade não apresenta relação com a microtextura.

Em uma análise global de todos os tipos de revestimentos asfálticos, comprovou-se que não há forte correlação entre os ensaios de Mancha de Areia e atrito pelo Pêndulo Britânico, constituindo-se variáveis independentes. Por meio destes dois valores, determinados em ensaios simples de campo, foi verificada a existência de forte correlação com os valores de IFI (F60) calculados. Os valores de IFI para revestimentos asfálticos são mais afetados pela variação do índice de textura do pavimento (determinado pela Mancha de Areia), do que pelo índice de atrito medido por equipamentos padronizados por essa norma.

\section{d) Estabelecer critérios e faixas de classificação para a aderência em função de IFI (Sp; $\left.F_{60}\right)$ :}

Este trabalho propõe faixas de classificação para os valores de IFI $\left(\mathrm{Sp} ; \mathrm{F}_{60}\right)$ com base nas características de macrotextura e microtextura, na interpretação dos resultados obtidos e coletados de valores reais de campo e na experiência prática da avaliação de pavimentos. Os limites propostos poderão servir como base futura para a evolução de uma especificação brasileira.

Pode-se inferir nesta pesquisa que as faixas propostas da $4^{\text {a }}$ Tentativa estão aptas para serem utilizadas em rodovias e vias urbanas de alto volume de tráfego, base do 
banco de dados desta tese, dadas as fortes correlações verificadas e confiabilidade dos resultados das análises.

O IFI pode ser empregado para avaliação de revestimentos de vias com tráfego pesado, operando inclusive em baixa velocidade, pois engloba as características de microtextura e macrotextura. Ressalta-se ainda que o IFI pode ser utilizado para avaliação e verificação de limite de velocidade da pista em função de suas características de aderência.

\section{e) Outras observações: Considerações complementares}

Vale ressaltar que as coletas de dados de acidentes, geralmente não são precisas, pois dificilmente consegue-se registrar todos os acidentes que ocorrem em um determinado trecho em avaliação. Destaca-se que somente nos acidentes com vitimas, dispõe-se de maior precisão de registros, proporcionalmente àqueles em que só ocorreram danos materiais.

As pesquisas que buscam relacionar a influência das características geométricas da via na ocorrência de acidentes são realizadas em seções pilotos, não refletindo a realidade de toda a rodovia, havendo, portanto necessidade da busca de mais dados quantitativos e qualitativos envolvendo essa relação. 


\section{Referências Bibliográficas}

AGUILLÓN, P. A. Recuento Histórico de la Tribologia Hasta la Primera Civilización. Revista Tribologia Y Lubricación, Medellín, 2002.

AMERICAN ASSOCIATION OF STATE HIGHWAY AND TRANSPORTATION OFFICIALS (AASHTO). A Policy on Geometric Design of Highways and Streets. Washington, D.C., EUA, 1994.

AMERICAN ASSOCIATION OF STATE HIGHWAY AND TRANSPORTATION OFFICIALS (AASHTO). A Policy on Geometric Design of Highways and Streets. Washington, D.C., EUA, 2000.

AMERICAN SOCIETY FOR TESTING AND MATERIALS. ASTM E 1960-98: Standard Practice for calculating International Friction Index of a Pavement Surface. West Conshohocken: ASTM Standards, 2001. 5 p.

AMERICAN SOCIETY FOR TESTING AND MATERIALS. ASTM E1911-98(2002): Standard Test Method for Measuring Paved Surface Frictional Properties Using the Dynamic Friction Tester. West Conshohocken: ASTM Standards, 2002, 8p.

AMERICAN SOCIETY FOR TESTING AND MATERIALS. ASTM E274-97: Standard Test Method for Skid Resistance of Paved Surfaces Using a Full-Scale Tire. West Conshohocken: ASTM Standards, 1997, 5p.

AMERICAN SOCIETY FOR TESTING AND MATERIALS. ASTM E303-93 (1998): Standard Method for Measuring Frictional Properties Using The British Pendulum Tester. West Conshohocken: ASTM Standards, 1998, vol. 04.03, 5 p.

AMERICAN SOCIETY FOR TESTING AND MATERIALS. ASTM E670-94 (2000): Standard Test Method for Side Force Friction on Paved Surfaces Using the Mu-meter. West Conshohocken: ASTM Standards, 2000, vol. 04.03, 11 p.

AMERICAN SOCIETY FOR TESTING AND MATERIALS. ASTM E867-97 (1997): Terminology Relating to Vehicle-Pavement Systems. West Conshohocken: ASTM Standards, 1997, vol. 04.03, 8 p.

AMERICAN SOCIETY FOR TESTING AND MATERIALS. ASTM E965-96 (2001): Standard Test Method for Measuring Surface Macro texture Depth Using a Volumetric Technique. West Conshohocken: ASTM Standards, 2001, vol. 04.03, 5 p.

AMERICAN SOCIETY FOR TESTING AND MATERIALS. ASTM G40-02 (2001): Standard Terminology Relating to Wear Erosion. West Conshohocken: ASTM Standards, 2001, vol. 03.02, $8 \mathrm{p}$.

ASSOCIAÇÃO NACIONAL DOS FABRICANTES DE VEÍCULOS AUTOMOTORES - ANFAVEA. ANUÁRIO DA IDÚSTRIA AUTOMOBILÍSTICA BRASILEIRA. São Paulo: Disponível em <http://www.anfavea.com.br/anuario2006/Cap02_2006.pdf> Acesso em: 16 ago. 2006 
APS, M. Análise de Métodos de Avaliação de Superfície de Pavimentos Asfálticos Aplicados em Vias Urbanas. 2000. 143 f. Dissertação (Mestrado em Engenharia de Transportes) - Escola Politécnica, Universidade de São Paulo, São Paulo, 2000.

APS, M.; BERNUCCI L. L. B.; RODRIGUES FILHO, O. S.; QUINTANILHA, J. A.; DARONCHO, C. Avaliação de Superfícies Antiderrapantes de Pavimentos Aeroportuários. In: CONGRESSO DE PESQUISA E ENSINO EM TRANSPORTES, 17, 2003-a, Rio de Janeiro.

APS, M.; BERNUCCI L. L. B.; RODRIGUES FILHO, O. S.; BERTOLLO, S. A. M. Avaliação de Superfícies Antiderrapantes de Pavimentos Asfálticos dos Aeroportos da Cidade de São Paulo - SP - Brasil. In: SEMINAR ON PAVEMENT MANAGEMENT SYSTEMS (PMS), 2003-b, Lima, Peru.

APS, M.; BERNUCCI L. L. B.; REIS, RAFAEL M.M.; MACHADO FILHO, P.R. Medidas de macro e microtextura em Revestimentos do tipo SMA (Stone Matrix Asphalt) em seção teste da Via Anchieta. In: REUNIÃO ANUAL DE PAVIMENTAÇÃO DA ABPV, 34., 2003-c, Campinas.

APS, M.; BERNUCCI L. L. B.; COSTA, A. L. A.; CANALE, A. C.; QUINTANILHA, J. A.; SINATORA, A.; MACHADO FILHO, P. R. Aderência pneu-pavimento obtida por meio de ensaios de macro e microtextura e em provas de frenagem com veículos comerciais e sua interface na simulação dinâmica de um veículo em pista. In: ENCONTRO NACIONAL DE CONSERVAÇÃO RODOVIÁRIA, 8., 2003-d, Gramado.

APS, M.; BERNUCCI L. L. B.; BERTOLLO, S. A. M.; GONÇALVES, A. L.; VILLAVERDE, R. B.; CORRÊA, F. R.; BARREIRO, N. P. Avaliação da macro e microtextura em pavimentos asfálticos urbanos visando a segurança viária. In: REUNIÃO URBANA DE PAVIMENTAÇÃO DA ABPv, 12., 2003--e, Aracaju.

APS, M.; BERNUCCI, L. L. B.; COSTA, A. L. A.; QUINTANILHA, J. A.; MACHADO FILHO, P. $R$. Aderência pneu-pavimento obtida por meio de ensaios de macro e microtextura e em provas de frenagem com veículos comerciais. Revista ESTRADAS, Porto Alegre, n. 05, p. 31-37, nov. 2003-f.

APS, M.; BERNUCCI L. L. B.; FABRÍCIO, J. M.; FABRÍCIO, J. V. Classificação da Aderência Pneu-Pavimento por meio de um Índice Combinado de Macro e Microtextura IFI - International Friction Index. In: ENCONTRO NACIONAL DE CONSERVAÇÃO RODOVIÁRIA, 9., 2004-a, Natal.

APS, M.; BERNUCCI, L. B.; FABRÍCIO, J. M.; FABRÍCIO, J. V. F.; DE MOURA, E. Determinação do IFI - Internatiotnal Friction Index - por intermédio de aparelhagem portátil (IBP 92304). In: ENCONTRO DE ASFALTO, 17., 2004, Rio de Janeiro. Trabalhos Técnicos. Rio de Janeiro: Instituto Brasileiro de Petróleo - Comissão de Asfalto, 2004-b. p. 84-91.

APS, M.; BERNUCCI, L. B. Medidas de Macro e Microtextura e Valores de Aderência em Revestimentos Asfálticos Visando a Segurança Viária. Boletim Informativo. Rio de Janeiro, n. 173, Encarte, 1을 semestre, 2004-c. 
ARAÚJO, J. A. As Condições de Atrito Superficial das Pistas de Aeroportos como Parte da Gerência de Pavimentos. 1994. 215 f. Dissertação (Mestrado em Engenharia Civil) - Escola de Engenharia, Universidade Federal Fluminense, Niterói, 1994.

ASSOCIAÇÃO BRASILEIRA DE CONCESSIONÁRIAS DE RODOVIAS (ABCR). Relatório Anual 2005. Uma década de concessões no Brasil. Disponível em <http://www.abcr.org.br/download/relatABCR2005.pdf>. Acesso em: 02 ago. 2006.

ASSOCIAÇÃO BRASILEIRA DE PAVIMENTAÇÃO (ABPv). Boletim Técnico № $\mathbf{1 8}$. Informativo Técnico sobre Avaliação da Resistência à Derrapagem através de Aparelhagem Portátil. 1998.

BERNHARD, R. J.; WAYSON, R. L. An introduction to tire/pavement noise. The Institute for Safe, Quiet, and Durable Highways Purdue University, 2005. (Report, SQDH 2005.

BERNUCCI, L. L. B. [ ]. 2002. 6 fotografias, color., digital.

BRASIL. DEPARTAMENTO NACIONAL DE ESTRADAS DE RODAGEM. Licitação na Modalidade de Leilão para Concessão da Exploração do Lote 13, Composto pelas Rodovias BR-116/PR, BR-376/PR e BR-101/SC Trecho Curitiba Joinville - Florianópolis. Edital 497/2000, Ministério dos Transportes, Departamento Nacional de Estradas de Rodagem.

BRASIL. DEPARTAMENTO NACIONAL DE INFRAESTRUTURA DE TRANSPORTES. Manual de Restauração de Pavimentos Asfálticos. Rio de Janeiro: DNIT, 2006. (Publicação IPR, 720).

BRASIL. DEPARTAMENTO NACIONAL DE ESTRADAS DE RODAGEM. Manual de Projeto Geométrico de Rodovias Rurais. Rio de Janeiro: IPR, 1999. 195 p.

BRASIL. DEPARTAMENTO NACIONAL DE INFRA-ESTRUTURA DE TRANSPORTES. DNIT 031/2004-ES: Pavimentos flexíveis: Concreto Asfáltico: Especificação de serviço. Rio de Janeiro: IPR, 2004, 13 p.

BRASIL. Lei no 7.565, de 19 de dezembro de 1986. Código Brasileiro de Aeronáutica. (Substitui o Código Brasileiro do Ar). Diário Oficial da União, Brasília, DF, 20 dez. 1986.

BROWN, E. R.; KANDHAL, P. S.; ZHANG, J. Performance Testing For Hot Mix Asphalt. Auburn: 2001. (Report, NCAT 01-05).

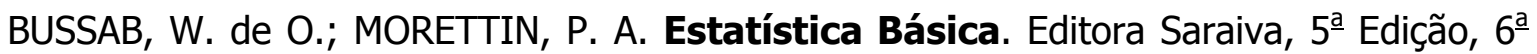
Tiragem. São Paulo, 2006.

CALEGARE, A. J. ALMEIDA Introdução ao Delineamento de Experimentos. Editora Edgard Blucher Ltda, São Paulo, 2001.

CAMPOS, G. M. Estatística Prática para Docentes e Pós-Graduandos.

Disponível em<http://www.forp.usp.br/restauradora/gmc/gmc_livro/gmc_livro.html >. Acesso em: 16 ago. 2006.

CARDOSO, S. H.; APS, M.; MARCON, A. F. A Implantação dos Centros de Análise e 
Controle de Acidentes (CACA) e suas Aplicações Práticas em Vias Urbanas. In: REUNIÃO DE PAVIMENTAÇÃO URBANA, 7., São José dos Campos. Anais. São Paulo: Associação Brasileira de Pavimentação, 1996. p. 211.

CLARK, S. K. Mechanics of Pneumatic Tires. Washington, D. C.: U.S. Dept. of Transportation, National Highway Traffic Safety Administration, 1981.

CORLEY-LAY, J. B. Friction and Surface Texture Characterization of 14 Pavement Test Sections in Greenville, North Carolina. Transportation Research Record, Washington, D. C., n. 1639, 1998.

COSTA, A.; SANTANA, L.; APS, M.; CANALE A. C.; BERNUCCI, L. L. B. Estudo da aderência pneu-pavimento e a sua influência na segurança veicular. In: CONGRESSO $E$ EXPOSIÇÃO INTERNACIONAIS DE TECNOLOGIA DA MOBILIDADE, 12., São Paulo. Anais. São Paulo: SAE Brasil, 2003.

FEDERAL AVIATION ADMNISTRATION. AC 150/5320-12: Methods for the Design, Construction and Maintenance of Skid Resistant Airport Pavement Surfaces. Washington, D.C.: FAA Advisory Circular, 1975.

FEDERAL AVIATION ADMNISTRATION. AC 150/5320-12A: Measurement, Construction, and Maintenance of Skid Resistant Airport Pavement Surface. Washington, D.C.: FAA Advisory Circular, 1986.

FERREIRA, N. P. Avaliação da Macrotextura de Trechos Pavimentados de Rodovias Estaduais Situadas na Região Insular do Município de Florianópolis. 2002. 161 f. Dissertação (Mestrado em Engenharia Civil) - Centro Tecnológico, Universidade Federal de Santa Catarina, Florianópolis, 2002.

GOTHIÉ, M. Indice International de Frottement: Un Exemple D'Application. AIPCR Routes/ Roads, Paris, n. 300 IV, p. 45-55, 1998.

GUZMÁN, B. R. Tratamientos y Mezclas Resistentes al Deslizamiento. El Asfalto: Boletín de la Comisión Permanente del Asfalto, Buenos Aires, n. 71, 1995.

HAAS, R.; HUDSON, W. R.; ZANIEWSKI, J. Modern Pavement Management. Malabar: Krieger Publishing Company, 1994. 583p.

HANSON, D. I.; PROWELL, B. D. Evaluation Of Circular Texture Meter For Measuring Surface Texture Of Pavements. Auburn: 2004. número de páginas. (Report, NCAT Report 04-05).

HANSON, D. I.; JAMES, R. S. Colorado DOT Tire/Pavement Noise Study. Department of Transportation Research, 2004. (Report, CDOT-DTD-R-2004-5).

HANSON, D. I.; PROWELL, B. D. Evaluation of circular texture meter for measuring surface of pavements. Auburn: 2004. número de páginas. (Report, NCAT 04-05).

HARRIS, A. J. Road Surface Texture and the Slipperiness of Wet Roads. Highway Research Record, Washington, D. C., n. 214, p. 18-32, 1968. 
HARVERSON, D. Friction Harmonics. World Highways: Routes du Monde, London, v.2, p. 46-47, mar. 1993.

HENRY, J. J.; HIRONARI, A.; KAMEYAMA, S.; TAMAI, A.; KASAHARA, A.; SAITO, K. Determination of the International Friction Index (IFI) using the Circular Texture Meter (CTM) and the Dynamic Friction Tester (DFT). Disponível em <http://www.kinkikensetsu.co.jp/topics/ronbun/pdf/002.pdf>. Acesso em: 29 ago. 2005.

HUTCHINGS, I. M. Tribology: Friction and Wear of Engineering Materials. London: Edward Arnold, 1992. 273 p.

INDIAN ROADS CONGRESS. State of The Art: Pavement Slipperiness and Skid Resistance. New Delhi: Highway Research Board, 1976. 50p. (Special Report, 2).

INTERNATIONAL CIVIL AVIATION ORGANIZATION. Airport Services Manual Part 2: Pavement Surfaces Conditions. Montreal: ICAO. 128 p.

IVEY, D. L. AND GALLAWAY, B. M. Tire-Pavement Friction: A Vital Design Objective. Evaluation of Pavement Surface Properties and Vehicle Interaction. Highway Research Record, Washingotn, D. C., n. 471, 1998.

LÓPEZ, B. S. Tratamiento del Problema del Deslizamiento por la Administración de Carreteras Española. El Asfalto: Boletín de la Comisión Permanente del Asfalto, Buenos Aires, n. 71, 1995.

MCDANIEL, R.; BERNHARD, B.; THORNTON, W. Field Evaluation of Porous Asphalt Pavements North Central Superpave Center. West Lafayette: 2004. Institute for Safe, Quiet and Durable Highways. (Report, SQDH 2004-3).

MOMM, L. Estudo dos Efeitos da Granulometria sobre a Macrotextura Superficial do Concreto Asfáltico e seu Comportamento Mecânico. 1998. 259 f. Tese (Doutorado em Engenharia de Transportes) - Escola Politécnica, Universidade de São Paulo, São Paulo, 1998.

MOURA, E. [ ]. 1998. 2 fotografias, color., digital.

NASCIMENTO, H. R. C.; REIS, R. M. M. Camada Porosa de Atrito com Utilização do Asfalto modificado com Polímeros. São Paulo: Ipiranga Asfaltos, 1999. páginas.

NASCIMENTO, H. R. C.; Estudo Comparativo de Revestimentos Asfálticos Usinados a Quente utilizando avaliação funcional e estrutural de pistas-teste. Dissertação (Mestrado em Engenharia de Transportes) - Escola Politécnica, Universidade de São Paulo, São Paulo, 2004.

NORDARI, C. T. Método de Avaliação da Segurança Potencial de Segmentos Rodoviários Rurais de Pista Simples. 2003. folhas. Tese (Doutorado em Engenharia Sistema de Transporte e Logística) - Escola de Engenharia, Universidade Federal do Rio Grande do Sul, Porto Alegre, 2003.

NOVA DUTRA - CENTRO DE PESQUISAS RODOVIÁRIAS. Relatório de Avaliação Monitoramento da Camada Drenante com Asfalto Modificado por Polímero. RA- 
2.1/P-GG.000-002. São Paulo, SP, 30 de junho 2000.

NOYCE, D. A.; BAHIA, H. U.; YAMBÓ, J. M.; KIM, G. Incorporating Road Safety into Pavement Management: Maximizing Asphalt Pavement Surface Friction for Road Safety Improvements. Madison: Midwest Regional University Transportation Center, 2005.

OLIVEIRA. J. A.; DAVID, D.; CERATTI, J. A. P. Estudo Comparativo entre os Revestimentos Delgados TSD e Cape Seal (IBP 396_04). In: ENCONTRO DE ASFALTO, 17., 2004, Rio de Janeiro. Trabalhos Técnicos. Rio de Janeiro: Instituto Brasileiro de Petróleo - Comissão de Asfalto, 2004. p. 174-181.

OSÓRIO, C. A. A. de C. Avaliação da Consistência do Traçado de Rodovias com Duas Faixas de Tráfego. 2000. 138 f. Dissertação (Mestrado em Engenharia de Transportes), Escola Politécnica, Universidade de São Paulo, São Paulo, 2000.

PONCINO, H. Adherencia neumatico-pavimento: Conceptos generales: estado del conocimiento. El Asfalto: Boletín de la Comisión Permanente del Asfalto, Buenos Aires, n. 94, 2002.

PONTES FILHO, G. Estradas de Rodagem: projeto geométrico. São Carlos: [s.n.], 1998. $432 \mathrm{p}$.

POTTINGER, M. G.; YAGER, T. J. Overview. In: The Tire Pavement Interface. Baltimore: ASTM Standards, 1986. p. 9-15. (STP, 929).

PREFEITURA MUNICIPAL DE SANTOS. Sumário de Dados, 3. Santos: PMS, 1994.

REIS, R. M. M. Revestimento Asfáltico Tipo SMA para Alto Desempenho em Vias de Tráfego Pesado. 2002. 95 f. Dissertação (Mestrado em Engenharia de Transportes) Escola Politécnica, Universidade de São Paulo, São Paulo, 2002.

SABEY, B. E. Road Safety and Value for Money. Crownthorne: Transport and Road Research Laboratory, 1980. (Supplementary Report, 581).

SECRETARIA DE ESTADO DOS TRANSPORTES. Os Transportes no Estado de São Paulo. Balanço Anual, 2005.

SILVA, A. M. Atrito em Pistas Molhadas. Revista da Diretoria de Engenharia da Aeronáutica, Rio de Janeiro, mês 1981.

SILVA, A. M.; RODRIGUES FILHO, O. S. GROOVING: Aspectos Teóricos e Executivos da Aplicação em Pavimentos Aeroportuários. São Paulo: COPASP, 1981.

SILVA, C. H. Estudo do efeito da carga normal e da velocidade no coeficiente de atrito do par polietileno de alta densidade e aço carbono galvanizado. 1998. 129 f. Dissertação (Mestrado em Engenharia Mecânica) - Escola Politécnica, Universidade de São Paulo, São Paulo, 1998.

TRANSIT NEW ZEALAND. State Highway Asset Management Manual. 3 ed. 
Wellington: State Highway Manager, 2000. 210 p.

TRANSPORTATION RESEARCH BOARD. Controle dos Pavimentos Derrapantes: Fendilhamento dos Pavimentos Asfálticos. Tradução Departamento Nacional de Estradas de Rodagem. Rio de Janeiro: DNER, 1977. 198 p. (Publicação, 618).

TRANSPORTATION RESEARCH BUREAU. Relationship between pavement surface texture and highway traffic noise. NCHRP Synthesis Report 268. Washington, D. C., 1998.

TRANSPORTATION RESEARCH BUREAU. Performance Survey on Open-Graded Friction Course Mixes. NCHRP Synthesis Report 284. Washington, D. C., 2000.

TRANSPORTATION RESEARCH BOARD. Evaluation of Pavement Friction Characteristics: A Synthesis of Highway Practice. NCHRP Synthesis Report 291, Washington, D. C., 66 p., 2000.

UNIVERSIDADE DE SÃO PAULO. Escola Politécnica. Departamento de Engenharia de Transportes. IS 01.01: Instrução de Ensaio Mancha de Areia. São Paulo: Laboratório de Tecnologia de Pavimentação, 2002. número de páginas.

WAMBOLD, J. C., ANDRESEN, A. The Measurement and Theory of Tire Friction on Contaminated Surfaces. Conference Proceedings, Washington, D. C., n. 18, p. 94-98, 1998.

WAMBOLD, J. C., HENRY, J. J. AND HEGMON, R. R. Skid Resistance of Wet-Weather Accident Sites. In: POTTINGER, M. G.; YAGER, T. J. The Tire Pavements Interface. Baltimore: ASTM Standards, 1986. p. 9-15. (STP, 929).

WAMBOLD, J. C., HENRY, J. J. NASA Wallops Tie/Runway Friction: Workshops 19932002. Montreal: TDC, 2002. 155p. (Publication, TP14190E).

WAMBOLD, J.C.; ANTLE, C. E.; HENRY, J. J.; RADO, Z. International PIARC Experience to Compare and Harmonize Texture and Skid resistance Measurements. Paris: PIARC, 1995. 423 p. (Publication, 01.04.T). 


\section{Referências Bibliográficas Consultadas}

ALVES FILHO, A.; OliVEIRA, E. F.; ROBORTELLA, J. L. C. Física: volume 1. São Paulo: Editora Ática, 1984.

ARANHA, F. A. D. et al. Experiência Paulista na Utilização dos Revestimentos Drenantes. In: SIMPÓSIO DE OBRAS RODOVIÁRIAS, 1., 1998, São Paulo. Rodo 98. Anais. São Paulo: ABGE, 1998. p. 51-67.

CAMPO, JUAN A. F, Nuevas técnicas de Renovación Superficial de Pavimentos. In: ENCONTRO DE ASLFATO, 10., 1990, Rio de Janeiro. Trabalhos Técnicos. Rio de Janeiro: Instituto Brasileiro de Petróleo - Comissão de Asfalto, 1990. p. 258-273.

CARDOSO, S. H. Implantação de um Sistema de Gerência de Pavimentos no Ministério da Aeronáutica: Uma Necessidade Urgente. Revista da Diretoria de Engenharia da Aeronáutica, Rio de Janeiro, n. 01, p. 30-35,1991.

CHELLIAH, T. et al. Developing a Design Policy to Improve Pavement Surface Characteristics. Transportation Research Record, Washington, D. C., número, 2003. 1 CD-ROM.

COSTA, A. Desenvolvimento de Pneus Utilizando-se Ensaios Laboratoriais e Simulações Computacionais. In: ENCONTRO TÉCNICO AEA: TESTES E ENSAIOS DE MATERIAIS PARA A INDÚSTRIA AUTOMOBILÍSTICA, São Bernardo do Campo. 2002.

COSTA, A. Vibrational behavior of tire-suspension system for commercial vehicles regarding comfort and tread wear. In: COLLOQUIUM INTERNACIONAL DE SUSPENSÕES, 2., COLLOQUIUM DE IMPLEMENTOS RODOVIÁRIOS, 1, Caxias do Sul. São Paulo: SAE Brasil, 2002.

DAHIR, S. H. M., GRAMLING, W. L. Wet-Pavement Safety Programs. NCHRP Synthesis 
Report, Washington, D. C., v. 158, 1990.

DAVIS, R. M. Comparison of Surface Characteristics of Hot-Mix Asphalt Pavement Surfaces at the Virginia Road. 2001. 245 f. Dissertação (Mestrado em Engenharia Civil e Ambiental) - Faculty of Virginia Polytechnic Institute and State University, Blacksburg, 2001.

DO, M. T. et al. Full Scale Tests for the Assessment of Wear of Pavement Surfaces. Transportation Research Record. Washington, D. C., número, 2003. 1 CD-ROM.

DOMINGUES, F. A. A. MID: Manual para Identificação de Defeitos de Revestimentos Asfálticos de Pavimentos. São Paulo: [s.n.], 1993. 87p.

FLINTSCH, G. W. et al. Pavement Surface Macrotexture Meassurent and Application. Transportation Research Record, Washington, D. C., número, 2003. 1 CD-ROM.

HOERNER, T.E. et al. Current Practice of PCC Pavement Texturing. Transportation Research Record. Washington, D.C., 2003. 1 CD-ROM.

JOURNAL OF THE EASTERN ASIA SOCIETY FOR TRANSPORTATION STUDIES. Kojimachi, Japan: EASTS, 1995- . Biannual. ISSN 1341-8521. Disponível em <http://www.easts.info/publications/journal_proceedings/j4-1.htm>. Acesso em 24 jan. 2005.

MANION, M. The Role of New Data Collection Technology in Performance Specified Maintenance Contracts. Transportation Research Record. Washington, D. C., 2003. 1 CD-ROM.

MOORE, D. F. The friction of Pneumatic Tyres. Amsterdam: Elsevier Scientific Publishing, 1975. 220p.

PERSSON; B. N. J. Sliding Friction: Physical Principles and Applications. Heidelberg: Springer. 1998. 515 p.

PINHEIRO, E. G. A.; COSTA L. A. ABAQUS aplicado em análises de pneus Pirelli. In: REUNIÃO LATINO-AMERICANA DE USUÁRIOS ABAQUS, 1., Buenos Aires. 1999.

PRADO, M. R.; COSTA NETO, C. A.; D'ELBOUX E.; COSTA A. Bus Handling Validation and Analysis Using ADAMS/Car. In: 2001 ADAMS USER CONFERENCE, Berchtesgaden. 2001.

RIZENBERGS, R. L.; BURCHETT, J. L.; NAPIER, C. T. Accidents on Rural Interstate and Parkway Roads and their Relation to Pavement Friction. Transportation Research Record, Washington, D. C., n. 584, p. 22-36, 1976.

SCHALLAMACH, A. The load dependence of Rubber friction. The Proceedings of Physical Society, Welwyn Garden City, v. 65, n. 393B, p. 657-661., set. 1952.

WANG, F.; MACCHENEHL, R. B. The Current Status and Variability of In-Service Truck Tire Pressures in Texas. Transportation Research Record, Washington, D. C., 2003. 1 CD-ROM. 
YAMAZAKI, S. Tire Friction Property on Indoor Drum Surface and Actual Road Surface. The Tire Technology Expo 2003, Hamburg, 2003.

YEAMAN, J. Are We Afraid of the IFI? Disponível em <http://www.pavement.com.au/downloads/papers/afraid\%20of\%20the\%20IFI.pdf>. Acesso em: 04 set. 2005. 
Anexo 1 Par de Valores de IFI $\left(\mathrm{Sp} ; \mathrm{F}_{60}\right)$

Anexo 1.1 Faixas Propostas $3^{\text {a }}$ Tentativa

\begin{tabular}{c|c}
\hline \hline Sp & F60 \\
\hline 5,56 & 0,06 \\
\hline 16,29 & 0,07 \\
\hline 21,19 & 0,08 \\
\hline 27,26 & 0,10 \\
\hline 28,56 & 0,11 \\
\hline 36,20 & 0,14 \\
\hline 37,98 & 0,15 \\
\hline 63,08 & 0,23 \\
\hline 59,80 & 0,24 \\
\hline 113,47 & 0,34 \\
\hline \hline
\end{tabular}

Anexo 1.2 Faixas Propostas $4^{\mathrm{a}}$ Tentativa

\begin{tabular}{c|c}
\hline \hline Sp & F60 \\
\hline 5,56 & 0,05 \\
\hline 16,29 & 0,08 \\
\hline 21,19 & 0,09 \\
\hline 27,26 & 0,11 \\
\hline 28,56 & 0,12 \\
\hline 36,20 & 0,14 \\
\hline 37,98 & 0,15 \\
\hline 63,08 & 0,21 \\
\hline 59,80 & 0,22 \\
\hline 113,47 & 0,35 \\
\hline
\end{tabular}


Anexo 2 Classificação e Tempo de Serviço dos Revestimentos Asfálticos

\begin{tabular}{|c|c|c|c|c|c|c|c|c|c|c|c|c|c|c|c|}
\hline \multirow{4}{*}{$\begin{array}{c}\text { Número } \\
\text { de } \\
\text { Pontos }\end{array}$} & \multirow{2}{*}{\multicolumn{2}{|c|}{ Unidade Amostragem }} & \multirow{4}{*}{$\begin{array}{l}\text { Anos de } \\
\text { Execução }\end{array}$} & \multirow{2}{*}{\multicolumn{3}{|c|}{$\begin{array}{c}\text { Macro Textura } \\
\text { Altura de Areia Hs (mm) }\end{array}$}} & \multirow{4}{*}{$\begin{array}{c}\begin{array}{c}\text { Drena- } \\
\text { bilidade }\end{array} \\
\text { I/s }\end{array}$} & \multirow{2}{*}{\multicolumn{2}{|c|}{$\begin{array}{c}\text { Micro Textura } \\
\text { Pend. Britanico } \\
\end{array}$}} & \multirow{4}{*}{$\begin{array}{l}\text { Mu- } \\
\text { meter }\end{array}$} & \multirow{4}{*}{$\mathbf{S}_{\mathrm{p}}$} & \multirow{4}{*}{$\begin{array}{c}\text { FR- } \\
60\end{array}$} & \multirow{4}{*}{ F60 } & \multirow{4}{*}{ Conceito } & \multirow{4}{*}{ LOCAL } \\
\hline & & & & & & & & & & & & & & & \\
\hline & \multirow{2}{*}{ No } & \multirow{2}{*}{ Tipo } & & \multirow{2}{*}{\begin{tabular}{|c|} 
Diam. \\
Med. cm \\
\end{tabular}} & \multirow{2}{*}{$H s=T x$} & \multirow{2}{*}{$\begin{array}{l}\text { Classi- } \\
\text { ficação }\end{array}$} & & Media & Classi- & & & & & & \\
\hline & & & & & & & & FRS & ficação & & & & & & \\
\hline 1 & 1 & Concreto Asfáltico & +6 & 24,5 & 0,53 & $M$ & 0,034 & 47,8 & MR & - & 48,64 & 17,10 & 0,19 & BOM & \multirow{4}{*}{$\begin{array}{l}\text { Campo de } \\
\text { Prova da } \\
\text { Pirreli }\end{array}$} \\
\hline 2 & 2 & Concreto Asfáltico & +6 & 23 & 0,60 & M & 0,063 & 51,2 & MR & - & 56,76 & 21,22 & 0,23 & MUITO BOM & \\
\hline 3 & 3 & Concreto Asfáltico & +6 & 27 & 0,44 & M & 0,013 & 55,4 & $\mathrm{R}$ & - & 38,00 & 14,86 & 0,17 & BOM & \\
\hline 4 & 4 & Concreto Asfáltico & +6 & 23,5 & 0,58 & $\mathrm{M}$ & 0,087 & 61 & $\mathrm{R}$ & - & 53,88 & 24,12 & 0,25 & MUITO BOM & \\
\hline 5 & 1 & SMA faixa alemã D0-11S & 0 & 16,8 & 1,13 & G & - & 59 & $\mathrm{R}$ & - & 116,52 & 38,41 & 0,36 & ÓTIM0 & \multirow{5}{*}{ Interlagos } \\
\hline 6 & 2 & SMA faixa alemã D0-11S & 0 & 19,9 & 0,80 & G & - & 59,5 & $\mathrm{R}$ & - & 79,71 & 31,78 & 0,31 & MUITO BOM & \\
\hline 7 & 3 & SMA faixa alemã D0-11S & 0 & 20,3 & 0,77 & M & - & 61 & $\mathrm{R}$ & - & 76,15 & 31,63 & 0,31 & MUITO BOM & \\
\hline 8 & 4 & SMA faixa alemã D0-11S & 0 & 17,2 & 1,08 & $\mathrm{G}$ & - & 52,8 & MR & - & 110,63 & 33,60 & 0,32 & MUITO BOM & \\
\hline 9 & 5 & SMA faixa alemã D0-11S & 0 & 20 & 0,80 & $\mathrm{G}$ & - & 50,4 & MR & - & 78,80 & 26,72 & 0,27 & MUITO BOM & \\
\hline 10 & 1 & CA convencional F III & 4 & 31,3 & 0,32 & $\mathrm{~F}$ & 0,028 & 54 & MR & - & 24,75 & 7,16 & 0,11 & REGULAR & \multirow[t]{17}{*}{ Santos } \\
\hline 11 & 2 & CA convencional F III & 4 & 26,8 & 0,44 & $M$ & 0,058 & 49 & MR & - & 38,38 & 13,32 & 0,16 & BOM & \\
\hline 12 & 3 & CA convencional F III & 4 & 24,7 & 0,52 & $M$ & 0,164 & 60 & $\mathrm{R}$ & - & 47,47 & 20,93 & 0,22 & MUITO BOM & \\
\hline 13 & 4 & CA convencional F III & 4 & 18,5 & 0,93 & G & 0,241 & 57 & $\mathrm{R}$ & - & 94,05 & 33,50 & 0,32 & MUITO BOM & \\
\hline 14 & 5 & CA convencional F III & 3 & 32,4 & 0,3 & $\mathrm{~F}$ & 0,055 & 58 & $\mathrm{R}$ & - & 22,48 & 6,27 & 0,11 & RUIM & \\
\hline 15 & 6 & CA convencional F III & 3 & 30,4 & 0,34 & $\mathrm{~F}$ & 0,047 & 49 & MR & - & 27,02 & 7,70 & 0,12 & REGULAR & \\
\hline 16 & 7 & CA convencional F III & 3 & 28,8 & 0,38 & $\mathrm{~F}$ & 0,031 & 56 & $\mathrm{R}$ & - & 31,57 & 11,49 & 0,15 & BOM & \\
\hline 17 & 8 & CA convencional F III & 0 & 26,2 & 0,46 & $M$ & 0,062 & 58 & $\mathrm{R}$ & - & 40,66 & 16,96 & 0,19 & BOM & \\
\hline 18 & 9 & CA convencional F III & 0 & 26,2 & 0,46 & $M$ & 0,038 & 58 & $\mathrm{R}$ & - & 40,66 & 16,96 & 0,19 & BOM & \\
\hline 19 & 10 & CA convencional F III & 4 & 16 & 1,24 & MG & 0,297 & 58 & $\mathrm{R}$ & - & 129,26 & 39,39 & 0,37 & ÓTIM0 & \\
\hline 20 & 11 & CA convencional F III & 4 & 18 & 0,98 & G & 0,108 & 59 & $\mathrm{R}$ & - & 99,73 & 35,74 & 0,34 & MUITO BOM & \\
\hline 21 & 12 & CA convencional F III & 3 & 24,9 & 0,51 & $\mathrm{M}$ & 0,052 & 48 & MR & - & 46,34 & 16,32 & 0,19 & BOM & \\
\hline 22 & 13 & CA convencional F III & 3 & 24,9 & 0,51 & $M$ & 0,089 & 54 & $\mathrm{R}$ & - & 46,34 & 18,36 & 0,20 & BOM & \\
\hline 23 & 14 & CA convencional F III & 0 & 25,7 & 0,48 & $M$ & 0,036 & 60 & $\mathrm{R}$ & - & 42,93 & 18,72 & 0,21 & BOM & \\
\hline 24 & 15 & CA convencional F III & 0 & 26,5 & 0,45 & $M$ & 0,021 & 57 & $\mathrm{R}$ & - & 39,52 & 16,08 & 0,18 & BOM & \\
\hline 25 & 16 & CA convencional F III & 3 & 27,7 & 0,41 & $M$ & 0,004 & 54 & $\mathrm{R}$ & - & 34,98 & 12,93 & 0,16 & BOM & \\
\hline 26 & 17 & CA convencional F III & 3 & 28,1 & 0,4 & $M$ & 0,019 & 54 & $\mathrm{R}$ & - & 33,84 & 12,32 & 0,15 & BOM & \\
\hline
\end{tabular}




\begin{tabular}{|c|c|c|c|c|c|c|c|c|c|c|c|c|c|c|c|}
\hline 27 & 18 & CA convencional F III & 0 & 28,4 & 0,39 & $\mathrm{~F}$ & 0,003 & 63 & $\mathrm{R}$ & - & 32,70 & 13,66 & 0,17 & $\mathrm{BOM}$ & \\
\hline 28 & 19 & CA convencional F III & 0 & 33,5 & 0,28 & $\mathrm{~F}$ & 0,005 & 59 & $\mathrm{R}$ & - & 20,21 & 4,97 & 0,10 & RUIM & \\
\hline 29 & 20 & CA convencional F III & 1 & 25,4 & 0,49 & $M$ & 0,034 & 58 & $\mathrm{R}$ & - & 44,06 & 18,65 & 0,21 & BOM & \\
\hline 30 & 21 & CA convencional F III & 1 & 25,7 & 0,48 & M & 0,013 & 53 & $\mathrm{R}$ & - & 42,93 & 16,54 & 0,19 & BOM & \\
\hline 31 & 22 & CA convencional F III & 1 & 34,7 & 0,26 & $\mathrm{~F}$ & 0,012 & 54 & $\mathrm{R}$ & - & 17,94 & 3,32 & 0,08 & RUIM & \\
\hline 32 & 1 & CA faixa III - PMSP CAP 20 & 2 & 24,2 & 0,54 & M & - & 66,6 & $\mathrm{R}$ & - & 50,12 & 24,56 & 0,25 & MUITO BOM & \multirow{15}{*}{$\begin{array}{l}\text { Coredor } \\
\text { Tecnológico }\end{array}$} \\
\hline 33 & 2 & CA faixa III - PMSP CAP 20 & 2 & 21 & 0,72 & M & - & 68 & $\mathrm{R}$ & - & 70,36 & 33,41 & 0,32 & MUITO BOM & \\
\hline 34 & 3 & CA faixa III - PMSP CAP 20 & 2 & 23,4 & 0,58 & M & - & 67 & $\mathrm{R}$ & - & 54,41 & 26,73 & 0,27 & MUITO BOM & \\
\hline 35 & 4 & CA faixa III - DERSA CAP 20 & 2 & 32,6 & 0,30 & $\mathrm{~F}$ & - & 62,4 & $\mathrm{R}$ & - & 22,41 & 6,70 & 0,11 & RUIM & \\
\hline 36 & 5 & CA faixa III - DERSA CAP 20 & 2 & 29,3 & 0,37 & $\mathrm{~F}$ & - & 60,2 & $\mathrm{R}$ & - & 30,50 & 11,69 & 0,15 & BOM & \\
\hline 37 & 6 & CA faixa III - DERSA CAP 20 & 2 & 28,4 & 0,39 & $\mathrm{~F}$ & - & 57,6 & $\mathrm{R}$ & - & 33,22 & 12,78 & 0,16 & BOM & \\
\hline 38 & 7 & CA IA faixa IV-b CAP 20 & 2 & 31,1 & 0,33 & $\mathrm{~F}$ & - & 46,6 & MR & - & 25,77 & 6,70 & 0,11 & RUIM & \\
\hline 39 & 8 & CA IA faixa IV-b CAP 20 & 2 & 28,1 & 0,40 & M & - & 47 & $\mathrm{MR}$ & - & 34,18 & 10,88 & 0,14 & BOM & \\
\hline 40 & 9 & CA IA faixa IV-b CAP 20 & 2 & 30,2 & 0,35 & $\mathrm{~F}$ & - & 45,8 & MR & - & 28,03 & 7,70 & 0,12 & REGULAR & \\
\hline 41 & 10 & CA IA faixa IV-b mod SBS & 2 & 33,5 & 0,28 & $\mathrm{~F}$ & - & 47,2 & MR & - & 20,61 & 4,17 & 0,09 & RUIM & \\
\hline 42 & 11 & CA IA faixa IV-b mod SBS & 2 & 33,3 & 0,29 & $\mathrm{~F}$ & - & 47,6 & $\mathrm{MR}$ & - & 21,00 & 4,40 & 0,09 & RUIM & \\
\hline 43 & 12 & CA IA faixa IV-b mod SBS & 2 & 32 & 0,31 & $\mathrm{~F}$ & - & 52 & MR & - & 23,70 & 6,31 & 0,11 & RUIM & \\
\hline 44 & 13 & SMA faixa alemã D0-11S & 2 & 21 & 0,72 & $M$ & - & 66,6 & $\mathrm{R}$ & - & 70,36 & 32,72 & 0,32 & MUITO BOM & \\
\hline 45 & 14 & SMA faixa alemã D0-11S & 2 & 22 & 0,66 & $M$ & - & 68 & $\mathrm{R}$ & - & 63,08 & 30,78 & 0,30 & MUITO BOM & \\
\hline 46 & 15 & SMA faixa alemã D0-11S & 2 & 22,1 & 0,65 & $\mathrm{M}$ & - & 67 & $\mathrm{R}$ & - & 62,41 & 30,07 & 0,30 & MUITO BOM & \\
\hline 47 & 1 & CA faixa III - PMSP CAP 20 & 4 & 25,20 & 0,50 & $M$ & - & 56,2 & $\mathrm{R}$ & - & 45,34 & 18,66 & 0,21 & $\mathrm{BOM}$ & \multirow{12}{*}{$\begin{array}{c}\text { Coredor } \\
\text { Tecnológicc }\end{array}$} \\
\hline 48 & 2 & CA faixa III - PMSP CAP 20 & 4 & 23,20 & 0,59 & $M$ & - & 59,6 & $\mathrm{R}$ & - & 55,58 & 24,24 & 0,25 & MUITO BOM & \\
\hline 49 & 3 & CA faixa III - PMSP CAP 20 & 4 & 24,13 & 0,55 & $M$ & - & 55,4 & $\mathrm{R}$ & - & 50,53 & 20,59 & 0,22 & MUITO BOM & \\
\hline 50 & 4 & CA faixa III - PMSP CAP 20 & 4 & 20,75 & 0,74 & $M$ & - & 57 & $\mathrm{R}$ & - & 72,38 & 28,57 & 0,28 & MUITO BOM & \\
\hline 51 & 5 & CA faixa III - PMSP CAP 20 & 4 & 25,25 & 0,50 & $M$ & - & 57 & $\mathrm{R}$ & - & 45,12 & 18,82 & 0,21 & BOM & \\
\hline 52 & 6 & CA faixa III - DERSA CAP 20 & 4 & 22,13 & 0,65 & M & - & 57 & $\mathrm{R}$ & - & 62,27 & 25,54 & 0,26 & MUITO BOM & \\
\hline 53 & 7 & CA faixa III - DERSA CAP 20 & 4 & 22,90 & 0,61 & $M$ & - & 57,2 & $\mathrm{R}$ & - & 57,35 & 23,92 & 0,25 & MUITO BOM & \\
\hline 54 & 8 & CA faixa III - DERSA CAP 20 & 4 & 23,50 & 0,58 & $M$ & - & 58,8 & $\mathrm{R}$ & - & 53,88 & 23,25 & 0,24 & MUITO BOM & \\
\hline 55 & 9 & CA faixa III - DERSA CAP 20 & 4 & 26,58 & 0,45 & M & - & 57,7 & $\mathrm{R}$ & - & 39,60 & 16,32 & 0,19 & BOM & \\
\hline 56 & 10 & CA faixa III - DERSA CAP 20 & 4 & 23,90 & 0,56 & $M$ & - & 57,7 & $\mathrm{R}$ & - & 51,70 & 21,94 & 0,23 & MUITO BOM & \\
\hline 57 & 11 & CA IA faixa IV-b CAP 20 & 4 & 28,35 & 0,40 & $\mathrm{~F}$ & - & 45 & $\mathrm{R}$ & - & 33,39 & 10,07 & 0,14 & REGULAR & \\
\hline 58 & 12 & CA IA faixa IV-b CAP 20 & 4 & 27,60 & 0,42 & M & - & 59,8 & $\mathrm{R}$ & - & 35,87 & 14,84 & 0,17 & BOM & \\
\hline
\end{tabular}




\begin{tabular}{|c|c|c|c|c|c|c|c|c|c|c|c|c|c|c|c|}
\hline 59 & 13 & CA IA faixa IV-b CAP 20 & 4 & 28,20 & 0,40 & $M$ & - & 51,4 & $\mathrm{R}$ & - & 33,87 & 11,74 & 0,15 & BOM & \\
\hline 60 & 14 & CA IA faixa IV-b CAP 20 & 4 & 30,75 & 0,34 & $\mathrm{~F}$ & - & 52 & $\mathrm{R}$ & - & 26,64 & 7,96 & 0,12 & REGULAR & \\
\hline 61 & 15 & CA IA faixa IV-b mod SBS & 4 & 27,48 & 0,42 & M & - & 50 & $\mathrm{R}$ & - & 36,30 & 12,61 & 0,16 & BOM & \\
\hline 62 & 16 & CA IA faixa IV-b mod SBS & 4 & 27,90 & 0,41 & M & - & 49,2 & $\mathrm{R}$ & - & 34,85 & 11,72 & 0,15 & BOM & \\
\hline 63 & 17 & CA IA faixa IV-b mod SBS & 4 & 26,85 & 0,44 & M & - & 48,4 & $\mathrm{R}$ & - & 38,56 & 13,23 & 0,16 & BOM & \\
\hline 64 & 18 & CA IA faixa IV-b mod SBS & 4 & 28,13 & 0,40 & M & - & 49,2 & $\mathrm{R}$ & - & 34,11 & 11,36 & 0,15 & BOM & \\
\hline 65 & 19 & SMA faixa alemã D0-11S & 4 & 21,25 & 0,70 & $\mathrm{M}$ & - & 48,6 & $\mathrm{R}$ & - & 68,48 & 23,42 & 0,24 & MUITO BOM & \\
\hline 66 & 20 & SMA faixa alemã D0-11S & 4 & 20,75 & 0,74 & M & - & 55 & $\mathrm{R}$ & - & 72,38 & 27,57 & 0,28 & MUITO BOM & \\
\hline 67 & 21 & SMA faixa alemã D0-11S & 4 & 19,30 & 0,85 & G & - & 48,6 & $\mathrm{R}$ & - & 85,48 & 27,08 & 0,27 & MUITO BOM & \\
\hline 68 & 22 & SMA faixa alemã D0-11S & 4 & 19,38 & 0,85 & $\mathrm{G}$ & - & 50,7 & $\mathrm{R}$ & - & 84,73 & 28,10 & 0,28 & MUITO BOM & \\
\hline 69 & 1 & Grooving & +10 & 31 & 1,55 & MG & 0,32 & 67 & $\mathrm{R}$ & \multirow{6}{*}{68} & 164,48 & 49,44 & 0,45 & ÓTIM0 & \multirow{6}{*}{ Guarulhos } \\
\hline 70 & 2 & Grooving & +10 & 29,3 & 1,32 & MG & 0,26 & 67 & $\mathrm{R}$ & & 138,35 & 46,68 & 0,43 & ÓTIMO & \\
\hline 71 & 3 & Grooving & +10 & 25,8 & 1,41 & MG & & 73 & $\mathrm{R}$ & & 148,58 & 52,14 & 0,47 & ÓTIM0 & \\
\hline 72 & 4 & Grooving & +10 & 29,2 & 1,02 & G & 0,21 & 68 & $\mathrm{R}$ & & 104,27 & 42,10 & 0,39 & ÓTIM0 & \\
\hline 73 & 5 & Grooving & +10 & 31 & 1,55 & MG & 0,27 & 80 & MuR & & 164,48 & 59,03 & 0,53 & ÓTIM0 & \\
\hline 74 & 6 & Concreto Asfáltico & +10 & 24,7 & 0,52 & $M$ & 0,12 & 60 & $\mathrm{R}$ & & 47,47 & 20,93 & 0,22 & MUITO BOM & \\
\hline 75 & 1 & Concreto Asfáltico & +6 & 26,2 & 0,46 & $M$ & 0,040 & 59 & $\mathrm{R}$ & - & 40,66 & 17,25 & 0,19 & BOM & \multirow{4}{*}{$\begin{array}{l}\text { Campo } \\
\text { Marte }\end{array}$} \\
\hline 76 & 2 & Concreto Asfáltico & +6 & 30 & 0,35 & $\mathrm{~F}$ & 0,040 & 59 & $\mathrm{R}$ & - & 28,16 & 9,99 & 0,14 & REGULAR & \\
\hline 77 & 3 & Concreto Asfáltico & +6 & 30,4 & 0,34 & $\mathrm{~F}$ & 0,050 & 64 & $\mathrm{R}$ & - & 27,02 & 10,06 & 0,14 & REGULAR & \\
\hline 78 & 4 & CA / Pintura & +6 & 30,9 & 0,33 & $\mathrm{~F}$ & 0,020 & 58 & $\mathrm{R}$ & - & 25,89 & 8,41 & 0,12 & REGULAR & \\
\hline 79 & 1 & Concreto Asfáltico & 3 & 27,7 & 0,41 & $M$ & 0,02 & 89 & MuR & - & 34,98 & 21,31 & 0,23 & MUITO BOM & \multirow{11}{*}{ Congonhas } \\
\hline 80 & 2 & Grooving & 3 & 17,3 & 1,06 & G & 0,44 & 82 & MuR & - & 108,82 & 51,79 & 0,47 & ÓTIM0 & \\
\hline 81 & 3 & Grooving & 3 & 18,8 & 0,90 & $\mathrm{G}$ & 0,41 & 72 & $\mathrm{R}$ & - & 90,64 & 41,47 & 0,39 & ÓTIM0 & \\
\hline 82 & 4 & Grooving & 3 & 14 & 1,62 & MG & 0,29 & 90 & MuR & - & 172,43 & 67,35 & 0,59 & ÓTIM0 & \\
\hline 83 & 5 & Grooving & 3 & 15,9 & 1,27 & MG & 0,25 & 95 & MuR & - & 132,67 & 65,17 & 0,58 & ÓTIM0 & \\
\hline 84 & 6 & Grooving S/E & 3 & 17,3 & 1,06 & $\mathrm{G}$ & 0,29 & 70 & $\mathrm{R}$ & - & 108,82 & 44,21 & 0,41 & ÓTIM0 & \\
\hline 85 & 7 & Grooving S/E & 3 & 15 & 1,41 & MG & 0,32 & 70 & $\mathrm{R}$ & - & 148,58 & 50,00 & 0,46 & ÓTIMO & \\
\hline 86 & 8 & Grooving/E & 3 & 21,3 & 0,70 & $M$ & 0,35 & 67 & $\mathrm{R}$ & - & 67,92 & 32,09 & 0,31 & MUITO BOM & \\
\hline 87 & 9 & Grooving/E & 3 & 19 & 0,88 & $\mathrm{G}$ & 0,27 & 69 & $\mathrm{R}$ & - & 88,37 & 39,18 & 0,37 & ÓTIMO & \\
\hline 88 & 10 & Grooving/E & 3 & 16,1 & 1,22 & MG & 0,3 & 65 & $\mathrm{R}$ & - & 126,99 & 43,85 & 0,41 & ÓTIMO & \\
\hline 89 & 11 & Grooving/E & 3 & 16 & 1,24 & MG & 0,46 & 68 & $\mathrm{R}$ & - & 129,26 & 46,19 & 0,43 & ÓTIM0 & \\
\hline 90 & 1 & SMA faixa alemã D0-11S & 1 & 23 & 0,60 & $M$ & - & 30 & $\mathrm{ML}$ & - & 56,76 & 12,43 & 0,16 & $\mathrm{BOM}$ & Santos \\
\hline
\end{tabular}




\begin{tabular}{|c|c|c|c|c|c|c|c|c|c|c|c|c|c|c|c|}
\hline 91 & 2 & SMA faixa alemã D0-11S & 1 & 25 & 0,50 & M & - & 40 & IR & - & 44,75 & 13,08 & 0,16 & BOM & \multirow[t]{18}{*}{ Dumont } \\
\hline 92 & 3 & SMA faixa alemã D0-11S & 1 & 26 & 0,46 & M & - & 35 & $\mathrm{~L}$ & - & 41,21 & 10,40 & 0,14 & REGULAR & \\
\hline 93 & 4 & SMA faixa alemã D0-11S & 1 & 25 & 0,52 & M & - & 35 & $\mathrm{~L}$ & - & 47,83 & 12,31 & 0,15 & BOM & \\
\hline 94 & 5 & SMA faixa alemã D0-11S & 1 & 25 & 0,52 & M & - & 35 & $\mathrm{~L}$ & - & 47,83 & 12,31 & 0,15 & BOM & \\
\hline 95 & 6 & SMA faixa alemã D0-11S & 1 & 24 & 0,54 & M & - & 35 & $\mathrm{~L}$ & - & 49,47 & 12,74 & 0,16 & BOM & \\
\hline 96 & 7 & Tratamento Superficial & 1 & 14,7 & 1,48 & MA & - & 62,8 & $\mathrm{R}$ & - & 156,53 & 45,63 & 0,42 & ÓTIM0 & \\
\hline 97 & 8 & Tratamento Superficial & 1 & 14,3 & 1,55 & MA & - & 58,4 & $\mathrm{R}$ & - & 164,48 & 43,09 & 0,40 & ÓTIM0 & \\
\hline 98 & 9 & Microrrevestimento & 1 & 21,8 & 0,67 & M & - & 54,2 & MR & - & 64,26 & 24,89 & 0,26 & MUITO BOM & \\
\hline 99 & 10 & Microrrevestimento & 1 & 21,7 & 0,68 & $M$ & - & 53,2 & MR & - & 65,43 & 24,78 & 0,25 & MUITO BOM & \\
\hline 100 & 11 & Microrrevestimento & 1 & 19,8 & 0,81 & $\mathrm{G}$ & - & 53,7 & MR & - & 80,33 & 28,82 & 0,29 & MUITO вом & \\
\hline 101 & 12 & Microrrevestimento & 1 & 20,5 & 0,76 & $M$ & - & 53,7 & MR & - & 74,45 & 27,43 & 0,28 & MUITO BOM & \\
\hline 102 & 13 & Microrrevestimento & 1 & 20,8 & 0,73 & $M$ & - & 53,7 & MR & - & 71,72 & 26,74 & 0,27 & MUITO вом & \\
\hline 103 & 14 & CA Faixa 2 DERSA & 1 & 36,8 & 0,23 & $\mathrm{~F}$ & - & 52 & $\mathrm{R}$ & - & 15,05 & 1,88 & 0,07 & MUITO RUIM & \\
\hline 104 & 15 & CA Faixa 2 DERSA & 1 & 39,5 & 0,20 & $\mathrm{~F}$ & - & 49,6 & MR & - & 11,58 & 0,66 & 0,06 & MUITO RUIM & \\
\hline 105 & 16 & CA Faixa 2 DERSA & 1 & 40,0 & 0,20 & $\mathrm{~F}$ & - & 50,8 & MR & - & 11,00 & 0,54 & 0,06 & MUITO RUIM & \\
\hline 106 & 17 & CA Faixa 2 DERSA & 1 & 38,8 & 0,21 & $\mathrm{~F}$ & - & 50,8 & MR & - & 12,38 & 0,89 & 0,06 & MUITO RUIM & \\
\hline 107 & 18 & CA Faixa 2 DERSA & 1 & 39,5 & 0,20 & $\mathrm{~F}$ & - & 50,8 & MR & - & 11,58 & 0,68 & 0,06 & MUITO RUIM & \\
\hline 108 & 19 & CA Faixa 2 DERSA & 1 & 39,8 & 0,20 & $\mathrm{~F}$ & - & 50,8 & MR & - & 11,19 & 0,58 & 0,06 & MUITO RUIM & \\
\hline 109 & 1 & SMA faixa alemã D0-11S & 1 & 17,30 & 1,06 & G & - & 54 & MR & - & 109,17 & 34,16 & 0,33 & MUITO BOM & \multirow{5}{*}{ Anchieta } \\
\hline 110 & 2 & SMA faixa alemã D0-11S & 1 & 17,25 & 1,07 & $\mathrm{G}$ & - & 47 & MR & - & 109,87 & 29,82 & 0,29 & MUITO BOM & \\
\hline 111 & 3 & SMA faixa alemã D0-11S & 1 & 18,70 & 0,91 & G & - & 49 & MR & - & 91,77 & 28,42 & 0,28 & MUITO BOM & \\
\hline 112 & 4 & SMA faixa alemã D0-11S & 1 & 16,25 & 1,20 & MG & - & 50 & MR & - & 125,28 & 33,55 & 0,32 & MUITO BOM & \\
\hline 113 & 5 & SMA faixa alemã D0-11S & 1 & 18,10 & 0,97 & $\mathrm{G}$ & - & 52 & MR & - & 98,73 & 31,34 & 0,31 & MUITO BOM & \\
\hline 114 & 1 & Concreto Asfáltico mod bor & 1 & 30 & 0,35 & $\mathrm{~F}$ & - & - & - & - & - & - & - & ÓTIM0 & \multirow[t]{9}{*}{ Anchieta } \\
\hline 115 & 2 & Concreto Asfáltico mod bor & 1 & 36,9 & 0,23 & $\mathrm{~F}$ & - & - & - & - & - & - & - & ÓTIM0 & \\
\hline 116 & 3 & Concreto Asfáltico mod bor & 1 & 29,2 & 0,37 & $\mathrm{~F}$ & - & - & - & - & - & - & - & ÓTIM0 & \\
\hline 117 & 4 & Concreto Asfáltico mod bor & 1 & 26,2 & 0,46 & $M$ & - & - & - & - & - & - & - & ÓTIM0 & \\
\hline 118 & 5 & Concreto Asfáltico mod bor & 1 & 28,1 & 0,4 & $M$ & - & - & - & - & - & - & - & ÓTIM0 & \\
\hline 119 & 6 & SMA faixa alemã D0-11S & 1 & 26,5 & 0,45 & M & - & - & - & - & - & - & - & ÓTIM0 & \\
\hline 120 & 7 & SMA faixa alemã D0-11S & 1 & 23,2 & 0,59 & $M$ & - & - & - & - & - & - & - & ÓTIM0 & \\
\hline 121 & 8 & SMA faixa alemã D0-11S & 1 & 19,7 & 0,82 & $\mathrm{G}$ & - & - & - & - & - & - & - & ÓTIM0 & \\
\hline 122 & 9 & SMA faixa alemã D0-11S & 1 & 20,2 & 0,78 & M & - & - & - & - & - & - & - & ÓTIMO & \\
\hline
\end{tabular}




\begin{tabular}{|c|c|c|c|c|c|c|c|c|c|c|c|c|c|c|c|}
\hline 123 & 10 & SMA faixa alemã D0-11S & 1 & 19,3 & 0,85 & G & - & - & - & - & - & - & - & ÓTIM0 & \\
\hline 124 & 11 & SMA faixa alemã D0-11S & 1 & 20,3 & 0,77 & M & - & - & - & - & - & - & - & ÓTIM0 & \\
\hline 125 & 12 & Concreto Asfáltico & 1 & 20,2 & 0,78 & $M$ & - & - & - & - & - & - & - & ÓTIM0 & \\
\hline 126 & 13 & Concreto Asfáltico & 1 & 21,5 & 0,69 & $\mathrm{M}$ & - & - & - & - & - & - & - & ÓTIM0 & \\
\hline 127 & 1 & Concreto Asfáltico mod bor & 2 & 31 & 0,3311 & $\mathrm{~F}$ & 0,119 & 30 & $M L$ & - & 26,01 & 4,39 & 0,09 & RUIM & \multirow{28}{*}{ Anchieta } \\
\hline 128 & 2 & Concreto Asfáltico mod bor & 2 & 29,2 & 0,37318 & $\mathrm{~F}$ & 0,063 & 40 & IR & - & 30,79 & 7,89 & 0,12 & REGULAR & \\
\hline 129 & 3 & Concreto Asfáltico mod bor & 2 & 29,3 & 0,37064 & $\mathrm{~F}$ & 0,097 & 31 & $\mathrm{ML}$ & - & 30,50 & 6,02 & 0,10 & RUIM & \\
\hline 130 & 4 & Concreto Asfáltico mod bor & 2 & 25,8 & 0,47802 & $M$ & 0,072 & 39 & LISA & - & 42,70 & 12,09 & 0,15 & BOM & \\
\hline 131 & 5 & Concreto Asfáltico mod bor & 2 & 27,8 & 0,41171 & $M$ & 0,058 & 48 & MR & - & 35,17 & 11,58 & 0,15 & BOM & \\
\hline 132 & 6 & Concreto Asfáltico mod bor & 2 & 26,7 & 0,44633 & $\mathrm{M}$ & 0,093 & 36 & LISA & - & 39,10 & 10,02 & 0,14 & REGULAR & \\
\hline 133 & 7 & SMA faixa alemã D0-11S & 2 & 24,8 & 0,51734 & M & 0,110 & 23 & $\mathrm{P}$ & - & 47,17 & 7,97 & 0,12 & REGULAR & \\
\hline 134 & 8 & SMA faixa alemã D0-11S & 2 & 22,3 & 0,63984 & M & - & 44 & IR & - & 61,09 & 19,41 & 0,21 & MUITO BOM & \\
\hline 135 & 9 & SMA faixa alemã D0-11S & 2 & 23,8 & 0,56173 & $\mathrm{M}$ & - & 44 & IR & - & 52,21 & 16,89 & 0,19 & BOM & \\
\hline 136 & 10 & SMA faixa alemã D0-11S & 2 & 20,2 & 0,7798 & $M$ & 0,140 & 41 & IR & - & 76,98 & 21,42 & 0,23 & MUITO BOM & \\
\hline 137 & 11 & SMA faixa alemã D0-11S & 2 & 20 & 0,79547 & $M$ & - & 45 & IR & - & 78,77 & 23,85 & 0,25 & MUITO BOM & \\
\hline 138 & 12 & SMA faixa alemã D0-11S & 2 & 19,3 & 0,85422 & G & - & 42 & IR & - & 85,44 & 23,39 & 0,24 & MUITO BOM & \\
\hline 139 & 13 & SMA faixa alemã D0-11S & 2 & 19,3 & 0,85422 & $\mathrm{G}$ & 0,208 & 41 & IR & - & 85,44 & 22,84 & 0,24 & MUITO BOM & \\
\hline 140 & 14 & SMA faixa alemã D0-11S & 2 & 20,3 & 0,77213 & M & 0,198 & 35 & LISA & - & 76,11 & 18,15 & 0,20 & BOM & \\
\hline 141 & 15 & SMA faixa alemã D0-11S & 2 & 20,2 & 0,7798 & M & - & 42 & IR & - & 76,98 & 21,94 & 0,23 & MUITO BOM & \\
\hline 142 & 16 & SMA faixa alemã D0-11S & 2 & 21,5 & 0,68835 & M & - & 35 & LISA & - & 66,60 & 16,52 & 0,19 & BOM & \\
\hline 143 & 17 & Concreto Asfáltico & 2 & 21,2 & 0,70796 & M & 0,150 & 48 & MR & - & 68,82 & 23,21 & 0,24 & MUITO BOM & \\
\hline 144 & 18 & Concreto Asfáltico & 2 & 23,5 & 0,57617 & M & 0,057 & 51 & MR & - & 53,85 & 20,15 & 0,22 & MUITO BOM & \\
\hline 145 & 19 & Concreto Asfáltico & 2 & 19,8 & 0,81162 & G & 0,140 & 46 & IR & - & 80,60 & 24,74 & 0,25 & MUITO BOM & \\
\hline 146 & 20 & Concreto Asfáltico & 2 & 24,3 & 0,53885 & M & 0,097 & 44,2 & IR & - & 49,61 & 16,13 & 0,19 & BOM & \\
\hline 147 & 21 & Concreto Asfáltico & 2 & 25,2 & 0,50105 & $\mathrm{M}$ & 0,085 & 47 & $\mathrm{MR}$ & - & 45,32 & 15,59 & 0,18 & BOM & \\
\hline 148 & 1 & TSD + Capa Selante & $<1$ & 12,8 & 1,93 & MuG & 0,473 & 56 & $\mathrm{R}$ & - & 207,65 & 44,02 & 0,41 & ÓTIM0 & \\
\hline 149 & 2 & TSD + Capa Selante & 2 & 12,1 & 2,18 & MuG & 0,609 & 56 & $\mathrm{R}$ & - & 236,05 & 45,31 & 0,42 & ÓTIM0 & \\
\hline 150 & 3 & TSD + Capa Selante & 2 & 13,7 & 1,7 & MuG & 0,556 & 56 & $\mathrm{R}$ & - & 181,52 & 42,52 & 0,40 & ÓTIMO & \\
\hline 151 & 4 & TSS + Lama (Cape Seal) & $<1$ & 22,9 & 0,61 & $M$ & 0,154 & 58 & $\mathrm{R}$ & - & 57,70 & 24,38 & 0,25 & MUITO BOM & \\
\hline 152 & 5 & TSS + Lama (Cape Seal) & 2 & 17,7 & 1,01 & G & 0,239 & 58 & $\mathrm{R}$ & - & 103,14 & 35,72 & 0,34 & MUITO BOM & \\
\hline 153 & 6 & TSS + Lama (Cape Seal) & 2 & 18,2 & 0,96 & G & 0,237 & 58 & $\mathrm{R}$ & - & 97,46 & 34,72 & 0,33 & MUITO BOM & \\
\hline 154 & 7 & TSS + Micro (Cape Seal) & $<1$ & 21,1 & 0,71 & $\mathrm{M}$ & 0,149 & 60 & $\mathrm{R}$ & - & 69,06 & 29,09 & 0,29 & MUITO BOM & \\
\hline
\end{tabular}




\begin{tabular}{|c|c|c|c|c|c|c|c|c|c|c|c|c|c|c|c|}
\hline 155 & 8 & TSS + Micro (Cape Seal) & 2 & 21,8 & 0,67 & M & 0,168 & 60 & $\mathrm{R}$ & - & 64,51 & 27,64 & 0,28 & MUITO BOM & \\
\hline 156 & 9 & TSS + Micro (Cape Seal) & 2 & 19,1 & 0,87 & G & 0,141 & 60 & $\mathrm{R}$ & - & 87,23 & 33,82 & 0,33 & мUITO вОм & \\
\hline 157 & 1 & SMA faixa alemã D0-11S & 5 & 18,50 & 0,93 & G & - & 50,4 & MR & - & 94,01 & 29,61 & 0,29 & MUITO BOM & \multirow{11}{*}{ Anchieta } \\
\hline 158 & 2 & SMA faixa alemã D0-11S & 5 & 18,38 & 0,94 & G & - & 47,8 & MR & - & 95,45 & 28,31 & 0,28 & MUITO BOM & \\
\hline 159 & 3 & SMA faixa alemã D0-11S & 5 & 18,38 & 0,94 & G & - & 52,6 & MR & - & 95,45 & 31,15 & 0,31 & MUITO вом & \\
\hline 160 & 4 & SMA faixa alemã D0-11S & 5 & 17,95 & 0,99 & G & - & 52,8 & MR & - & 100,58 & 32,12 & 0,31 & MUITO вом & \\
\hline 161 & 5 & SMA faixa alemã D0-11S & 5 & 18,68 & 0,91 & G & - & 55,6 & MR & - & 92,04 & 32,30 & 0,31 & MUITO вом & \\
\hline 162 & 6 & SMA faixa alemã D0-11S & 5 & 17,83 & 1,00 & G & - & 45,4 & MR & - & 102,16 & 27,83 & 0,28 & MUITO вом & \\
\hline 163 & 7 & SMA faixa alemã D0-11S & 5 & 20,68 & 0,74 & G & - & 47,6 & MR & - & 72,96 & 23,99 & 0,25 & MUITO ВОм & \\
\hline 164 & 8 & SMA faixa alemã D0-11S & 5 & 18,50 & 0,93 & G & - & 47,6 & MR & - & 94,01 & 27,97 & 0,28 & MUITO BOM & \\
\hline 165 & 9 & SMA faixa alemã D0-11S & 5 & 21,73 & 0,67 & G & - & 49,4 & MR & - & 64,98 & 22,89 & 0,24 & MUITO вом & \\
\hline 166 & 10 & SMA faixa alemã D0-11S & 5 & 19,03 & 0,88 & G & - & 47,6 & MR & - & 88,26 & 27,01 & 0,27 & MUITO вом & \\
\hline 167 & 11 & SMA faixa alemã D0-11S & 5 & 18,98 & 0,88 & $\mathrm{G}$ & 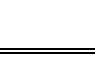 & 45,2 & MR & - & 88,79 & 25,74 & 0,26 & MUITO ВОМ & \\
\hline 168 & 1 & CPA mod SBS & 2 & 16,35 & 1,19 & G & - & 55 & $\mathrm{R}$ & - & 123,58 & 36,70 & 0,35 & MUITO вом & \multirow{5}{*}{ Dutra } \\
\hline 169 & 2 & CPA mod SBS & 2 & 14,50 & 1,51 & MG & - & 53 & MR & - & 159,94 & 38,77 & 0,37 & ÓTIM0 & \\
\hline 170 & 3 & CPA mod SBS & 2 & 15,25 & 1,37 & MG & - & 49 & MR & - & 144,03 & 34,63 & 0,33 & MUITO вОМ & \\
\hline 171 & 4 & CPA mod SBS & 2 & 16,80 & 1,13 & $\mathrm{G}$ & - & 49 & MR & - & 116,77 & 31,93 & 0,31 & MUITO вОМ & \\
\hline 172 & 5 & CPA mod SBS & 2 & 16,35 & 1,19 & $\mathrm{G}$ & - & 58 & $\mathrm{R}$ & - & 123,58 & 38,70 & 0,37 & ÓTIM0 & \\
\hline 173 & 1 & SMA 0/16 & 0 & 15,35 & 1,35 & MG & - & 64,4 & $\mathrm{R}$ & - & 141,76 & 45,26 & 0,42 & ÓTIM0 & \multirow{3}{*}{ LTP } \\
\hline 174 & 2 & Areia Asfalto & 0 & 42,30 & 0,18 & MF & - & 55 & $\mathrm{R}$ & - & 8,85 & 0,19 & 0,06 & MUITO RUIM & \\
\hline 175 & 3 & CPA & 0 & 12,68 & 1,98 & MG & - & 71 & $\mathrm{R}$ & - & 213,33 & 56,17 & 0,51 & ÓTIM0 & \\
\hline 176 & 1 & Concreto Asfáltico & 0 & 31,50 & 0,32 & $\mathrm{~F}$ & 0,016 & 49,8 & $\mathrm{R}$ & - & 24,75 & 6,61 & 0,11 & RUIM & \multirow{3}{*}{ Bandeirantes } \\
\hline 177 & 2 & Concreto Asfáltico & 0 & 25,33 & 0,50 & $M$ & 0,044 & 47,6 & MR & - & 45,20 & 15,75 & 0,18 & BOM & \\
\hline 178 & 3 & Concreto Asfáltico & 0 & 31,17 & 0,33 & $\mathrm{~F}$ & 0,039 & 56,8 & $\mathrm{R}$ & - & 25,89 & 8,23 & 0,12 & REGULAR & \\
\hline
\end{tabular}


Anexo 3 Molde do Pavimento

Algumas tentativas de reproduzir o perfil do pavimento foram executadas, porém não apresentaram resultados satisfatórios, como:

1) Gesso comum: aderiu ao pavimento, apresentou retração de volume e formação de bolhas resultando em vazios.

2) Gesso pedra: de uso odontológico - aderiu ao pavimento, menor retração e menos formação de bolhas. Houve necessidade de se aprender como realizar a adequada espatulação do gesso.
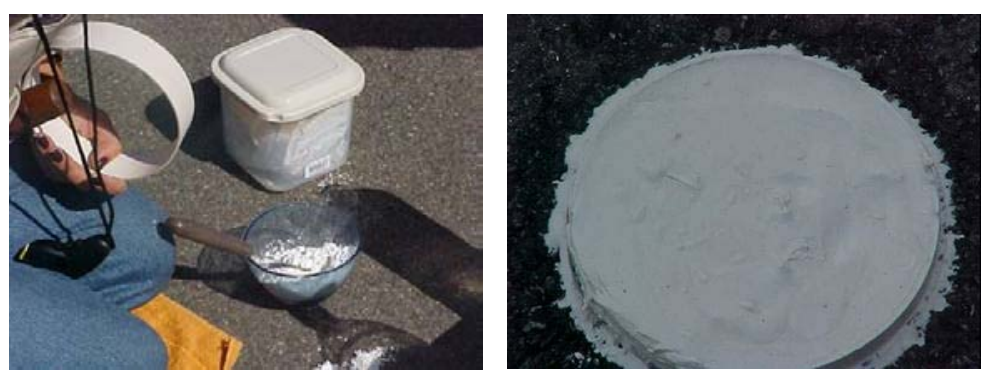

3) Alginato: Material Odontológico usado para molde, apresentou melhor resultado quando a superfície foi pulverizada com spray de vaselina mas mesmo assim deixou resíduo do material no revestimento. Material caro. Dificuldade de "vazar" o molde em laboratório para produzir o "positivo" do pavimento.
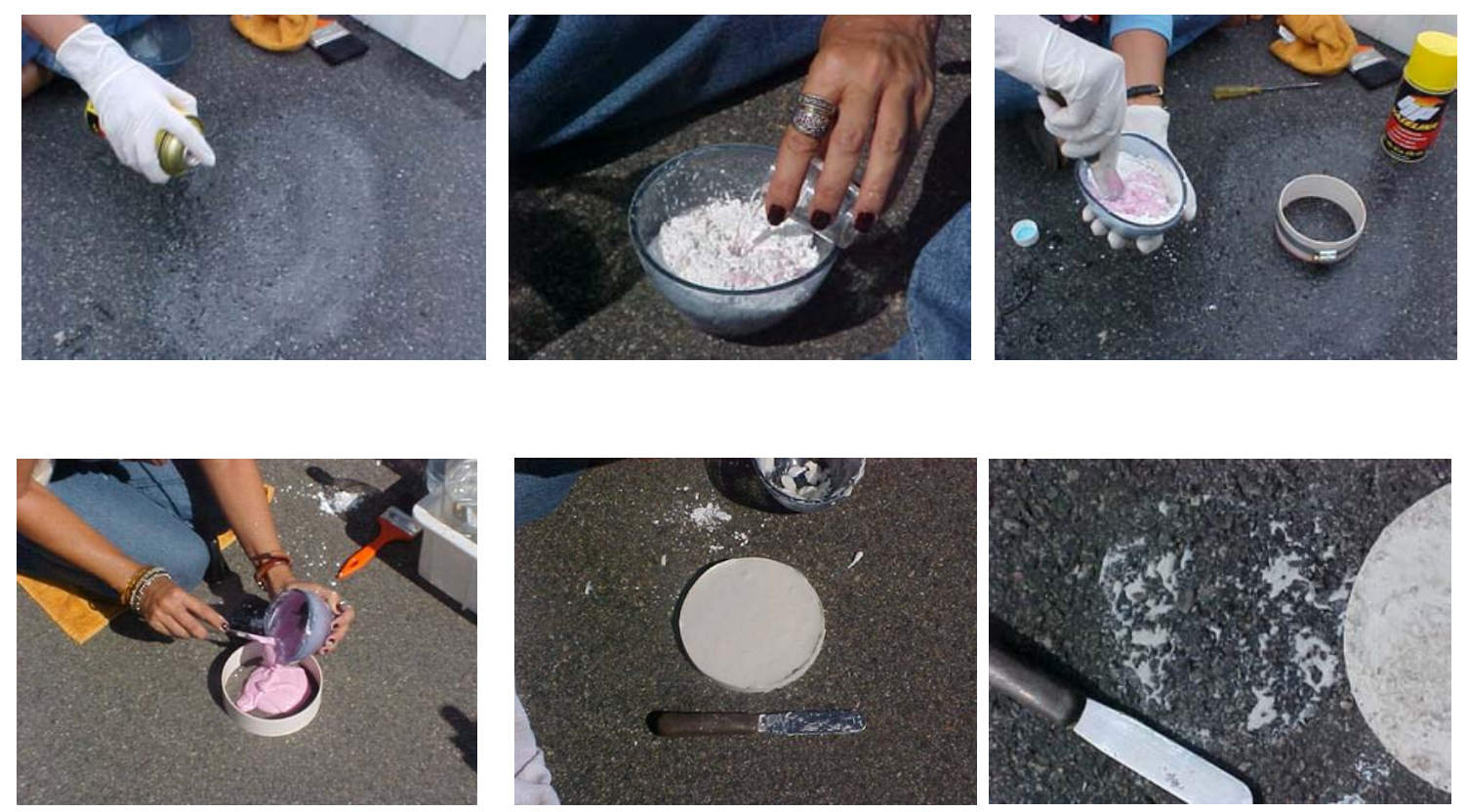